\title{
Tumor cell plasticity: vascularisation beyond angiogenesis
}

Citation for published version (APA):

Hillen, F. (2008). Tumor cell plasticity: vascularisation beyond angiogenesis. [Doctoral Thesis, Maastricht University]. Universiteit Maastricht. https://doi.org/10.26481/dis.20080221fh

Document status and date:

Published: 01/01/2008

DOI:

$10.26481 /$ dis.20080221fh

Document Version:

Publisher's PDF, also known as Version of record

\section{Please check the document version of this publication:}

- A submitted manuscript is the version of the article upon submission and before peer-review. There can be important differences between the submitted version and the official published version of record.

People interested in the research are advised to contact the author for the final version of the publication, or visit the DOI to the publisher's website.

- The final author version and the galley proof are versions of the publication after peer review.

- The final published version features the final layout of the paper including the volume, issue and page numbers.

Link to publication

\footnotetext{
General rights rights.

- You may freely distribute the URL identifying the publication in the public portal. please follow below link for the End User Agreement:

www.umlib.nl/taverne-license

Take down policy

If you believe that this document breaches copyright please contact us at:

repository@maastrichtuniversity.nl

providing details and we will investigate your claim.
}

Copyright and moral rights for the publications made accessible in the public portal are retained by the authors and/or other copyright owners and it is a condition of accessing publications that users recognise and abide by the legal requirements associated with these

- Users may download and print one copy of any publication from the public portal for the purpose of private study or research.

- You may not further distribute the material or use it for any profit-making activity or commercial gain

If the publication is distributed under the terms of Article $25 \mathrm{fa}$ of the Dutch Copyright Act, indicated by the "Taverne" license above, 


\section{Tumor cell plasticity: \\ vascularisation beyond angiogenesis}


(C) Copyright Femke Hillen, Maastricht 2008 ISBN 978-90-6464-210-4

Press: Grafisch bedrijf Ponsen en Looijen B.V. 


\title{
Tumor cell plasticity: vascularisation beyond angiogenesis
}

\author{
Proefschrift \\ ter verkrijging van de graad van doctor aan de Universiteit Maastricht, \\ op gezag van de Rector Magnificus, Prof. mr. G.P.M.F. Mols \\ volgens het besluit van het College van Decanen, \\ in het openbaar te verdedigen op \\ donderdag 21 februari 2008 om 14 uur \\ door

\section{Femke Hillen} \\ geboren op 17 juni 1980 te Leuven
}


Promotor

Prof. dr. A.W. Griffioen

Beoordelingscommissie

Prof. dr. J.W. Cohen Tervaert (Voorzitter)

Dr. M.G.A. oude Egbrink

Prof. dr. P. Pauwels (UZ Gent, Belgium)

Prof. dr. F.C.S Ramaekers

Prof. dr. L.J.I. Zimmermann

Financial support by the 'Stichting Nationaal Fonds tegen Kanker', Greiner Bio-One, Hycult Biotechnology, Sanquin and Pfizer for the publication of this thesis is gratefully acknowledged. 


\section{Abbreviations}

\begin{tabular}{|c|c|}
\hline $\mathrm{aFGF}$ & acid fibroblast growth factor \\
\hline $\mathrm{AP}$ & alkaline phosphatase \\
\hline bFGF & basic fibroblast growth factor \\
\hline$c-a b l$ & Abelson murine leukaemia viral oncogene homolog \\
\hline CAIX & carbonic anhydrase IX \\
\hline cDNA & complementary DNA \\
\hline c-kit & v-kit Hardy-Zuckerman 5 feline sarcoma viral oncogene homolog \\
\hline DAB & diaminobenzidine \\
\hline DNA & deoxyribonucleic acid \\
\hline DC & dendritic cells \\
\hline EC & endothelial cell \\
\hline eNOS & endothelial nitric oxide synthase \\
\hline EphA2 & ephrin A2 \\
\hline ERBB2 & v-ERB-B2 avian erythroblastic leukaemia viral oncogen homolog 2 \\
\hline FasL & fas ligand \\
\hline FCS & fetal calf serum \\
\hline FOXP3 & forkhead box P3 \\
\hline GLUT & glucose transporter \\
\hline HIF & hypoxia inducible factor \\
\hline HRE & hypoxia response elements \\
\hline HUVEC & human umbilical vein endothelial cells \\
\hline ICAM & intracellular adhesion molecule \\
\hline IL & interleukin \\
\hline MCAM & melanoma adhesion molecule \\
\hline MTIF & Melan-A, microphthalmia-associated transcription factor \\
\hline MHC & major histocompatibility complex \\
\hline MMP & matrix metalloproteinase \\
\hline MT-MMP & membrane-type matrix metalloproteinase \\
\hline mTOR & mammalian target of rapamycin \\
\hline MVD & microvessel density \\
\hline NK & natural killer \\
\hline PAS & periodic acid Schiff \\
\hline PCR & polymerase chain reaction \\
\hline PDGF & platelet derived growth factor \\
\hline PDGFR & platelet derived growth factor receptor \\
\hline PI3K & phosphoinositide 3-kinase \\
\hline PLGF & placental growth factor \\
\hline PMN & polymorphonuclear cells \\
\hline RNA & ribonucleic acid \\
\hline s. & subcutaneous \\
\hline
\end{tabular}


siRNA

TAM

Tie

TCR

TFPI

TGF

TNF

TRAIL

VCAM

VEGF

VEGFR

VM small interfering RNA

tumor infiltrated macrophages

tyrosine kinase with immunoglobulin and EGF-like domains

T cell receptor

tissue factor pathway inhibitor

transforming growth factor

tumor necrosis factor

tumor necrosis factor-related apoptosis-inducing ligand

vascular cell adhesion molecule

vascular endothelial growth factor

vascular endothelial growth factor receptor

vasculogenic mimicry 


\section{Contents}

Chapter 1

Chapter 2

Chapter 3

Chapter 4

Chapter 5

Chapter 6

Chapter 7

Summary

Samenvatting

Dankwoord

Curriculum Vitae

General discussion

Proliferating endothelial cells, but not microvessel density, is a prognostic parameter in human cutaneous melanoma

Leukocyte infiltration and tumor cell plasticity are parameters of aggressiveness in primary cutaneous melanoma

Tumor cell plasticity in Ewing sarcoma, an alternative circulation system stimulated by hypoxia 



\section{Chapter 1}

\section{General introduction}

\section{Tumor vascularisation and immunity: two targets for tumor inhibition}

Based on:

Femke Hillen, Veerle Melotte, Judy R. van Beijnum, Arjan W. Griffioen

Endothelial cell biology. In: Staton CA, Lewis C, Bicknell R, editors. Angiogenesis assays: a critical appraisal of current techniques.

2006, Chapter 1,1-28. London, United Kingdom: John Wiley and Sons 


\section{Introduction}

The outgrowth of tumors is limited to $1-2 \mathrm{~mm}^{3}$ in size due to sufficient supply of oxygen and nutrients being the rate limiting step in this process. In order to grow beyond this size, the tumor switches to an angiogenic phenotype and attracts blood vessels from the surrounding stroma. This process is regulated by a variety of pro- and anti-angiogenic factors, and is a prerequisite for further growth of the tumor and for metastasis formation ${ }^{1}$.

Once a tumor is vascularized, it is not only supplied with oxygen, nutrients and other blood components but also with cells from the immune system. Already in the mid $19^{\text {th }}$ century, Virchow postulated that cancer originates from inflamed tissues ${ }^{2}$. He suggested that sites of chronic inflammation formed the origin of cancer. While this can be true, it is now generally known that the presence of immune cells is also a consequence of specific immune reactions against the tumor. Due to dedifferentiation and uncontrolled proliferation of cancer cells, antigens are expressed that can be recognised by the immune system. Specific immune cells are activated, expand clonally and migrate to the tumor ${ }^{3}$.

Over the last decades, a lot of attention was focussed on anti-angiogenesis- and immunotherapy. However, these therapies had limited clinical success. The idea that cancer could be repressed by the immune system, was complicated with the first evidence of tumor immune escape ${ }^{2}$. Above that, it is clear now that tumors, next to angiogenesis, have different forms of tumor vasculature that stimulate tumor progression and metastasis. In 1999, the process of vasculogenic mimicry was described to indicate a process in aggressive tumors in which tumor cells dedifferentiate into an endothelial phenotype and make tube-like structures that can contribute to blood circulation. With this mechanism, it has been suggested that tumor cells provide themselves of a secondary circulation system of vasculogenic structures lined by tumor cells, independently from angiogenesis ${ }^{4}$.

\section{Tumor angiogenesis}

Tumor angiogenesis is the sprouting of new capillary vessels out of pre-existing ones. Expanding tissues and organs will be supplied through these blood vessels with oxygen and nutrients, and in that way the metabolic waste is removed. Angiogenesis is a key event in physiological situations, such as embryonic development, wound healing and reproduction. Excessive angiogenesis is also observed in many pathologies, like diabetes, rheumatoid arthritis, cardiovascular ischemic complications, and cancer ${ }^{5}$. In cancer, sprouting angiogenesis in not only important in primary tumors, it is also involved in metastasis formation and further outgrowth of metastases $^{6}$. 


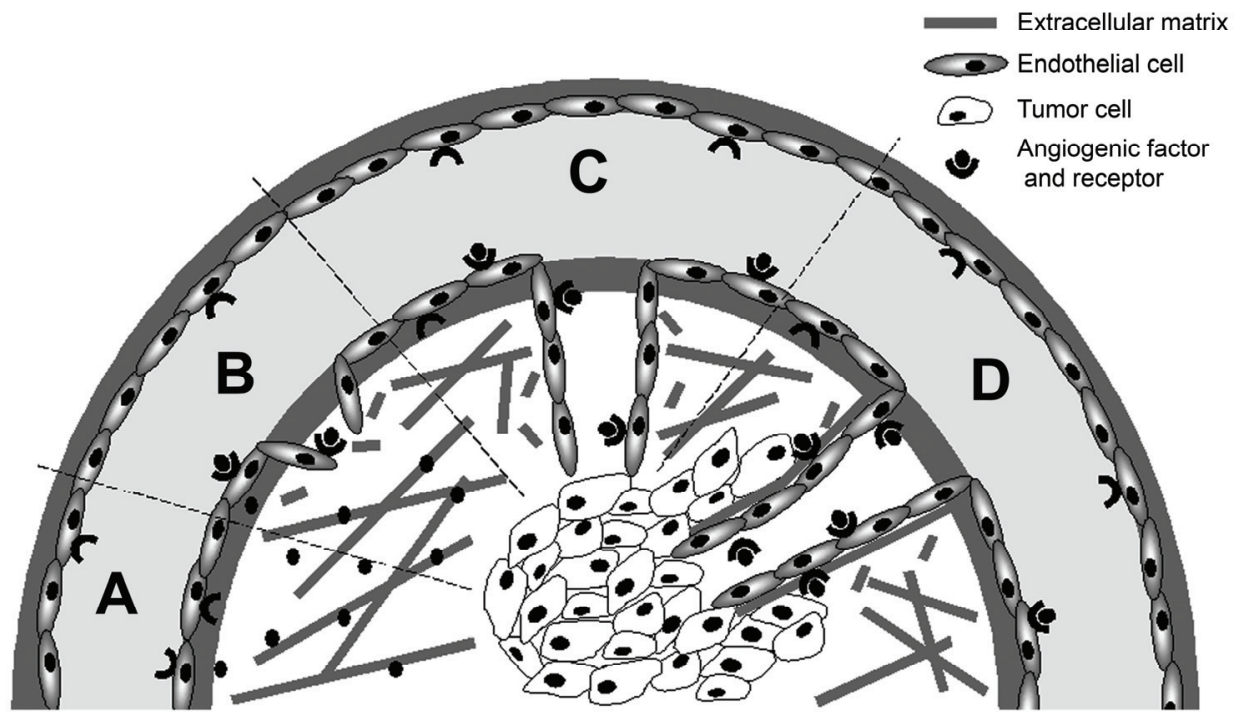

Figure 1. Schematic representation of tumor angiogenesis

A. Due to insufficient supply of oxygen and nutrients, the tumor switches to an angiogenic phenotype and starts to produce angiogenic factors that activate the blood vessels nearby. B. Subsequently, the extracelullar matrix is degraded and activated endothelial cells will invade the matrix. C. The endothelial cells starts to proliferate and form a lumen. D. Vessel maturation is completed with the deposition of extracellular matrix and the recruitment of pericytes. A newly formed vessel allows the tumor to continue its growth.

The process of sprouting angiogenesis involves several sequential steps (figure 1). The angiogenic cascade starts with the activation of endothelial cells by specific growth factors that bind to its receptors. Before endothelial cells can migrate in the direction of the stimulus, the extracellular matrix and basement membrane are degraded locally by activated matrix metalloproteinases. Subsequently, endothelial cells can proliferate and migrate through the matrix. An immature blood vessel is formed after the polarization of the migrating endothelial cells into a lumen ${ }^{7}$. These immature vessels are stabilized by the recruitment of mural cells and the generation of extracellular matrix ${ }^{8}$. This process of sprouting angiogenesis is tightly controlled by positive and negative regulators, the balance of which determines the level of ongoing angiogenesis. Due to continuous angiogenic stimulation in tumors, tumor vasculature is organised in a chaotic manner which lacks mural cell coverage, shows excessive branching and has discontinuous basement membrane, widened interendothelial junctions. As a result, tumor vessels are leaky and irregular, resulting in a poorly efficient perfusion and hypoxic regions in the tumor which consequently results in new angiogenic stimulation. 


\section{Pro-angiogenic factors}

The first angiogenic growth factor, fibroblast growth factor (bFGF), also known as FGF2 , was discovered in the early 1980s ${ }^{9}$. The FGF family consists of 23 members, of which FGF-2 and FGF-1 (aFGF) are the best known, and can signal through four different FGF tyrosine kinase receptors (FGFR1-4). bFGF is involved in endothelial cell proliferation, extracellular matrix degradation, endothelial cell migration and modulation of junctional adhesion molecules. It is produced by many cells, among which are macrophages and tumor cells and released in the extracellular matrix after which angiogenesis is initiated ${ }^{10}$. In both mouse and human tumors, the role of bFGF in tumor growth and neovascularization has been demonstrated ${ }^{11}$.

Vascular endothelial cell growth factor (VEGF) or vascular permeability factor, is another and one of the best-characterised pro-angiogenic factors. The VEGF family of growth factors consists of six members (VEGF, VEGF-B, VEGF-C, VEGF-D, VEGF-E and placental growth factor) that interact differentially with three cell surface receptor tyrosine kinases, the VEGFRs, or a second class of non signalling co-receptors, the neuropilins. VEGF induces endothelial cell survival, proliferation, migration, angiogenesis and vascular permeability ${ }^{12}$. To date, the VEFG-A/VEGFR2 interaction appears to play a major role in sprouting angiogenesis ${ }^{7}$. In tumors, higher levels of VEGF are detected and many tumor cell lines were found to be inhibited in vivo by antibody targeting methods or the use of small-molecule inhibitors of VEGF or VEGFR2 ${ }^{12}$.

Placental growth factor (PLGF), a member of the VEGF family that only binds VEGFR1, is also a key player in the angiogenic switch, though its role was underestimated. Activated endothelial cells can produce large amount of PLGF and thereby the regulation of VEGF-mediated angiogenic stimulation. Also other cell types like smooth muscle cells, inflammatory cells and tumor cells can produce PLGF when activated. Importantly, PLGF seems to play a role in vascular development but does not affect the functionality of physiological vessel formation during development and reproduction ${ }^{13,14}$.

Another important growth factor family in angiogenesis, the angiopoietin family, includes 3 members (in humans), angiopoietin-1, angiopoietin-2 and angiopoietin-4, that all signal through the endothelial tyrosine kinase receptor Tie- 2 . The most remarkable characteristic of this family is the opposing effect of the different ligands binding to the same receptor. While angiopoietin-1 activates the Tie-2 signalling, angiopoietin-2 inhibits this activation. Angiopoietin-1 is a mediator in endothelial cell migration, adhesion and the recruitment of pericytes and smooth muscle cells, while angiopoietin- 2 is vessel destabilizer ${ }^{15,16}$.

Besides the above described angiogenic factors, tumor cells can produce other factors like transforming growth factor- $\beta$, which stabilizes newly formed vessels and suppresses the immune system ${ }^{17}$, platelet-derived growth factor, which is a 
chemoattractant for pericytes 18, epidermal growth factor, which promotes tumorangiogenesis by upregulating VEGF 19 and interleukin 8 that specifically enhances endothelial cell migration ${ }^{20}$.

\section{Angiogenesis inhibition}

Angiogenesis is also regulated by endogenous inhibitors. One of the first naturally occurring angiostatic agent to be discovered was thrombospondin-1 ${ }^{21}$. In time, more endogenous molecules with angiostatic activity were described such as the $16 \mathrm{kD}$ fragment of prolactin ${ }^{22}$, platelet factor- 4 and interferon- $\alpha{ }^{23}$ and interferon- $\gamma$ inducible protein-10 ${ }^{24}$. Other components of this class of endogenously produced anti-angiogenic proteins are angiostatin ${ }^{25}$, endostatin ${ }^{26}$, bactericidal/permeability increasing protein ${ }^{27}$, tumstatin ${ }^{28}$. Interesting, many of these molecules are proteolytic fragments of collagens and other endogenous macromolecules. Although for several of the currently described angiogenesis inhibitors receptors have been described, detailed mechanisms of action have not been elucidated yet ${ }^{29}$.

Next to anti-angiogenesis approaches with endogenous inhibitors, several blocking strategies of the above described angiogenic factors have been reported. Strategies that block the VEGF-A/VEGFR2 signalling are the most abundant ones in the clinical field of anti-angiogenisis therapy. A lot of attention is focussed on the approval of the first anti-angiogenic agent, Avastin, by the Food and Drug administration ${ }^{30,31}$. Avastin in combination with chemotherapy demonstrated a survival benefit in patients with metastatic colorectal cancer of several months ${ }^{32}$. Besides Avastin, several other VEGF inhibitors are being clinically implicated. The most advanced receptor tyrosine kinase inhibitors that target VEGF receptors are SU11428 (Sutent), BAY 43-9006 (Sorafenib) ${ }^{31}$.

\section{Hypoxia-induced angiogenesis}

When tumors expand, diffusion limits due to the lack of vascular supply increases. The resulting low levels of oxygen, or hypoxia, have been identified as a primary regulator of the angiogenic switch. The key regulator of hypoxia-induced angiogenesis is hypoxia inducible factor- 1 (HIF-1). HIF- 1 belongs to a family of transcription factors consisting of $\alpha \beta$-heterodimers that include HIF- $1 \alpha$, HIF- $2 \alpha$, HIF- $3 \alpha$ and HIF- $1 \beta$. While HIF- $1 \beta$ is constitutively expressed, the HIF1- $\alpha$ subunits are regulated by oxygen. HIF- $1 \alpha$ is the main regulator of oxygen homeostasis in many cell types ${ }^{33}$. Molecular regulation of HIF- $1 \alpha$ involves mostly control of protein stability. Under normoxic conditions, HIF- $1 \alpha$ is hydroxylated in two proline residues. Hydroxylation mediates the binding of the tumor suppressor protein von Hippel-Lindau which is targeted by a ubiquitin-protein ligase. Subsequently rapid proteosomal degradation of HIF-1 $\alpha$ is executed. Under hypoxic conditions HIF- $1 \alpha$ escapes protein degradation and can bind to the heterodimer HIF-1 $\beta$. HIF- $1 \alpha$ and HIF- $2 \alpha$ are closely related and are both able to interact with hypoxia response elements (HREs) that are present in the promoter regions of several genes and to activate them. Among these are genes with angiogenic potential, 
Chapter 1

like VEGF, endothelial nitric oxide synthase (eNOS), platelet derived growth factor (PDGF) and bFGF ${ }^{34}$ (table 1).

Table 1. Direct transcriptional targets of HIF-1 $\alpha$ that are involved in different steps of angiogenesis

\begin{tabular}{lll}
\hline Involvement in angiogenesis & Stimulatory factor & Inhibitory factor \\
\hline Vasodilatation & Nitric oxide synthase & \\
Vascular permeability & VEGF & \\
& VEGFR1 & \\
Extravasation of plasma proteins & VEGF & TIMP-1 \\
Degradation of extracellular matrix & Collagen prolyl-4-hydroxylase & PAI-1 \\
Liberation of growth factors & uPA receptor & \\
Endothelial proliferation and migration & VEGF & \\
Endothelial assembly, lumen formation & VEGF & \\
Stabilisation of nacsent cells & PAI-1 &
\end{tabular}

VEGF, vascular endothelial growth factor; VEGFR, vascular endothelial growth factor receptor; TIMP, tissue inhibitor of metalloproteinase; uPA, urokinase plasminogen activator; PAI, plasminogen activator inhibitor (based on Pugh et al, 2003).

Next to the HIF-1 $\alpha$ signalling, there are also other pathways independent from HIF that are capable of inducing angiogenesis in response to hypoxia. Within the VEGF promoter region a binding site for the transcription factor nuclear factor kappa B (NF$\mathrm{kB}$ ) has been identified ${ }^{35}$. The importance of NF-kB in angiogenesis induction was demonstrated in a human cancer prostate cell line with constitutive elevated NF-kB activity. Blockade of NF-kB in these cells resulted in downregulation of VEGF expression both in vitro and in vivo and impaired tumor angiogenesis in vivo ${ }^{36}$. In addition, oncogene K-ras, junB, and IL-8 were identified to be involved in hypoxia induced-angiogenesis and VEGF expression ${ }^{36-38}$.

The significant contribution of HIFs to tumor progression has been demonstrated in several gene deletion studies. The loss of HIF-1 $\alpha$ in mouse embryonic stem cells resulted in reduced tumor mass and increased apoptosis ${ }^{39}$. A recent paper reported on the positive role of HIF- $1 \alpha$ in tumor progression and metastasis in a transgenic mouse model of cancer ${ }^{40}$. In human tumors, hypoxia-related proteins like HIF-1 $\alpha$, glucose transporter-1 (GLUT-1) and carbonic anhydrase IX (CAIX), have been suggested as a negative prognostic factor for patient outcome ${ }^{41}$.

The important stimulation of angiogenesis by hypoxia, makes HIF an attractive target for cancer therapy. Moreover, tumor hypoxia is associated with 
resistance to radiotherapy, but has also shown diminishing effect of chemotherapy, phototherapy and immunotherapy ${ }^{42}$. Therefore, there is growing interest in targeting hypoxia cell signalling for tumor inhibition. Before the discovery of the HIFs, several strategies have been explored to target tumor hypoxia. The goal of the use of hypoxiaactivated pro-drugs, like tirapazamine, is to generate an hypoxia-selective cytotoxicity and to potentiate radiotherapy or chemotherapy. The administration of tirapazamine, together with chemotherapy, was shown to increase the response rate and overall survival of patients with lung cancer ${ }^{43}$. Another approach is the use of anaerobic bacteria that may function as a direct anti-tumor activity or as a carrier for therapeutic enzymes of genes. Recently, certain Clostridium strains have been used to enhance the release of doxorubicine of liposomes within hypoxic areas of the tumor ${ }^{44}$. The discovery of HIF-1 made it possible to develop molecular targets for hypoxia. Some inhibitors attack oncogenic pathways, while others try to intervene with HIF-1 $\alpha$ protein production ${ }^{34}$. Examples of components in clinical trials that interfere with oncogenic pathways are (1) Gleevec, that intervenes with c-kit, c-abl and PDGFR, (2) Herceptin, which blocks the ERBB2 receptor and (3) temsirolimus, that inhibits mTOR function. Agents that inhibit HIF-1 $\alpha$ protein accumulation are: (1) topotecan, that blocks topoisomerase I DNA replication, (2) 2-methoxyestradiol, which inhibits polymerisation of tubuline and (3) 17-AAG, that suppresses the function of Hsp90. Nevertheless, none of these targeting components are specific for HIF-1. Further work is needed to identify more selective HIF-1 inhibitors. Moreover, HIF-1 $\alpha$ has been identified to have a dual role in tumorigenesis. Recent data, on the role of HIF- $2 \alpha$ in cMyc transcriptional activity, suggested a two-faced potential role of HIF-1 $\alpha$ in the promotion and suppression of tumorigenesis, depending on the context ${ }^{45}$.

\section{Tumor immunity: from immune surveillance to immune escape}

It is well known that tumor invasion can be heavily influenced by the presence of an inflammatory infiltrate, a feature of solid cancers. Inflammation in a tumor is the consequence of a specific immune reaction to the tumor, where the immune system recognizes the tumor as foreign and tries to destroy the expanding tumor cells. Both in animal models and cancer patients, there is evidence that tumor cells express specific tumor-associated antigens that can be recognized by immune cells. This process was described as immune surveillance ${ }^{46}$. In humans, several studies report the amount of tumor infiltrating leukocytes as a prognostic factor in e.g. prostatic adenocarcinoma ${ }^{47}$, breast carcinoma 48, cervix squamous cell carcinoma 49, colorectal carcinoma 50, esophageal carcinoma ${ }^{51,52}$, ovarian cancer ${ }^{53,54}$, head and neck cancer ${ }^{55}$, non-small cell lung cancer ${ }^{56}$. Although mostly associated with a better prognosis, immune responses in tumors are often weak and are not able to destroy the tumor. In addition, there is also debate about the beneficial effects of an inflammatory infiltrate, since some leukocyte subsets, e.g. macrophages have been described to induce tumor progression 
by induction of angiogenesis. There is growing evidence that tumors can escape from their immune surveillance ${ }^{2}$.

\section{Inflammatory cells in the tumor microenvironment and their prognostic value}

The inflammatory microenvironment of tumors is characterised by the presence of host leukocytes both in the surrounding stroma and in intratumoral areas. The infiltration of these leukocytes into tumor tissues is controlled by the local microenvironment and precedes the lytic cascade by which leukocytes attack tumor cells ${ }^{57}$. In tumor infiltrates, many different leukocyte subsets can be found (figure 2).

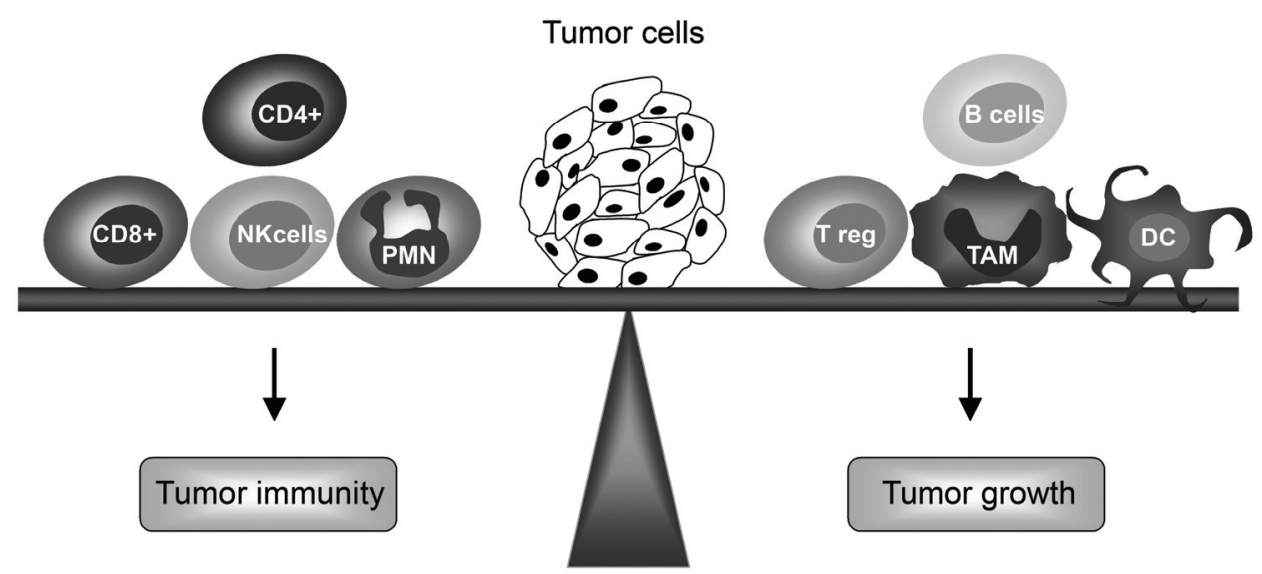

Figure 2. Several subsets of leukocytes implicated in tumor immunology

Almost all subsets of immune cells CD8+ cytotoxic T cells, CD4+ helper T cells, polymorphonuclear cells (PMN), Natural killer (NK) cells, can affect tumor development. However, as tumors progress, they often develop mechanism to escape from tumor immunity. Regulatory T cells (Tregs), tumor associated macrophages (TAM), B lymphocytes and dendritic cells (DC) are known to suppress the activity of other subsets and have been associated with tumor growth.

Polymorphonuclear cells (PMN), a class of specialised granulocytes, are the most abundant effector cells that provide the first-line defence against infections. Because they do not show any specificity for antigens, their predominant roles are cell killing and phagocytosis. PMNs are usually scarce in both human and animal tumors. However, they are considered to play an important role in immune surveillance because they release a variety of soluble chemotactic factors that guides the recruitment of other immune effector cells ${ }^{58}$. Their potential anti-tumor effect is questioned by clinical studies that have contradictory results on the function of PMNs in tumors. One study of Caruso et al describes an effector role of PMNs against cancer cells ${ }^{59}$, while others report on the negative prognostic value of PMNs in both melanomas ${ }^{60,61}$ and lung carcinomas ${ }^{62}$. 
Next to PMNs, natural killer (NK) cells also represent a group of innate effectors. They produce immunostimulatory cytokines and establish cytotoxicity against particular target cells and without the recognition of MHC antigens. The produced cytokines are regulating adaptive ( $\mathrm{T}$ - and B-cell mediated) immune responses. The apoptotic characteristics of NK cells is established by their ability to activate the perforin/granzyme pathway and extrinsic apoptotic-related pathways involving tumor necrosis factor-related apoptosis-inducing ligand (TRAIL) or Fas. In human cancer, the role of NK cells have been debated for a long time. However, abnormal cytotoxic function of NK cells in patients with Chediak Higashi syndrome was associated with the development of malignancies ${ }^{63}$. Similarly, mutation in the perforin gene was a predisposition for Hodgkin's and non-Hodgkin's lymphoma ${ }^{64}$ and polymorphism in Fas ligand was associated with increased incidence of cervical carcinoma ${ }^{65}$. In patients with established cancers, a study on pulmonary adenocarcinoma rejects the hypothesis that NK cells are mediators in tumor rejection ${ }^{6}$. High levels of NK cell infiltration present in tumor samples from patients with gastric carcinoma and lung cancer were associated with better survival 67,68 .

$\mathrm{T}$ lymphocytes are the most abundant leukocytes present in tumors, which can constitute up to $60 \%$ of the total infiltrate. T cells are able to recognize tumor-associated antigens and can finally kill the tumor cells. Since cancer is a disease caused by several mutations in several types of cells, different subsets of $\mathrm{T}$ cells are present for mediating tumor rejection. The mature $\mathrm{T}$ cell population is composed of CD4+ and CD8+ cells expressing the $\mathrm{T}$ cell receptor (TCR). CD8+ cells recognize antigens presented by the MHC class I molecules, while CD4+ cells are activated through MHC class II molecules 69. The role of $\mathrm{CD} 4+\mathrm{T}$ cells in tumor rejection is debated. Next to recognition of tumor antigens and migration to the tumor site, where they can help the CD8+ cells to attack the tumor, they also may be able to counteract the cytotoxic activity of CD8+ cells. The subset of CD4+ cells consist out of CD4+ helper cells and CD4+ regulatory cells ${ }^{69}$. The role of $\mathrm{CD} 4+$ regulatory $\mathrm{T}$ cells will be described in the paragraph of 'Tumor escape'. In humans, a high infiltrate of $\mathrm{T}$ cells was associated with both a longer survival $53,70-72$ and a short survival ${ }^{61,73,74}$.

Dendritic cells (DCs) are considered as the most potent antigen-presenting cells to initiate an immune response to pathogens. After uptake of antigens of peripheral blood or tissues, DCs migrate to the lymph nodes or secondary lymphoid tissue where they present the captured antigens to the cellular arm of the immune system. Subsequently, they play a crucial role in the activation, stimulation and recruitment of T lymphocytes. DCs are not often found in tumor infiltrates 70,75,76 and if present, they are mostly immature and unable to mount an effective immune response 77. Also there is controversy on the prognostic value of the amount of mature DCs present in tumors. Some papers report on the beneficial effect of DCs on survival ${ }^{78,79}$ while Sandel et al shows that patients with a high number of dentritic cells have a shorter survival ${ }^{80}$. However, since DCs are the most professional antigen-presenting cells of the immune system, they have been exploited in treatment of cancer. 
Marcophages are released from the bone marrow as immature monocytes. When they migrate into tissues, they will differentiate to mature, resident macrophages. Once they infiltrate into the tumor, they become activated by Th1 cells and will produce an increased number of lysosomes. In parallel, antigens will be processed into antigen epitopes which can be recognised by T lymphocytes. Due to the production of chemoattractants by tumor cells, there is a constant recruitment of monocytes to the tumor ${ }^{81}$. Macrophages are known to infiltrate abundantly in tumor tissues and may represent up to $80 \%$ of the total mass of the tumor $70,82,83$. Some papers showed a favourable prognostic value of tumor associated macrophages (TAM) ${ }^{84,85}$, however, most papers linked the amount of TAMs to a reduced patient survival ${ }^{86-91}$. It is clear that TAMs have contradictory effect on tumor growth. TAMs are capable of killing tumor cells and can produce angiostatic compounds. On the other hand, they can also produce pro-angiogenic compounds (like VEGF, bFGF, interleukin-8, tumor necrosis factor- $\alpha$ and several matrix metallo proteinase) and stimulate tumor progression. In addtion, TAMs respond to hypoxia by up-regulating the hypoxiainducible factors HIF-1 and HIF-2 and subsequently VEGF ${ }^{81,92}$, and high numbers of TAMs have been associated with the early establishment of metastasis ${ }^{82,93}$.

B lymphocytes are the third class of antigen presenting cells, next to the macrophages and dendritic cells. They are the immune cells that express and produce antibodies. B cells are activated and start to proliferate, resulting in expansion of the clones of antigen-specific cells and differentiate and undergo maturation, resulting in the generation of effector cells that actively secrete antibodies that act to eliminate the antigen. Cancer patients are known to have a high number of antibodies against tumor antigens ${ }^{94}$. There is only little data on the prognostic value of B cells in tumor progression. A higher amount of B cells in the peripheral blood was associated with a good prognosis in melanoma patients ${ }^{95}$. The amount of B cells that infiltrate in tumor, however, is very low ${ }^{61,96}$.

In conclusion, the prognostic value of different subsets of infiltrating leukocytes is still controversial. Together with the limited success of clinical trials, there is a growing believe that many anti-tumor immune responses act as a double-edged sword and under different conditions they could either become ineffective or even protumorigenic.

\section{Tumor escape}

There is a large amount of evidence that tumors can escape from immunity. In some papers, it seems that the immune system itself is incapable of interfering with tumor progression. Others report on the fact that the immune system can prevent tumor growth initially but is becoming ineffective later on.

There is evidence of secretion of immunosuppressive cytokines. The two most studied cytokines are interleukin-10 and transforming growth factor- $\beta$ (TGF- $\beta$ ). Interleukin-10 has been shown to interfere with several immune functions like $\mathrm{T}$ cell proliferation, Th1 cytokine production, antigen presentation and activated NK 
cytotoxicity ${ }^{97}$. In early stage tumors TGF- $\beta$ inhibits tumor development while in later stage TGF- $\beta$ is involved in tumor promotion. Its immunosuppressive role is in the inhibition of proliferation of $\mathrm{T}$ lymphocytes, NK Tcells, NK cells, neutrophils, macrophages and B-cells ${ }^{98}$.

Tumor cells seem to prevent the recognition and lysis by cytotoxic $T$ cells due to the downregulation or even loss of MHC class I molecules ${ }^{99}$. A key player of this effect is $\beta 2$-microglobulin ${ }^{100}$. Moreover, there is evidence that both DC and tumor cells failed to express important co-stimulatory molecules, like CD80 and CD86 on DCs ${ }^{101}$ or ICAM-1 and CD40 on tumor cells ${ }^{102,}{ }^{103}$. This causes inefficient priming because the right 'foreign' signal is missing. Also the alterations in signal-transducing molecules can cause immunosuppression. In several cancer types, the loss of the CD3 zeta chain in TCR was observed and was able to block the activation of T cells ${ }^{104}$.

More direct examples of tumor escape concern $\mathrm{T}$ cell destruction, $\mathrm{T}$ cell anergy and the induction of suppressor cells. The involvement of fas/fas ligand pathway in clonal deletion of $\mathrm{T}$ cells was observed, however, the exact mechanism still need to be resolved ${ }^{105}$. More recent data suggest that the T cells express FasL causing them to kill themselves ${ }^{106}$. Not only the destruction of $\mathrm{T}$ cells but also mechanisms involving anergy-induction can cause tumor escape. On the surface of melanoma cells naturally occurring peptide sequences, form endogenous and foreign antigens, can act as agonist for the MelanA antigen. This causes deficiency in cytotoxic activity of anti-tumor T cells ${ }^{107}$. Dendritic cells have been reported to produce indoleamine2,3-dioxygenase. This component can suppresses $\mathrm{T}$ cell proliferation and can cause $\mathrm{T}$ cell apoptosis and $\mathrm{T}$ cell anergy ${ }^{108}$.

There is also a rising interest in the role of immunosuppressive cells in tumor immunity. Many of the above described mechanisms of tumor escape result in the development of $\mathrm{T}$ regulatory $\mathrm{CD} 4+\mathrm{CD} 25+$ cells. Recent data showed that only a subset of regulatory $\mathrm{T}$ cells, those that are FoxP3+, are functionally regulatory $\mathrm{T}$ cells ${ }^{109}$. They are able to suppress $\mathrm{CD} 8+$ and $\mathrm{CD} 4+\mathrm{T}$ cells without killing them through cell-cell contact and they produce of immunosuppressive factors such as IL-10 and TGF- $\beta$. The exact contact-mechanisms $\mathrm{T}$ regulatory cells with $\mathrm{T}$ cells are still not understood ${ }^{110}$. The number of regulatory $\mathrm{T}$ cells was found to be elevated in cancer patients ${ }^{111}$. These cells could account for the failure of some cancer immunotherapies. The manipulation of regulatory $\mathrm{T}$ cells is therefore discussed as a novel strategy in tumor inhibition.

It is likely that, in order to eradicate human tumors, a combination of strategies is needed, including adoptive transfer of tumor-specific $\mathrm{T}$ cells and tumor-associated antigen presenting DCs, interference with the suppressive tumor microenvironment, the administration of immune-activating cytokines and the manipulation of regulatory $\mathrm{T}$ cells. 


\section{Vasculogenic mimicry}

In 1999, the term "vasculogenic mimicry" was introduced to describe the masquerade of tumor cells as endothelial cells. This process of tumor cell plasticity manifests mainly in aggressive tumors in which tumor cells dedifferentiate to an endothelial phenotype and make tube-like structures. This mechanism supplies tumor cells with a secondary circulation system of vasculogenic structures lined by tumor cells, independently of angiogenesis ${ }^{4}$. This form of tumor cell plasticity was first detected in melanomas. In tissue sections of uveal and cutaneous melanomas and their respective liver metastases patterned networks of interconnected loops of extracellular matrix were observed. The presence of these periodic acid-Shiff's (PAS) patterns was associated with worse patient outcome ${ }^{112}$. Furthermore, analysis of these PAS positive networks demonstrated a connection with regular blood vessels. However, endothelial cells could not be identified, strongly suggesting that these vessel-like structures are lined by tumor cells. In in vitro experiments the same patterned networks in collagen and matrigel threedimensional cultures with aggressive melanoma cell lines were observed while poorly invasive melanoma cell lines did not execute these patterned structures ${ }^{4}$. Importantly, the term vasculogenic mimicry is used to describe three different phenomenons that are observed in aggressive tumors. Not only PAS patterns of extracellular matrix, but also the presence of mosaic vessels, partly lined by endothelial cells and partly by tumor cells and the presence of blood lakes, lakes of red blood cells lined by tumor cells, are defined as being vasculogenic mimicry (figure 3).

Analysis of gene expression, by means of a microarray, of highly invasive versus poorly invasive melanoma cells from the same patient demonstrated a genetic dedifferentiation of aggressive melanoma cells to an embryonic-like phenotype ${ }^{113}$. Genes such as VE-cadherin, Ephrin A2 and tissue factor pathway inhibitors, CD34, tyrosine kinase receptor 1, neuropilin 1, E-selectin and endoglin (CD105), that are normally associated with endothelial cells, showed a more than 2-fold increased expression in vasculogenic mimicry positive cells. On the other hand, genes that are related to a melanocytic phenotype, like Melan-A, microphthalmia-associated transcription factor (MTIF) and tyrosinase, were more than 20-fold downregulated. Futhermore, it seems that the matrix composition is essential for tube-formation of tumor cells since genes such as laminin $5 \gamma 2$, fibronectin, collagen IV $\alpha 2$, collagen I had an increased expression.

Several attempts have been made to unravel the exact mechanism underlying vasculogenic mimicry. Some molecules have been identified to have a functional role, however, their exact role and signalling cascade still need to be determined. First of all, PI3 kinase (PI3K) was suggested as a mediator in activating the transmembrane metalloproteinase MT1MMP ${ }^{113}$. MT1MMP in his turn activates matrix metalloproteinase- 2 that cleaves laminin $5 \gamma 2$ into pro-migratory fragments to create a pro-migratory environment for tumor cells ${ }^{114}$. The downregulation of VE-cadherin and 


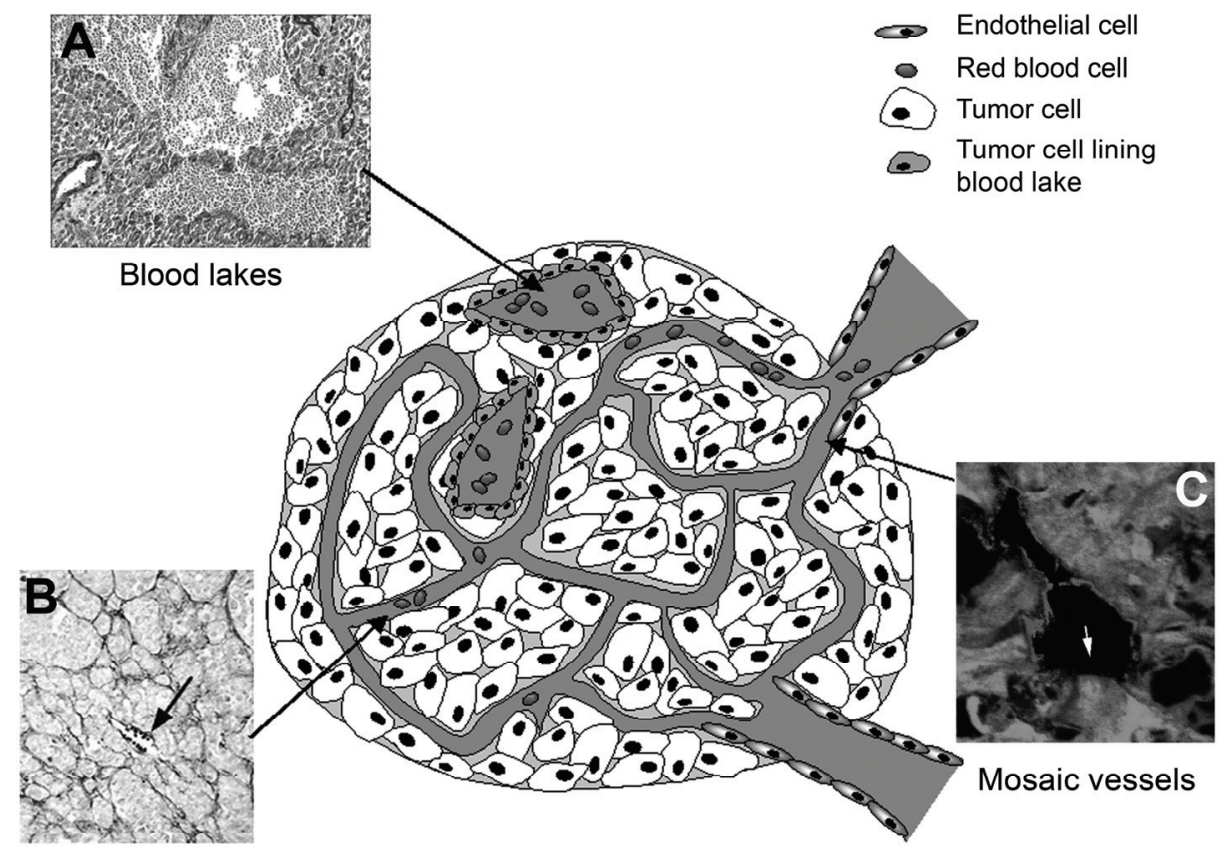

PAS patterns

Figure 3. Schematic representation of vasculogenic mimicry

This diagram represents the current interpretation of different forms of vasculogenic mimicry. A. Lakes with red blood cells lines by tumor cells, blood lakes, have been characterized in human Ewing sarcomas ${ }^{126}$. B. The fluid-conducting extracellular matrix PAS patterns have first been described in melanoma in which also erythrocytes were present ${ }^{4}$. C. Vessels, partly lined by tumor cells and endothelial cells, named mosaic vessels were observed in breast carcinoma xenograft ${ }^{127}$.

Ephrin A2 in melanoma cells resulted in an abrogation of their ability to form vasculogenic-like structures ${ }^{115}$. Both molecules are found to co-localize and EphA2 expression can be regulated by binding of VE-cadherin on its receptor ephrin-A1. In addition, several other molecules, mostly found by means of siRNA techniques or antibody blocking techniques, have been identified to be important vasculogenic structure formation. Tissue factor pathway inhibitor 2 (TFPI-2) was found to be involved in the activation MMP-2 and in that way in the process of vasculogenic mimicry. Furthermore, several recent papers reported on different molecules like focal adhesion kinase, cyclooxygenase-2, bone morphogenetic protein-4, insuline-like growth factor binding protein 3 and Nodal and their role in promoting an aggressive melanoma phenotype ${ }^{116-120}$. 
As already described above, also the extracellular matrix, as a component of the microenvironment, is of great importance in the process of vasculogenic mimicry. Exposure of normal epidermal melanocytes to a matrix conditioned by metastatic cutaneous melanoma, resulted in reprogrammation of melanocytes to a genotype with specific genes that were associated with the ability to form vasculogenic-like networks. These changes in gene expression were only transient, because the dedifferentiated pheno- and genotype was restored back to a normal melanocyte phenotype after 7 to 21 days ${ }^{121}$. Also, a role of oxygen, another microenviromental component, has been described in melanocyte transformation. Low levels of oxygen or hypoxia, are able to stimulate melanoma cell invasion, metastasis and transformation ${ }^{122,}{ }^{123}$. In addition, vasculogenic mimicry tube formation was stimulated in vitro by hypoxic conditions ${ }^{124}$. The role of hypoxia in vasculogenic mimicry has also been observed in vivo in a B16 melanoma ischemic limb mouse model. In these tumors, the amount of vasculogenic mimicry channels and the gene expression of HIF-1 $\alpha$, MMP-2, MMP-9 and VEGF was increased ${ }^{125}$. Several growth factors, such as basic fibroblast growth factor, vascular endothelial growth factor, Transforming Growth Factor- $\beta$, platelet derived growth factor and tumor necrosis factor- $\alpha$ were also studied in their role in vasculogenic mimicry. However, they were found not to be able to induce formation of vascular networks even when added to the poorly invasive melanoma cell lines ${ }^{4}$. This indicates that angiogenesis and vasculogenic mimicry, in contrast to the previous described tumor vascularization types, are not sharing the same signalling pathways. Moreover, anti-angiogenesis targeting strategies do not inhibit the process of vasculogenic mimicry ${ }^{126}$ and could even induce the formation of vasculogenic mimicry vessels as an escape mechanism of the tumor to keep on growing.

The recent findings on the 'plastic' endothelial-like phenotype of melanoma and other tumor cells confused the field of cancer biology even more. The idea that these structures could form a functional secondary vascular network that provides the tumor of blood, independent from angiogenic growth factors, makes tumor growth inhibition even more complex. 


\section{Aim and outline of the thesis}

Cancer is one of the most important causes of death in western countries. Although mouse studies showed promising tumor inhibition strategies, most clinical trials have been showing limited results until now. In this thesis, we focus on several mechanisms and processes that are associated to tumor escape mechanisms of immunosurveillance and anti-angiogenesis strategies. The discovery of the process of vasculogenic mimicry brought new but confusing insights in the complex field of tumorigenesis. It is obvious that more knowledge on this process is needed to be able to develop better tumor targeting strategies.

The mechanism of vasculogenic mimicry was used as a red thread through this thesis. Several other mechanisms important in tumorigenesis, such as angiogenesis, tumor immunity, different growth factors and microenviromental conditions, were investigated in their involvement and/or regulatory function with/in vasculogenic mimicry.

In chapter 2, we reviewed the different vascularisation types that are present in solid tumors. With the identification of sprouting angiogenesis and specific angiogenic factors, it was thought that anti-angiogenesis strategies could be the cure for cancer. However, the discovery of the contribution of intussusceptive angiogenesis, recruitment of endothelial progenitor cells, vessel co-option, vasculogenic mimicry and lymphangiogenesis to tumour growth makes anti-tumour targeting strategies more complex than initially thought. Analysis of these additional mechanisms, their molecular players and clinical relevance, urged us to suggest combination of a multimodal anti-vascular approach to inhibit tumor growth.

To develop new anti-angiogenesis therapies and to evaluate the amount of sprouting angiogenesis, it is very important to be able to quantify angiogenesis in an accurate way. In chapter 3 , we described a new method to analyse sprouting angiogenesis. We investigated a series of cutaneous melanomas for the presence of active neovascularisation by quantifying the amount of proliferating endothelial cells and report that it has prognostic value in contrast to the measurement of only the amount of vessels.

Since vasculogenic mimicry channels have been suggested to play a role in tumor circulation, we investigated the relationship between vasculogenic mimicry and sprouting angiogenesis and its contribution in tumor immunity. Although we were not able to find a correlation between vasculogenic mimicry and angiogenesis, there was a clear association between vasculogenic mimicry and the amount of infiltrated leukocytes (Chapter 4). In this series of melanoma tissues, vasculogenic mimicry and the amount of $\mathrm{T}$ cells and polymorphonuclear cells were identified as a negative prognostic marker. This urged us to analyse the activating status of lymphocytes. We observed that tumor progression was associated with a lower amount of activated lymphocytes. 
|Chapter 1

Furthermore, vasculogenic mimicry was investigated in a different tumor type, Ewing sarcoma. In chapter 5, we show that Ewing sarcomas have blood lakes lined by tumor cells. The presence of these structures could be correlated with a worse prognosis for the patient. Furthermore, three dimensional in vitro experiments and gene expression assays confirmed the presence of vasculogenic mimicry.

Evidence suggested that process of vasculogenic mimicry was not stimulated by angiogenic growth factors, but could be mediated by hypoxia. Microarray analysis, in vitro experiments in hypoxic conditions and siRNA techniques suggested a role of hypoxia and HIF1-alpha in vasculogenic mimicry (chapter 6). 


\section{References}

1. Carmeliet, P. and Jain, R. K. Angiogenesis in cancer and other diseases. Nature, 407: 249-257, 2000.

2. Balkwill, F. and Mantovani, A. Inflammation and cancer: back to Virchow? Lancet, 357: 539545, 2001.

3. Ramirez-Montagut, T., Turk, M. J., Wolchok, J. D., Guevara-Patino, J. A., and Houghton, A. N. Immunity to melanoma: unraveling the relation of tumor immunity and autoimmunity. Oncogene, 22: 3180-3187, 2003.

4. Maniotis, A. J., Folberg, R., Hess, A., Seftor, E. A., Gardner, L. M., Pe'er, J., Trent, J. M., Meltzer, P. S., and Hendrix, M. J. Vascular channel formation by human melanoma cells in vivo and in vitro: vasculogenic mimicry. Am J Pathol, 155: 739-752, 1999.

5. Griffioen, A. W. and Molema, G. Angiogenesis: potentials for pharmacologic intervention in the treatment of cancer, cardiovascular diseases, and chronic inflammation. Pharmacol Rev, 52: 237-268, 2000.

6. Hanahan, D. and Weinberg, R. A. The hallmarks of cancer. Cell, 100: 57-70, 2000.

7. Ferrara, N., Gerber, H. P., and LeCouter, J. The biology of VEGF and its receptors. Nat Med, 9: 669-676, 2003.

8. Jain, R. K. Molecular regulation of vessel maturation. Nat Med, 9: 685-693, 2003.

9. Kerbel, R. S. Tumor angiogenesis: past, present and the near future. Carcinogenesis, 21: 505515, 2000.

10. Itoh, N. and Ornitz, D. M. Evolution of the Fgf and Fgfr gene families. Trends Genet, 20: 563569, 2004.

11. Presta, M., Dell'Era, P., Mitola, S., Moroni, E., Ronca, R., and Rusnati, M. Fibroblast growth factor/fibroblast growth factor receptor system in angiogenesis. Cytokine Growth Factor Rev, 16: 159-178, 2005.

12. Ferrara, N. and Davis-Smyth, T. The biology of vascular endothelial growth factor. Endocr Rev, 18: 4-25, 1997.

13. Iyer, S. and Acharya, K. R. Role of placenta growth factor in cardiovascular health. Trends Cardiovasc Med, 12: 128-134, 2002.

14. Carmeliet, P., Moons, L., Luttun, A., Vincenti, V., Compernolle, V., De Mol, M., Wu, Y., Bono, F., Devy, L., Beck, H., Scholz, D., Acker, T., DiPalma, T., Dewerchin, M., Noel, A., Stalmans, I., Barra, A., Blacher, S., Vandendriessche, T., Ponten, A., Eriksson, U., Plate, K. H., Foidart, J. M., Schaper, W., Charnock-Jones, D. S., Hicklin, D. J., Herbert, J. M., Collen, D., and Persico, M. G. Synergism between vascular endothelial growth factor and placental growth factor contributes to angiogenesis and plasma extravasation in pathological conditions. Nat Med, 7: 575-583, 2001.

15. Davis, S., Aldrich, T. H., Jones, P. F., Acheson, A., Compton, D. L., Jain, V., Ryan, T. E., Bruno, J., Radziejewski, C., Maisonpierre, P. C., and Yancopoulos, G. D. Isolation of angiopoietin-1, a ligand for the TIE2 receptor, by secretion-trap expression cloning. Cell, 87: 1161-1169, 1996.

16. Maisonpierre, P. C., Suri, C., Jones, P. F., Bartunkova, S., Wiegand, S. J., Radziejewski, C., Compton, D., McClain, J., Aldrich, T. H., Papadopoulos, N., Daly, T. J., Davis, S., Sato, T. N., and Yancopoulos, G. D. Angiopoietin-2, a natural antagonist for Tie2 that disrupts in vivo angiogenesis. Science, 277: 55-60, 1997.

17. Elliott, R. L. and Blobe, G. C. Role of transforming growth factor Beta in human cancer. J Clin Oncol, 23: 2078-2093, 2005.

18. Armulik, A., Abramsson, A., and Betsholtz, C. Endothelial/pericyte interactions. Circ Res, 97: 512-523, 2005.

19. Petit, A. M., Rak, J., Hung, M. C., Rockwell, P., Goldstein, N., Fendly, B., and Kerbel, R. S. Neutralizing antibodies against epidermal growth factor and ErbB-2/neu receptor tyrosine kinases down-regulate vascular endothelial growth factor production by tumor cells in vitro and in vivo: angiogenic implications for signal transduction therapy of solid tumors. Am J Pathol, 151: 1523-1530, 1997. 
20. Li, A., Dubey, S., Varney, M. L., Dave, B. J., and Singh, R. K. IL-8 directly enhanced endothelial cell survival, proliferation, and matrix metalloproteinases production and regulated angiogenesis. J Immunol, 170: 3369-3376, 2003.

21. Rastinejad, F., Polverini, P. J., and Bouck, N. P. Regulation of the activity of a new inhibitor of angiogenesis by a cancer suppressor gene. Cell, 56: 345-355, 1989.

22. Ferrara, N., Clapp, C., and Weiner, R. The 16K fragment of prolactin specifically inhibits basal or fibroblast growth factor stimulated growth of capillary endothelial cells. Endocrinology, 129: 896-900, 1991.

23. Kolber, D. L., Knisely, T. L., and Maione, T. E. Inhibition of development of murine melanoma lung metastases by systemic administration of recombinant platelet factor 4 . J Natl Cancer Inst, 87: 304-309, 1995.

24. Luster, A. D., Greenberg, S. M., and Leder, P. The IP-10 chemokine binds to a specific cell surface heparan sulfate site shared with platelet factor 4 and inhibits endothelial cell proliferation. J Exp Med, 182: 219-231, 1995.

25. O'Reilly, M. S., Holmgren, L., Shing, Y., Chen, C., Rosenthal, R. A., Moses, M., Lane, W. S., Cao, Y., Sage, E. H., and Folkman, J. Angiostatin: a novel angiogenesis inhibitor that mediates the suppression of metastases by a Lewis lung carcinoma. Cell, 79: 315-328, 1994.

26. O'Reilly, M. S., Boehm, T., Shing, Y., Fukai, N., Vasios, G., Lane, W. S., Flynn, E., Birkhead, J. R., Olsen, B. R., and Folkman, J. Endostatin: an endogenous inhibitor of angiogenesis and tumor growth. Cell, 88: 277-285, 1997.

27. van der Schaft, D. W., Toebes, E. A., Haseman, J. R., Mayo, K. H., and Griffioen, A. W. Bactericidal/permeability-increasing protein (BPI) inhibits angiogenesis via induction of apoptosis in vascular endothelial cells. Blood, 96: 176-181, 2000.

28. Maeshima, Y., Colorado, P. C., Torre, A., Holthaus, K. A., Grunkemeyer, J. A., Ericksen, M. B., Hopfer, H., Xiao, Y., Stillman, I. E., and Kalluri, R. Distinct antitumor properties of a type IV collagen domain derived from basement membrane. J Biol Chem, 275: 21340-21348, 2000.

29. Tabruyn, S. P. and Griffioen, A. W. Molecular pathways of angiogenesis inhibition. Biochem Biophys Res Commun, 355: 1-5, 2007.

30. Marx, J. Angiogenesis. A boost for tumor starvation. Science, 301: 452-454, 2003.

31. Ferrara, N. and Kerbel, R. S. Angiogenesis as a therapeutic target. Nature, 438: 967-974, 2005.

32. Hurwitz, H., Fehrenbacher, L., Novotny, W., Cartwright, T., Hainsworth, J., Heim, W., Berlin, J., Baron, A., Griffing, S., Holmgren, E., Ferrara, N., Fyfe, G., Rogers, B., Ross, R., and Kabbinavar, F. Bevacizumab plus irinotecan, fluorouracil, and leucovorin for metastatic colorectal cancer. N Engl J Med, 350: 2335-2342, 2004.

33. Pugh, C. W. and Ratcliffe, P. J. Regulation of angiogenesis by hypoxia: role of the HIF system. Nat Med, 9: 677-684, 2003.

34. Semenza, G. L. Targeting HIF-1 for cancer therapy. Nat Rev Cancer, 3: 721-732, 2003.

35. Pages, G. and Pouyssegur, J. Transcriptional regulation of the Vascular Endothelial Growth Factor gene--a concert of activating factors. Cardiovasc Res, 65: 564-573, 2005.

36. Huang, S., Pettaway, C. A., Uehara, H., Bucana, C. D., and Fidler, I. J. Blockade of NF-kappaB activity in human prostate cancer cells is associated with suppression of angiogenesis, invasion, and metastasis. Oncogene, 20: 4188-4197, 2001.

37. Mizukami, Y., Li, J., Zhang, X., Zimmer, M. A., Iliopoulos, O., and Chung, D. C. Hypoxiainducible factor-1-independent regulation of vascular endothelial growth factor by hypoxia in colon cancer. Cancer Res, 64: 1765-1772, 2004.

38. Mizukami, Y., Jo, W. S., Duerr, E. M., Gala, M., Li, J., Zhang, X., Zimmer, M. A., Iliopoulos, O., Zukerberg, L. R., Kohgo, Y., Lynch, M. P., Rueda, B. R., and Chung, D. C. Induction of interleukin-8 preserves the angiogenic response in HIF-1alpha-deficient colon cancer cells. Nat Med, 11: 992-997, 2005.

39. Ryan, H. E., Lo, J., and Johnson, R. S. HIF-1 alpha is required for solid tumor formation and embryonic vascularization. Embo J, 17: 3005-3015, 1998.

40. Liao, D., Corle, C., Seagroves, T. N., and Johnson, R. S. Hypoxia-inducible factor-1alpha is a key regulator of metastasis in a transgenic model of cancer initiation and progression. Cancer Res, 67: 563-572, 2007. 
41. Vaupel, P. and Mayer, A. Hypoxia in cancer: significance and impact on clinical outcome. Cancer Metastasis Rev, 2007.

42. Vaupel, P. The role of hypoxia-induced factors in tumor progression. Oncologist, 9 Suppl 5: 10-17, 2004.

43. von Pawel, J., von Roemeling, R., Gatzemeier, U., Boyer, M., Elisson, L. O., Clark, P., Talbot, D., Rey, A., Butler, T. W., Hirsh, V., Olver, I., Bergman, B., Ayoub, J., Richardson, G., Dunlop, D., Arcenas, A., Vescio, R., Viallet, J., and Treat, J. Tirapazamine plus cisplatin versus cisplatin in advanced non-small-cell lung cancer: A report of the international CATAPULT I study group. Cisplatin and Tirapazamine in Subjects with Advanced Previously Untreated NonSmall-Cell Lung Tumors. J Clin Oncol, 18: 1351-1359, 2000.

44. Cheong, I., Huang, X., Bettegowda, C., Diaz, L. A., Jr., Kinzler, K. W., Zhou, S., and Vogelstein, B. A bacterial protein enhances the release and efficacy of liposomal cancer drugs. Science, 314: 1308-1311, 2006.

45. Gordan, J. D., Bertout, J. A., Hu, C. J., Diehl, J. A., and Simon, M. C. HIF-2alpha promotes hypoxic cell proliferation by enhancing c-myc transcriptional activity. Cancer Cell, 11: 335347, 2007.

46. Brigati, C., Noonan, D. M., Albini, A., and Benelli, R. Tumors and inflammatory infiltrates: friends or foes? Clin Exp Metastasis, 19: 247-258, 2002.

47. Vesalainen, S., Lipponen, P., Talja, M., and Syrjanen, K. Histological grade, perineural infiltration, tumour-infiltrating lymphocytes and apoptosis as determinants of long-term prognosis in prostatic adenocarcinoma. Eur J Cancer, 30A: 1797-1803, 1994.

48. Marrogi, A. J., Munshi, A., Merogi, A. J., Ohadike, Y., El-Habashi, A., Marrogi, O. L., and Freeman, S. M. Study of tumor infiltrating lymphocytes and transforming growth factor-beta as prognostic factors in breast carcinoma. Int J Cancer, 74: 492-501, 1997.

49. Chao, H. T., Wang, P. H., Tseng, J. Y., Lai, C. R., Chiang, S. C., and Yuan, C. C. Lymphocyteinfiltrated FIGO Stage IIB squamous cell carcinoma of the cervix is a prominent factor for disease-free survival. Eur J Gynaecol Oncol, 20: 136-140, 1999.

50. Naito, Y., Saito, K., Shiiba, K., Ohuchi, A., Saigenji, K., Nagura, H., and Ohtani, H. CD8+ T cells infiltrated within cancer cell nests as a prognostic factor in human colorectal cancer. Cancer Res, 58: 3491-3494, 1998.

51. Schumacher, K., Haensch, W., Roefzaad, C., and Schlag, P. M. Prognostic significance of activated CD8(+) T cell infiltrations within esophageal carcinomas. Cancer Res, 61: 3932-3936, 2001.

52. Cho, Y., Miyamoto, M., Kato, K., Fukunaga, A., Shichinohe, T., Kawarada, Y., Hida, Y., Oshikiri, T., Kurokawa, T., Suzuoki, M., Nakakubo, Y., Hiraoka, K., Murakami, S., Shinohara, T., Itoh, T., Okushiba, S., Kondo, S., and Katoh, H. CD4+ and CD8+ T cells cooperate to improve prognosis of patients with esophageal squamous cell carcinoma. Cancer Res, 63: 1555-1559, 2003.

53. Zhang, L., Conejo-Garcia, J. R., Katsaros, D., Gimotty, P. A., Massobrio, M., Regnani, G., Makrigiannakis, A., Gray, H., Schlienger, K., Liebman, M. N., Rubin, S. C., and Coukos, G. Intratumoral T cells, recurrence, and survival in epithelial ovarian cancer. N Engl J Med, 348: 203-213, 2003.

54. Sato, E., Olson, S. H., Ahn, J., Bundy, B., Nishikawa, H., Qian, F., Jungbluth, A. A., Frosina, D., Gnjatic, S., Ambrosone, C., Kepner, J., Odunsi, T., Ritter, G., Lele, S., Chen, Y. T., Ohtani, H., Old, L. J., and Odunsi, K. Intraepithelial CD8+ tumor-infiltrating lymphocytes and a high $\mathrm{CD} 8+/$ regulatory $\mathrm{T}$ cell ratio are associated with favorable prognosis in ovarian cancer. Proc Natl Acad Sci U S A, 102: 18538-18543, 2005.

55. Badoual, C., Hans, S., Rodriguez, J., Peyrard, S., Klein, C., Agueznay Nel, H., Mosseri, V., Laccourreye, O., Bruneval, P., Fridman, W. H., Brasnu, D. F., and Tartour, E. Prognostic value of tumor-infiltrating CD4+ T-cell subpopulations in head and neck cancers. Clin Cancer Res, 12: 465-472, 2006.

56. Hiraoka, K., Miyamoto, M., Cho, Y., Suzuoki, M., Oshikiri, T., Nakakubo, Y., Itoh, T., Ohbuchi, T., Kondo, S., and Katoh, H. Concurrent infiltration by CD8+ T cells and CD4+ T cells is a favourable prognostic factor in non-small-cell lung carcinoma. Br J Cancer, 94: 275280, 2006. 
57. Chen, Q., Wang, W. C., and Evans, S. S. Tumor microvasculature as a barrier to antitumor immunity. Cancer Immunol Immunother, 52: 670-679, 2003.

58. Di Carlo, E., Forni, G., Lollini, P., Colombo, M. P., Modesti, A., and Musiani, P. The intriguing role of polymorphonuclear neutrophils in antitumor reactions. Blood, 97: 339-345, 2001.

59. Caruso, R. A., Bellocco, R., Pagano, M., Bertoli, G., Rigoli, L., and Inferrera, C. Prognostic value of intratumoral neutrophils in advanced gastric carcinoma in a high-risk area in northern Italy. Mod Pathol, 15: 831-837, 2002.

60. Schmidt, H., Suciu, S., Punt, C. J., Gore, M., Kruit, W., Patel, P., Lienard, D., von der Maase, H., Eggermont, A. M., and Keilholz, U. Pretreatment levels of peripheral neutrophils and leukocytes as independent predictors of overall survival in patients with American Joint Committee on Cancer Stage IV Melanoma: results of the EORTC 18951 Biochemotherapy Trial. J Clin Oncol, 25: 1562-1569, 2007.

61. Hillen, F., Baeten, C. I., van de Winkel, A., Creytens, D., van der Schaft, D. W., Winnepenninckx, V., and Griffioen, A. W. Leukocyte infiltration and tumor cell plasticity are parameters of aggressiveness in primary cutaneous melanoma. Cancer Immunol Immunother, 57(1):97-106, 2008.

62. Bellocq, A., Antoine, M., Flahault, A., Philippe, C., Crestani, B., Bernaudin, J. F., Mayaud, C., Milleron, B., Baud, L., and Cadranel, J. Neutrophil alveolitis in bronchioloalveolar carcinoma: induction by tumor-derived interleukin-8 and relation to clinical outcome. Am J Pathol, 152: 83-92, 1998.

63. Kobayashi, N. Malignant neoplasms in registered cases of primary immunodeficiency syndrome. Jpn J Clin Oncol, 15 Suppl 1: 307-312, 1985.

64. Clementi, R., Locatelli, F., Dupre, L., Garaventa, A., Emmi, L., Bregni, M., Cefalo, G., Moretta, A., Danesino, C., Comis, M., Pession, A., Ramenghi, U., Maccario, R., Arico, M., and Roncarolo, M. G. A proportion of patients with lymphoma may harbor mutations of the perforin gene. Blood, 105: 4424-4428, 2005.

65. Sun, T., Zhou, Y., Li, H., Han, X., Shi, Y., Wang, L., Miao, X., Tan, W., Zhao, D., Zhang, X., Guo, Y., and Lin, D. FASL -844C polymorphism is associated with increased activationinduced T cell death and risk of cervical cancer. J Exp Med, 202: 967-974, 2005.

66. Takanami, I., Takeuchi, K., and Giga, M. The prognostic value of natural killer cell infiltration in resected pulmonary adenocarcinoma. J Thorac Cardiovasc Surg, 121: 1058-1063, 2001.

67. Ishigami, S., Natsugoe, S., Tokuda, K., Nakajo, A., Che, X., Iwashige, H., Aridome, K., Hokita, S., and Aikou, T. Prognostic value of intratumoral natural killer cells in gastric carcinoma. Cancer, 88: 577-583, 2000.

68. Villegas, F. R., Coca, S., Villarrubia, V. G., Jimenez, R., Chillon, M. J., Jareno, J., Zuil, M., and Callol, L. Prognostic significance of tumor infiltrating natural killer cells subset CD57 in patients with squamous cell lung cancer. Lung Cancer, 35: 23-28, 2002.

69. Yu, P. and Fu, Y. X. Tumor-infiltrating T lymphocytes: friends or foes? Lab Invest, 86: 231-245, 2006.

70. Kataki, A., Scheid, P., Piet, M., Marie, B., Martinet, N., Martinet, Y., and Vignaud, J. M. Tumor infiltrating lymphocytes and macrophages have a potential dual role in lung cancer by supporting both host-defense and tumor progression. J Lab Clin Med, 140: 320-328, 2002.

71. Nielsen, H. J., Hansen, U., Christensen, I. J., Reimert, C. M., Brunner, N., and Moesgaard, F. Independent prognostic value of eosinophil and mast cell infiltration in colorectal cancer tissue. J Pathol, 189: 487-495, 1999.

72. Kondratiev, S., Sabo, E., Yakirevich, E., Lavie, O., and Resnick, M. B. Intratumoral CD8+ T lymphocytes as a prognostic factor of survival in endometrial carcinoma. Clin Cancer Res, 10: 4450-4456, 2004.

73. Shibakita, M., Tachibana, M., Dhar, D. K., Kotoh, T., Kinugasa, S., Kubota, H., Masunaga, R., and Nagasue, N. Prognostic significance of Fas and Fas ligand expressions in human esophageal cancer. Clin Cancer Res, 5: 2464-2469, 1999.

74. Nakano, O., Sato, M., Naito, Y., Suzuki, K., Orikasa, S., Aizawa, M., Suzuki, Y., Shintaku, I., Nagura, H., and Ohtani, H. Proliferative activity of intratumoral CD8(+) T-lymphocytes as a prognostic factor in human renal cell carcinoma: clinicopathologic demonstration of antitumor immunity. Cancer Res, 61: 5132-5136, 2001. 
75. Tazi, A., Bouchonnet, F., Grandsaigne, M., Boumsell, L., Hance, A. J., and Soler, P. Evidence that granulocyte macrophage-colony-stimulating factor regulates the distribution and differentiated state of dendritic cells/Langerhans cells in human lung and lung cancers. J Clin Invest, 91: 566-576, 1993.

76. Dallal, R. M., Christakos, P., Lee, K., Egawa, S., Son, Y. I., and Lotze, M. T. Paucity of dendritic cells in pancreatic cancer. Surgery, 131: 135-138, 2002.

77. Figdor, C. G., de Vries, I. J., Lesterhuis, W. J., and Melief, C. J. Dendritic cell immunotherapy: mapping the way. Nat Med, 10: 475-480, 2004.

78. Iwamoto, M., Shinohara, H., Miyamoto, A., Okuzawa, M., Mabuchi, H., Nohara, T., Gon, G., Toyoda, M., and Tanigawa, N. Prognostic value of tumor-infiltrating dendritic cells expressing CD83 in human breast carcinomas. Int J Cancer, 104: 92-97, 2003.

79. Eisenthal, A., Polyvkin, N., Bramante-Schreiber, L., Misonznik, F., Hassner, A., and LifschitzMercer, B. Expression of dendritic cells in ovarian tumors correlates with clinical outcome in patients with ovarian cancer. Hum Pathol, 32: 803-807, 2001.

80. Sandel, M. H., Dadabayev, A. R., Menon, A. G., Morreau, H., Melief, C. J., Offringa, R., van der Burg, S. H., Janssen-van Rhijn, C. M., Ensink, N. G., Tollenaar, R. A., van de Velde, C. J., and Kuppen, P. J. Prognostic value of tumor-infiltrating dendritic cells in colorectal cancer: role of maturation status and intratumoral localization. Clin Cancer Res, 11: 2576-2582, 2005.

81. Bingle, L., Brown, N. J., and Lewis, C. E. The role of tumour-associated macrophages in tumour progression: implications for new anticancer therapies. J Pathol, 196: 254-265, 2002.

82. Leek, R. D., Lewis, C. E., Whitehouse, R., Greenall, M., Clarke, J., and Harris, A. L. Association of macrophage infiltration with angiogenesis and prognosis in invasive breast carcinoma. Cancer Res, 56: 4625-4629, 1996.

83. Hussein, M. R. Tumour-associated macrophages and melanoma tumourigenesis: integrating the complexity. Int J Exp Pathol, 87: 163-176, 2006.

84. Ohno, S., Inagawa, H., Dhar, D. K., Fujii, T., Ueda, S., Tachibana, M., Suzuki, N., Inoue, M., Soma, G., and Nagasue, N. The degree of macrophage infiltration into the cancer cell nest is a significant predictor of survival in gastric cancer patients. Anticancer Res, 23: 5015-5022, 2003.

85. Piras, F., Colombari, R., Minerba, L., Murtas, D., Floris, C., Maxia, C., Corbu, A., Perra, M. T., and Sirigu, P. The predictive value of CD8, CD4, CD68, and human leukocyte antigen-Drelated cells in the prognosis of cutaneous malignant melanoma with vertical growth phase. Cancer, 104: 1246-1254, 2005.

86. Leek, R. D., Landers, R. J., Harris, A. L., and Lewis, C. E. Necrosis correlates with high vascular density and focal macrophage infiltration in invasive carcinoma of the breast. Br J Cancer, 79: 991-995, 1999.

87. Lissbrant, I. F., Stattin, P., Wikstrom, P., Damber, J. E., Egevad, L., and Bergh, A. Tumor associated macrophages in human prostate cancer: relation to clinicopathological variables and survival. Int J Oncol, 17: 445-451, 2000.

88. Ohno, S., Ohno, Y., Suzuki, N., Kamei, T., Koike, K., Inagawa, H., Kohchi, C., Soma, G., and Inoue, M. Correlation of histological localization of tumor-associated macrophages with clinicopathological features in endometrial cancer. Anticancer Res, 24: 3335-3342, 2004.

89. Hamada, I., Kato, M., Yamasaki, T., Iwabuchi, K., Watanabe, T., Yamada, T., Itoyama, S., Ito, H., and Okada, K. Clinical effects of tumor-associated macrophages and dendritic cells on renal cell carcinoma. Anticancer Res, 22: 4281-4284, 2002.

90. Jadus, M. R., Irwin, M. C., Irwin, M. R., Horansky, R. D., Sekhon, S., Pepper, K. A., Kohn, D. B., and Wepsic, H. T. Macrophages can recognize and kill tumor cells bearing the membrane isoform of macrophage colony-stimulating factor. Blood, 87: 5232-5241, 1996.

91. Farinha, P., Masoudi, H., Skinnider, B. F., Shumansky, K., Spinelli, J. J., Gill, K., Klasa, R., Voss, N., Connors, J. M., and Gascoyne, R. D. Analysis of multiple biomarkers shows that lymphoma-associated macrophage (LAM) content is an independent predictor of survival in follicular lymphoma (FL). Blood, 106: 2169-2174, 2005.

92. Lewis, C. E. and Pollard, J. W. Distinct role of macrophages in different tumor microenvironments. Cancer Res, 66: 605-612, 2006. 
93. Hanada, T., Nakagawa, M., Emoto, A., Nomura, T., Nasu, N., and Nomura, Y. Prognostic value of tumor-associated macrophage count in human bladder cancer. Int J Urol, 7: 263-269, 2000.

94. Disis, M. L. and Cheever, M. A. Oncogenic proteins as tumor antigens. Curr Opin Immunol, 8: 637-642, 1996.

95. Martinez-Escribano, J. A., Hernandez-Caselles, T., Campillo, J. A., Campos, M., Frias, J. F., Garcia-Alonso, A., and Alvarez-Lopez, M. R. Changes in the number of CD80(+), CD86(+), and CD28(+) peripheral blood lymphocytes have prognostic value in melanoma patients. Hum Immunol, 64: 796-801, 2003.

96. Baeten, C. I., Castermans, K., Hillen, H. F., and Griffioen, A. W. Proliferating endothelial cells and leukocyte infiltration as prognostic markers in colorectal cancer. Clin Gastroenterol Hepatol, 4: 1351-1357, 2006.

97. Salazar-Onfray, F., Lopez, M. N., and Mendoza-Naranjo, A. Paradoxical effects of cytokines in tumor immune surveillance and tumor immune escape. Cytokine Growth Factor Rev, 18: 171$182,2007$.

98. Jakowlew, S. B. Transforming growth factor-beta in cancer and metastasis. Cancer Metastasis Rev, 25: 435-457, 2006.

99. Schrier, P. I. and Peltenburg, L. T. Relationship between myc oncogene activation and MHC class I expression. Adv Cancer Res, 60: 181-246, 1993.

100. Paschen, A., Mendez, R. M., Jimenez, P., Sucker, A., Ruiz-Cabello, F., Song, M., Garrido, F., and Schadendorf, D. Complete loss of HLA class I antigen expression on melanoma cells: a result of successive mutational events. Int J Cancer, 103: 759-767, 2003.

101. Chaux, P., Moutet, M., Faivre, J., Martin, F., and Martin, M. Inflammatory cells infiltrating human colorectal carcinomas express HLA class II but not B7-1 and B7-2 costimulatory molecules of the T-cell activation. Lab Invest, 74: 975-983, 1996.

102. Vora, A. R., Rodgers, S., Parker, A. J., Start, R., Rees, R. C., and Murray, A. K. An immunohistochemical study of altered immunomodulatory molecule expression in head and neck squamous cell carcinoma. Br J Cancer, 76: 836-844, 1997.

103. Holub, M., Zakeri, S. M., Lichtenberger, C., Pammer, J., Paolini, P., Leifeld, L., Rockenschaub, S., Wolschek, M. F., Steger, G., Willheim, M., Gangl, A., and Reinisch, W. Heterogeneous expression and regulation of CD40 in human hepatocellular carcinoma. Eur J Gastroenterol Hepatol, 15: 119-126, 2003.

104. Pawelec, G. Tumour escape from the immune response. Cancer Immunol Immunother, 53: $843,2004$.

105. Hahne, M., Rimoldi, D., Schroter, M., Romero, P., Schreier, M., French, L. E., Schneider, P., Bornand, T., Fontana, A., Lienard, D., Cerottini, J., and Tschopp, J. Melanoma cell expression of Fas(Apo-1/CD95) ligand: implications for tumor immune escape. Science, 274: 1363-1366, 1996.

106. Restifo, N. P. Not so Fas: Re-evaluating the mechanisms of immune privilege and tumor escape. Nat Med, 6: 493-495, 2000.

107. Loftus, D. J., Squarcina, P., Nielsen, M. B., Geisler, C., Castelli, C., Odum, N., Appella, E., Parmiani, G., and Rivoltini, L. Peptides derived from self-proteins as partial agonists and antagonists of human CD8+ T-cell clones reactive to melanoma/melanocyte epitope MART1(27-35). Cancer Res, 58: 2433-2439, 1998.

108. Munn, D. H. and Mellor, A. L. Indoleamine 2,3-dioxygenase and tumor-induced tolerance. J Clin Invest, 117: 1147-1154, 2007.

109. Hori, S., Nomura, T., and Sakaguchi, S. Control of regulatory T cell development by the transcription factor Foxp3. Science, 299: 1057-1061, 2003.

110. Zou, W. Regulatory T cells, tumour immunity and immunotherapy. Nat Rev Immunol, 6: 295307, 2006.

111. Bach, J. F. Regulatory T cells under scrutiny. Nat Rev Immunol, 3: 189-198, 2003.

112. Folberg, R., Rummelt, V., Parys-Van Ginderdeuren, R., Hwang, T., Woolson, R. F., Pe'er, J., and Gruman, L. M. The prognostic value of tumor blood vessel morphology in primary uveal melanoma. Ophthalmology, 100: 1389-1398, 1993. 
113. Hendrix, M. J., Seftor, E. A., Hess, A. R., and Seftor, R. E. Vasculogenic mimicry and tumourcell plasticity: lessons from melanoma. Nat Rev Cancer, 3: 411-421, 2003.

114. Seftor, R. E., Seftor, E. A., Koshikawa, N., Meltzer, P. S., Gardner, L. M., Bilban, M., StetlerStevenson, W. G., Quaranta, V., and Hendrix, M. J. Cooperative interactions of laminin 5 gamma2 chain, matrix metalloproteinase-2, and membrane type-1-matrix/metalloproteinase are required for mimicry of embryonic vasculogenesis by aggressive melanoma. Cancer Res, 61: 6322-6327, 2001.

115. Hendrix, M. J., Seftor, E. A., Meltzer, P. S., Gardner, L. M., Hess, A. R., Kirschmann, D. A., Schatteman, G. C., and Seftor, R. E. Expression and functional significance of VE-cadherin in aggressive human melanoma cells: role in vasculogenic mimicry. Proc Natl Acad Sci U S A, 98: 8018-8023, 2001.

116. Hess, A. R., Postovit, L. M., Margaryan, N. V., Seftor, E. A., Schneider, G. B., Seftor, R. E., Nickoloff, B. J., and Hendrix, M. J. Focal adhesion kinase promotes the aggressive melanoma phenotype. Cancer Res, 65: 9851-9860, 2005.

117. Basu, G. D., Liang, W. S., Stephan, D. A., Wegener, L. T., Conley, C. R., Pockaj, B. A., and Mukherjee, P. A novel role for cyclooxygenase-2 in regulating vascular channel formation by human breast cancer cells. Breast Cancer Res, 8: R69, 2006.

118. Rothhammer, T., Bataille, F., Spruss, T., Eissner, G., and Bosserhoff, A. K. Functional implication of BMP4 expression on angiogenesis in malignant melanoma. Oncogene, 2006.

119. Xi, Y., Nakajima, G., Hamil, T., Fodstad, O., Riker, A., and Ju, J. Association of insulin-like growth factor binding protein-3 expression with melanoma progression. Mol Cancer Ther, 5: 3078-3084, 2006.

120. Topczewska, J. M., Postovit, L. M., Margaryan, N. V., Sam, A., Hess, A. R., Wheaton, W. W., Nickoloff, B. J., Topczewski, J., and Hendrix, M. J. Embryonic and tumorigenic pathways converge via Nodal signaling: role in melanoma aggressiveness. Nat Med, 12: 925-932, 2006.

121. Seftor, E. A., Brown, K. M., Chin, L., Kirschmann, D. A., Wheaton, W. W., Protopopov, A., Feng, B., Balagurunathan, Y., Trent, J. M., Nickoloff, B. J., Seftor, R. E., and Hendrix, M. J. Epigenetic transdifferentiation of normal melanocytes by a metastatic melanoma microenvironment. Cancer Res, 65: 10164-10169, 2005.

122. Rofstad, E. K., Rasmussen, H., Galappathi, K., Mathiesen, B., Nilsen, K., and Graff, B. A. Hypoxia promotes lymph node metastasis in human melanoma xenografts by up-regulating the urokinase-type plasminogen activator receptor. Cancer Res, 62: 1847-1853, 2002.

123. Bedogni, B., Welford, S. M., Cassarino, D. S., Nickoloff, B. J., Giaccia, A. J., and Powell, M. B. The hypoxic microenvironment of the skin contributes to Akt-mediated melanocyte transformation. Cancer Cell, 8: 443-454, 2005.

124. Rybak, S. M., Sanovich, E., Hollingshead, M. G., Borgel, S. D., Newton, D. L., Melillo, G., Kong, D., Kaur, G., and Sausville, E. A. "Vasocrine" formation of tumor cell-lined vascular spaces: implications for rational design of antiangiogenic therapies. Cancer Res, 63: 2812-2819, 2003.

125. Sun, B., Zhang, D., Zhang, S., Zhang, W., Guo, H., and Zhao, X. Hypoxia influences vasculogenic mimicry channel formation and tumor invasion-related protein expression in melanoma. Cancer Lett, 2006.

126. van der Schaft, D. W., Hillen, F., Pauwels, P., Kirschmann, D. A., Castermans, K., Egbrink, M. G., Tran, M. G., Sciot, R., Hauben, E., Hogendoorn, P. C., Delattre, O., Maxwell, P. H., Hendrix, M. J., and Griffioen, A. W. Tumor cell plasticity in Ewing sarcoma, an alternative circulatory system stimulated by hypoxia. Cancer Res, 65: 11520-11528, 2005.

127. Shirakawa, K., Kobayashi, H., Heike, Y., Kawamoto, S., Brechbiel, M. W., Kasumi, F., Iwanaga, T., Konishi, F., Terada, M., and Wakasugi, H. Hemodynamics in vasculogenic mimicry and angiogenesis of inflammatory breast cancer xenograft. Cancer Res, 62: 560-566, 2002. 



\section{Chapter 2}

\section{Tumour vascularization:}

\section{sprouting angiogenesis and beyond}

Femke Hillen, Arjan W. Griffioen

Cancer Metastasis Rev. 2008 Dec; 26(3-4):489-502 


\begin{abstract}
Tumour angiogenesis is a fast growing domain in tumour biology. Many growth factors and mechanisms have been unravelled. For almost 30 years, the sprouting of new vessels out of existing ones was considered as an exclusive way of tumour vascularisation. However, over the last years several additional mechanisms have been identified. With the discovery of the contribution of intussusceptive angiogenesis, recruitment of endothelial progenitor cells, vessel co-option, vasculogenic mimicry and lymphangiogenesis to tumour growth, anti-tumour targeting strategies will be more complex than initially thought. This review highlights these processes and intervention as an potential application in cancer therapy. It is concluded that future anti-vascular therapies might be most beneficial when based on multimodal anti-angiogenic, antivasculogenic mimicry and anti-lymphangiogenic strategies.
\end{abstract}

\title{
Introduction
}

Tumours can grow to a size of approximately 1-2 $\mathrm{mm}^{3}$ before their metabolic demands are restricted due to the diffusion limit of oxygen and nutrients. In order to grow beyond this size, the tumour switches to an angiogenic phenotype and attracts blood vessels from the surrounding stroma. This process is regulated by a variety of pro- and anti-angiogenic factors, and is a prerequisite for further outgrowth of the tumour ${ }^{1}$. Next to sprouting angiogenesis, the process by which new vessels are formed from preexisting vasculature, several other mechanisms of neovascularization have been identified in tumours, including intussusceptive angiogenesis, the recruitment of endothelial progenitor cells, vessel co-option, vasculogenic mimicry and lymphangiogenesis (figure 1). Due to application for treatment of disease, these processes gained a lot of interest over the last years. This review summarizes the different mechanisms of tumour vascularization, the molecular players that are involved and their relevance in clinical practice.

\section{Sprouting angiogenesis}

Sprouting angiogenesis is the growth of new capillary vessels out of pre-existing ones. These blood vessels will provide expanding tissues and organs with oxygen and nutrients, and remove the metabolic waste. Angiogenesis takes place in physiological situations, such as embryonic development, wound healing and reproduction. It also plays an important role in many pathologies, like diabetes ${ }^{2}$, rheumatoid arthritis ${ }^{3}$, cardiovascular ischemic complications ${ }^{4}$, and cancer ${ }^{5}$. In cancer, sprouting angiogenesis is not only important in primary tumours, it is also involved in metastasis formation and further outgrowth of metastases ${ }^{6}$. 


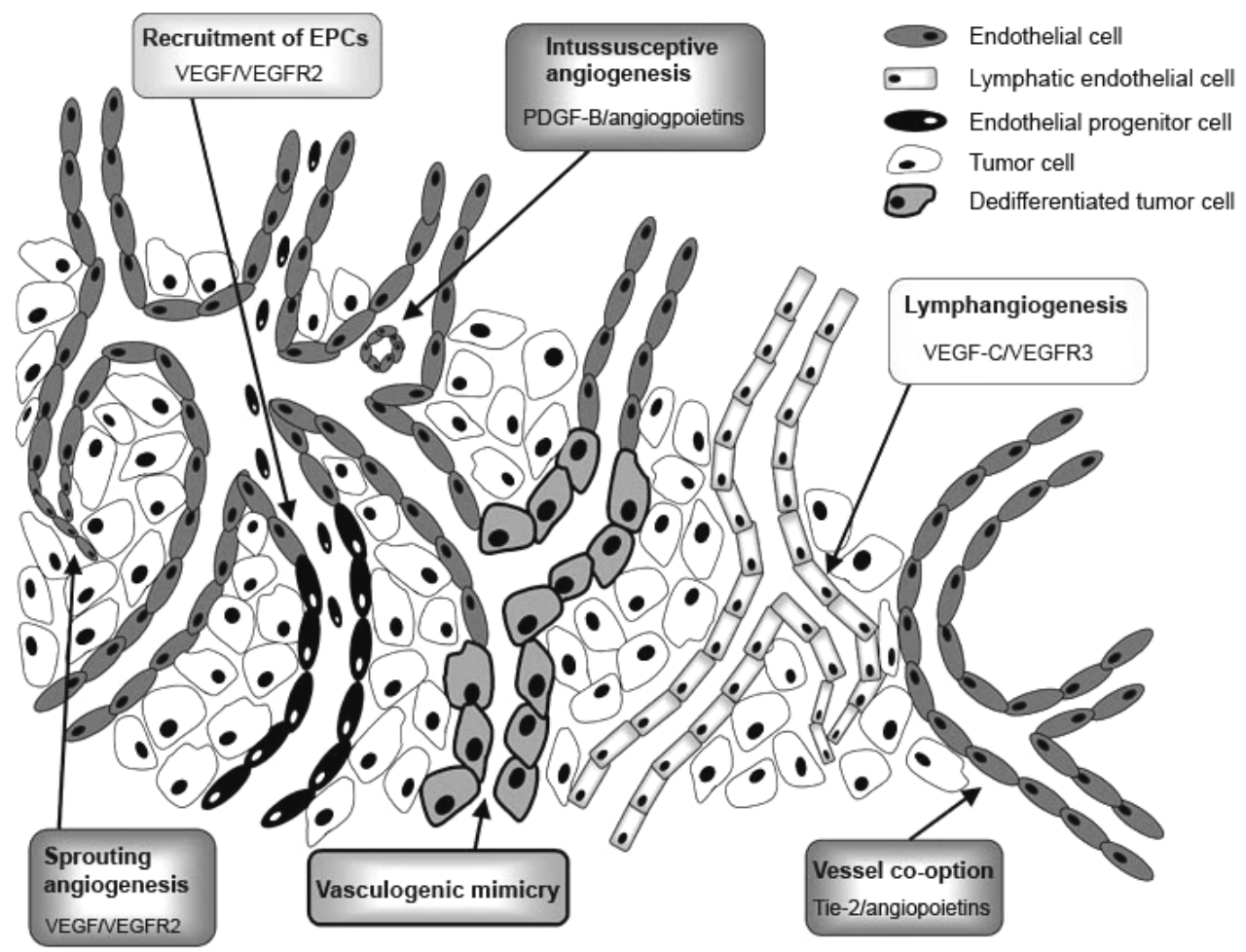

Figure 1. Different mechanisms of tumour vascularisation.

This diagram represents the six different types of vascularisation observed in solid tumours, including sprouting angiogenesis, intussusceptive angiogenesis, recruitment of endothelial progenitor cells, vessel co-option, vasculogenic mimicry, and lymphangiogenesis. The main keyplayers involved in these processes, if known, are indicated.

The process of sprouting angiogenesis involves several sequential steps. Tumour angiogenesis starts with the activation of endothelial cells by specific growth factors that bind to its receptors. As a result, the extracellular matrix and basement membrane, surrounding the endothelial cells, are degraded locally by activated proteases. This allows the endothelial cells to invade into the surrounding matrix and, subsequently, to proliferate and migrate through the matrix. By polarization of the migrating endothelial cells a lumen is created, and an immature blood vessel is formed 7. The stabilisation of the immature vessels is established by recruitment of mural cells and generation of extracellular matrix 8 . This process of sprouting angiogenesis is tightly controlled by positive and negative regulators, the balance of which determines the level of ongoing angiogenesis.

The first angiogenic growth factor, fibroblast growth factor (bFGF), also known as FGF-2, was discovered in the early 1980s ${ }^{9}$. The FGF family consists of 23 members, of which FGF-2 and FGF-1 (aFGF) are the best known, and four FGF tyrosine kinase 
receptors have been described. bFGF stimulates all major steps in the angiogenesis cascade and is produced by many cells, among which are macrophages and tumour cells. Although FGF does not have a signal sequence that allows regular secretion, it is released in the extracellular matrix after which angiogenesis is initiated. bFGF is a pleiotropic mitogen for growth and differentiation, known to be involved in endothelial cell proliferation, extracellular matrix degradation, endothelial cell migration and modulation of junctional adhesion molecules. Moreover, the intricate interaction with other growth factors can result in many synergistic activities in endothelial cell functions ${ }^{10}$. In both mouse and human tumours, the role of bFGF in tumour growth and neovascularization has been demonstrated ${ }^{11}$. Neutralizing antibodies and siRNA techniques have been described to inhibit tumour growth and neovascularization in mouse models ${ }^{12,13}$.

Vascular endothelial cell growth factor (VEGF) or vascular permeability factor, is another important player in the stimulation of angiogenesis. VEGF is a general activator of endothelial cell proliferation and mobility. It is the most potent factor that induces vasodilatation of the existing vessels and increases permeability of the vessel wall ${ }^{14}$. Moreover, it increases the expression of matrix metalloproteinases and plasminogen activators for the degradation of the extracellular matrix and subsequently endothelial cell migration ${ }^{15}$. The VEGF family of growth factors consists of six members (VEGF-A, VEGF-B, VEGF-C, VEGF-D, VEGF-E, and placental growth factor) that interact differentially with three cell surface receptor tyrosine kinases, the VEGFRs, or a second class of non signalling co-receptors, the neuropilins. To date, the VEFG-A/VEGFR2 interaction appears to play a major role in sprouting angiogenesis 7 . In tumours, higher levels of VEGF are detected and many tumour cell lines were found to be inhibited in vivo by antibody targeting methods or the use of small-molecule inhibitors of VEGF or VEGFR2 ${ }^{14}$.

Placental growth factor (PLGF), a member of the VEGF family that only binds VEGFR1, is also a mediator of the angiogenic switch, though its role was underestimated. However, activated endothelial cells are known to produce large amount of PLGF and thereby regulating the VEGF-mediated angiogenic switch. Moreover, other cell types like smooth muscle cells, inflammatory cells and tumour cells can also produce PLGF when activated ${ }^{16,17}$. Importantly, PLGF seems to play a role in vascular development but does not affect the functionality of physiological vessel formation during development and reproduction ${ }^{17}$.

The angiopoietin family, another important growth factor family in angiogenesis, includes 3 members (in humans), angiopoietin-1, angiopoietin-2, and angiopoietin-4, that all bind to the endothelial tyrosine kinase receptor Tie-2. The most remarkable characteristic of this family is the opposing effect of the different ligands binding to the same receptor. Angiopoietin-1 activates the Tie-2 signalling while angiopoietin-2 inhibits this activation. Angiopoietin-1 is involved in endothelial cell migration, adhesion and the recruitment of pericytes and smooth muscle cells, while angiopoietin-2 is vessel destabilizer ${ }^{18,19}$. 
Besides the above described angiogenic factors, tumour cells can produce other factors like transforming growth factor- $\beta$, which stabilizes newly formed vessels and suppresses the immune system ${ }^{20}$, platelet-derived growth factor, which is a chemoattractant for pericytes ${ }^{21}$, epidermal growth factor, which promotes tumourangiogenesis by upregulating VEGF 22 and interleukin 8 that specifically enhances endothelial cell migration ${ }^{23}$.

Recent studies have shown similarities in the molecular regulation of guidance of neural and endothelial cells. Specialized endothelial cells, resembling axonal growth cones, are located at the tips of growing capillaries. These tip cells extend and retract their filopodia continuously to explore the environment and to define the direction in which a new vascular sprout grows ${ }^{24}$. Both axon growth cones and endothelial tip cells seem to use a repertoire of molecular ligand/receptor signalling systems including the family of Ephrins, Semaphorins, Slits, Netrins and Notchs. Most of these molecules seem to play a role in tumour angiogenesis. The injection of soluble Ephrin receptors was found to successfully inhibit tumour angiogenesis in an animal model ${ }^{25}$. Also semaphorins are hypothesised to have tumour suppressor characteristics since overexpression has been shown to inhibit metastasis in melanomas and highly metastatic melanoma cells showed a downregulation of expression ${ }^{26}$. On the other hand, Sema4D, a pro-angiogenic factor released by tumour cells, promoted invasion and metastasis 27. Likewise, the Slit/Robo signalling seems to promote tumour angiogenesis. Neutralization of Robo1 reduced the microvessel density and the tumour mass of human malignant melanoma in vivo. Moreover, there is evidence of molecular crosstalk between cancer cells and endothelial cells ${ }^{28}$. Furthermore, the implication of netrins and their receptors has been studied. The positive signalling pathway of netrins that normally activates apoptosis, seems to be inactivated in tumours. Binding of netrin-1 to its receptors inhibits the tumour suppressor activity of p53 ${ }^{29}$. There is increasing evidence that Notch signalling is also involved in tumour angiogenesis, although it seems to have both oncogenic and tumour suppressive roles ${ }^{30}$. It is obvious that the specific role (stimulatory and inhibitory effects) of these molecules in angiogenesis needs further research.

Sprouting angiogenesis can also be negatively regulated. Thrombospondin-1 was among the first naturally occurring angiostatic agent to be discovered ${ }^{31}$. Later on, more endogenous molecules with angiostatic activity were described. Among these were the $16 \mathrm{kD}$ fragment of prolactin ${ }^{32}$, platelet factor- 4 and interferon- $\alpha 33$, and interferon- $\gamma$ inducible protein-10 ${ }^{34}$. Other members of this class of endogenously produced anti-angiogenic proteins are angiostatin 35, endostatin 36, bactericidal/permeability increasing protein ${ }^{37}$, tumstatin ${ }^{38}$. It is interesting to note that many of these molecules are proteolytic fragments of endogenous macromolecules. Although for several of the currently described angiogenesis inhibitors receptors have been described, detailed mechanisms of action, in most cases, are still obscure ${ }^{39}$. 
Next to anti-angiogenesis approaches with endogenous inhibitors, several blocking strategies of the above described angiogenic factors have been reported. Strategies that block the VEGF-A/VEGFR2 signalling are the most abundant ones in the clinical field of anti-angiogenic therapy. A lot of attention is focussed on the approval of the first anti-angiogenic agent, Avastin, by the Food and Drug administration ${ }^{40,41}$. Avastin in combination with chemotherapy demonstrated a survival benefit in patients with metastatic colorectal cancer of several months ${ }^{42}$. Although a beneficial clinical effect is present, in some patients gastrointestinal perforations, thromboembolic events and impaired wound healing was observed ${ }^{42}$. Moreover, recent warnings about possible visual and neurological long-term problems in patients administrated with Avastin, will probably delay the FDA approval for more applications ${ }^{43}{ }^{44}$. Besides Avastin, several other VEGF inhibitors are being clinically implicated. The most advanced receptor tyrosine kinase inhibitors that target VEGF receptors are SU11428, BAY 43-9006 ${ }^{41}$.

Next to the reported side effects of anti-angiogenic inhibitors, also induction of resistance against these agents must be acknowledged. There is emerging evidence that VEGF-A may be replaced by other angiogenic pathways and other members of the VEFG family ${ }^{45}$. Other mechanisms that can participate in resistance are the selection of more hypoxia resistant cells that are less dependent on angiogenesis ${ }^{46}$ and the normalization of tumour vessel that become less responsive to anti-angiogenic therapy 47. Moreover, the hypothesis that endothelial cells are more genetically stable than tumour cells (and thus less sensible to develop resistance) is now questioned, especially after several reports on genetic abnormalities in endothelial cells of tumour vessels 48,49 .

Although a lot of mediators and pathways that are involved in sprouting angiogenesis have been identified, it is clear that the inhibition of this process is very complex. Clinical trials in patients with less advanced stages of cancer, and the longterm effects of approved compounds will guide us to the use of angiostasis in the clinical management of cancer. However, already now, it seems very likely that efficient cancer therapy will be composed of combination of chemotherapy and antiangiogenic strategies that target multiple angiogenic pathways.

\section{Intussusceptive angiogenesis}

A variant of angiogenesis, different from sprouting, is intussusceptive angiogenenesis. This process was first observed in postnatal remodelling of capillaries in the lung ${ }^{50}$. In the third week of rat life and during the first 2 years in humans, the volume of the lungs increases by more than 20 times. In this developmental process, a new concept of vessel formation was found where pre-existing vessels split in two new vessels by the formation of transvascular tissue pillar into the lumen of the vessel.

Intussusceptive microvascular growth is a fast process that can take place within hours or even minutes, because it does not need proliferation of endothelial cells. In this process endothelial cells are remodelled by increasing in volume and 
becoming thinner. Intussusception is believed to take place after vasculogenesis or angiogenesis to expand the capillary plexus, in a short time and with a little amount of energy. Transmission electron microscopy revealed four consecutive steps ${ }^{51}$. First, the endothelial cells of opposite walls make a "kissing contact", by which a transluminal bridge is formed. Secondly, a reorganisation of the interendothelial junctions and perforation of the endothelial bilayer is executed. In the third phase, the interstitial pillar is formed and pericytes and myofibroblasts invade and cover the newly formed interstitial wall. In this stage, transluminar pillars have a diameter of $\leq 2.5 \mu \mathrm{m}$. It is hypothesised that pericytes, with their contractile characteristics, are the main stimulator in this phase. During the final phase, the pillars grow in diameter and the endothelial cells retract and two separated vessels are formed. Pillar formation and remodelling is not only observed in capillary plexuses but also within smaller arteries and veins 52 .

In 1993, the first in vivo intussusceptive microvascular growth was demonstrated by video microscopy in a chick chorioallantoic membrane ${ }^{53}$. This process has now been detected in various organs, tissue repair processes and also in tumour angiogenesis. Tissue pillars were detected in a colon carcinoma xenograft model. At the growing edge both sprouting and intussusceptive angiogenesis were observed, in the stabilised regions mostly intussusception was detected ${ }^{54}$. Patan et al. also hypothesised that intravascular blood flow patterns or changes in shear stress are parameters that regulate pillar formation ${ }^{54}$. In mammary tumours of c-neu transgenic mice, smaller tumour regions exhibited numerous sprouts, while in larger tumours regions frequently pilar- and mesh formations were observed. Very often, these two forms of angiogenesis were seen in parallel in the same nodule. There are some indications that absence of VEGF is important in the induction of intussusceptive angiogenesis in fast growing tumours ${ }^{55}$. Also in human melanomas a high number of intraluminal tissue folds and a correlation between VEGF and intussusceptive angiogenesis has been observed ${ }^{56}$.

Although the mechanism of intussusception is not fully understood, there are several key players that could influence pillar formation. Alteration in blood flow dynamics in arterial branches could stimulate this process, as observed in the chick chorioallantoic membranes ${ }^{52}$. Furthermore, changes in shear stress on the endothelial cells, and in wall stress on the pericytes, can activate a biochemical cascade which might result in cytoskeletal rearrangements and adaptations of gap junction complexes 51. The changes in shear stress can be sensed by the endothelial cells and transduced by molecules such as CD31, resulting in increased expression of angiogenic factors, adhesion molecules and endothelial nitric oxide synthase ${ }^{52}$. Although many cells appear to play a role in the process of intussusception, such as the endothelial cells, pericytes, macrophages and blood cells, it is now widely thought that it is mainly mediated by endothelial cell-endothelial cell and endothelial cell-pericyte interactions. Factors, that are known to be involved in these interactions in sprouting angiogenesis, such as the angiopoietins and their Tie-receptors, platelet derived growth factor-B, 
monocyte chemotactic protein-1, ephrins and EphB-receptors, are candidates for the mediation of intussusceptive angiogenesis ${ }^{51}$. Injection of platelet derived growth factor-B in a developing chick chorioallantoic membrane stimulated the process of intussusception ${ }^{57}$. Transgenic mice that overexpress VEGF-A and angiopoietin-1 developed blood vessels that showed small holes in the capillary plexus, representing transluminal pillar formation ${ }^{58}$.

It can be hypothesized that inhibition of sprouting angiogenesis may stimulate the process of intussusceptive angiogenesis. Therefore, it could be a means of drugresistance against anti-angiogenic agents. The fact that intussusception only involves migration of endothelial cells and vascular remodelling but not cell proliferation, makes it unlikely that anti-proliferative agents will be able to prevent intussusception. In order to develop effective anti-angiogenesis strategies, novel compounds should involve anti-migration characteristics as well.

\section{Endothelial progenitor cells}

Until 1997, the growth of new blood vessels in adults was considered to exclusively occur through the mechanism of sprouting and intussusceptive angiogenesis. This paradigm of vascular development changed after the discovery of CD34-enriched subpopulation of mononuclear blood cells ${ }^{59}$. These cells were able to adapt ex vivo to an adherent cell type with an endothelial phenotype. They were named endothelial progenitor cells or angioblasts. It is now generally accepted that new vessels can also grow through the recruitment of endothelial progenitor cells (EPCs) that are circulating in the blood. EPCs express several endothelial specific markers like CD34, CD31, VEGFR2, Tie-2 ${ }^{59}$ and CD14 ${ }^{60}$. The first in vivo observations of incorporation of EPCs in blood vessels were evident from different mouse and rabbit bone marrow transplantation models. In these models, with heterologous, homologous and autologous transplantation/incorporation of CD34+, CD133+, VEGFR2+ mononuclear blood cells, EPCs incorporated exclusively in blood vessels of neovascularised ischemic limbs ${ }^{59}$. Moreover, transplantation of endothelial progenitor cells improved limb perfusion, increased capillary density and reduced the risk of limb loss ${ }^{60}$. In another setting, Lin et al. showed incorporation of cultured mononuclear cells in blood vessels after a sex-mismatched bone marrow transplantation ${ }^{61}$.

The mobilization and recruitment of EPCs is promoted by several growth factors, chemokines and cytokines, which are produced during processes such as physiological stress (tissue ischemia), physical exercise and tumour growth. Mobilization of endothelial progenitor cells starts with the activation of matrix metalloproteinase-9, which in turn promotes the transformation of membrane bound Kit ligand to a soluble form. Subsequently, early c-kit positive progenitor cells will detach from the bone marrow niche, move to the vascular zone of the bone marrow and will be released in the circulation ${ }^{62}$. Angiogenic factors like PLGF and VEGF, which bind to the highly expressed VEGFR2 on EPCs, stimulate the release of EPCs 
form the bone marrow ${ }^{63},{ }^{64}$. Other factors that can elevate the release of EPCs are stromal cell-derived factor-1, which binds to CXCR-4 on the EPCs, and angiopoetin-1 ${ }^{65}$. A key player in the activation of matrix metalloproteinase- 9 by VEGF and stromal cellderived factor-1, was found to be endothelial nitric oxide synthase ${ }^{6}$. Furthermore, factors like granulocyte colony-stimulating factor and granulocyte-macrophage colonystimulating factor have identified as bone marrow stem cell mobilizing factors ${ }^{67}$.

The recruitment and integration of EPCs implicates a complex multistep process, including chemoattraction, active arrest and homing within angiogenic vasculature, transmigration to the interstitial space, incorporation into the microvasculature and differentiation into mature endothelial cells. P-selectin, E-selectin and integrins are considered to be important in the adhesion of EPCs to the vessel wall and in transendothelial migration 68,69 . A recent paper demonstrated a functional role of highmobility group box 1 (HMGB1) in the homing of EPCs. The HMGB1-induced migration of EPCs could be inhibited by antibodies against $\beta_{1}$ and $\beta_{2}$ integrins ${ }^{70}$. The differentiation of EPCs to mature endothelial cells is mainly mediated by VEGF 59,71 . After differentiation to a mature endothelial cell, EPCs lose their progenitor properties and start to express endothelial markers like VE-cadherin, von Willebrand factor and endothelial nitric oxide synthase ${ }^{61}$.

EPCs also home in at the site of neovascularization in tumours. Asahara et al. were the first to report the incorporation of $\beta$-galactosidase labelled progenitor cells in both tumour stroma and the endothelial layer of tumour blood vessels ${ }^{72}$. These findings led to the hypothesis that EPCs not only incorporate into the vascular endothelium but also can secrete pro-angiogenic factors in the perivascular sites in the tumour stroma. Later on, the family of Id (inhibitor of DNA binding) proteins was shown to play an important role during incorporation of EPCs in tumour endothelium. Id $1 / 3$ double-mutant mouse embryos had vascular malformations in the brain, leading to fatal haemorrhage ${ }^{73}$. Moreover, adult Id $1^{+/ / / \mathrm{Id} 3 /}$ mice could not support metastasis and growth of 3 different tumour cell lines, while transplantation of bone marrow cells of wild-type mice could restore this effect ${ }^{74}$. The contribution of EPCs to the actual vessel growth, however, is variable. In tumours there are reports of EPCs being the leading process in tumour angiogenesis, while others described a minimal contribution to tumour vasculature ${ }^{74-80}$. In studies with cancer patients similar mixed results were found. In breast carcinoma patients, a higher level of EPCs was detected in the peripheral blood and was suggested as a prognostic marker in tumour patients ${ }^{81}$. In contrast, the number of EPCs in the blood was not found to be increase in a patient group of 52 gastric cancer and 19 breast cancer patients in comparison to control patients ${ }^{82}$. These contradictory results on the contribution EPCs could be due to difference in methodology.

Although most clinical applications of EPCs are in the field of ischemic tissue recovery, inhibition of EPC mobilization from bone marrow has tremendous potential in cancer treatment. Some studies have demonstrated an impaired role of EPCs in 
angiogenesis after specific interventions. In Id mutant knock out mice with xenograft tumours impaired tumour growth was observed ${ }^{73}$. In a study by Capillo et al., endostatin was described as a potent inhibitor of mobilization and clonogenic potential of EPCs ${ }^{83}$. Similarly, simultaneous inhibition of VEGFR2 and VEGFR1 demonstrated an effective inhibition of mobilization and incorporation of EPCs in tumour vasculature 74. Another clinical application of EPCs is their use as a marker for validation of effectiveness of anti-angiogenic therapy. In 8 different mouse strains there was a striking correlation between bFGF- of VEGF-induced angiogenesis and the level of EPCs ${ }^{84}$. Alternatively, EPCs might be another source of tumour-homing cells to deliver toxins to the tumour. CD34+ cells that where transfected with a thymidine kinase gene showed a co-localisation with tumour vasculature. As expected, the recruitment of these transfected EPCs inhibited tumour growth ${ }^{85}$. However, the success of the use of EPCs in cancer treatment depends on the isolation of the proper CD34+, VEGFR2+ haematopoietic cells from the bone marrow or out of circulation. There is still controversy on the exact characterisation of EPCs and possible contamination of the EPC population with circulating endothelial cells ${ }^{86}$. Moreover, the exact molecular pathways that are involved in the mobilization and homing of EPCs to tumours, still have to be elucidated. Improvement of purification of these progenitor cells and study of their long-term effect to generate endothelial cells in vivo will clarify this embryonic field of cancer research. Nonetheless, it is obvious that the impact of EPCs in tumour vascularization can not be neglected and the development of targeting strategies to prevent them from incorporating in regions of neovascularization in the tumour is a new challenge.

\section{Vessel co-option}

As stated above, it is generally accepted that growth of tumours and metastases start as an avascular mass and must induce the development of new vessels to grow beyond a few millimeters in size. However, it has been suggested that many tumours can grow in an avascular stage, mainly in well vascularized tissue like brain and lung ${ }^{87-89}$. Tumour cells can grow along existing vessels without evoking an angiogenic response. This process was defined as vessel co-option.

The first evidence of this process was found during experiments for the search for the molecular players, like angiopoietins, that are involved in early angiogenic events ${ }^{90}$. After one or two week(s) after implantation of C6 glioma cells in a rat brain, the small tumours were already well vascularized with vessels that had characteristics of normal brain vessels. Moreover, no angiogenic response was observed. After 4 weeks, blood vessels had underwent a dramatic regression without any compensatory angiogenic response. In the center of the tumour, tumour cells were organised around the few functional vessels and massive tumour cell death was detected. In the tumour periphery, in contrast, a robust angiogenic response was observed. These data showed that most malignancies and metastases originate as an avascular mass, co-opt with host 
vessels and are rescued. It can be hypothesized that the regression of the initial coopted vessels is a host defence mechanism. Unfortunately these remaining tumour cells are rescued in a later stage, by robust angiogenesis at the outer rim of the tumour.

The finding that vessel regression was associated with the regression of endothelial cells, due to detachment of pericytes and smooth muscle cells, raised the hypothesis that angiopoietins could be involved in this process. Holasch et al. discovered high angiopoietin-2 expression in co-opted vessels of 2 weeks old tumours and in late-stage tumours with a necrotic core. The expression of VEGF, however, was rather low in early-stage tumours and increased later on. The expression of angiopoietin-1 did not change throughout tumour development. Angiopoietin-2 seems to be the key regulator in the regression of initially co-opted tumour vessels. While the expression of angiopoietin-2 in the absence of VEGF facilitated vessel regression, the co-expression of angiopoietin-2 and VEGF, induced the activity of VEGF and subsequently vessel sprouting. This operation between the two angiogenic factors is similarly present in developmental angiogenesis ${ }^{19}$. The same expression levels of angiopoietin-2 and angiopoietin-1 were found in human glioblastomas and not in normal brain vasculature ${ }^{90}$. Vessel co-option has now been observed in different tumour types like murine Lewis lung carcinoma, murine ovarian cancer, human melanoma and human Kaposi sarcoma ${ }^{90-93}$. The role of VEGF in vessel co-option suggests that anti-VEGF therapies may be considered not only for blocking angiogenesis but also to inhibit maturation of vessels in the process of vessel co-option. However, the systemic anti-angiogenesis treatment of a glioblastoma with an antiVEGFR2 antibody was able to reduce tumour angiogenesis but led to an increased cooption of host vessels in the brain ${ }^{94}$. Thus, more potent VEGF-inhibitors are needed to prevent both angiogenesis and vessel co-option. Maybe targeting of VEGF, together with angiopoietins, could overcome the growth of tumours along existing vessels.

\section{Vasculogenic mimicry}

In 1999, the term "vasculogenic mimicry" was introduced to describe the masquerade of tumour cells as endothelial cells. This process of cell plasticity occurs mainly in aggressive tumours in which tumour cells dedifferentiate to an endothelial phenotype and make tube-like structures. This mechanism provides tumour cells with a secondary circulation system of vasculogenic structures lined by tumour cells, independently of angiogenesis ${ }^{95}$. This phenomenon was described for the first time in melanomas. Tissue sections of uveal and cutaneous melanomas and their respective liver metastases revealed patterned networks of interconnected loops of extracellular matrix, as identified by periodic acid-Shiff's reagent (PAS) staining. Importantly, the presence of PAS patterns was associated with worse patient outcome ${ }^{96}$. Further research suggested that these PAS positive networks might be in close connection with regular blood vessels and can be detected with markers for endothelial cells. Furthermore, endothelial cells could not be identified, strongly suggesting that these vessel-like 
structures are lined by tumour cells. The same patterned networks could be obtained in vitro in collagen and matrigel three-dimensional cultures with aggressive melanoma cell lines but not with poorly invasive melanoma cell lines ${ }^{95}$.

Microarray analysis comparing highly invasive and poorly invasive melanoma cells from the same patient indicated a genetic reversion of aggressive melanoma cells to an undifferentiated embryonic-like phenotype ${ }^{97}$. Endothelium associated genes such as VE-cadherin, Ephrin A2 and tissue factor pathway inhibitors, CD34, tyrosine kinase receptor 1, neuropilin 1, E-selectin and endoglin (CD105) had a more than 2-fold increased expression in vasculogenic mimicry positive cells. Also several matrix related components had an increased expression such as laminin $5 \gamma 2$, fibronectin, collagen IV $\alpha 2$, collagen I. Genes related to a melanocytic phenotype, like Melan-A, microphthalmia-associated transcription factor (MTIF) and tyrosinase, were more than 20-fold downregulated.

The exact mechanism underlying vasculogenic mimicry still needs to be unravelled. Several molecules have been identified to have a functional role. For example, PI3 kinase (PI3K) was proposed as the key player in activating the transmembrane metalloproteinase MT1MMP ${ }^{97}$. This protease activates matrix metalloproteinase-2 that cleaves laminin $5 \gamma 2$ into pro-migratory fragments used for tumour cell migration in vasculogenic mimicry ${ }^{98}$. There is also a role for VE-cadherin and Ephrin A2 since downregulation of these genes in melanoma cells resulted in an abrogation of their ability to form vasculogenic-like structures ${ }^{99}$. Both molecules are found to co-localize and VE-cadherin can regulate the expression of EphA2 through its receptor ephrin-A1. So far, several other molecules, mostly found by means of siRNA techniques or anti-body blocking techniques, have been described to play a role in vasculogenic mimicry. Tissue factor pathway inhibitor 2 (TFPI-2) was discovered to be necessary for vasculogenic network formation and is involved in the activation MMP-2. Furthermore, several recent papers reported on different molecules like focal adhesion kinase, cyclooxygenase-2, bone morphogenetic protein-4, insuline-like growth factor binding protein 3 and Nodal and their role in promoting an aggressive melanoma phenotype ${ }^{100-104}$.

Next to the above described mediators, genetic characterisation of cell plasticity of tumour cells revealed several molecules that are related to extracellular matrix like fibronectin, collagen IV $\alpha 2$, collagen I. The importance of the extracellular matrix, as a component of the microenvironment, in vasculogenic mimicry was demonstrated by Seftor et al. ${ }^{105}$. Normal epidermal melanocytes, exposed for 4 days to an extracellular matrix conditioned by metastatic cutaneous melanoma, were reprogrammed to a genotype with specific genes that were associated with the ability to form vasculogenic-like networks. Importantly, these changes in gene expression were only transient, because gene analysis after 7 to 21 days revealed a normal melanocyte phenotype. Recent findings suggested that another microenviromental component, oxygen, may be essential in melanocyte transformation. Low levels of oxygen or hypoxia, are known to promote melanoma cell invasion, metastasis and 
transformation ${ }^{106,107}$. Moreover, hypoxia induces vasculogenic mimicry tube formation in vitro in a matrigel assay ${ }^{108,}{ }^{109}$. In another paper, a B16 melanoma ischemic limb mouse model was used to mimic an hypoxic environment. Initially a decreased tumour growth was observed while later on there was no difference in size with the control tumours. However, the amount of vasculogenic mimicry channels and the gene expression of HIF-1 $\alpha$, MMP-2, MMP-9 and VEGF was increased ${ }^{110}$. The role of several known tumour growth factors has also been studied, though with disappointing results. Several growth factors, such as basic fibroblast growth factor, vascular endothelial growth factor, transforming Growth Factor- $\beta$, platelet derived growth factor and tumour necrosis factor- $\alpha$ were found not to be able to induce formation of vascular networks when added to the poorly invasive melanoma cell lines ${ }^{95}$. This indicates that angiogenesis and vasculogenic mimicry, in contrast to the previous described tumour vascularization types, are not sharing the same signalling pathways. Moreover, anti-angiogenic targeting strategies do not inhibit the process of vasculogenic mimicry ${ }^{109}$ and could even induce the formation of vasculogenic mimicry vessels as an escape mechanism of the tumour to keep on growing.

Although the functionality and the contribution of vasculogenic-like channels to circulation was criticised at first, several papers evidenced its functional role in tumour circulation. The contribution of vasculogenic mimicry patterns was first proven in vitro. Looping patterns, that were formed in vitro by highly aggressive melanoma cell lines, distributed fluid after microinjection ${ }^{95}$. Several groups tried to prove the fluidconducting characteristic of vasculogenic mimicry channels in vivo. Clarijs et al. colocalised an intravenous injected tracer with both blood vessels and matrix patterns in a uveal melanoma xenograft model ${ }^{111}$. Shirakawa et al. reported on blood flow in areas of vasculogenic mimicry in a breast carcinoma model using MRI techniques ${ }^{112}$. Another approach was used by Ruf et al., where Doppler ultrasonography was used to show blood flow in these vasculogenic-like channels ${ }^{113}$. The first in vivo demonstration of blood circulation in vasculogenic mimicry tubes in humans was observed with laser scanning confocal angiography in patients with a choroidal melanoma ${ }^{114}$. Up to now, tumour cell plasticity has been described in uveal 96, cutaneous 115 and oral 116 melanoma, breast carcinoma 112, prostatic carcinoma 117, ovarian carcinoma 118, hepatocellular carcinoma 119 , bladder carcinoma 120, rhabdomyosarcoma and mesothelial sarcoma ${ }^{121}$, osteosarcoma ${ }^{122}$, astrocytoma ${ }^{123}$, pheochromocytoma ${ }^{124}$ and Ewing sarcoma ${ }^{109}$.

The recent findings on the 'plastic' endothelial-like phenotype of melanoma and other tumour cells confused the field of cancer biology even more. The idea that these structures could form a functional secondary vascular network that provides the tumour of blood, independent from angiogenic growth factors, makes tumour growth inhibition even more complex. A variety of genes has been investigated concerning their role in tubular network formation of tumour cells. An option for therapy is the use of monoclonal antibodies to these molecules for drug targeting. However, the therapeutic functionality and the choice of the best targets still need to be elucidated. It 
is evident now that the microenvironment plays an important role in tumour progression and therefore is a novel target for therapy. An initial study to target MMPs was perfomed. The administration of a chemically modified tetracycline, COL-3, to aggressive melanoma cells in three-dimensional culture, inhibited MMP-2, MMP-9, MT1-MMP and VE-cadherin expression. Next to that, the cleavage of laminin 5 was inhibited and decreased vascular network formation was observed ${ }^{125}$. However, caution is warranted since administration of modified tetracyclines have reported serious side effects ${ }^{126,127}$. In another paper, the addition of anti-angiogenic compounds TNP470, anginex and endostatin could not block the formation of networks ${ }^{128}$. Until now, only very limited data on targeting vasculogenic mimicry is available. Clearly, more investigation, on essential regulatory pathways of plastic tumour cells that do not overlap normal biological processes, is needed to develop new promising therapeutic approaches.

\section{Lymphangiogenesis}

Lymphatic vessels are also part of the vascular circulatory system. The lymphatic system is a network of capillaries, collecting vessels and ducts that drain most of the organs. In contrast to the blood vascular network, the lymphatic network is an open ended, one way transport system, without a driving force, that drains extravasated fluid, collects lymphocytes and returns it to circulation ${ }^{129}$. Over the last years there is accumulating evidence for a role of the lymphatic system in tumour progression. Metastasis of malignant tumours to regional lymph nodes is one of the early signs of cancer spread in patients. In certain cancer types, such as breast cancer, lymphatic metastasis is one of the predominant routes of cancer spread ${ }^{130}$. From the lymphatic system, cancer cells can spread to other organs and tissues.

The lymphatic system has not received as much scientific attention as the blood vascular system, maybe due to a lack of specific markers and to the lack of knowledge about the molecular regulation of its development and function. The possibility and optimisation to isolate and culture lymphatic endothelial cells, however, has led to the identification of several markers that are specific for the lymphatic vasculature ${ }^{131}$. Vascular endothelial growth factor receptor-3 (VEGFR-3) was the first lymphatic marker that was identified ${ }^{132}$. Later on specific markers such as lymphatic vascular endothelial hyaluronan receptor-1 (LYVE-1) 133, podoplanin 134 and transcription factor Prox $1{ }^{135}$ were identified.

Similar to blood endothelial cells, lymphatic endothelial cells are quiescent under physiological conditions. Experimental evidence for a 'lymphangiogenic switch' is still lacking. Nonetheless, it seems likely that the formation of new lymphatic vessels is triggered in a similar way as angiogenesis of blood vessels. Already now, a range of lymphangiogenic factors/receptors that are produced by tumour cells and inflammatory cells have been identified. 
After the identification of the lymphatic specific marker VEGFR-3, both VEGF$\mathrm{C}$ and VEGF-D were cloned as unique ligands for this receptor ${ }^{136}$. In the development of the lymphatic system, the role of VEGF-D is dispensable ${ }^{137}$, whereas VEGF-C null mouse embryos completely lack a lymphatic vasculature and die prenatally ${ }^{138}$. In vitro, VEGF-C stimulated proliferation, migration and survival of lymphatic endothelial cells 139. To demonstrate the VEGF-C/VEGF-D/VEGFR-3 signalling pathway in tumour lymphangiogenesis, tumour cells expressing VEGF-C and -D were used in a mouse tumour model. Both the expression of VEGF-C and -D increased intratumoural lymphangiogenesis and metastasis. In addition, a blocking VEGF-D antibody could inhibit this lymphatic spread ${ }^{140,141}$. Furthermore, there are indications that there is a crosstalk between blood vessel angiogenesis and lymphangiogenesis. Angiogenic mediators are identified to play a role in lymphangiogenesis but their role is mostly studied in physiological situations. The VEGF-A/VEGFR-2 signalling pathway stimulates lymphangiogenesis. However, the new lymphatic vessels generated by VEGF-A are functionally and structurally abnormal ${ }^{142}$. The group of Chang et al. demonstrated that bFGF could induce both blood vessel angiogenesis and lymphangiogenesis and even lymphangiogenesis alone depending on the dose of bFGF that was administrated on mouse cornea ${ }^{143}$. In the same mouse cornea model, PDGFBB was found to be the most potent of the PDGF family in stimulating lymphangiogenesis ${ }^{144}$. Above that, PDGFs are often found to be highly expressed in tumours that have increased incidence of lymphatic metastasis ${ }^{145}$. The first evidence of a role of angiopoietin-2 in lymphangiogenesis was suggested by the angiopoietin-2-null mice that displayed disorganized and hypoplastic lymphatic capillaries ${ }^{146}$. Importantly, the lymphatic but not the blood vessel phenotype could be rescued by genetic transfer of angiopoietin-1. In addition, Morisada et al. was able to demonstrate the stimulation of both in vitro growth of lymphatic endothelial cells and lymphangiogenesis in the mouse cornea by angiopoietin-1 ${ }^{147}$. Similarly to angiopoietin-2-null mice, NRP-2 mutants showed absence or severe reduction of small lymphatic vessels and capillaries 148. Also an in vitro and in vivo stimulatory role of hepatocyte growth factor ${ }^{149}$ and insulin-like growth factor-1 and $-2{ }^{150}$ on the lymphatic vessel formation was observed.

Now that specific markers are available and some insight into the biology of lymphangiogenesis is available, it becomes evident that lymphangiogenesis is an important parameter in the process of tumour growth ${ }^{151}$. Nevertheless, there is still an ongoing debate on the role of lymphangiogenesis in tumour progression. It was previously thought that lymphatic metastasis occurred by pre-existing lymphatic vessels that are present at the outer rim of the tumour. However, other papers report on the presence of peritumoural and/or intratumoural lymphatics, not only in mouse studies but also in human tumours. Nevertheless, intratumoural lymphatics are rare and their functionality and role in tumour metastasis is still discussed ${ }^{152,153}$. There are also reports that lymph angiogenesis parameters such as lymph vessel density, lymph angiogenic growth factors ${ }^{154}$, or the presence of tumour cells within lymph vessels or lymph nodes are valuable prognostic markers ${ }^{155-159}$. 
The high incidence of metastatic lymphatic spread and the knowledge of several lymphangiogenic markers urged researchers to investigate the inhibition of lymphangiogenesis as a strategy of tumour treatment. Stacker et al. reported the reduction of lymphatic spread by blocking VEGF-D with a monoclonal antibody ${ }^{141}$. The application of a VEGFR-3 fusion protein (called VEGF-C/D trap) was able to inhibit the growth of tumour-associated lymphatic vessels and inhibited tumour metastasis ${ }^{160}$. On the other hand, administration of VEGF-C seem to have therapeutic potential for patients with lymphedema since lymphatic function ameliorated significantly ${ }^{161}$. However, the regulation of lymphatic vessel growth is more difficult because it is not only promoted by the VEGF-C, VEGF-D/VEGFR-3 system. Several other growth factors and molecules that are specific for lymphangiogenesis, of which the exact function has not been resolved yet, could play an important role. An efficient anti-lymphangiogenic therapy should target different lymphatic growth factors. Furthermore, additional information is needed on specific tumour lymphatic markers. A recent paper of Zhang et al. presented some promising results. In search for a lymphatic tissue specific signature, it was demonstrated that tumour development is associated with organ- and stage-specific changes in lymphatics ${ }^{162}$. Although clinical implementation will take years, cancer patients will benefit from anti-metastatic therapy that can decrease metastatic lymphatic spread.

\section{Conclusion}

Tumours depend on a the growth of a vascular network, which is stimulated by a variety of angiogenic mediators, providing them with blood and oxygen. Inhibition of sprouting angiogenesis has gained a lot of progression. Several clinical trials, in which specific growth factors or receptors are being blocked, are currently being performed. Strategies that block the VEGF-A/VEGFR2 signalling are the most abundant ones in the field of anti-angiogenic therapy. After successful clinical trials, Avastin is now entering into the clinic. Because side effects are observed, the emphasis of such growth factor inhibition mediated treatment may shift towards other growth factors, e.g. PLGF ${ }^{17}$, or to simultaneous targeting of multiple pathways.

Clinical success of anti-angiogenesis therapy is present but still limited. Since anti-angiogenic therapy alone seems not to be sufficient to improve patient survival, clinical studies are all in combination with conventional strategies, such as chemo- and radiotherapy. The successful combination of chemotherapy and anti-angiogenesis therapy may benefit from the normalization of the tumour vasculature by antiangiogenic therapy and subsequently a better administration of chemotherapy ${ }^{163}$.

It is clear now that tumour vasculature is not necessarily dependent of endothelial cell proliferation and sprouting of new capillaries. Several additional mechanisms can provide the tumour of oxygen and nutrients. The molecular players involved and their specific role in tumour development still need to be elucidated. The current knowledge that anti-angiogenesis therapy work best in combination with 
chemotherapy, should probably in the near future be extended to other types of vascularization as well. There is still a long way to go before we fully understand the different mechanisms of tumor vascularization. But we anticipate that combination of a multimodal anti-vascular approach, representing anti-angiogenesis, antilymphangiogenesis and vasculogenic mimicry targeting, together with chemotherapy may become the best possible strategy in the fight against cancer. 


\section{References}

1. Carmeliet, P. and Jain, R. K. Angiogenesis in cancer and other diseases. Nature, 407: 249-257, 2000.

2. Martin, A., Komada, M. R., and Sane, D. C. Abnormal angiogenesis in diabetes mellitus. Med Res Rev, 23: 117-145, 2003.

3. Koch, A. E. Angiogenesis as a target in rheumatoid arthritis. Ann Rheum Dis, 62 Suppl 2: ii6067, 2003.

4. Cao, Y., Hong, A., Schulten, H., and Post, M. J. Update on therapeutic neovascularization. Cardiovasc Res, 65: 639-648, 2005.

5. Carmeliet, P. Angiogenesis in life, disease and medicine. Nature, 438: 932-936, 2005.

6. Hanahan, D. and Weinberg, R. A. The hallmarks of cancer. Cell, 100: 57-70, 2000.

7. Ferrara, N., Gerber, H. P., and LeCouter, J. The biology of VEGF and its receptors. Nat Med, 9: 669-676, 2003.

8. Jain, R. K. Molecular regulation of vessel maturation. Nat Med, 9: 685-693, 2003.

9. Kerbel, R. S. Tumor angiogenesis: past, present and the near future. Carcinogenesis, 21: 505515, 2000.

10. Itoh, N. and Ornitz, D. M. Evolution of the Fgf and Fgfr gene families. Trends Genet, 20: 563569, 2004.

11. Presta, M., Dell'Era, P., Mitola, S., Moroni, E., Ronca, R., and Rusnati, M. Fibroblast growth factor/fibroblast growth factor receptor system in angiogenesis. Cytokine Growth Factor Rev, 16: 159-178, 2005.

12. Gross, J. L., Herblin, W. F., Dusak, B. A., Czerniak, P., Diamond, M. D., Sun, T., Eidsvoog, K., Dexter, D. L., and Yayon, A. Effects of modulation of basic fibroblast growth factor on tumor growth in vivo. J Natl Cancer Inst, 85: 121-131, 1993.

13. Wang, Y. and Becker, D. Antisense targeting of basic fibroblast growth factor and fibroblast growth factor receptor-1 in human melanomas blocks intratumoral angiogenesis and tumor growth. Nat Med, 3: 887-893, 1997.

14. Ferrara, N. and Davis-Smyth, T. The biology of vascular endothelial growth factor. Endocr Rev, 18: 4-25, 1997.

15. Bergers, G., Brekken, R., McMahon, G., Vu, T. H., Itoh, T., Tamaki, K., Tanzawa, K., Thorpe, P., Itohara, S., Werb, Z., and Hanahan, D. Matrix metalloproteinase- 9 triggers the angiogenic switch during carcinogenesis. Nat Cell Biol, 2: 737-744, 2000.

16. Iyer, S. and Acharya, K. R. Role of placenta growth factor in cardiovascular health. Trends Cardiovasc Med, 12: 128-134, 2002.

17. Carmeliet, P., Moons, L., Luttun, A., Vincenti, V., Compernolle, V., De Mol, M., Wu, Y., Bono, F., Devy, L., Beck, H., Scholz, D., Acker, T., DiPalma, T., Dewerchin, M., Noel, A., Stalmans, I., Barra, A., Blacher, S., Vandendriessche, T., Ponten, A., Eriksson, U., Plate, K. H., Foidart, J. M., Schaper, W., Charnock-Jones, D. S., Hicklin, D. J., Herbert, J. M., Collen, D., and Persico, M. G. Synergism between vascular endothelial growth factor and placental growth factor contributes to angiogenesis and plasma extravasation in pathological conditions. Nat Med, 7: 575-583, 2001.

18. Davis, S., Aldrich, T. H., Jones, P. F., Acheson, A., Compton, D. L., Jain, V., Ryan, T. E., Bruno, J., Radziejewski, C., Maisonpierre, P. C., and Yancopoulos, G. D. Isolation of angiopoietin-1, a ligand for the TIE2 receptor, by secretion-trap expression cloning. Cell, 87: 1161-1169, 1996.

19. Maisonpierre, P. C., Suri, C., Jones, P. F., Bartunkova, S., Wiegand, S. J., Radziejewski, C., Compton, D., McClain, J., Aldrich, T. H., Papadopoulos, N., Daly, T. J., Davis, S., Sato, T. N., and Yancopoulos, G. D. Angiopoietin-2, a natural antagonist for Tie2 that disrupts in vivo angiogenesis. Science, 277: 55-60, 1997.

20. Elliott, R. L. and Blobe, G. C. Role of transforming growth factor Beta in human cancer. J Clin Oncol, 23: 2078-2093, 2005.

21. Armulik, A., Abramsson, A., and Betsholtz, C. Endothelial/pericyte interactions. Circ Res, 97: 512-523, 2005. 
22. Petit, A. M., Rak, J., Hung, M. C., Rockwell, P., Goldstein, N., Fendly, B., and Kerbel, R. S. Neutralizing antibodies against epidermal growth factor and ErbB-2/neu receptor tyrosine kinases down-regulate vascular endothelial growth factor production by tumor cells in vitro and in vivo: angiogenic implications for signal transduction therapy of solid tumors. Am J Pathol, 151: 1523-1530, 1997.

23. Li, A., Dubey, S., Varney, M. L., Dave, B. J., and Singh, R. K. IL-8 directly enhanced endothelial cell survival, proliferation, and matrix metalloproteinases production and regulated angiogenesis. J Immunol, 170: 3369-3376, 2003.

24. Gerhardt, H., Golding, M., Fruttiger, M., Ruhrberg, C., Lundkvist, A., Abramsson, A., Jeltsch, M., Mitchell, C., Alitalo, K., Shima, D., and Betsholtz, C. VEGF guides angiogenic sprouting utilizing endothelial tip cell filopodia. J Cell Biol, 161: 1163-1177, 2003.

25. Brantley, D. M., Cheng, N., Thompson, E. J., Lin, Q., Brekken, R. A., Thorpe, P. E., Muraoka, R. S., Cerretti, D. P., Pozzi, A., Jackson, D., Lin, C., and Chen, J. Soluble Eph A receptors inhibit tumor angiogenesis and progression in vivo. Oncogene, 21: 7011-7026, 2002.

26. Bielenberg, D. R., Hida, Y., Shimizu, A., Kaipainen, A., Kreuter, M., Kim, C. C., and Klagsbrun, M. Semaphorin 3F, a chemorepulsant for endothelial cells, induces a poorly vascularized, encapsulated, nonmetastatic tumor phenotype. J Clin Invest, 114: 1260-1271, 2004.

27. Conrotto, P., Valdembri, D., Corso, S., Serini, G., Tamagnone, L., Comoglio, P. M., Bussolino, F., and Giordano, S. Sema4D induces angiogenesis through Met recruitment by Plexin B1. Blood, 105: 4321-4329, 2005.

28. Wang, B., Xiao, Y., Ding, B. B., Zhang, N., Yuan, X., Gui, L., Qian, K. X., Duan, S., Chen, Z., Rao, Y., and Geng, J. G. Induction of tumor angiogenesis by Slit-Robo signaling and inhibition of cancer growth by blocking Robo activity. Cancer Cell, 4: 19-29, 2003.

29. Arakawa, H. Netrin-1 and its receptors in tumorigenesis. Nat Rev Cancer, 4: 978-987, 2004.

30. Rehman, A. O. and Wang, C. Y. Notch signaling in the regulation of tumor angiogenesis. Trends Cell Biol, 16: 293-300, 2006.

31. Rastinejad, F., Polverini, P. J., and Bouck, N. P. Regulation of the activity of a new inhibitor of angiogenesis by a cancer suppressor gene. Cell, 56: 345-355, 1989.

32. Ferrara, N., Clapp, C., and Weiner, R. The $16 \mathrm{~K}$ fragment of prolactin specifically inhibits basal or fibroblast growth factor stimulated growth of capillary endothelial cells. Endocrinology, 129: 896-900, 1991.

33. Kolber, D. L., Knisely, T. L., and Maione, T. E. Inhibition of development of murine melanoma lung metastases by systemic administration of recombinant platelet factor 4 . J Natl Cancer Inst, 87: 304-309, 1995.

34. Luster, A. D., Greenberg, S. M., and Leder, P. The IP-10 chemokine binds to a specific cell surface heparan sulfate site shared with platelet factor 4 and inhibits endothelial cell proliferation. J Exp Med, 182: 219-231, 1995.

35. O'Reilly, M. S., Holmgren, L., Shing, Y., Chen, C., Rosenthal, R. A., Moses, M., Lane, W. S., Cao, Y., Sage, E. H., and Folkman, J. Angiostatin: a novel angiogenesis inhibitor that mediates the suppression of metastases by a Lewis lung carcinoma. Cell, 79: 315-328, 1994.

36. O'Reilly, M. S., Boehm, T., Shing, Y., Fukai, N., Vasios, G., Lane, W. S., Flynn, E., Birkhead, J. R., Olsen, B. R., and Folkman, J. Endostatin: an endogenous inhibitor of angiogenesis and tumor growth. Cell, 88: 277-285, 1997.

37. van der Schaft, D. W., Toebes, E. A., Haseman, J. R., Mayo, K. H., and Griffioen, A. W. Bactericidal/permeability-increasing protein (BPI) inhibits angiogenesis via induction of apoptosis in vascular endothelial cells. Blood, 96: 176-181, 2000.

38. Maeshima, Y., Colorado, P. C., Torre, A., Holthaus, K. A., Grunkemeyer, J. A., Ericksen, M. B., Hopfer, H., Xiao, Y., Stillman, I. E., and Kalluri, R. Distinct antitumor properties of a type IV collagen domain derived from basement membrane. J Biol Chem, 275: 21340-21348, 2000.

39. Tabruyn, S. P. and Griffioen, A. W. Molecular pathways of angiogenesis inhibition. Biochem Biophys Res Commun, 355: 1-5, 2007.

40. Marx, J. Angiogenesis. A boost for tumor starvation. Science, 301: 452-454, 2003.

41. Ferrara, N. and Kerbel, R. S. Angiogenesis as a therapeutic target. Nature, 438: 967-974, 2005. 
42. Hurwitz, H., Fehrenbacher, L., Novotny, W., Cartwright, T., Hainsworth, J., Heim, W., Berlin, J., Baron, A., Griffing, S., Holmgren, E., Ferrara, N., Fyfe, G., Rogers, B., Ross, R., and Kabbinavar, F. Bevacizumab plus irinotecan, fluorouracil, and leucovorin for metastatic colorectal cancer. N Engl J Med, 350: 2335-2342, 2004.

43. Glusker, P., Recht, L., and Lane, B. Reversible posterior leukoencephalopathy syndrome and bevacizumab. N Engl J Med, 354: 980-982; discussion 980-982, 2006.

44. Ozcan, C., Wong, S. J., and Hari, P. Reversible posterior leukoencephalopathy syndrome and bevacizumab. N Engl J Med, 354: 980-982; discussion 980-982, 2006.

45. Alitalo, K., Tammela, T., and Petrova, T. V. Lymphangiogenesis in development and human disease. Nature, 438: 946-953, 2005.

46. Yu, J. L., Rak, J. W., Coomber, B. L., Hicklin, D. J., and Kerbel, R. S. Effect of p53 status on tumor response to antiangiogenic therapy. Science, 295: 1526-1528, 2002.

47. Glade Bender, J., Cooney, E. M., Kandel, J. J., and Yamashiro, D. J. Vascular remodeling and clinical resistance to antiangiogenic cancer therapy. Drug Resist Updat, 7: 289-300, 2004.

48. Hida, K., Hida, Y., Amin, D. N., Flint, A. F., Panigrahy, D., Morton, C. C., and Klagsbrun, M. Tumor-associated endothelial cells with cytogenetic abnormalities. Cancer Res, 64: 8249-8255, 2004.

49. Streubel, B., Chott, A., Huber, D., Exner, M., Jager, U., Wagner, O., and Schwarzinger, I. Lymphoma-specific genetic aberrations in microvascular endothelial cells in B-cell lymphomas. N Engl J Med, 351: 250-259, 2004.

50. Caduff, J. H., Fischer, L. C., and Burri, P. H. Scanning electron microscope study of the developing microvasculature in the postnatal rat lung. Anat Rec, 216: 154-164, 1986.

51. Burri, P. H., Hlushchuk, R., and Djonov, V. Intussusceptive angiogenesis: its emergence, its characteristics, and its significance. Dev Dyn, 231: 474-488, 2004.

52. Djonov, V. G., Kurz, H., and Burri, P. H. Optimality in the developing vascular system: branching remodeling by means of intussusception as an efficient adaptation mechanism. Dev Dyn, 224: 391-402, 2002.

53. Patan, S., Haenni, B., and Burri, P. H. Evidence for intussusceptive capillary growth in the chicken chorio-allantoic membrane (CAM). Anat Embryol (Berl), 187: 121-130, 1993.

54. Patan, S., Munn, L. L., and Jain, R. K. Intussusceptive microvascular growth in a human colon adenocarcinoma xenograft: a novel mechanism of tumor angiogenesis. Microvasc Res, 51: 260-272, 1996.

55. Djonov, V., Andres, A. C., and Ziemiecki, A. Vascular remodelling during the normal and malignant life cycle of the mammary gland. Microsc Res Tech, 52: 182-189, 2001.

56. Ribatti, D., Nico, B., Floris, C., Mangieri, D., Piras, F., Ennas, M. G., Vacca, A., and Sirigu, P. Microvascular density, vascular endothelial growth factor immunoreactivity in tumor cells, vessel diameter and intussusceptive microvascular growth in primary melanoma. Oncol Rep, 14: 81-84, 2005.

57. Oh, S. J., Kurz, H., Christ, B., and Wilting, J. Platelet-derived growth factor-B induces transformation of fibrocytes into spindle-shaped myofibroblasts in vivo. Histochem Cell Biol, 109: 349-357, 1998.

58. Thurston, G., Suri, C., Smith, K., McClain, J., Sato, T. N., Yancopoulos, G. D., and McDonald, D. M. Leakage-resistant blood vessels in mice transgenically overexpressing angiopoietin-1. Science, 286: 2511-2514, 1999.

59. Asahara, T., Murohara, T., Sullivan, A., Silver, M., van der Zee, R., Li, T., Witzenbichler, B., Schatteman, G., and Isner, J. M. Isolation of putative progenitor endothelial cells for angiogenesis. Science, 275: 964-967, 1997.

60. Kalka, C., Masuda, H., Takahashi, T., Kalka-Moll, W. M., Silver, M., Kearney, M., Li, T., Isner, J. M., and Asahara, T. Transplantation of ex vivo expanded endothelial progenitor cells for therapeutic neovascularization. Proc Natl Acad Sci U S A, 97: 3422-3427, 2000.

61. Lin, Y., Weisdorf, D. J., Solovey, A., and Hebbel, R. P. Origins of circulating endothelial cells and endothelial outgrowth from blood. J Clin Invest, 105: 71-77, 2000.

62. Heissig, B., Hattori, K., Dias, S., Friedrich, M., Ferris, B., Hackett, N. R., Crystal, R. G., Besmer, P., Lyden, D., Moore, M. A., Werb, Z., and Rafii, S. Recruitment of stem and progenitor cells 
from the bone marrow niche requires MMP-9 mediated release of kit-ligand. Cell, 109: 625637, 2002.

63. Asahara, T., Takahashi, T., Masuda, H., Kalka, C., Chen, D., Iwaguro, H., Inai, Y., Silver, M., and Isner, J. M. VEGF contributes to postnatal neovascularization by mobilizing bone marrow-derived endothelial progenitor cells. Embo J, 18: 3964-3972, 1999.

64. Hattori, K., Heissig, B., Wu, Y., Dias, S., Tejada, R., Ferris, B., Hicklin, D. J., Zhu, Z., Bohlen, P., Witte, L., Hendrikx, J., Hackett, N. R., Crystal, R. G., Moore, M. A., Werb, Z., Lyden, D., and Rafii, S. Placental growth factor reconstitutes hematopoiesis by recruiting VEGFR1(+) stem cells from bone-marrow microenvironment. Nat Med, 8: 841-849, 2002.

65. Moore, M. A., Hattori, K., Heissig, B., Shieh, J. H., Dias, S., Crystal, R. G., and Rafii, S. Mobilization of endothelial and hematopoietic stem and progenitor cells by adenovectormediated elevation of serum levels of SDF-1, VEGF, and angiopoietin-1. Ann N Y Acad Sci, 938: 36-45; discussion 45-37, 2001.

66. Aicher, A., Heeschen, C., Mildner-Rihm, C., Urbich, C., Ihling, C., Technau-Ihling, K., Zeiher, A. M., and Dimmeler, S. Essential role of endothelial nitric oxide synthase for mobilization of stem and progenitor cells. Nat Med, 9: 1370-1376, 2003.

67. Takahashi, T., Kalka, C., Masuda, H., Chen, D., Silver, M., Kearney, M., Magner, M., Isner, J. M., and Asahara, T. Ischemia- and cytokine-induced mobilization of bone marrow-derived endothelial progenitor cells for neovascularization. Nat Med, 5: 434-438, 1999.

68. Vajkoczy, P., Blum, S., Lamparter, M., Mailhammer, R., Erber, R., Engelhardt, B., Vestweber, D., and Hatzopoulos, A. K. Multistep nature of microvascular recruitment of ex vivoexpanded embryonic endothelial progenitor cells during tumor angiogenesis. J Exp Med, 197: 1755-1765, 2003.

69. Deb, A., Skelding, K. A., Wang, S., Reeder, M., Simper, D., and Caplice, N. M. Integrin profile and in vivo homing of human smooth muscle progenitor cells. Circulation, 110: 2673-2677, 2004.

70. Chavakis, E., Hain, A., Vinci, M., Carmona, G., Bianchi, M. E., Vajkoczy, P., Zeiher, A. M., Chavakis, T., and Dimmeler, S. High-mobility group box 1 activates integrin-dependent homing of endothelial progenitor cells. Circ Res, 100: 204-212, 2007.

71. Gehling, U. M., Ergun, S., Schumacher, U., Wagener, C., Pantel, K., Otte, M., Schuch, G., Schafhausen, P., Mende, T., Kilic, N., Kluge, K., Schafer, B., Hossfeld, D. K., and Fiedler, W. In vitro differentiation of endothelial cells from AC133-positive progenitor cells. Blood, 95: 3106$3112,2000$.

72. Asahara, T., Masuda, H., Takahashi, T., Kalka, C., Pastore, C., Silver, M., Kearne, M., Magner, M., and Isner, J. M. Bone marrow origin of endothelial progenitor cells responsible for postnatal vasculogenesis in physiological and pathological neovascularization. Circ Res, 85: 221-228, 1999.

73. Lyden, D., Young, A. Z., Zagzag, D., Yan, W., Gerald, W., O'Reilly, R., Bader, B. L., Hynes, R. O., Zhuang, Y., Manova, K., and Benezra, R. Id1 and Id3 are required for neurogenesis, angiogenesis and vascularization of tumour xenografts. Nature, 401: 670-677, 1999.

74. Lyden, D., Hattori, K., Dias, S., Costa, C., Blaikie, P., Butros, L., Chadburn, A., Heissig, B., Marks, W., Witte, L., Wu, Y., Hicklin, D., Zhu, Z., Hackett, N. R., Crystal, R. G., Moore, M. A., Hajjar, K. A., Manova, K., Benezra, R., and Rafii, S. Impaired recruitment of bone-marrowderived endothelial and hematopoietic precursor cells blocks tumor angiogenesis and growth. Nat Med, 7: 1194-1201, 2001.

75. Machein, M. R., Renninger, S., de Lima-Hahn, E., and Plate, K. H. Minor contribution of bone marrow-derived endothelial progenitors to the vascularization of murine gliomas. Brain Pathol, 13: 582-597, 2003.

76. Ruzinova, M. B., Schoer, R. A., Gerald, W., Egan, J. E., Pandolfi, P. P., Rafii, S., Manova, K., Mittal, V., and Benezra, R. Effect of angiogenesis inhibition by Id loss and the contribution of bone-marrow-derived endothelial cells in spontaneous murine tumors. Cancer Cell, 4: 277289, 2003.

77. Gothert, J. R., Gustin, S. E., van Eekelen, J. A., Schmidt, U., Hall, M. A., Jane, S. M., Green, A. R., Gottgens, B., Izon, D. J., and Begley, C. G. Genetically tagging endothelial cells in vivo: 
bone marrow-derived cells do not contribute to tumor endothelium. Blood, 104: 1769-1777, 2004.

78. Rajantie, I., Ilmonen, M., Alminaite, A., Ozerdem, U., Alitalo, K., and Salven, P. Adult bone marrow-derived cells recruited during angiogenesis comprise precursors for periendothelial vascular mural cells. Blood, 104: 2084-2086, 2004.

79. Peters, B. A., Diaz, L. A., Polyak, K., Meszler, L., Romans, K., Guinan, E. C., Antin, J. H., Myerson, D., Hamilton, S. R., Vogelstein, B., Kinzler, K. W., and Lengauer, C. Contribution of bone marrow-derived endothelial cells to human tumor vasculature. Nat Med, 11: 261-262, 2005.

80. Larrivee, B., Niessen, K., Pollet, I., Corbel, S. Y., Long, M., Rossi, F. M., Olive, P. L., and Karsan, A. Minimal contribution of marrow-derived endothelial precursors to tumor vasculature. J Immunol, 175: 2890-2899, 2005.

81. Sussman, L. K., Upalakalin, J. N., Roberts, M. J., Kocher, O., and Benjamin, L. E. Blood markers for vasculogenesis increase with tumor progression in patients with breast carcinoma. Cancer Biol Ther, 2: 255-256, 2003.

82. Kim, H. K., Song, K. S., Kim, H. O., Chung, J. H., Lee, K. R., Lee, Y. J., Lee, D. H., Lee, E. S., Kim, H. K., Ryu, K. W., and Bae, J. M. Circulating numbers of endothelial progenitor cells in patients with gastric and breast cancer. Cancer Lett, 198: 83-88, 2003.

83. Capillo, M., Mancuso, P., Gobbi, A., Monestiroli, S., Pruneri, G., Dell'Agnola, C., Martinelli, G., Shultz, L., and Bertolini, F. Continuous infusion of endostatin inhibits differentiation, mobilization, and clonogenic potential of endothelial cell progenitors. Clin Cancer Res, 9: 377382, 2003.

84. Shaked, Y., Bertolini, F., Man, S., Rogers, M. S., Cervi, D., Foutz, T., Rawn, K., Voskas, D., Dumont, D. J., Ben-David, Y., Lawler, J., Henkin, J., Huber, J., Hicklin, D. J., D'Amato, R. J., and Kerbel, R. S. Genetic heterogeneity of the vasculogenic phenotype parallels angiogenesis; Implications for cellular surrogate marker analysis of antiangiogenesis. Cancer Cell, 7: 101111, 2005.

85. Arafat, W. O., Casado, E., Wang, M., Alvarez, R. D., Siegal, G. P., Glorioso, J. C., Curiel, D. T., and Gomez-Navarro, J. Genetically modified CD34+ cells exert a cytotoxic bystander effect on human endothelial and cancer cells. Clin Cancer Res, 6: 4442-4448, 2000.

86. Ingram, D. A., Caplice, N. M., and Yoder, M. C. Unresolved questions, changing definitions, and novel paradigms for defining endothelial progenitor cells. Blood, 106: 1525-1531, 2005.

87. Wesseling, P., van der Laak, J. A., de Leeuw, H., Ruiter, D. J., and Burger, P. C. Quantitative immunohistological analysis of the microvasculature in untreated human glioblastoma multiforme. Computer-assisted image analysis of whole-tumor sections. J Neurosurg, 81: 902909, 1994.

88. Holmgren, L., O'Reilly, M. S., and Folkman, J. Dormancy of micrometastases: balanced proliferation and apoptosis in the presence of angiogenesis suppression. Nat Med, 1: 149-153, 1995.

89. Pezzella, F., Pastorino, U., Tagliabue, E., Andreola, S., Sozzi, G., Gasparini, G., Menard, S., Gatter, K. C., Harris, A. L., Fox, S., Buyse, M., Pilotti, S., Pierotti, M., and Rilke, F. Non-smallcell lung carcinoma tumor growth without morphological evidence of neo-angiogenesis. Am J Pathol, 151: 1417-1423, 1997.

90. Holash, J., Maisonpierre, P. C., Compton, D., Boland, P., Alexander, C. R., Zagzag, D., Yancopoulos, G. D., and Wiegand, S. J. Vessel cooption, regression, and growth in tumors mediated by angiopoietins and VEGF. Science, 284: 1994-1998, 1999.

91. Zhang, L., Yang, N., Park, J. W., Katsaros, D., Fracchioli, S., Cao, G., O'Brien-Jenkins, A., Randall, T. C., Rubin, S. C., and Coukos, G. Tumor-derived vascular endothelial growth factor up-regulates angiopoietin-2 in host endothelium and destabilizes host vasculature, supporting angiogenesis in ovarian cancer. Cancer Res, 63: 3403-3412, 2003.

92. Dome, B., Paku, S., Somlai, B., and Timar, J. Vascularization of cutaneous melanoma involves vessel co-option and has clinical significance. J Pathol, 197: 355-362, 2002.

93. Kim, E. S., Serur, A., Huang, J., Manley, C. A., McCrudden, K. W., Frischer, J. S., Soffer, S. Z., Ring, L., New, T., Zabski, S., Rudge, J. S., Holash, J., Yancopoulos, G. D., Kandel, J. J., and 
Yamashiro, D. J. Potent VEGF blockade causes regression of coopted vessels in a model of neuroblastoma. Proc Natl Acad Sci U S A, 99: 11399-11404, 2002.

94. Kunkel, P., Ulbricht, U., Bohlen, P., Brockmann, M. A., Fillbrandt, R., Stavrou, D., Westphal, M., and Lamszus, K. Inhibition of glioma angiogenesis and growth in vivo by systemic treatment with a monoclonal antibody against vascular endothelial growth factor receptor-2. Cancer Res, 61: 6624-6628, 2001.

95. Maniotis, A. J., Folberg, R., Hess, A., Seftor, E. A., Gardner, L. M., Pe'er, J., Trent, J. M., Meltzer, P. S., and Hendrix, M. J. Vascular channel formation by human melanoma cells in vivo and in vitro: vasculogenic mimicry. Am J Pathol, 155: 739-752, 1999.

96. Folberg, R., Rummelt, V., Parys-Van Ginderdeuren, R., Hwang, T., Woolson, R. F., Pe'er, J., and Gruman, L. M. The prognostic value of tumor blood vessel morphology in primary uveal melanoma. Ophthalmology, 100: 1389-1398, 1993.

97. Hendrix, M. J., Seftor, E. A., Hess, A. R., and Seftor, R. E. Vasculogenic mimicry and tumourcell plasticity: lessons from melanoma. Nat Rev Cancer, 3: 411-421, 2003.

98. Seftor, R. E., Seftor, E. A., Koshikawa, N., Meltzer, P. S., Gardner, L. M., Bilban, M., StetlerStevenson, W. G., Quaranta, V., and Hendrix, M. J. Cooperative interactions of laminin 5 gamma2 chain, matrix metalloproteinase-2, and membrane type-1-matrix/metalloproteinase are required for mimicry of embryonic vasculogenesis by aggressive melanoma. Cancer Res, 61: 6322-6327, 2001.

99. Hendrix, M. J., Seftor, E. A., Meltzer, P. S., Gardner, L. M., Hess, A. R., Kirschmann, D. A., Schatteman, G. C., and Seftor, R. E. Expression and functional significance of VE-cadherin in aggressive human melanoma cells: role in vasculogenic mimicry. Proc Natl Acad Sci U S A, 98: 8018-8023, 2001.

100. Hess, A. R., Postovit, L. M., Margaryan, N. V., Seftor, E. A., Schneider, G. B., Seftor, R. E., Nickoloff, B. J., and Hendrix, M. J. Focal adhesion kinase promotes the aggressive melanoma phenotype. Cancer Res, 65: 9851-9860, 2005.

101. Basu, G. D., Liang, W. S., Stephan, D. A., Wegener, L. T., Conley, C. R., Pockaj, B. A., and Mukherjee, P. A novel role for cyclooxygenase-2 in regulating vascular channel formation by human breast cancer cells. Breast Cancer Res, 8: R69, 2006.

102. Rothhammer, T., Bataille, F., Spruss, T., Eissner, G., and Bosserhoff, A. K. Functional implication of BMP4 expression on angiogenesis in malignant melanoma. Oncogene, 2006.

103. Xi, Y., Nakajima, G., Hamil, T., Fodstad, O., Riker, A., and Ju, J. Association of insulin-like growth factor binding protein-3 expression with melanoma progression. Mol Cancer Ther, 5: 3078-3084, 2006.

104. Topczewska, J. M., Postovit, L. M., Margaryan, N. V., Sam, A., Hess, A. R., Wheaton, W. W., Nickoloff, B. J., Topczewski, J., and Hendrix, M. J. Embryonic and tumorigenic pathways converge via Nodal signaling: role in melanoma aggressiveness. Nat Med, 12: 925-932, 2006.

105. Seftor, E. A., Brown, K. M., Chin, L., Kirschmann, D. A., Wheaton, W. W., Protopopov, A., Feng, B., Balagurunathan, Y., Trent, J. M., Nickoloff, B. J., Seftor, R. E., and Hendrix, M. J. Epigenetic transdifferentiation of normal melanocytes by a metastatic melanoma microenvironment. Cancer Res, 65: 10164-10169, 2005.

106. Rofstad, E. K., Rasmussen, H., Galappathi, K., Mathiesen, B., Nilsen, K., and Graff, B. A. Hypoxia promotes lymph node metastasis in human melanoma xenografts by up-regulating the urokinase-type plasminogen activator receptor. Cancer Res, 62: 1847-1853, 2002.

107. Bedogni, B., Welford, S. M., Cassarino, D. S., Nickoloff, B. J., Giaccia, A. J., and Powell, M. B. The hypoxic microenvironment of the skin contributes to Akt-mediated melanocyte transformation. Cancer Cell, 8: 443-454, 2005.

108. Rybak, S. M., Sanovich, E., Hollingshead, M. G., Borgel, S. D., Newton, D. L., Melillo, G., Kong, D., Kaur, G., and Sausville, E. A. "Vasocrine" formation of tumor cell-lined vascular spaces: implications for rational design of antiangiogenic therapies. Cancer Res, 63: 2812-2819, 2003.

109. van der Schaft, D. W., Hillen, F., Pauwels, P., Kirschmann, D. A., Castermans, K., Egbrink, M. G., Tran, M. G., Sciot, R., Hauben, E., Hogendoorn, P. C., Delattre, O., Maxwell, P. H., Hendrix, M. J., and Griffioen, A. W. Tumor cell plasticity in Ewing sarcoma, an alternative circulatory system stimulated by hypoxia. Cancer Res, 65: 11520-11528, 2005. 
110. Sun, B., Zhang, D., Zhang, S., Zhang, W., Guo, H., and Zhao, X. Hypoxia influences vasculogenic mimicry channel formation and tumor invasion-related protein expression in melanoma. Cancer Lett, 2006.

111. Clarijs, R., Otte-Holler, I., Ruiter, D. J., and de Waal, R. M. Presence of a fluid-conducting meshwork in xenografted cutaneous and primary human uveal melanoma. Invest Ophthalmol Vis Sci, 43: 912-918, 2002.

112. Shirakawa, K., Kobayashi, H., Heike, Y., Kawamoto, S., Brechbiel, M. W., Kasumi, F., Iwanaga, T., Konishi, F., Terada, M., and Wakasugi, H. Hemodynamics in vasculogenic mimicry and angiogenesis of inflammatory breast cancer xenograft. Cancer Res, 62: 560-566, 2002.

113. Ruf, W., Seftor, E. A., Petrovan, R. J., Weiss, R. M., Gruman, L. M., Margaryan, N. V., Seftor, R. E., Miyagi, Y., and Hendrix, M. J. Differential role of tissue factor pathway inhibitors 1 and 2 in melanoma vasculogenic mimicry. Cancer Res, 63: 5381-5389, 2003.

114. Frenkel, S., Barzel, I., Levy, J., Lin, A. Y., Bartsch, D. U., Majumdar, D., Folberg, R., and Pe'er, J. Demonstrating circulation in vasculogenic mimicry patterns of uveal melanoma by confocal indocyanine green angiography. Eye, 2007.

115. Thies, A., Mangold, U., Moll, I., and Schumacher, U. PAS-positive loops and networks as a prognostic indicator in cutaneous malignant melanoma. J Pathol, 195: 537-542, 2001.

116. Lee, Y. J., Nagai, N., Siar, C. H., Nakano, K., Nagatsuka, H., Tsujigiwa, H., Roan, C. H., and Gunduz, M. Angioarchitecture of primary oral malignant melanomas. J Histochem Cytochem, 50: 1555-1562, 2002.

117. Sharma, N., Seftor, R. E., Seftor, E. A., Gruman, L. M., Heidger, P. M., Jr., Cohen, M. B., Lubaroff, D. M., and Hendrix, M. J. Prostatic tumor cell plasticity involves cooperative interactions of distinct phenotypic subpopulations: role in vasculogenic mimicry. Prostate, 50: 189-201, 2002.

118. Sood, A. K., Seftor, E. A., Fletcher, M. S., Gardner, L. M., Heidger, P. M., Buller, R. E., Seftor, R. E., and Hendrix, M. J. Molecular determinants of ovarian cancer plasticity. Am J Pathol, 158: 1279-1288, 2001.

119. Sun, B., Zhang, S., Zhang, D., Du, J., Guo, H., Zhao, X., Zhang, W., and Hao, X. Vasculogenic mimicry is associated with high tumor grade, invasion and metastasis, and short survival in patients with hepatocellular carcinoma. Oncol Rep, 16: 693-698, 2006.

120. Fujimoto, A., Onodera, H., Mori, A., Nagayama, S., Yonenaga, Y., and Tachibana, T. Tumour plasticity and extravascular circulation in ECV304 human bladder carcinoma cells. Anticancer Res, 26: 59-69, 2006.

121. Sun, B., Zhang, S., Zhao, X., Zhang, W., and Hao, X. Vasculogenic mimicry is associated with poor survival in patients with mesothelial sarcomas and alveolar rhabdomyosarcomas. Int J Oncol, 25: 1609-1614, 2004.

122. Cai, X. S., Jia, Y. W., Mei, J., and Tang, R. Y. Tumor blood vessels formation in osteosarcoma: vasculogenesis mimicry. Chin Med J (Engl), 117: 94-98, 2004.

123. Yue, W. Y. and Chen, Z. P. Does vasculogenic mimicry exist in astrocytoma? J Histochem Cytochem, 53: 997-1002, 2005.

124. Favier, J., Plouin, P. F., Corvol, P., and Gasc, J. M. Angiogenesis and vascular architecture in pheochromocytomas: distinctive traits in malignant tumors. Am J Pathol, 161: 1235-1246, 2002.

125. Seftor, R. E., Seftor, E. A., Kirschmann, D. A., and Hendrix, M. J. Targeting the tumor microenvironment with chemically modified tetracyclines: inhibition of laminin 5 gamma2 chain promigratory fragments and vasculogenic mimicry. Mol Cancer Ther, 1: 1173-1179, 2002.

126. Rudek, M. A., Horne, M., Figg, W. D., Dahut, W., Dyer, V., Pluda, J. M., and Reed, E. Reversible sideroblastic anemia associated with the tetracycline analogue COL-3. Am J Hematol, 67: 51-53, 2001.

127. Ghate, J. V., Turner, M. L., Rudek, M. A., Figg, W. D., Dahut, W., Dyer, V., Pluda, J. M., and Reed, E. Drug-induced lupus associated with COL-3: report of 3 cases. Arch Dermatol, 137: 471-474, 2001. 
128. van der Schaft, D. W., Seftor, R. E., Seftor, E. A., Hess, A. R., Gruman, L. M., Kirschmann, D. A., Yokoyama, Y., Griffioen, A. W., and Hendrix, M. J. Effects of angiogenesis inhibitors on vascular network formation by human endothelial and melanoma cells. J Natl Cancer Inst, 96: 1473-1477, 2004.

129. Pepper, M. S. and Skobe, M. Lymphatic endothelium: morphological, molecular and functional properties. J Cell Biol, 163: 209-213, 2003.

130. Perou, C. M., Sorlie, T., Eisen, M. B., van de Rijn, M., Jeffrey, S. S., Rees, C. A., Pollack, J. R., Ross, D. T., Johnsen, H., Akslen, L. A., Fluge, O., Pergamenschikov, A., Williams, C., Zhu, S. X., Lonning, P. E., Borresen-Dale, A. L., Brown, P. O., and Botstein, D. Molecular portraits of human breast tumours. Nature, 406: 747-752, 2000.

131. Podgrabinska, S., Braun, P., Velasco, P., Kloos, B., Pepper, M. S., and Skobe, M. Molecular characterization of lymphatic endothelial cells. Proc Natl Acad Sci U S A, 99: 16069-16074, 2002.

132. Kaipainen, A., Korhonen, J., Mustonen, T., van Hinsbergh, V. W., Fang, G. H., Dumont, D., Breitman, M., and Alitalo, K. Expression of the fms-like tyrosine kinase 4 gene becomes restricted to lymphatic endothelium during development. Proc Natl Acad Sci U S A, 92: 35663570, 1995.

133. Banerji, S., Ni, J., Wang, S. X., Clasper, S., Su, J., Tammi, R., Jones, M., and Jackson, D. G. LYVE-1, a new homologue of the CD44 glycoprotein, is a lymph-specific receptor for hyaluronan. J Cell Biol, 144: 789-801, 1999.

134. Breiteneder-Geleff, S., Soleiman, A., Kowalski, H., Horvat, R., Amann, G., Kriehuber, E., Diem, K., Weninger, W., Tschachler, E., Alitalo, K., and Kerjaschki, D. Angiosarcomas express mixed endothelial phenotypes of blood and lymphatic capillaries: podoplanin as a specific marker for lymphatic endothelium. Am J Pathol, 154: 385-394, 1999.

135. Oliver, G. and Detmar, M. The rediscovery of the lymphatic system: old and new insights into the development and biological function of the lymphatic vasculature. Genes Dev, 16: 773$783,2002$.

136. Joukov, V., Kumar, V., Sorsa, T., Arighi, E., Weich, H., Saksela, O., and Alitalo, K. A recombinant mutant vascular endothelial growth factor- $\mathrm{C}$ that has lost vascular endothelial growth factor receptor-2 binding, activation, and vascular permeability activities. J Biol Chem, 273: 6599-6602, 1998.

137. Baldwin, M. E., Halford, M. M., Roufail, S., Williams, R. A., Hibbs, M. L., Grail, D., Kubo, H., Stacker, S. A., and Achen, M. G. Vascular endothelial growth factor D is dispensable for development of the lymphatic system. Mol Cell Biol, 25: 2441-2449, 2005.

138. Karkkainen, M. J., Haiko, P., Sainio, K., Partanen, J., Taipale, J., Petrova, T. V., Jeltsch, M., Jackson, D. G., Talikka, M., Rauvala, H., Betsholtz, C., and Alitalo, K. Vascular endothelial growth factor $C$ is required for sprouting of the first lymphatic vessels from embryonic veins. Nat Immunol, 5: 74-80, 2004.

139. Makinen, T., Veikkola, T., Mustjoki, S., Karpanen, T., Catimel, B., Nice, E. C., Wise, L., Mercer, A., Kowalski, H., Kerjaschki, D., Stacker, S. A., Achen, M. G., and Alitalo, K. Isolated lymphatic endothelial cells transduce growth, survival and migratory signals via the VEGFC/D receptor VEGFR-3. Embo J, 20: 4762-4773, 2001.

140. Skobe, M., Hawighorst, T., Jackson, D. G., Prevo, R., Janes, L., Velasco, P., Riccardi, L., Alitalo, K., Claffey, K., and Detmar, M. Induction of tumor lymphangiogenesis by VEGF-C promotes breast cancer metastasis. Nat Med, 7: 192-198, 2001.

141. Stacker, S. A., Caesar, C., Baldwin, M. E., Thornton, G. E., Williams, R. A., Prevo, R., Jackson, D. G., Nishikawa, S., Kubo, H., and Achen, M. G. VEGF-D promotes the metastatic spread of tumor cells via the lymphatics. Nat Med, 7: 186-191, 2001.

142. Nagy, J. A., Vasile, E., Feng, D., Sundberg, C., Brown, L. F., Detmar, M. J., Lawitts, J. A., Benjamin, L., Tan, X., Manseau, E. J., Dvorak, A. M., and Dvorak, H. F. Vascular permeability factor/vascular endothelial growth factor induces lymphangiogenesis as well as angiogenesis. J Exp Med, 196: 1497-1506, 2002.

143. Chang, L. K., Garcia-Cardena, G., Farnebo, F., Fannon, M., Chen, E. J., Butterfield, C., Moses, M. A., Mulligan, R. C., Folkman, J., and Kaipainen, A. Dose-dependent response of FGF-2 for lymphangiogenesis. Proc Natl Acad Sci U S A, 101: 11658-11663, 2004. 
144. Cao, R., Bjorndahl, M. A., Religa, P., Clasper, S., Garvin, S., Galter, D., Meister, B., Ikomi, F., Tritsaris, K., Dissing, S., Ohhashi, T., Jackson, D. G., and Cao, Y. PDGF-BB induces intratumoral lymphangiogenesis and promotes lymphatic metastasis. Cancer Cell, 6: 333-345, 2004.

145. Anan, K., Morisaki, T., Katano, M., Ikubo, A., Kitsuki, H., Uchiyama, A., Kuroki, S., Tanaka, M., and Torisu, M. Vascular endothelial growth factor and platelet-derived growth factor are potential angiogenic and metastatic factors in human breast cancer. Surgery, 119: 333-339, 1996.

146. Gale, N. W., Thurston, G., Hackett, S. F., Renard, R., Wang, Q., McClain, J., Martin, C., Witte, C., Witte, M. H., Jackson, D., Suri, C., Campochiaro, P. A., Wiegand, S. J., and Yancopoulos, G. D. Angiopoietin-2 is required for postnatal angiogenesis and lymphatic patterning, and only the latter role is rescued by Angiopoietin-1. Dev Cell, 3: 411-423, 2002.

147. Morisada, T., Oike, Y., Yamada, Y., Urano, T., Akao, M., Kubota, Y., Maekawa, H., Kimura, Y., Ohmura, M., Miyamoto, T., Nozawa, S., Koh, G. Y., Alitalo, K., and Suda, T. Angiopoietin-1 promotes LYVE-1-positive lymphatic vessel formation. Blood, 105: 4649-4656, 2005.

148. Yuan, L., Moyon, D., Pardanaud, L., Breant, C., Karkkainen, M. J., Alitalo, K., and Eichmann, A. Abnormal lymphatic vessel development in neuropilin 2 mutant mice. Development, 129: 4797-4806, 2002.

149. Kajiya, K., Hirakawa, S., Ma, B., Drinnenberg, I., and Detmar, M. Hepatocyte growth factor promotes lymphatic vessel formation and function. Embo J, 24: 2885-2895, 2005.

150. Bjorndahl, M., Cao, R., Nissen, L. J., Clasper, S., Johnson, L. A., Xue, Y., Zhou, Z., Jackson, D., Hansen, A. J., and Cao, Y. Insulin-like growth factors 1 and 2 induce lymphangiogenesis in vivo. Proc Natl Acad Sci U S A, 102: 15593-15598, 2005.

151. Saharinen, P., Tammela, T., Karkkainen, M. J., and Alitalo, K. Lymphatic vasculature: development, molecular regulation and role in tumor metastasis and inflammation. Trends Immunol, 25: 387-395, 2004.

152. Ji, R. C. Lymphatic endothelial cells, tumor lymphangiogenesis and metastasis: New insights into intratumoral and peritumoral lymphatics. Cancer Metastasis Rev, 25: 677-694, 2006.

153. Achen, M. G., Mann, G. B., and Stacker, S. A. Targeting lymphangiogenesis to prevent tumour metastasis. Br J Cancer, 94: 1355-1360, 2006.

154. Stacker, S. A., Achen, M. G., Jussila, L., Baldwin, M. E., and Alitalo, K. Lymphangiogenesis and cancer metastasis. Nat Rev Cancer, 2: 573-583, 2002.

155. Schoppmann, S. F., Bayer, G., Aumayr, K., Taucher, S., Geleff, S., Rudas, M., Kubista, E., Hausmaninger, H., Samonigg, H., Gnant, M., Jakesz, R., and Horvat, R. Prognostic value of lymphangiogenesis and lymphovascular invasion in invasive breast cancer. Ann Surg, 240: 306-312, 2004.

156. Lee, A. H., Pinder, S. E., Macmillan, R. D., Mitchell, M., Ellis, I. O., Elston, C. W., and Blamey, R. W. Prognostic value of lymphovascular invasion in women with lymph node negative invasive breast carcinoma. Eur J Cancer, 42: 357-362, 2006.

157. van der Schaft, D. W., Pauwels, P., Hulsmans, S., Zimmermann, M., van de Poll-Franse, L. V., and Griffioen, A. W. Absence of lymphangiogenesis in ductal breast cancer at the primary tumor site. Cancer Lett, 2007.

158. Arigami, T., Natsugoe, S., Uenosono, Y., Arima, H., Mataki, Y., Ehi, K., Yanagida, S., Ishigami, S., Hokita, S., and Aikou, T. Lymphatic invasion using D2-40 monoclonal antibody and its relationship to lymph node micrometastasis in pN0 gastric cancer. Br J Cancer, 93: 688-693, 2005.

159. Lotan, Y., Gupta, A., Shariat, S. F., Palapattu, G. S., Vazina, A., Karakiewicz, P. I., Bastian, P. J., Rogers, C. G., Amiel, G., Perotte, P., Schoenberg, M. P., Lerner, S. P., and Sagalowsky, A. I. Lymphovascular invasion is independently associated with overall survival, cause-specific survival, and local and distant recurrence in patients with negative lymph nodes at radical cystectomy. J Clin Oncol, 23: 6533-6539, 2005.

160. Karpanen, T., Egeblad, M., Karkkainen, M. J., Kubo, H., Yla-Herttuala, S., Jaattela, M., and Alitalo, K. Vascular endothelial growth factor C promotes tumor lymphangiogenesis and intralymphatic tumor growth. Cancer Res, 61: 1786-1790, 2001. 
161. Szuba, A., Skobe, M., Karkkainen, M. J., Shin, W. S., Beynet, D. P., Rockson, N. B., Dakhil, N., Spilman, S., Goris, M. L., Strauss, H. W., Quertermous, T., Alitalo, K., and Rockson, S. G. Therapeutic lymphangiogenesis with human recombinant VEGF-C. Faseb J, 16: 1985-1987, 2002.

162. Zhang, L., Giraudo, E., Hoffman, J. A., Hanahan, D., and Ruoslahti, E. Lymphatic zip codes in premalignant lesions and tumors. Cancer Res, 66: 5696-5706, 2006.

163. Jain, R. K. Normalization of tumor vasculature: an emerging concept in antiangiogenic therapy. Science, 307: 58-62, 2005. 



\section{Chapter 3}

\section{Proliferating endothelial cells, but not microvessel density, is a prognostic parameter in human cutaneous melanoma}

Femke Hillen, Anouk van de Winkel, David Creytens,

Anton H.M. Vermeulen, Arjan W. Griffioen

Melanoma Res. 2006 Oct; 16(5):453-7 


\section{Abstract}

The induction of angiogenesis is crucial in the development of most human tumors. Angiogenesis is routinely assessed by the density of tumor microvessels. This technique reveals controversial results on the clinical and prognostic value of angiogenesis in melanoma. We investigated angiogenesis in tumor tissues of 58 cutaneous melanoma patients, of which a clinical follow-up of over ten years was available, through assessment of microvessel density and by enumeration of the number of proliferating endothelial cells. To that end, vessels were immunohistochemically detected by CD31/CD34 staining, and proliferating endothelial cells were enumerated in a double staining with the proliferation marker Ki67. We found that microvessel density did not correlate with tumor stage or survival, neither in intratumoral nor in peritumoral areas. In contrast, proliferating endothelial cells were only observed in intratumoral areas and were correlated positively to tumor stage and the presence of distant metastases. In addition, a strong positive correlation was found with the number of proliferating tumor cells. Finally, high numbers of growing endothelial cells predicted short survival. Our results show that angiogenesis could best be measured by enumeration of proliferating endothelial cells and that this parameter has prognostic value in patients with cutaneous melanoma.

\section{Introduction}

The incidence of malignant melanoma is increasing faster than that of any other cancer, and this has been a consistent trend since $1950{ }^{1}$. Despite the decrease in mortality due to increased screening ${ }^{2}$, cutaneous malignant melanoma remains the most fatal of all skin cancers ${ }^{3}$ and the most common cancer in women aged between 20 and $29{ }^{4}$. Several markers have been proposed to have prognostic value in melanoma. Among them are clinical and pathological parameters such as tumor thickness, ulceration, anatomic site, age, gender, Clark level (level of invasion), mitotic rate, histological regression, and vascular invasion ${ }^{5}$. The Breslow thickness, or depth of tumor invasion, has become the gold standard to predict the risk of metastatic disease in patients with cutaneous melanoma. However, the use of one single histological indicator is not sufficiently predictive, as was demonstrated in an earlier study ${ }^{6}$.

A large number of studies attempted to relate angiogenesis to prognosis, mainly by quantification of the amount of blood vessels ${ }^{7}$. Microvessel density in tumors can be assessed by several techniques. Popular techniques are assessment of vessel density in the most dense area (hotspot) ${ }^{8}$, as a mean throughout the tumor ${ }^{9}$ e.g. through Chalkley point counting ${ }^{10}$, or machine-based image analysis systems (CIAS) ${ }^{11}$ 12. Although these methods seem reproducible between different observers, several studies, using the same technique of quantification, reported controversial findings 9, 13 . An alternative approach to quantify ongoing angiogenesis is the enumeration of proliferating endothelial cells (EC) as suggested by Vermeulen et al. ${ }^{14}$. In the present 
study, we investigated a series of cutaneous melanomas for the presence of active neovascularisation and report the prognostic significance of angiogenesis, quantified by the amount of proliferating EC.

\section{Material and methods}

\section{Patients}

Tumor tissues of 58 patients (69\% females, 31\% males), diagnosed with cutaneous melanoma between 1985 and 1995, were retrieved from the archival tissue bank of the Department of Pathology, Maastricht. The diagnosis of melanoma was reconfirmed by two pathologists (A.V, D.C.). 58.6\% (34/58) of the patients were diagnosed with superficial spreading melanoma, an invasive melanoma with a horizontal and a vertical growth component. $41.3 \%(24 / 58)$ were diagnosed with a nodular type of melanoma, typically characterised for its invasive growth, with little ( $<3$ epidermal rete ridges) or no adjacent intra-epidermal growth component ${ }^{15}$. Ulceration was observed in $20.6 \%$ $(12 / 58)$ of the patients. In this group $37.9 \%(22 / 58)$ of the tumor tissues were surgically resected of extremities, $29.3 \%(17 / 58)$ of the trunk and $10.3 \%(6 / 58)$ of the head and neck. For $22.4 \%$ of patients $(13 / 58)$ the location of the primary tumor was unknown. Lymph node metastasis was observed in $20.7 \%$ (12/58) and distant metastasis in $34.5 \%$ $(20 / 58)$ of the patients, $31 \%(18 / 58)$ of the patients died from melanoma. The mean age at diagnosis was 52.69 years (range 22-88 years) and the mean overall survival of the total patient group was 7.7 years (range 5 months-10 years). Patient population was categorized in 4 groups based on Breslow thickness, according to the guidelines of the Dutch Society of Melanomas: $\leq 0.75 \mathrm{~mm}(24.1 \%, 14 / 58)$, group 1; 0.76-1.5 mm $(39.7 \%$, $23 / 58)$, group $2 ; 1.51-3 \mathrm{~mm}(20.7 \%, 12 / 58)$, group 3 and $>3 \mathrm{~mm}(15.5 \%, 9 / 58)$, group 4 .

\section{Immunohistochemistry}

Paraffin sections ( $6 \mu \mathrm{m}$ thickness) were deparaffinized in ethanol, incubated in $0.3 \%$ $\mathrm{H}_{2} \mathrm{O}_{2}$ in methanol for $20^{\prime}$ to quench endogenous peroxidase activity, after which antigen retrieval was carried out by heating the sections in a Tris-EDTA buffer $(10 \mathrm{mM}$ Tris- $1 \mathrm{mM}$ EDTA, $\mathrm{pH} 8$ ) for $15^{\prime}$ in a microwave. Subsequently, the slides were incubated for $30^{\prime}$ in 5\% BSA in PBS for blocking of non-specific antibody binding. Sections were incubated for 1 hour with a rabbit-polyclonal Ki67 (Neomarker, 1/50), followed by a polyclonal biotin-labelled swine anti-rabbit IgG (Dako; 1/200) for 30' and avidin-biotin complex HRP (DAKO; 1/500) for 30'. Diaminobenzidine (DAB, Sigma) with $0.03 \% \mathrm{NiCl}_{2}$ was used as a black chromogen to be able to distinguish the black stained proliferating nuclei from the brown melanin. The second staining was performed with a mixture of CD31 (DAKO; 1/50) and CD34 (Monosan; 1/200). This was followed by a biotin-labelled goat anti-mouse IgG (DAKO; 1/200) for 30' and another 30 ' incubation with an avidin-biotin complex AP (DAKO; 1/200), the slides were developed with alkaline phosphatase substrate kit III (Vector Laboraties) and were 
Chapter 3

treated with imsolmount (Klinipath) to prevent alkaline phosphatase bleaching. Finally, slides were mounted with entellan (Merck).

\section{Analysis}

Microvessel density was determined by 2 independent observers (F.H., A.V.) in four randomly selected fields (200x). This was performed in intratumoral and peritumoral areas, and presented as the amount of blood vessels $/ \mathrm{mm}^{2}$. A second parameter for angiogenesis was evaluated through detection of active neovascularization. Therefore, the amount of proliferating EC was observed in the same intratumoral high power fields (200x) as was determined the MVD and is shown as the number of proliferating EC/vessel.

\section{Statistical analysis}

Statistical calculations were performed with SPSS software. Student T-test, MannWitney, Pearson, Spearman, Kruskal-Wallis and Log Rank tests were used. The statistical significance level was set at $\mathrm{p}<0.05$.

\section{Results}

The number of proliferating endothelial cells, but not microvessel density, is correlated to tumor stage

Melanoma tissues of 58 patients were staged by Breslow thickness (group 1, $\leq 0.75 \mathrm{~mm}$; group 2, 0.76-1.5 mm; group 3, 1.51-3 $\mathrm{mm}$ and group 4, >3 mm), which revealed a strong correlation to survival $(\mathrm{p}<0.0001$, Figure $1 \mathrm{~A})$. To investigate the prognostic value of angiogenesis parameters, microvessel density (MVD) and proliferating endothelial cells (EC) were assessed in these tissues. Intratumoral microvasculature was mostly characterised by smaller vessels in the centre and larger vessels in the outer rim of the tumor. In very thin and small melanomas, only small microvessels were present. In peritumoral areas both large and small vessels were observed.

The density of microvessels in peritumoral areas was not significantly correlated with tumor stage or survival (data not shown). Intratumoral MVD was on average $30 \%$ lower as compared to peritumoral areas, and did also not correlate to tumor stage (Figure 1B). There were also no correlations found between MVD and distant metastases, ulceration and localization of the primary tumor.

As it has been suggested that the number of proliferating EC would reflect ongoing angiogenesis better than MVD 14, double stainings were performed for CD31/CD34 and the proliferation marker Ki67. For reference, two images of equally vascularized tumor tissues but largely differing in number of proliferating EC are shown (Figure 1C and D). Interestingly, while proliferating EC were only observed in intratumoral areas, a significant correlation to tumor stage was observed. Tumors with a Breslow thickness of more than $3 \mathrm{~mm}$, had a significantly higher amount of proliferating EC as compared with the other 3 groups (group 1 vs. group 4, p<0.02; 
A
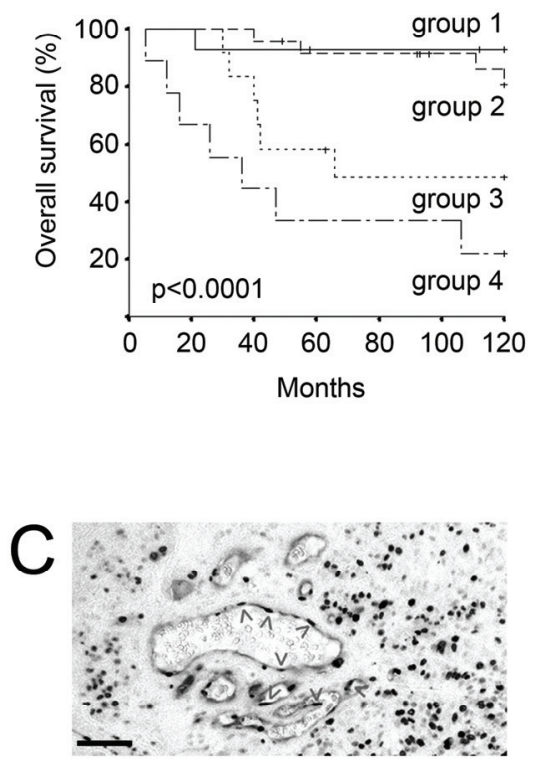

D

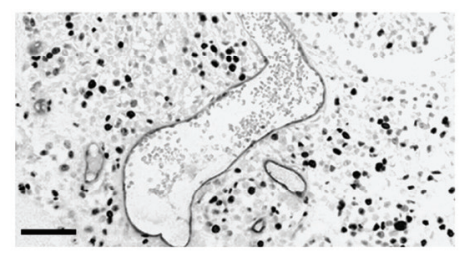

B
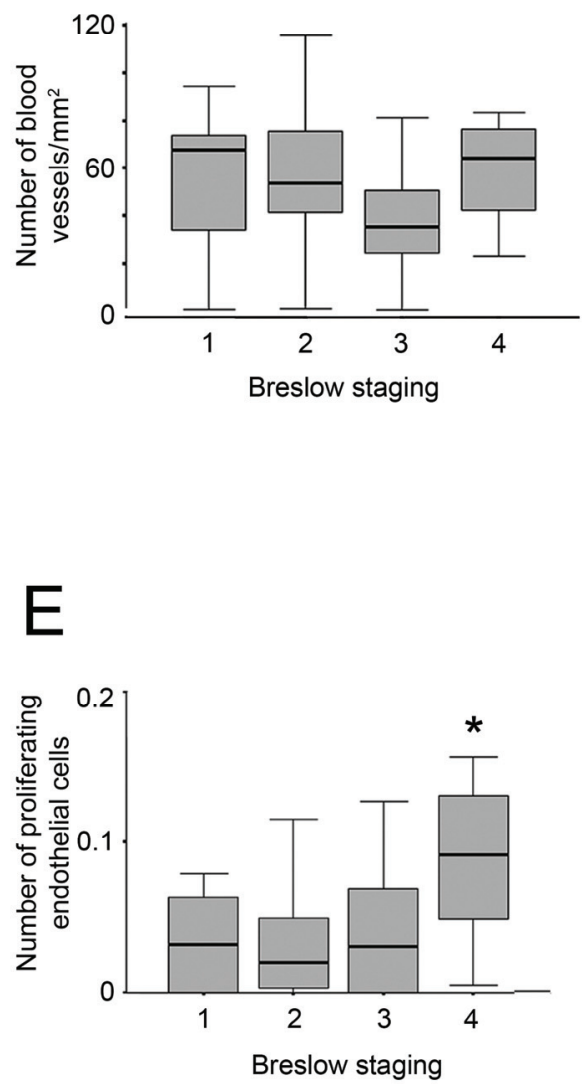

Figure 1. Angiogenic parameters in cutaneous melanomas.

A. Survival of melanoma patients stratified by Breslow staging (group 1, $\leq 0.75 \mathrm{~mm}$; group 2, 0.76-1.5 $\mathrm{mm}$; group 3, 1.51-3 mm; group 4,>3 mm), indicating the statistical significance (Log Rank testing, $\mathrm{p}<0.0001)$ of Breslow thickness. B. Microvessel density in cutaneous melanoma does not correlate with Breslow thickness. C-D. Examples of a double immunostaining for blood vessels (CD31/CD34, blue) and proliferating cells (Ki67, black) of a tissue with a high (C) and low (D) amount of proliferating endothelial cells but similar MVD (scalebars $40 \mu \mathrm{m}$ ). Proliferating endothelial cells are indicated by arrow heads. E, Amount of proliferating endothelial cells is correlated to Breslow staging $(\mathrm{p}<0.05)$.

group 2 vs. group 4, $\mathrm{p}<0.01$; group 3 vs. group 4, $\mathrm{p}<0.05$, Figure $1 \mathrm{E})$. Next to its relationship with Breslow staging, the number of proliferating EC also positively correlated with the presence of distant metastases $(p<0.05)$. No correlations were found with ulceration, and localization of the primary tumor. The number of proliferating EC also did not correlate to MVD. Interestingly, we also found a correlation with the histological subtype. Nodular melanomas, as opposed to superficial, radially growing melanomas, were observed to have higher numbers of proliferating EC. 
|Chapter 3

The number of proliferating endothelial cells is correlated to tumor cell proliferation Immunohistochemical staining with Ki67 also revealed information on the proliferation status of the tumor cells. Tumor cell proliferation correlated positively, as expected, with Breslow stage $(\mathrm{p}<0.02)$ and negatively with survival $(\mathrm{p}<0.03)$. It was also significantly and positively correlated with the amount of proliferating EC $(p<0.005)$, suggesting that a higher tumor cell proliferation is associated with a more pronounced angiogenic phenotype.

\section{The number of proliferating endothelial cells predicts survival}

Because more progressive melanomas (Breslow staging, group 4) were characterised with a significantly higher amount of proliferating EC, we next investigated the relationship to patient survival dividing our patients in two groups according to the median value of MVD and proliferating EC. Kaplan-Meier analysis revealed that both proliferating EC and proliferating tumor cells are negatively and significantly correlated to 5- and 10-year survival $(\mathrm{p}<0.003$ and $\mathrm{p}<0.009$ for $\mathrm{EC}, \mathrm{p}<0.02$ and $\mathrm{p}<0.02$ for tumor cells, respectively), while MVD is not ( $p>0.3$, Figure $3 A$ and $B)$.
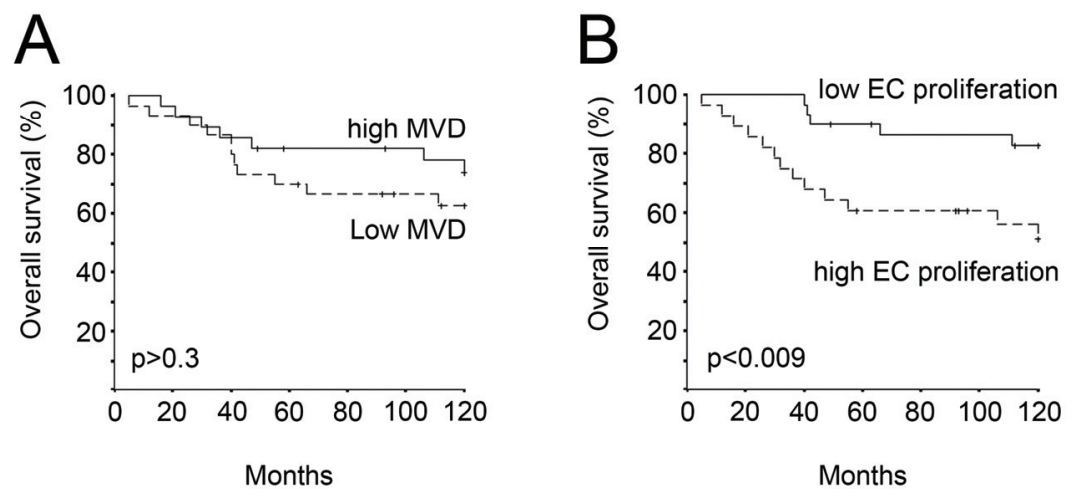

Figure 2. Overall survival of melanoma patients stratified according to microvessel density and endothelial cell proliferation.

Patients were separated in two groups based on the median values for microvessel density and proliferating endothelial cells, respectively. The amount of proliferating endothelial cells was a prognostic parameter $(\mathrm{p}<0.009)$ while microvessel density was not. 


\section{Discussion}

Tumor growth, progression and metastasis is associated with an angiogenic phenotype in various tumor types ${ }^{7}$. Several studies have demonstrated that angiogenesis is an important ongoing process in cutaneous melanoma ${ }^{16-18}$. The clinical and prognostic value of melanoma vascularization, however, has remained controversial. Various histological and immunohistochemical studies reported a positive correlation between tumor microvessel density and survival of melanoma patients or tumor progression ${ }^{19-32}$ while others showed an inverse correlation or no prognostic significance at all ${ }^{33-39}$.

In this study, we determined microvessel density by staining the tumor vasculature with a mixture of CD31 and CD34 antibodies. MVD was determined to be variable between the different groups of Breslow staging and lower in group 2 and 3. This trend could be explained by co-option of vessels by tumor cells, where the tumor uses the existing host vessels without evoking an angiogenic response ${ }^{40}$. Most of the microvasculature in the skin is present in the papillary dermis 1-2 mm below the epidermal surface ${ }^{41}$. When a melanocyte starts to proliferate continuously and obtains carcinogenic characteristics, the tumor will grow through the epidermal base and will be able to use the existing plexus of the dermis. Melanomas with a Breslow thickness larger then 1 to $2 \mathrm{~mm}$, could be capable to incorporate or co-opt host vessels situated in the dermis ${ }^{42}$. However, only continued growth of the tumor leads to hypoxia and leads to an angiogenic response ${ }^{40}$.

In an earlier study, it was suggested that MVD reflects the intercapillary distance or metabolic need of the tumor cells, and not the angiogenic activity of the tumor ${ }^{43}$. To gain a better insight in ongoing angiogenesis in melanomas, we performed a double staining with CD31/CD34, staining all vessels, and Ki67, a nuclear proliferation marker, to determine the number of proliferating endothelial cells. A significantly higher EC proliferation per vessel was observed in the most progressive group (Breslow thickness $>3 \mathrm{~mm}$ ), moreover, the amount of EC proliferation was strongly correlated with Breslow thickness and the number of proliferating tumor cells. The strong significant prognostic value of EC proliferation was confirmed by KaplanMeier analyses and showed an unfavourable outcome for patient with a high amount of proliferating EC per vessel. It should be realized that melanoma of more than $3 \mathrm{~mm}$ in depth is nowadays a rare disease with a high propensity to give metastasis. Consequently, it may be argued whether a relationship with proliferating EC would support prognosis. For these tumors clinical benefit of proliferating EC as a parameter might be limited, still these findings are of scientific interest.

In most survival studies application of adjuvant therapy, after surgical resection of a melanoma, was never taken into account. In our patient group, 9 patients (15.5\%) had been treated with different types of chemotherapy after diagnosis of metastasis. Only in 1 patient (with a Breslow thickness $\leq 0.75 \mathrm{~mm}$ ) adjuvant therapy resulted in an overall survival of 120 months. Except for high-dose interferon, as an adjuvant therapy in melanoma patients with only lymph node metastasis, no 
|Chapter 3

therapeutic options are available for metastasized melanomas ${ }^{4}$. We included these patients in our first survival analysis because they would have died earlier without therapy and the prognostic value of our parameter would have been more significant. Because of the biased survival of patients with metastases, even though with small effects, we performed Kaplan Meier without these 9 patients. The amount of EC proliferation per vessel was still a strong prognostic factor for prediction of both 5- and 10-year survival $(\mathrm{p}<0.02)$.

In summary, our study demonstrates, for the first time, that ongoing angiogenesis in cutaneous melanoma can be assessed by the amount of proliferating cells and, moreover, that this parameter is of prognostic value and can aid in therapy monitoring purposes. 


\section{References}

1. Levi, F., Lucchini, F., Negri, E., Boyle, P., and La Vecchia, C. Cancer mortality in Europe, 19951999, and an overview of trends since 1960. Int J Cancer, 110: 155-169, 2004.

2. La Vecchia, C., Lucchini, F., Negri, E., and Levi, F. Recent declines in worldwide mortality from cutaneous melanoma in youth and middle age. Int J Cancer, 81: 62-66, 1999.

3. de Vries, E. and Coebergh, J. W. Cutaneous malignant melanoma in Europe. Eur J Cancer, 40: 2355-2366, 2004.

4. Tsao, H., Atkins, M. B., and Sober, A. J. Management of cutaneous melanoma. N Engl J Med, 351: 998-1012, 2004.

5. Li, N., Mangini, J., and Bhawan, J. New prognostic factors of cutaneous melanoma: a review of the literature. J Cutan Pathol, 29: 324-340, 2002.

6. Slingluff, C. L., Jr., Vollmer, R. T., Reintgen, D. S., and Seigler, H. F. Lethal "thin" malignant melanoma. Identifying patients at risk. Ann Surg, 208: 150-161, 1988.

7. Hanahan, D. and Folkman, J. Patterns and emerging mechanisms of the angiogenic switch during tumorigenesis. Cell, 86: 353-364, 1996.

8. Weidner, N., Semple, J. P., Welch, W. R., and Folkman, J. Tumor angiogenesis and metastasis-correlation in invasive breast carcinoma. N Engl J Med, 324: 1-8, 1991.

9. Vermeulen, P. B., Gasparini, G., Fox, S. B., Colpaert, C., Marson, L. P., Gion, M., Belien, J. A., de Waal, R. M., Van Marck, E., Magnani, E., Weidner, N., Harris, A. L., and Dirix, L. Y. Second international consensus on the methodology and criteria of evaluation of angiogenesis quantification in solid human tumours. Eur J Cancer, 38: 1564-1579, 2002.

10. Fox, S. B., Leek, R. D., Weekes, M. P., Whitehouse, R. M., Gatter, K. C., and Harris, A. L. Quantitation and prognostic value of breast cancer angiogenesis: comparison of microvessel density, Chalkley count, and computer image analysis. J Pathol, 177: 275-283, 1995.

11. Fox, S. B. and Harris, A. L. Histological quantitation of tumour angiogenesis. Apmis, 112: 413430, 2004.

12. Wild, R., Ramakrishnan, S., Sedgewick, J., and Griffioen, A. W. Quantitative assessment of angiogenesis and tumor vessel architecture by computer-assisted digital image analysis: effects of VEGF-toxin conjugate on tumor microvessel density. Microvasc Res, 59: 368-376, 2000.

13. Vermeulen, P. B., Gasparini, G., Fox, S. B., Toi, M., Martin, L., McCulloch, P., Pezzella, F., Viale, G., Weidner, N., Harris, A. L., and Dirix, L. Y. Quantification of angiogenesis in solid human tumours: an international consensus on the methodology and criteria of evaluation. Eur J Cancer, 32A: 2474-2484, 1996.

14. Vermeulen, P. B., Verhoeven, D., Hubens, G., Van Marck, E., Goovaerts, G., Huyghe, M., De Bruijn, E. A., Van Oosterom, A. T., and Dirix, L. Y. Microvessel density, endothelial cell proliferation and tumour cell proliferation in human colorectal adenocarcinomas. Ann Oncol, 6: 59-64, 1995.

15. Mooi W.J., K. T. Biopsy Pathology of Melanocytic Disorder. Chapman \& Hall Medical, 1992.

16. Warren, B. A. and Shubik, P. The growth of the blood supply to melanoma transplants in the hamster cheek pouch. Lab Invest, 15: 464-478, 1966.

17. Hubler, W. R., Jr. and Wolf, J. E., Jr. Melanoma. Tumor angiogenesis and human neoplasia. Cancer, 38: 187-192, 1976.

18. Srivastava, A., Laidler, P., Hughes, L. E., Woodcock, J., and Shedden, E. J. Neovascularization in human cutaneous melanoma: a quantitative morphological and Doppler ultrasound study. Eur J Cancer Clin Oncol, 22: 1205-1209, 1986.

19. Srivastava, A., Laidler, P., Davies, R. P., Horgan, K., and Hughes, L. E. The prognostic significance of tumor vascularity in intermediate-thickness $(0.76-4.0 \mathrm{~mm}$ thick) skin melanoma. A quantitative histologic study. Am J Pathol, 133: 419-423, 1988.

20. Fallowfield, M. E. and Cook, M. G. The vascularity of primary cutaneous melanoma. J Pathol, 164: 241-244, 1991.

21. Barnhill, R. L. and Levy, M. A. Regressing thin cutaneous malignant melanomas $(<$ or $=1.0$ $\mathrm{mm}$ ) are associated with angiogenesis. Am J Pathol, 143: 99-104, 1993. 
22. Graham, C. H., Rivers, J., Kerbel, R. S., Stankiewicz, K. S., and White, W. L. Extent of vascularization as a prognostic indicator in thin $(<0.76 \mathrm{~mm})$ malignant melanomas. Am J Pathol, 145: 510-514, 1994.

23. Marcoval, J., Moreno, A., Graells, J., Vidal, A., Escriba, J. M., Garcia-Ramirez, M., and Fabra, A. Angiogenesis and malignant melanoma. Angiogenesis is related to the development of vertical (tumorigenic) growth phase. J Cutan Pathol, 24: 212-218, 1997.

24. Vlaykova, T., Muhonen, T., Hahka-Kemppinen, M., Pyrhonen, S., and Jekunen, A. Vascularity and prognosis of metastatic melanoma. Int J Cancer, 74: 326-329, 1997.

25. Erhard, H., Rietveld, F. J., van Altena, M. C., Brocker, E. B., Ruiter, D. J., and de Waal, R. M. Transition of horizontal to vertical growth phase melanoma is accompanied by induction of vascular endothelial growth factor expression and angiogenesis. Melanoma Res, 7 Suppl 2: S19-26, 1997.

26. Straume, O., Salvesen, H. B., and Akslen, L. A. Angiogenesis is prognostically important in vertical growth phase melanomas. Int J Oncol, 15: 595-599, 1999.

27. de Waal, R. M., van Altena, M. C., Erhard, H., Weidle, U. H., Nooijen, P. T., and Ruiter, D. J. Lack of lymphangiogenesis in human primary cutaneous melanoma. Consequences for the mechanism of lymphatic dissemination. Am J Pathol, 150: 1951-1957, 1997.

28. Straume, O. and Akslen, L. A. Expresson of vascular endothelial growth factor, its receptors (FLT-1, KDR) and TSP-1 related to microvessel density and patient outcome in vertical growth phase melanomas. Am J Pathol, 159: 223-235, 2001.

29. Zamolo, G., Gruber, F., Cabrijan, L., Micovic, V., Iternicka, Z., and Jonjic, N. Influence of tumor thickness and vascularity on survival in cutaneous melanoma. Acta Med Okayama, 55: 289-293, 2001.

30. Kashani-Sabet, M., Sagebiel, R. W., Ferreira, C. M., Nosrati, M., and Miller, J. R., 3rd Tumor vascularity in the prognostic assessment of primary cutaneous melanoma. J Clin Oncol, 20: 1826-1831, 2002.

31. Ribatti, D., Ennas, M. G., Vacca, A., Ferreli, F., Nico, B., Orru, S., and Sirigu, P. Tumor vascularity and tryptase-positive mast cells correlate with a poor prognosis in melanoma. Eur J Clin Invest, 33: 420-425, 2003.

32. Valencak, J., Heere-Ress, E., Kopp, T., Schoppmann, S. F., Kittler, H., and Pehamberger, H. Selective immunohistochemical staining shows significant prognostic influence of lymphatic and blood vessels in patients with malignant melanoma. Eur J Cancer, 40: 358-364, 2004.

33. Carnochan, P., Briggs, J. C., Westbury, G., and Davies, A. J. The vascularity of cutaneous melanoma: a quantitative histological study of lesions $0.85-1.25 \mathrm{~mm}$ in thickness. Br J Cancer, 64: 102-107, 1991.

34. Barnhill, R. L., Busam, K. J., Berwick, M., Blessing, K., Cochran, A. J., Elder, D. E., Fandrey, K., Karaoli, T., and White, W. L. Tumour vascularity is not a prognostic factor for cutaneous melanoma. Lancet, 344: 1237-1238, 1994.

35. Guffey, J. M., Chaney, J. V., Stevens, G. L., Schroer, K. R., Fenske, N. A., Reintgen, D., and Glass, L. F. Immunohistochemical assessment of tumor vascularity in recurrent Clark II melanomas using antibody to type IV collagen. J Cutan Pathol, 22: 122-127, 1995.

36. Busam, K. J., Berwick, M., Blessing, K., Fandrey, K., Kang, S., Karaoli, T., Fine, J., Cochran, A. J., White, W. L., Rivers, J., and et al. Tumor vascularity is not a prognostic factor for malignant melanoma of the skin. Am J Pathol, 147: 1049-1056, 1995.

37. Pierard, G. E. and Pierard-Franchimont, C. Stochastic relationship between the growth fraction and vascularity of thin malignant melanomas. Eur J Cancer, 33: 1888-1892, 1997.

38. Massi, D., Franchi, A., Borgognoni, L., Paglierani, M., Reali, U. M., and Santucci, M. Tumor angiogenesis as a prognostic factor in thick cutaneous malignant melanoma. A quantitative morphologic analysis. Virchows Arch, 440: 22-28, 2002.

39. Jonjic, N., Zamolo, G., Stifter, S., Fuckar, D., Gruber, F., Sasso, F., Rizzardi, C., and Melato, M. Cytomorphological variations, proliferation and angiogenesis in the prognosis of cutaneous melanoma. Clin Exp Dermatol, 28: 310-314, 2003.

40. Auguste, P., Lemiere, S., Larrieu-Lahargue, F., and Bikfalvi, A. Molecular mechanisms of tumor vascularization. Crit Rev Oncol Hematol, 54: 53-61, 2005.

41. Braverman, I. M. The cutaneous microcirculation. J Investig Dermatol Symp Proc, 5: 3-9, 2000. 
42. Dome, B., Paku, S., Somlai, B., and Timar, J. Vascularization of cutaneous melanoma involves vessel co-option and has clinical significance. J Pathol, 197: 355-362, 2002.

43. Hlatky, L., Hahnfeldt, P., and Folkman, J. Clinical application of antiangiogenic therapy: microvessel density, what it does and doesn't tell us. J Natl Cancer Inst, 94: 883-893, 2002. 



\section{Chapter 4}

\section{Leukocyte infiltration and tumor cell plasticity are parameters of aggressiveness in primary cutaneous melanoma}

Femke Hillen, Coen I.M. Baeten, Anouk van de Winkel, David Creytens, Daisy W.J. van der Schaft, Véronique Winnepenninckx, Arjan W. Griffioen

Cancer Immunol Immunoth. 2008 Jan, 57(1):97-106 


\begin{abstract}
Various clinical and experimental observations detected an immunological host defence in cutaneous melanoma. In order to investigate the prognostic value of leukocyte effector mechanisms, we examined the presence of different subsets of leukocytes in tumor samples of 58 patients diagnosed with primary cutaneous melanoma. The presence of $\mathrm{T}$ lymphocytes, cytotoxic T lymphocytes, B lymphocytes, CD16+ cells and macrophages was correlated to Breslow depth. A significantly higher amount of several subsets of leukocytes was found in samples with a more progressed tumor stage and survival analysis demonstrated that a higher amount of $\mathrm{T}$ lymphocytes and CD16+ cells was associated with a short survival. The amount of FOXP3+ regulatory $\mathrm{T}$ lymphocytes did not correlate with survival, nevertheless, it correlated with the amount of total infiltrate. In contrast, analysis of the expression of CD69, a marker for activated lymphocytes, demonstrated that patients with a higher amount of CD69+ lymphocytes had a better survival. In addition, a new parameter for aggressiveness of melanoma, tumor cell plasticity (i.e. the presence of periodic acid Schiff's (PAS) reagent positive loops), also predicted short survival and a trend of a higher amount of tumor infiltrating leukocytes in tumors with PAS positive loops was observed. These findings demonstrate that leukocyte infiltration and the presence of PAS loops is a sign of tumor aggressiveness and may have prognostic value.
\end{abstract}

\title{
Introduction
}

Due to dedifferentiation and uncontrolled proliferation, cancerous cells express antigens that can be recognised by the immune system. Leukocytes are activated, expand clonally and migrate to the tumor ${ }^{1}$. The infiltration of these leukocytes into tumor tissues is controlled by the local microenvironment and precedes the lytic cascade in which leukocytes attack tumor cells ${ }^{2}$. Several studies report the amount of tumor infiltrating leukocytes as a prognostic factor in e.g. prostatic adenocarcinoma ${ }^{3}$, breast carcinoma ${ }^{4}$, cervix squamous cell carcinoma ${ }^{5}$, colorectal carcinoma ${ }^{6}$, esophageal carcinoma ${ }^{7,8}$, ovarian cancer ${ }^{9}, 10$, head and neck cancer ${ }^{11}$, non-small cell lung cancer ${ }^{12}$. However, most studies were only investigating the role of $\mathrm{T}$ lymphocytes in relation to survival. There is a complex relationship between tumor infiltrating leukocytes and the patient outcome due to heterogeneity of infiltration in different patients and different regions of the tumor, the variety of subtypes of leukocytes that are present in the tumor and the differences in localisation of the leukocytes within the tumor and the surrounding tissue ${ }^{2}$.

Even though the presence of a heavy leukocyte infiltrate is a frequent characteristic in melanoma, this fails to control tumor growth ${ }^{13}$. The prognostic value of tumor infiltrating leukocytes in human melanoma has been contradictory. Clark et al. proposed a definition of tumor infiltrating leukocytes categorizing them by intensity in 
brisk, non-brisk and absent. They saw a favourable outcome in patients with a brisk intensity of tumor infiltrating leukocytes ${ }^{14}$. These findings were confirmed by Clemente et al. ${ }^{15}$. However, in the large patient studies of Thorn and Barnhill, a more favourable outcome in patients with a higher intensity of leukocyte infiltration was not observed 16, 17. The Clark-method appears to be subject to a large interobserver variability and does not distinguish between the several subsets of tumor infiltrating leukocytes. Furthermore, discrimination between intratumoral and peritumoral infiltration may be necessary, as it is a prerequisite of an attacking lymphocyte to infiltrate inside the tumor tissue ${ }^{2}$.

In the current study, we investigated a variety of subsets of leukocytes in intratumoral and peritumoral areas, and their prognostic value in patients diagnosed with primary cutaneous melanoma. In addition, we analysed the activation status of the lymphocytes and the presence of immunosuppressive lymphocytes or $\mathrm{T}$ regulatory cells. Furthermore, we were interested in the relationship between leukocyte infiltration and angiogenesis. Since tumor cell plasticity is contributing to the circulatory system of tumors ${ }^{18}$, we also investigated this parameter in relationship to leukocyte infiltration.

\section{Material and methods}

\section{Patients}

We collected tumor tissues of 58 patients (69\% (40/58) females, 31\% (18/58) males), diagnosed with primary cutaneous melanoma between 1985 and 1995, from the archival tissue bank of the Department of Pathology, Maastricht. A clinical follow-up of ten years was obtained. The diagnosis of melanoma was reconfirmed by a pathologist (D.C., V.W.). Of these patients, 64\% (37/58) were diagnosed with superficial spreading melanoma. The other $36 \%(21 / 58)$ of the patients were diagnosed with a nodular type of melanoma. Radial growth phase was observed in $10 \%(6 / 58)$ of the patients, tumor with both radial and vertical growth phase were observed in 54\% (31/58) of the patients and $36 \%(21 / 58)$ of the tumor samples presented only vertical growth phase. Mean age at diagnosis was 52.69 years (range 22-88 years). The presence of ulceration was found in $20.6 \%(12 / 58)$ of the patients. In this group of primary tumors, $37.9 \%(22 / 58)$ of the tumor tissues were located on extremities, $29.3 \%(17 / 58)$ on the trunk and $10.3 \%(6 / 58)$ on the head and neck. For $22.4 \%$ of the patients $(13 / 58)$ there was no data in the archive on the location of the primary tumor . Lymph node metastasis was detected in $20.7 \%$ $(12 / 58)$ and distant metastasis in $34.5 \%(20 / 58)$ of the patients, $31 \%(18 / 58)$ of the patients died from melanoma. Mean overall survival of the total patient group was 7.7 years (range 5 months-10 years). Regression was observed in 31\% (18/58) of the patients. Patient population was categorized in 4 groups based on Breslow thickness, according to the guidelines of the Dutch Society of Melanomas: $\leq 0.75 \mathrm{~mm}(24.1 \%$, $14 / 58)$, group $1 ; 0.76-1.5 \mathrm{~mm}(39.7 \%, 23 / 58)$, group $2 ; 1.51-3 \mathrm{~mm}(20.7 \%, 12 / 58)$, group 3 and $>3 \mathrm{~mm}(15.5 \%, 9 / 58)$, group 4 . This revealed a strong correlation to survival (log 
rank, $\mathrm{p}<0.0001)$. The presence of distant metastasis, positive lymph nodes, ulceration and the histological subtype (being superficial spreading melanoma versus nodular melanoma) demonstrated a significant negative correlation $(\mathrm{p}<0.003)$ with survival, as we have previously described ${ }^{19}$. To compare our observations with previous reports on infiltration, tumor samples were classified according to the classification of Clark et al. 14. $41.4 \%(24 / 58)$ of the tumor samples were classified as brisk, 37.9\% (22/58) were analysed as non-brisk and $20,7 \%$ (12/58) were observed with an absent infiltrate, according to this classification.

\section{Immunohistochemistry}

Paraffin sections (6 $\mu \mathrm{m}$ thickness) were deparaffinized in xylene and ethanol, incubated in $0.3 \% \mathrm{H}_{2} \mathrm{O}_{2}$ in methanol to quench endogenous peroxidase activity for $20^{\prime}$, after which antigen retrieval was carried out by heating the sections in a Tris-EDTA buffer $(10 \mathrm{mM}$ Tris- $1 \mathrm{mM}$ EDTA, $\mathrm{pH} 8$ ) for 15 minutes in a microwave oven for most of the antibodies except for the CD45 and CD20 antibodies. The staining with the CD68 antibody required an incubation of $30^{\prime}$ with $0.1 \%$ pepsin in $1 \mathrm{~N} \mathrm{HCl}$. The antigen retrieval step for the FOXP3 antibody was performed with a citric buffer $(10 \mathrm{mM}$ citric acid, $\mathrm{pH} 6)$ while the slides for the CD69 antibody were heated with an EDTA buffer (1mM EDTA, $\mathrm{pH}$ 8). Subsequently, the slides were incubated in a $5 \%$ BSA/PBS solution for $30^{\prime}$. Sections were incubated for 1 hour with the primary antibody for CD45, CD3 (Dakocytomation, Glostrup, Denmark), CD8 (Novacastra, Newcastle Upon Tyne, UK), CD68, CD20 (Dakocytomation, Glostrup, Denmark) and CD16 (Neomarkers, Fremont, CA), FOXP3 (eBioscience, San Diego, USA), CD69 (Novacastra, New Castle Upon Tyne, UK), followed by a secondary biotin-labelled rabbit anti-mouse IgG (Dakocytomation, Glostrup Denmark) for 30'and avidin-biotin complex HRP (Dakocytomation) for 30'. The secondary antibody for FOXP3 was a biotin-labelled donkey anti-rat, since the primary antibody was of rat origin (Jackson Immunoresearch, West Grove, USA). Diaminobenzidine (DAB) as a brown chromogen (Sigma, St. Loius, MO) but for most leukocyte infiltration $\mathrm{DAB}$ combined with $0.03 \% \mathrm{NiCl}_{2}$ as a black chromogen was used to distinguish leukocytes in pigmented tumors. Because of the high deposition of melanin within the macrophages, CD68 staining was visualised with a red chromogen (avidin-biotin complex with alkaline phosphatase, Dakocytomation; alkaline phosphatase substrate kit II, Vector Laboraties, Burlingame, CA) and the sections were afterwards treated with imsolmount (Klinipath, Duiven, the Netherlands) to prevent alkaline phosphatase bleaching. Finally, the slides were mounted with entellan (Merck, Darmstadt, Germany).

The same series of slides was stained with periodic acid Schiff's (PAS). After deparafinization and rehydration slides were incubated in $1 \%$ periodic acid (VWR Prolab, Fontenay/Bois, France) for $5 \mathrm{~min}$ and subsequently, for $5 \mathrm{~min}$, in periodic acid Schiff's reagent (Sigma diagnositics, St. Louis, USA), dehydrated and mounted with entellan. 
As we previously reported, a double staining with Ki67 and CD31/CD34 was performed on this same series of tumor samples ${ }^{19}$. In short, sections were incubated with a rabbit- anti human polyclonal Ki67 (Neomarkers, Fremont, California, USA), followed by a polyclonal biotin-labelled swine anti-rabbit IgG (Dakocytomation, Glostrup, Denmark). This staining was developed with an avidin-biotin complex HRP (Dakocytomation) followed by $\mathrm{DAB}$ with $0.03 \% \mathrm{NiCl} 2$ (black chromogen). A second staining was performed with a mixture of CD31 (Dakocytomation) and CD34 (Monosan, Uden, the Netherlands). This was followed by a biotin-labelled goat antimouse IgG (Dakocytomation) and an avidin-biotin complex AP (Dakocytomation). Finally, the slides were developed with alkaline phosphatase substrate kit III (Vector Laboratories, Burlingame, California, USA), treated with insulmount (Klinipath, Duiven, the Netherlands) and mounted with entellan (Merck, Darmstadt, Germany).

\section{Analysis}

The amount of each subset of tumor infiltrating leukocytes was quantified by 3 independent observers (F.H., C.B., A.W.) in four high power fields at 400 times magnification. Both intratumoral and peritumoral leukocytes were quantified, each in four randomly chosen regions that where representative for the whole tumor. The amount of FOXP3+ cells was quantified in eight high power fields at 400 times magnification both intratumoral and peritumoral. Since the amount of CD69+ cells was so low, we screened the whole tumor, both intratumorally and peritumorally, at 400 times magnification. With the CD16 staining we quantified only granulocytes and NK cells, while macrophages were quantified with a CD68 staining. The numbers are presented as the amount of tumor infiltrating leukocytes $/ \mathrm{mm}^{2}$. Intratumoral leukocytes where leukocytes that were nested inside the tumor tissue in contact with tumor cells, while peritumoral leukocytes were located outside the border of the tumor.

The presence of PAS positive loops was scored as present or absent. We scored each tumor for the presence of parallel cross linked patterns or back to back loops ${ }^{20}$.

Regression was evaluated to be present when there was a replacement of tumor tissue with fibrosis, degenerated melanoma cells, leukocytic proliferation and telangiectasia formation.

A radial growth phase was evaluated when the tumor had a tendency to grow horizontally within the epidermal and superficial dermal layers. A vertical growth phase was defined as a pattern of growth in which tumor cells spread vertically from the epidermis into the dermis.

As we previously described, we evaluated a parameter for active neovascularization or angiogenesis ${ }^{19}$. Therefore, the amount of proliferating endothelial cells, being Ki67 positive endothelial cells, was observed in four intratumoral high power fields (200x) and is shown as the number of proliferating EC/vessel. Proliferating Ki67 positive tumor cells were quantified in the same fields and presented as the amount of Ki67 positive tumor cells $/ \mathrm{mm}^{2}$. 
|Chapter 4

\section{Statistical analysis}

Statistical analyses were performed with SPSS-10 software (SPSS Inc., Chicago, USA). Kolmogorov-Smirnov was used for normality-testing of the data. Student's T-test, Mann-Witney and Kruskal-Wallis were applied to detect significant differences between groups. With the Spearman test, the correlation between the different data groups was examined. The equality of the survival distributions was analysed using the Log Rank test. Results were considered to be statistically significant when $\mathrm{p}<0.05$.


Figure 1. Peritumoral and intratumoral leukocytes in cutaneous melanoma.

A-F. Examples of immunostainings of peri-and intratumoral leukocytes. (A) All leukocytes (CD45+), (B) T lymphocytes (CD3+), (C) cytotoxic T lymphocytes (CD8+), (D) CD16+ cells, (E) B lymphocytes (CD20+), and (F) macrophages (CD68+). The dotted lines indicate the border between the tumor and the surrounding tissue. Arrow heads indicate intratumoral leukocytes. Scale bar, $20 \mu \mathrm{m}$. G. The quantification of different subsets of leukocytes in the melanomas. The amount of peritumoral leukocytes are shown in black bars, while the amount of intratumoral leukocytes are demonstrated in white bars. Error bars show standard error of the mean. 


\section{Results}

\section{Leukocyte infiltration is positively correlated with tumor stage}

To study leukocyte infiltration in human cutaneous melanoma, we investigated the total amount of leukocytes (CD45+), as well as the subsets of T lymphocytes (CD3+), cytotoxic T lymphocytes (CD8+), B cells (CD20+), CD16+ cells and macrophages $(\mathrm{CD} 68+)$, in both peritumoral and intratumoral areas (Figure 1A-F). As shown in Figure $1 G$, most leukocytes are present in peritumoral areas. Furthermore, we found that in peritumoral areas the majority of leukocytes are T lymphocytes, while within the tumor the leukocyte population consists of mostly macrophages. Another finding was that the number of CD16+ cells was very low as compared to the other leukocyte subsets. The composition of the leukocyte infiltrate was comparable for all patients (not shown).

We found a significant correlation between the "brisk" classification (dividing tumor samples in three groups: absent, non-brisk and brisk) and the amount of peritumoral $\mathrm{CD} 45+(\mathrm{p}=0.001), \mathrm{CD} 3+(\mathrm{p}=0.001), \mathrm{CD} 8+(\mathrm{p}=0.001), \mathrm{CD} 20+(\mathrm{p}=0.001), \mathrm{CD} 68+$ $(\mathrm{p}=0.001)$ and the amount of intratumoral $\mathrm{CD} 45+(\mathrm{p}=0.001), \mathrm{CD} 3+(\mathrm{p}=0.001), \mathrm{CD} 8+$ $(\mathrm{p}=0.001), \mathrm{CD} 16+(\mathrm{p}=0.027), \mathrm{CD} 20+(\mathrm{p}=0.001)$.

Leukocyte infiltration was positively correlated to aggressiveness of the tumors as determined by three different ways. (i) The group of nodular melanomas, known to have a poor prognosis (also in this study, log rank p-value $=0.039$ ), were characterised by a significantly higher amount of intratumoral $\mathrm{CD} 3+(\mathrm{p}=0.036)$ and CD16+ cells $(p=0.001)$, and peritumoral CD45+ $(p=0.034), C D 16+(p=0.001)$ and CD20+ $(\mathrm{p}=0.044)$, as compared to superficial spreading melanoma (Figure 2 A-B). (ii) There was a significant higher amount infiltration by different subsets of leukocytes in tumors with a higher amount of proliferating tumor cells [peritumoral CD3+ $(p=0.004), C D 8+$ $(\mathrm{p}=0.005), \mathrm{CD} 16+(\mathrm{p}=0.002)$ cells and intratumoral CD45+ $(\mathrm{p}=0.038), \mathrm{CD} 3+(\mathrm{p}=0.001)$, $\mathrm{CD} 8+(\mathrm{p}=0.037), \mathrm{CD} 16+(\mathrm{p}=0.002)$ ] (Figure $2 \mathrm{C}-\mathrm{F})$. (iii) We identified a higher amount of intratumoral leukocyte infiltration (for CD45+, CD8+ and CD16+ cells, respectively $\mathrm{p}=0.042, \mathrm{p}=0.032, \mathrm{p}=0.0001$, Figure $3 \mathrm{~A}-\mathrm{C}$ ) in patients with a Breslow depth $>3 \mathrm{~mm}$. A similar trend was observed for peritumoral leukocyte subsets.

Dividing the patients by the type of growth phase, being radial or vertical growth phase, a higher amount of peritumoral CD8+ $(\mathrm{p}=0.045), \mathrm{CD} 16+(\mathrm{p}=0.001)$, CD20+ $(p=0.049)$ cells and intratumoral CD3+ $(p=0.030), C D 16+(p=0.001), C D 68+$ $(\mathrm{p}=0.040)$ cells is shown in patients with vertical growth phase. All other subsets of leukocytes showed the same trend in more leukocytes in patients with a vertical growth phase.

The presence of regression did not show any correlation with intratumoral or peritumoral leukocytes, but was mostly observed in thin melanomas (15/18 tumor samples with regression had a Breslow thickness $<1.5 \mathrm{~mm}$ ). Kaplan Meier analysis did not show any predictive value of regression in patient with primary cutaneous melanoma. 

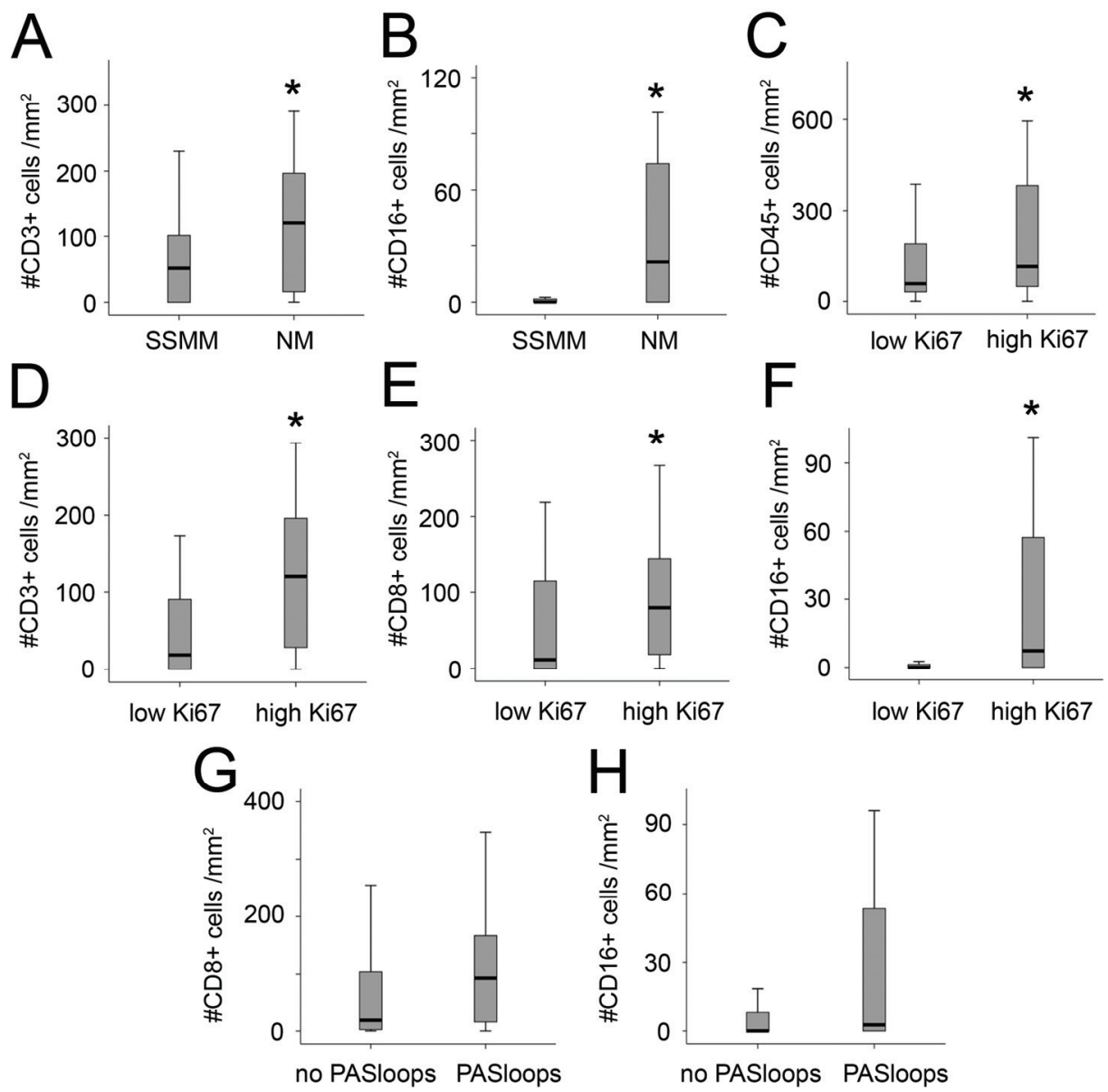

Figure 2. Leukocyte infiltration in relation to parameters of progression and aggressiveness in cutaneous melanoma.

A-H. The amount of several subsets of intratumoral leukocytes divided in two groups according to the histological subtype (A-B), the amount of proliferating tumor cells (C-F) and the presence of PAS loops $(\mathrm{G}-\mathrm{H})$. Significant difference between the groups $(\mathrm{p}<0.05)$ is indicated by an asterisk. Black lines in the box plots present the median, upper and lower quartiles and the error bars show minimum and maximum data values.

\section{The amount of CD16+ cells and T cells predict short survival}

Survival analysis was performed by dividing the patient population on basis of the median value of leukocyte infiltration. Kaplan Meier analysis revealed that a higher amount of intratumoral CD3+ cells or CD16+ cells predicted shorter survival, both for 10 and 5 years of follow up (respectively, $\mathrm{p}=0.003$ and $\mathrm{p}=0.01$, Figure $3 \mathrm{D}$ and $\mathrm{E}$ ). For the other subsets (Figure $3 \mathrm{~F}$ ) and for the peritumoral infiltrates (not shown), no significant 
relationship was found with survival (Table 1). Multivariate analysis indicated that none of these parameters outperformed Breslow depth as a predictor for survival. However, for meaningful multivariate analysis the patient numbers were too low.
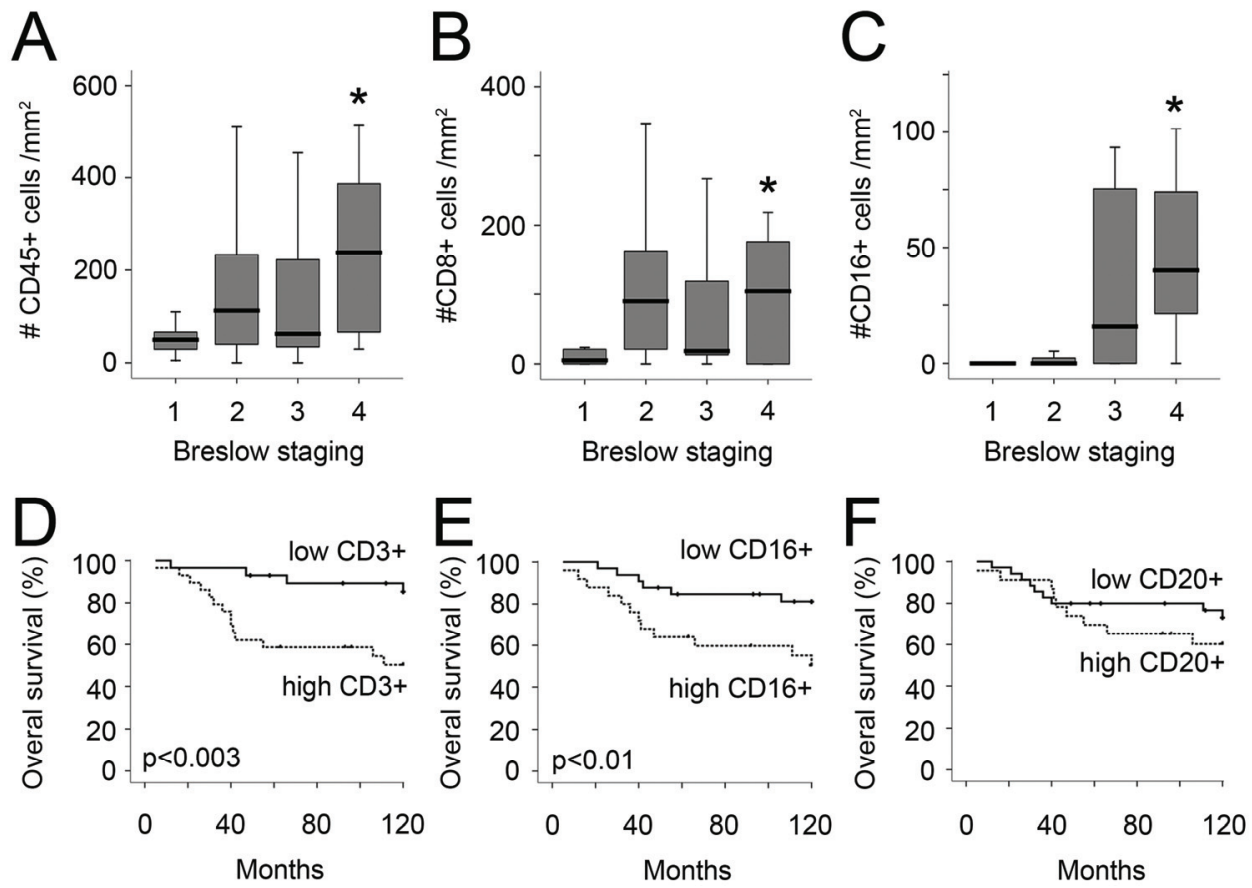

Figure 3. Staging and survival in relation to leukocyte infiltration.

A-C. The amount of leukocytes of the different subsets are stratified by Breslow staging (group $1, \leq 0.75$ $\mathrm{mm}$; group 2, 0.76-1.5 mm; group 3, 1.51-3 $\mathrm{mm}$ and group 4, $>3 \mathrm{~mm}$ ). Significant difference between the four groups $(\mathrm{p}<0.05)$ is indicated by an asterisk. Black lines in the box plots present the median and the error bars show quartiles. D-F. Kaplan Meier survival plots for melanoma patients based on the amount of CD3+ cells (D), CD16+ cells (E) and CD20+ cells (F). Patients were divided in two groups stratified based on the median value for $\mathrm{CD} 3+, \mathrm{CD} 16+$ and $\mathrm{CD} 20+$ cells, respectively.

The amount of immunosuppressive $T$ regulatory cells does not predict survival, while the amount of activated lymphocytes is positively correlated to survival

To analyse the activation status and immunosuppressive regulatory $\mathrm{T}$ lymphocytes in our patient population, we quantified the amount of FOXP3+ and CD69+ cells, both in intratumoral and peritumoral areas (Figure $4 \mathrm{~A}-\mathrm{B}$ ).

The presence of intratumoral FOXP3 regulatory $\mathrm{T}$ cells was not significantly different between the different stages of melanoma (Figure $4 \mathrm{C}$ ). The amount of intratumoral FOXP3 $+\mathrm{T}$ lymphocytes did not predict survival (Figure $4 \mathrm{E}$ ), but correlated to the amount of peritumoral CD3+ $(\mathrm{p}=0.003), \mathrm{CD} 8+(\mathrm{p}=0.001), \mathrm{CD} 16+$ $(\mathrm{p}=0.049), \mathrm{CD} 68(\mathrm{p}=0.020)$ cells and the amount of intratumoral CD3+ $(\mathrm{p}=0.006), \mathrm{CD} 8+$ $(\mathrm{p}=0.032), \mathrm{CD} 16+(\mathrm{p}=0.043)$ and $\mathrm{CD} 68+(\mathrm{p}=0.034)$ cells. 
Chapter 4

Table 1. Kaplan Meier analysis for leukocyte infiltration and PAS patterns.

Significant P-values are indicated with an asterisk.

\begin{tabular}{lcc}
\hline & Log rank $\chi^{2}$ & P-value \\
\hline CD45+ peritumoral & 0.58 & 0.4466 \\
CD45+ intratumoral & 1.09 & 0.2967 \\
CD3+ peritumoral & 1.08 & 0.2981 \\
CD3+ intratumoral & 8.70 & $\mathbf{0 . 0 0 3 2}$ \\
CD8+ peritumoral & 1.20 & 0.2731 \\
CD8+ intratumoral & 0.26 & 0.6131 \\
CD16+ peritumoral & 1.75 & 0.1859 \\
CD16+ intratumoral & 6.08 & $\mathbf{0 . 0 1 3 7}$ \\
CD20+ peritumoral & 0.34 & 0.5582 \\
CD20+ intratumoral & 0.92 & 0.3387 \\
CD68+ peritumoral & 0.01 & 0.9283 \\
CD68+ intratumoral & 0.29 & 0.5922 \\
FOXP3+ peritumoral & 1.51 & 0.2186 \\
FOXP3+ intratumoral & 0.00 & 0.9788 \\
CD69+ peritumoral & 0.43 & 0.5128 \\
CD69+ intratumoral & 2.07 & 0.1504 \\
PAS patterns & 10.01 & $\mathbf{0 . 0 0 1 6}$ \\
\hline
\end{tabular}

The amount of CD69+ cells was significantly lower in the tumor samples with a Breslow depth of more than $3 \mathrm{~mm}$ (Figure $4 \mathrm{D}$ ). Univariate analysis showed a trend of a shorter survival for patients with a low amount of CD69+ cells, though this was not significant (Figure $4 \mathrm{~F}, \mathrm{p}=0.15$ ). The amount of $\mathrm{CD} 69+$ cells was positively correlated to survival $(p=0.025)$ and negatively correlated to lymph node metastasis $(p=0.049)$, ulceration $(p=0.022)$ and the histological subtype $(p=0.020)$.

\section{Leukocyte infiltration is not correlated with parameters of angiogenesis and tumor cell plasticity}

Since leukocytes home to the tumor by extravasation from the intratumoral blood vessels, we were interested in the relationship between angiogenesis and the amount of leukocytes. We previously reported that angiogenic potential of melanoma tissue, as measured by the number of proliferating endothelial cells, is associated to tumor progression, predicting short survival ${ }^{19}$. In human melanoma we did not find a correlation between neovascularisation, being the amount of Ki67 positive endothelial cells, and the presence of infiltrated leukocytes.

We and others recently demonstrated that plastic tumor cells, that are dedifferentiating into an endothelial cell phenotype, can form vessel-like structures that contribute to blood circulation ${ }^{18}$, a process also referred to as vasculogenic mimicry ${ }^{21}$. This urged us to investigate a relationship between vasculogenic like structures and leukocyte infiltration. We evaluated the amount of tumor cell plasticity by the presence of patterned networks of interconnected loops of extracellular matrix that were stained 



Figure 4. The activation status and presence of immunosuppressive regulatory T lymphocytes.

A-B. Examples of immunostainings of peri-and intratumoral FOXP3+ (A) and intratumoral CD69+ (B) lymphocytes. The dotted lines indicate the border between the tumor and the surrounding tissue. Scale bar, $20 \mu \mathrm{m}$. C-D. The amount of FOXP3+ (C) and CD69+ (D) cells classified according to Breslow depth (group 1, $\leq 0.75 \mathrm{~mm}$; group 2, 0.76-1.5 mm; group 3, 1.51-3 mm and group 4, $>3 \mathrm{~mm}$ ). Significant difference $(\mathrm{p}<0.05)$ is indicated by an asterisk. Black lines in the box plots present the median, upper and lower quartiles and the error bars show minimum and maximum data values. E-F. Univariate survival analysis based on the amount of FOXP3+ cells (E) and CD69+ cells (F). Patients were divided in two groups stratified based on the median value for FOXP3+ and CD69+ cells, respectively. 
with periodic acid-Schiff (PAS) reagent. Two clinical samples of patients with cutaneous melanoma with PAS positive patterns are shown in figure $5 \mathrm{~A}-\mathrm{B}$. We found that $38 \%$ of the tissues presented these patterns. The presence of these loops was significantly higher in the patients with a higher Breslow depth (Figure $5 \mathrm{C}$ ). In addition, Kaplan Meier analysis revealed a strong prognostic value for the presence of PAS positive loops (Figure $5 \mathrm{D}, \mathrm{p}=0.002$ ), which confirms earlier results ${ }^{20,22}$. Similar to the angiogenesis parameters of conventional blood vessels, no significant correlations were found between PAS loops and leukocyte infiltration. However, for all leukocyte subsets a trend towards more infiltration in melanoma samples with PAS-positive loops was observed [e.g. intratumoral CD16+ cells $(p=0.094)$ and intratumoral CD8+ T cells ( $\mathrm{p}=0.059)$, Figure $2 \mathrm{G}-\mathrm{H}]$.
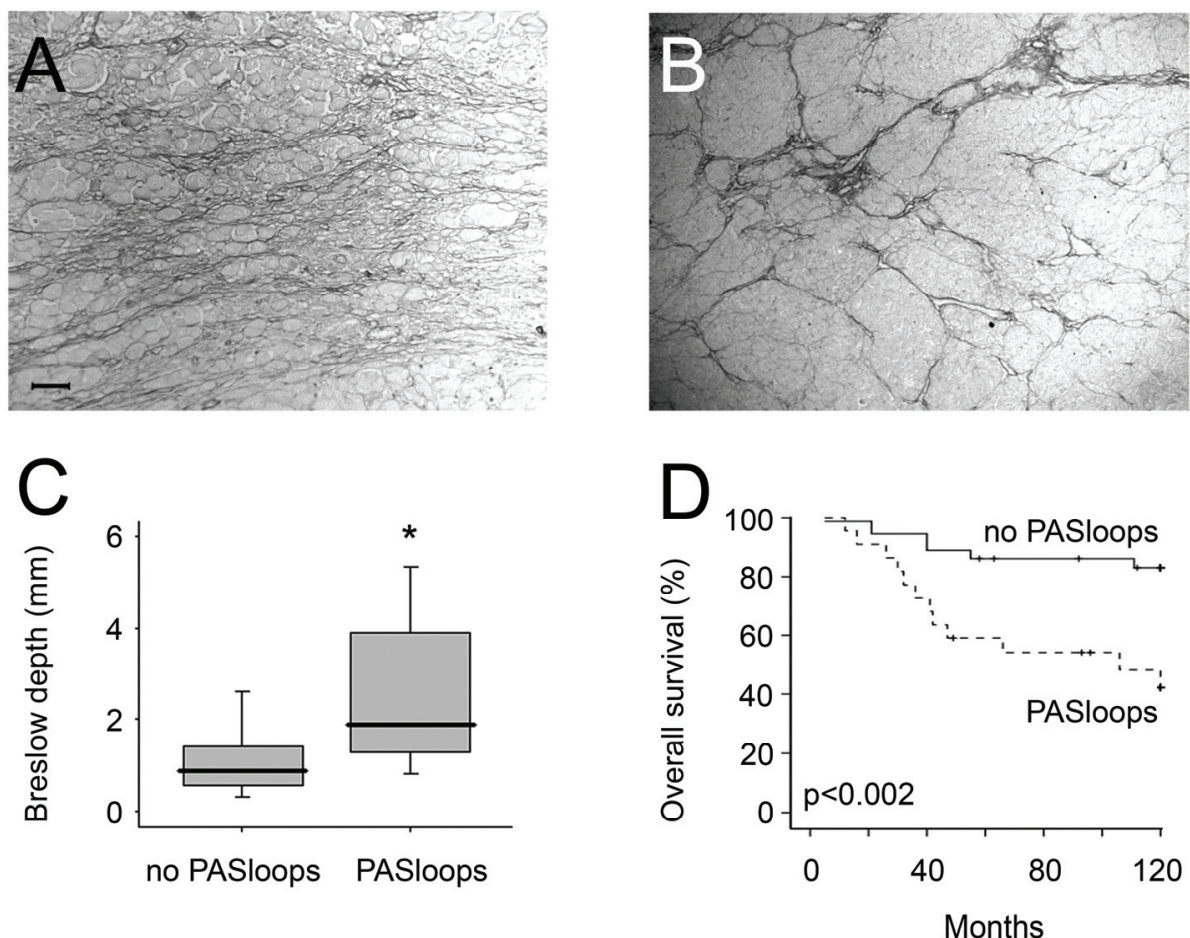

Figure 5. The presence of tumor cell plasticity is a prognostic factor in human cutaneous melanoma. A-B. Two clinical samples of patients with cutaneous melanoma with PAS positive patterns in intratumoral regions. Scale bare, $50 \mu \mathrm{m}$. C. Presence of PAS positive loops in the tumor tissue was related to a higher Breslow thickness. Significant difference between the two groups is indicated by an asterisk. Black lines in the box plots present the median and the error bars show quartiles. D. Kaplan Meier survival curve for patients with melanoma with or without PAS loops present inside the tumor tissue. 


\section{Discussion}

Cutaneous melanoma is a highly malignant tumor type. It is one of the most frequent malignant tumors in young adults and its incidence is still rising ${ }^{23}$. Among the potential prognostic markers, the American Joint Committee on Cancer staging system for melanoma incorporates tumor thickness, level of invasion, ulceration, satellite metastases, lymph node metastases ${ }^{24}$, but not tumor infiltrating leukocytes. Because most melanomas are characterised by a heavy infiltrate, several attempts have been made to develop immunotherapies in melanomas. In animal models, transfer of high numbers of tumor infiltrating lymphocytes could stimulate tumor rejection ${ }^{25-27}$. However, only some clinical responses could be established in the many clinical immunotherapy protocols and vaccination strategies ${ }^{28-31}$.

In an attempt to verify the presence of different subsets of tumor infiltrating leukocytes as an independent histological parameter, we evaluated tumor tissues of 58 patients diagnosed with primary nodular or superficial spreading cutaneous melanoma for the amount of infiltrated CD45, CD3, CD8, CD20, CD16 and CD68 positive cells. We found that leukocyte infiltration is associated with markers of tumor progressiveness, as evidenced by the following observations. (i) Dividing the patients by Breslow thickness, we found that high Breslow depth was significantly associated with a higher amount of intratumoral CD45+, CD8+ and CD16+ cells . The other subsets of leukocytes showed a same trend, although not significantly, of more leukocyte infiltration in more progressed tumors, both intratumorally and peritumorally. (ii) In nodular melanomas, more leukocytes were present than in superficial spreading melanoma and (iii) almost all subsets of leukocytes where more abundantly presented in patient with a higher proliferation rate of tumor cells. This suggests that immune cell reactions are more pronounced in aggressive tumors. A recent paper of Hussein et al ${ }^{32}$ reported the same for CD3+ and CD20+ cells. Bröcker et al described also that an increased amount of intratumoral T lymphocytes is associated with progression in melanoma, though, in contrast to our observations, they observed in their patient population that peritumoral densities of $\mathrm{T}$ lymphocytes was lower in more progressed melanomas ${ }^{33}$.

In contrast to a recent publication ${ }^{34}$, we did not find a positive correlation between patient survival and the presence of $\mathrm{CD} 3+$ and $\mathrm{CD} 16+$ cells present in the tumor.

Our results show that CD16+ cells, macrophages and B cells are better able to infiltrate into the tumor itself, while $\mathrm{T}$ cells tend to reside in the peritumoral areas (Figure 1G). Little is known on the exact contribution of these leukocytes in the process of melanoma rejection.

Some effects were observed with the use of CD16+ cells in therapeutic applications in melanoma. Additional infiltration of Natural killer (NK) cells (CD56+) and monocytes during treatment with a therapy consisting of histamine, interferon- $\alpha$ and interleukin- 2 was seen only in patients responding to the treatment ${ }^{35}$. Impaired activity of NK cells has also been observed. Jovic et al. reported that the dysfunction of NK cells in patients with metastatic melanoma was not associated with a decrease in 
amount of these cells but in a defect detected in NK cell perforin-mediated cytotoxic activity ${ }^{36}$.

Tumor-associated macrophages have an important role in presenting antigens, but their clinical application as immunotherapy has limited success. This may be due to the paradox concerning tumor associated macrophages. On the one hand, tumor associated macrophages are able destroy neoplastic cells thereby reducing tumor growth. On the other hand, both macrophages and tumor cells can produce growth factors that can stimulate tumor growth ${ }^{37-39}$.

Several in vivo studies in mice revealed an attenuating effect on B lymphocytes by unknown mechanisms leading to cytotoxic T-lymphocyte anergy and in that way to a less effective immune response ${ }^{40-42}$. On the other hand, normal human peripheral $\mathrm{B}$ cells were activated in vitro through CD40 ligation and were able to stimulate autologous $\mathrm{T}$ cells in the presence of melanoma cell line lysate ${ }^{43}$. Unfortunately, patient studies have also been contradictory. CD80+ B cells in combination with a higher amount of CD8+ cytotoxic cells correlated with a good prognosis in melanoma ${ }^{44}$, while another study was not able to improve the response rate by a B cell depletion therapy ${ }^{45}$.

We observed that a high amount of CD3 and CD16 expressing leukocytes predicts short survival. This suggests the inability of tumor infiltrating leukocytes to mount an effective immune response. These findings are supported by several papers that report possible escape mechanisms of melanoma cells from immunological responses. This escape from tumor immunity can be explained by several mechanisms: (1) the secretion of immunosuppressive cytokines by melanoma cells 46,47, (2) the defective or incomplete activation status of the infiltrating $T$ cells 48 , (3) the immunosuppressive effect of melanoma cell expressing proteins ${ }^{49}, 50$ and a variety of other escape mechanisms ${ }^{51}$.

In our study, we analysed the amount of FOXP3+ cells. FOXP3 is a unique functional marker of regulatory $\mathrm{T}$ cells ${ }^{52}$. Cancer patients have been described to have an enlarged pool of immunosuppressive regulatory $\mathrm{T}$ cells in the peripheral blood and/or the tumor. Only a few papers correlated this to the progression of the tumor ${ }^{53-61}$. Data on this correlation in cutaneous melanoma are lacking until know. We report the absence of the significant correlation between FOXP3+ cells and the different Breslow stages of melanoma and that it is not a prognostic factor in this type of tumors. The amount of FOXP3+ cells was positively correlated to the amount of several subsets of leukocytes. It appears that regulatory $\mathrm{T}$ cells are as much recruited as the other subsets of lymphocytes and other leukocytes. This observation was already reported in several earlier papers. Immunotherapy in melanomas with a Melan-A peptide vaccine resulted in more CD8+ cells, however, clinical benefit was limited due to a simultaneous induction of regulatory T cells, that suppressed the activity of the recruited CD8+ cells 62. Similarly, the administration of IL-2 resulted in an increase of FOXP3+ cells with a high suppressive activity in both melanoma and renal cancer patients ${ }^{63}$. Some 
promising results were described in a recent paper of Nair et al. where targeting FOXP3 by vaccination resulted in an enhanced tumor immunity in a mouse model ${ }^{64}$.

The activation status of lymphocytes was studied by the quantification of CD69+ cells. CD69 is among the earliest inducible cell surface glycoproteins during lymphoid activation ${ }^{65}$. Several manuscripts describe the decrease of CD69+ cells in tumors with a more progressed stage and a higher amount of CD69+ cells predicted better survival $11,66,67$. We are the first to report on the prognostic value of CD69+ cells in primary cutaneous melanoma. We found a significantly lower amount of CD69+ cells in melanomas with the most progressed stage. Univariate analysis showed an inverse pattern in comparison to the other subsets of leukocytes. There was a clear trend that a higher amount of CD69+ cells predicts a better prognosis for melanoma patients. It is clear that the detection of only infiltrating leukocytes is not a sensitive marker to evaluate tumor immune response.

The impact of regression is still unclear. As in most studies regression was mainly observed in thin melanomas. Some studies indicated that regression is a negative prognostic factor $14,68,69$, while others could not find a relationship between regression and survival ${ }^{70-73}$. We could not find a relationship with survival nor a correlation with intratumoral and peritumoral leukocytes.

Since leukocytes home into tumors by extravasation from blood vessels, we investigated the relationship between leukocyte infiltration and parameters of angiogenesis 74,75 . We did not find any correlation. Therefore, we studied the plasticity of the melanoma cells, which has been discovered in melanoma to contribute to circulation ${ }^{18,76}$. We did not find any significant evidence that this alternative way of blood circulation in the tumor ${ }^{18}$ contributes to the formation of an inflammatory infiltrate. However, we did find a trend in this direction. This might be due to the fact that vasculogenic mimicry is a marker of tumor aggressiveness, resulting in the attraction of more immune cells. Since it is known that leukocyte infiltrate can recognize and eradicate tumor mass, this might be seen as a contradictory observation. However, it can be argued that the high number of infiltrated leukocytes reflects the enhanced antigenicity of more aggressive tumor cells ${ }^{32}$.

In summary, we demonstrated that leukocyte infiltration in melanoma predicts a short survival. In our study, we included all stages of Breslow depth. We conclude that more advanced melanomas are characterised by more tumor infiltrating leukocytes, maybe because of the more aggressive behaviour of the tumors. From survival analysis it is concluded that this is insufficient for an effective immune response. Our observation that all stages of Breslow depth are infiltrated with regulatory $\mathrm{T}$ cells but that the amount of $\mathrm{CD} 69+$ activated lymphocytes is a possible prognostic factor, should be taken into account in future studies. It is clear that more research on the immunosuppressive mechanisms and the stimulation of antigen driven leukocyte responses is necessary in order to improve immunotherapeutic applications. 


\section{References}

1. Ramirez-Montagut, T., et al. (2003) Immunity to melanoma: unraveling the relation of tumor immunity and autoimmunity. Oncogene 22 (20): 3180-7.

2. Chen, Q., W.C. Wang, and S.S. Evans (2003) Tumor microvasculature as a barrier to antitumor immunity. Cancer Immunol Immunother 52 (11): 670-9.

3. Vesalainen, S., et al. (1994) Histological grade, perineural infiltration, tumour-infiltrating lymphocytes and apoptosis as determinants of long-term prognosis in prostatic adenocarcinoma. Eur J Cancer 30A (12): 1797-803.

4. Marrogi, A.J., et al. (1997) Study of tumor infiltrating lymphocytes and transforming growth factor-beta as prognostic factors in breast carcinoma. Int J Cancer 74 (5): 492-501.

5. Chao, H.T., et al. (1999) Lymphocyte-infiltrated FIGO Stage IIB squamous cell carcinoma of the cervix is a prominent factor for disease-free survival. Eur J Gynaecol Oncol 20 (2): 136-40.

6. Naito, Y., et al. (1998) CD8+ T cells infiltrated within cancer cell nests as a prognostic factor in human colorectal cancer. Cancer Res 58 (16): 3491-4.

7. Schumacher, K., et al. (2001) Prognostic significance of activated CD8(+) T cell infiltrations within esophageal carcinomas. Cancer Res 61 (10): 3932-6.

8. Cho, Y., et al. (2003) CD4+ and CD8+ T cells cooperate to improve prognosis of patients with esophageal squamous cell carcinoma. Cancer Res 63 (7): 1555-9.

9. Zhang, L., et al. (2003) Intratumoral T cells, recurrence, and survival in epithelial ovarian cancer. N Engl J Med 348 (3): 203-13.

10. Sato, E., et al. (2005) Intraepithelial CD8+ tumor-infiltrating lymphocytes and a high CD8+/regulatory $\mathrm{T}$ cell ratio are associated with favorable prognosis in ovarian cancer. Proc Natl Acad Sci U S A 102 (51): 18538-43.

11. Badoual, C., et al. (2006) Prognostic value of tumor-infiltrating CD4+ T-cell subpopulations in head and neck cancers. Clin Cancer Res 12 (2): 465-72.

12. Hiraoka, K., et al. (2006) Concurrent infiltration by CD8+ T cells and CD4+ T cells is a favourable prognostic factor in non-small-cell lung carcinoma. Br J Cancer 94 (2): 275-80.

13. Hussein, M.R. (2005) Tumour-infiltrating lymphocytes and melanoma tumorigenesis: an insight. Br J Dermatol 153 (1): 18-21.

14. Clark, W.H., Jr., et al. (1989) Model predicting survival in stage I melanoma based on tumor progression. J Natl Cancer Inst 81 (24): 1893-904.

15. Clemente, C.G., et al. (1996) Prognostic value of tumor infiltrating lymphocytes in the vertical growth phase of primary cutaneous melanoma. Cancer 77 (7): 1303-10.

16. Thorn, M., et al. (1994) Trends in tumour characteristics and survival of malignant melanoma 1960-84: a population-based study in Sweden. Br J Cancer 70 (4): 743-8.

17. Barnhill, R.L., et al. (1996) Predicting five-year outcome for patients with cutaneous melanoma in a population-based study. Cancer 78 (3): 427-32.

18. van der Schaft, D.W., et al. (2005) Tumor cell plasticity in Ewing sarcoma, an alternative circulatory system stimulated by hypoxia. Cancer Res 65 (24): 11520-8.

19. Hillen, F., et al. (2006) Proliferating endothelial cells, but not microvessel density, is a prognostic parameter in human cutaneous melanoma. Melanoma Res 16: 453-457.

20. Warso, M.A., et al. (2001) Prognostic significance of periodic acid-Schiff-positive patterns in primary cutaneous melanoma. Clin Cancer Res 7 (3): 473-7.

21. Hendrix, M.J., et al. (2003) Vasculogenic mimicry and tumour-cell plasticity: lessons from melanoma. Nat Rev Cancer 3 (6): 411-21.

22. Thies, A., et al. (2001) PAS-positive loops and networks as a prognostic indicator in cutaneous malignant melanoma. J Pathol 195 (5): 537-42.

23. Levi, F., et al. (2004) Cancer mortality in Europe, 1995-1999, and an overview of trends since 1960. Int J Cancer 110 (2): 155-69.

24. Carlson, J.A., et al. (2003) Malignant melanoma 2003: predisposition, diagnosis, prognosis, and staging. Am J Clin Pathol 120 Suppl: S101-27. 
25. Eberlein, T.J., M. Rosenstein, and S.A. Rosenberg (1982) Regression of a disseminated syngeneic solid tumor by systemic transfer of lymphoid cells expanded in interleukin 2. J Exp Med 156 (2): 385-97.

26. Rosenberg, S.A., P. Spiess, and R. Lafreniere (1986) A new approach to the adoptive immunotherapy of cancer with tumor-infiltrating lymphocytes. Science 233 (4770): 1318-21.

27. Overwijk, W.W., et al. (1998) gp100/pmel 17 is a murine tumor rejection antigen: induction of "self"-reactive, tumoricidal T cells using high-affinity, altered peptide ligand. J Exp Med 188 (2): 277-86.

28. Dudley, M.E., et al. (2002) Cancer regression and autoimmunity in patients after clonal repopulation with antitumor lymphocytes. Science 298 (5594): 850-4.

29. Yee, C., et al. (2002) Adoptive T cell therapy using antigen-specific CD8+ T cell clones for the treatment of patients with metastatic melanoma: in vivo persistence, migration, and antitumor effect of transferred T cells. Proc Natl Acad Sci U S A 99 (25): 16168-73.

30. Dudley, M.E., et al. (2005) Adoptive cell transfer therapy following non-myeloablative but lymphodepleting chemotherapy for the treatment of patients with refractory metastatic melanoma. J Clin Oncol 23 (10): 2346-57.

31. Morgan, R.A., et al. (2006) Cancer regression in patients after transfer of genetically engineered lymphocytes. Science 314 (5796): 126-9.

32. Hussein, M.R., et al. (2006) Immunohistological characterisation of tumour infiltrating lymphocytes in melanocytic skin lesions. J Clin Pathol 59 (3): 316-24.

33. Brocker, E.B., et al. (1988) Inflammatory cell infiltrates in human melanoma at different stages of tumor progression. Int J Cancer 41 (4): 562-7.

34. Piras, F., et al. (2005) The predictive value of CD8, CD4, CD68, and human leukocyte antigenD-related cells in the prognosis of cutaneous malignant melanoma with vertical growth phase. Cancer 104 (6): 1246-54.

35. Jorkov, A.S., et al. (2003) Immune response in blood and tumour tissue in patients with metastatic malignant melanoma treated with IL-2, IFN alpha and histamine dihydrochloride. Anticancer Res 23 (1B): 537-42.

36. Jovic, V., et al. (2001) Impaired perforin-dependent NK cell cytotoxicity and proliferative activity of peripheral blood T cells is associated with metastatic melanoma. Tumori 87 (5): 324-9.

37. Mantovani, A., et al. (1992) The origin and function of tumor-associated macrophages. Immunol Today 13 (7): 265-70.

38. Bingle, L., N.J. Brown, and C.E. Lewis (2002) The role of tumour-associated macrophages in tumour progression: implications for new anticancer therapies. J Pathol 196 (3): 254-65.

39. Dirkx, A.E., et al. (2006) Monocyte/macrophage infiltration in tumors: modulators of angiogenesis. J Leukoc Biol 80 (6): 1183-96.

40. Bennett, S.R., et al. (1998) B cells directly tolerize CD8(+) T cells. J Exp Med 188 (11): 1977-83.

41. Perricone, M.A., et al. (2004) Enhanced efficacy of melanoma vaccines in the absence of B lymphocytes. J Immunother 27 (4): 273-81.

42. Shah, S., et al. (2005) Increased rejection of primary tumors in mice lacking B cells: inhibition of anti-tumor CTL and TH1 cytokine responses by B cells. Int J Cancer 117 (4): 574-86.

43. Lapointe, R., et al. (2003) CD40-stimulated B lymphocytes pulsed with tumor antigens are effective antigen-presenting cells that can generate specific T cells. Cancer Res 63 (11): 283643.

44. Martinez-Escribano, J.A., et al. (2003) Changes in the number of CD80(+), CD86(+), and CD28(+) peripheral blood lymphocytes have prognostic value in melanoma patients. Hum Immunol 64 (8): 796-801.

45. Aklilu, M., et al. (2004) Depletion of normal B cells with rituximab as an adjunct to IL-2 therapy for renal cell carcinoma and melanoma. Ann Oncol 15 (7): 1109-14.

46. Massague, J. (1990) The transforming growth factor-beta family. Annu Rev Cell Biol 6: 597641.

47. Fiorentino, D.F., et al. (1991) IL-10 acts on the antigen-presenting cell to inhibit cytokine production by Th1 cells. J Immunol 146 (10): 3444-51. 
48. Ladanyi, A., et al. (2004) T-cell activation marker expression on tumor-infiltrating lymphocytes as prognostic factor in cutaneous malignant melanoma. Clin Cancer Res 10 (2): 521-30.

49. Rubinstein, N., et al. (2004) Targeted inhibition of galectin-1 gene expression in tumor cells results in heightened $\mathrm{T}$ cell-mediated rejection; A potential mechanism of tumor-immune privilege. Cancer Cell 5 (3): 241-51.

50. Le, Q.T., et al. (2005) Galectin-1: a link between tumor hypoxia and tumor immune privilege. J Clin Oncol 23 (35): 8932-41.

51. Pawelec, G. (2004) Tumour escape from the immune response. Cancer Immunol Immunother 53 (10): 843.

52. Hori, S., T. Nomura, and S. Sakaguchi (2003) Control of regulatory T cell development by the transcription factor Foxp3. Science 299 (5609): 1057-61.

53. Woo, E.Y., et al. (2001) Regulatory CD4(+)CD25(+) T cells in tumors from patients with earlystage non-small cell lung cancer and late-stage ovarian cancer. Cancer Res 61 (12): 4766-72.

54. Woo, E.Y., et al. (2002) Cutting edge: Regulatory T cells from lung cancer patients directly inhibit autologous T cell proliferation. J Immunol 168 (9): 4272-6.

55. Sasada, T., et al. (2003) CD4+CD25+ regulatory $\mathrm{T}$ cells in patients with gastrointestinal malignancies: possible involvement of regulatory T cells in disease progression. Cancer 98 (5): 1089-99.

56. Wolf, A.M., et al. (2003) Increase of regulatory T cells in the peripheral blood of cancer patients. Clin Cancer Res 9 (2): 606-12.

57. Viguier, M., et al. (2004) Foxp3 expressing CD4+CD25(high) regulatory $T$ cells are overrepresented in human metastatic melanoma lymph nodes and inhibit the function of infiltrating T cells. J Immunol 173 (2): 1444-53.

58. Alvaro, T., et al. (2005) Outcome in Hodgkin's lymphoma can be predicted from the presence of accompanying cytotoxic and regulatory T cells. Clin Cancer Res 11 (4): 1467-73.

59. Wolf, D., et al. (2005) The expression of the regulatory $\mathrm{T}$ cell-specific forkhead box transcription factor FoxP3 is associated with poor prognosis in ovarian cancer. Clin Cancer Res 11 (23): 8326-31.

60. Hiraoka, N., et al. (2006) Prevalence of FOXP3+ regulatory T cells increases during the progression of pancreatic ductal adenocarcinoma and its premalignant lesions. Clin Cancer Res 12 (18): 5423-34.

61. Bates, G.J., et al. (2006) Quantification of regulatory T cells enables the identification of highrisk breast cancer patients and those at risk of late relapse. J Clin Oncol 24 (34): 5373-80.

62. Appay, V., et al. (2006) New generation vaccine induces effective melanoma-specific CD8+ T cells in the circulation but not in the tumor site. J Immunol 177 (3): 1670-8.

63. Ahmadzadeh, M. and S.A. Rosenberg (2006) IL-2 administration increases CD4+ CD25(hi) Foxp3+ regulatory T cells in cancer patients. Blood 107 (6): 2409-14.

64. Nair, S., et al. (2007) Vaccination against the forkhead family transcription factor Foxp3 enhances tumor immunity. Cancer Res 67 (1): 371-80.

65. Cambiaggi, C., et al. (1992) Constitutive expression of CD69 in interspecies T-cell hybrids and locus assignment to human chromosome 12. Immunogenetics 36 (2): 117-20.

66. Healy, C.G., et al. (1998) Impaired expression and function of signal-transducing zeta chains in peripheral $\mathrm{T}$ cells and natural killer cells in patients with prostate cancer. Cytometry 32 (2): 109-19.

67. Koch, M., et al. (2006) Tumor infiltrating T lymphocytes in colorectal cancer: Tumor-selective activation and cytotoxic activity in situ. Ann Surg 244 (6): 986-92; discussion 992-3.

68. Slingluff, C.L., Jr., et al. (1988) Lethal "thin" malignant melanoma. Identifying patients at risk. Ann Surg 208 (2): 150-61.

69. Blessing, K. and K.M. McLaren (1992) Histological regression in primary cutaneous melanoma: recognition, prevalence and significance. Histopathology 20 (4): 315-22.

70. Trau, H., et al. (1983) Metastases of thin melanomas. Cancer 51 (3): 553-6. 


\section{Leukocyte infiltration and tumor cell plasticity in melanomas}

71. Wanebo, H.J., P.H. Cooper, and R.W. Hagar (1985) Thin (less than or equal to $1 \mathrm{~mm}$ ) melanomas of the extremities are biologically favorable lesions not influenced by regression. Ann Surg 201 (4): 499-504.

72. Shaw, H.M., et al. (1987) Thin malignant melanomas and recurrence potential. Arch Surg 122 (10): 1147-50.

73. Fontaine, D., et al. (2003) Partial regression of primary cutaneous melanoma: is there an association with sub-clinical sentinel lymph node metastasis? Am J Dermatopathol 25 (5): 3716.

74. Molema, G. and A.W. Griffioen (1998) Rocking the foundations of solid tumor growth by attacking the tumor's blood supply. Immunol Today 19 (9): 392-4.

75. Dirkx, A.E.M., et al. (2006) Monocyte/macrophage infiltration in tumors:modulators of angiogenesis. Journal of Leukocyte Biology In press.

76. Maniotis, A.J., et al. (1999) Vascular channel formation by human melanoma cells in vivo and in vitro: vasculogenic mimicry. Am J Pathol 155 (3): 739-52. 



\section{Chapter 5}

\section{Tumor cell plasticity in Ewing sarcoma; an alternative circulatory system stimulated by hypoxia}

Daisy W.J. van der Schaft, Femke Hillen, Patrick Pauwels, Dawn A. Kirschmann, Karolien Castermans, Mirjam G.A. oude Egbrink, Maxine G.B. Tran, Rafael Sciot, Esther Hauben, Pancras C.W. Hogendoorn, Olivier Delattre, Patrick H. Maxwell, Mary J.C. Hendrix, Arjan W. Griffioen

Cancer Research. 2005 Dec; 65(24):11520-8 


\section{Abstract}

A striking feature of Ewing's sarcoma is the presence of blood lakes lined by tumor cells. The significance of these structures, if any, is unknown. Here, we report that the extent of blood lakes correlates with poor clinical outcomes, whereas parameters of angiogenesis do not. We also show that ES cells form vessel-like tubes in vitro, and express genes associated with vasculogenic mimicry. In tumor models, we demonstrate that there is blood flow through the blood lakes, suggesting that these structures in Ewing's sarcoma contribute to the circulation. Furthermore, we present evidence that reduced oxygen tension may be instrumental in tube formation by plastic tumor cells. The abundant presence of these vasculogenic structures, in contrast to other tumor types, makes Ewing's sarcoma the ideal model system to study these phenomena.

The results suggest that optimal tumor treatment may require targeting of these structures in combination with prevention of angiogenesis.

\section{Introduction}

Ewing's sarcoma/primitive neuroectodermal tumor has been defined as a round cell sarcoma showing different degrees of neuroectodermal differentiation that present mostly in the bone or soft tissues ${ }^{1}$. Ewing sarcoma is a relatively rare highly aggressive neoplasm with clinically evident metastatic disease at presentation in approximately $25 \%$ of all patients. A striking feature of Ewing sarcoma, often arise at adolescence ${ }^{2-4}$, is the presence of lakes of red blood cells. This was first recognized by James Ewing which led him to regard the tumor as an endothelioma ${ }^{5}$. Furthermore, Ewing sarcoma are characterized by a translocation that involves the Fli-1 gene, usually expressed specifically by endothelial cells. Prompted by these striking features we considered that these tumors could provide unusual insight into the relationship between a growing solid tumor and the circulation.

When a growing tumor exceeds the size of about $1 \mathrm{~mm}^{3}$, diffusion fails to provide the essential nutrients for continuous growth. Angiogenesis, a well-established paradigm in tumors, is subsequently stimulated driven by tumor derived cytokines, such as vascular endothelial (VEGF) and fibroblast growth factors (FGFs). Microvessels lined by endothelium grow into the tumor, providing a blood supply and allowing the tumor to grow beyond the limits imposed by substrate diffusion. It is observed in many tumor types that the extent of the capillary network, as assessed by the density of microvessels, is associated with poor prognosis ${ }^{6,7}$. There is considerable interest in the therapeutic potential of targeting the growth of new vessels (anti-angiogenesis) and the patency of those that have been formed (vascular targeting).

Patients with ES have previously been reported to have high levels of circulating VEGF ${ }^{8}$. In view of this, and the relatively poor prognosis of these tumors, we anticipated that the microvessel density (MVD) would be high, supported by dynamic contrast enhanced magnetic resonance imaging studies ${ }^{9}$. Surprisingly, we 
actually observed a relatively low MVD. This observation, together with the fact that the tumors contain blood lakes, led us to investigate the microcirculation of these tumors. We showed plasticity of tumor cells, using a combination of approaches, which we interpret as vasculogenic mimicry.

Vasculogenic mimicry was initially recognized in aggressive melanomas in $1999^{10}$, as a process in which tumor cells gain characteristics normally restricted to endothelial cells. Through this means, tumor cells could contribute to conducting blood in vascular-like structures, a process which would be independent of regular angiogenesis and endothelial cell proliferation. After these initial observations in melanoma, evidence for vasculogenic mimicry has been reported in other tumors 11-14. However, the mechanisms driving the vasculogenic mimicry process, and the contribution of the tumor cell channels to the circulation, have been uncertain.

\section{Materials and methods}

\section{Patient tissue materials}

Tumor tissues from 33 patients from the University of Leuven and the Leiden University Medical Center were studied, who presented with Ewing's sarcoma (ES) between 1987 and 2004. Most patients were included in the European Intergroup Cooperative Ewing's sarcoma studies and EuroEwing studies ${ }^{15}$. Mean age was 23.8 years at diagnosis (range: 3-59 years). Patient data were available from 31 patients; 11 died before the moment of data analysis. Mean follow-up was 50 months and mean survival was 34 months. 20 patients of 23 analyzed had an 11;22 translocation. All patient material was handled in a coded fashion according to the protocols as detailed by the Dutch association of Medical Scientific Associations.

\section{Immunohistochemistry}

Paraffin sections were dried for 48 hours at $37{ }^{\circ} \mathrm{C}$ prior to staining. Histochemical staining included H\&E staining and periodic acid Schiff's (PAS) reagent staining. The amount of blood lakes and PAS positive loops was semiquantitatively assessed by scoring $0-4$ ( $0=$ absent, $1=<5 \%, 2=5-20 \%, 3=20-50 \%, 4=>50 \%$ of tissue area). For immunohistochemistry, primary antibodies employed were CD31 (1:50 dilution, DAKOCytomation, Glostrup, Denmark), CD34 (1:50, Novocastra, Valkenswaard, the Netherlands), Ki-67 (1:100, Labvision, Fremont CA, USA), VEGF (1:100 dilution, Santa Cruz, Tebu Bio, Heerhugowaard, the Netherlands), endoglin/CD105 (1:50 dilution, Monosan, Uden, the Netherlands), VE-cadherin (1:50, Cayman, Ann Arbor, MI, USA) and Tissue Factor Pathway Inhibitor (TFPI, 1:40, American Diagnostica inc. Stamford, CT). After washing, the sections were incubated with anti-mouse Ig (1:200, DAKOCytomation) or anti-rabbit Ig biotin-labeled secondary antibody (1:200, DAKOCytomation) followed by avidin/biotin-HRP (DAKOCytomation) and DAB as substrate. For dual-staining, sections were first labeled for Ki-67 using HRP and then CD31 and CD34 using alkaline phosphatase reaction (DAKOCytomation). MVD, 
proliferating tumor cells and proliferating endothelial cells, were assessed by counting in quadruplicate randomly chosen fields at 200x magnification $\left(0.25 \mathrm{~mm}^{2}\right)$, by three independent observers. MVD was assessed in Ewing sarcoma tissues and also in 117 colorectal carcinomas, 211 renal cell carcinomas, 121 breast carcinomas and 78 melanomas.

\section{Cell culture and in vitro $3 D$ tube formation}

Melanoma cell lines MUM-2B, MUM-2C, C8161, C81-61 were used. Ewing sarcoma cell lines EW-7, A673, RD-ES, SIM/EW27 were previously characterized by Dr. O. Delattre, RD-ES was obtained from American Tissue Type Culture Collection. Cells were maintained in RPMI-1640, supplemented with $10 \%$ fetal calf serum and $2 \mathrm{mM}$ glutamine, except for C81-61 (HAM F-10) and A673 (DMEM) (Gibco, Paisley, UK). Cells grew on standard culture dishes except for the SIM-EW27 which were grown on collagen coated culture dishes. Human umbilical vein derived endothelial cells (HUVEC) were cultured on gelatin coated culture dishes in RPMI-1640, supplemented with $20 \%$ human serum, 100 units $/ \mathrm{ml}$ penicillin and $0.1 \mathrm{mg} / \mathrm{ml}$ streptomycin. For the 3dimensional culture, cells were plated at 100,000 cells per well on 24-well dishes coated with rat tail collagen, as described previously (10), and cultured for 10 days.

Vasculogenic tube formation was tested using a commercial Matrigel assay kit (BD Biocoat, Woerden, the Netherlands). Cells were plated at 20,000 cells per well and grown for 16 hours prior to calcein labeling and fluorescence microscopy. The effect of VEGF at 1, 10 and $50 \mathrm{ng} / \mathrm{ml}$ (Peprotech, Rocky Hill NJ, USA) or VEGF blocking antibody HuMV833 (1:50 dilution, Protein Design Labs, Inc.) was assessed on Matrigel for 16 hours followed by counting the number of branch points per microscopic field.

\section{RNA isolation and RT-PCR Analysis}

Total RNA was isolated from tissue sections using RNeasy (Qiagen, Venlo, the Netherlands), followed by RNase-free DNase treatment (Qiagen, Hilden, Germany). RNA concentration was measured by nanodrop (Nanodrop Wilmington, DE ). cDNA was synthesized with $400 \mathrm{U}$ of M-MLV RNase H- reverse transcriptase (Promega, Leiden, the Netherlands) in $20 \mu \mathrm{l}$ of $1 \mathrm{x}$ first strand buffer (Promega, Leiden, the Netherlands), and $1 \mathrm{mM}$ dNTPs in the presence of $10 \mathrm{U}$ RNase inhibitor RNasin (Promega, Leiden, the Netherlands), $0.5 \mu \mathrm{g}$ random primers (Promega, Leiden, the Netherlands) and $1 \mu \mathrm{g}$ total RNA. RNA from cell lines was isolated using TRIzoL (Invitrogen, Breda, the Netherlands). Semi-quantitative PCR amplifications were performed with primer sequences listed in Table 1 with GAPDH primers (BD Clontech) as a control. PCR fragments were ligated into pCR2.1-TOPO (Invitrogen) and two independent clones were sequenced from each primer set and shown to be identical to the expected DNA sequence. Quantitative real-time RT-PCR (qRT-PCR) was performed for cyclophylin A, $\beta$-actin, VEGF-A, VEGF-C, VEGF-D, Angiopoeitin-1, bFGF, and PIGF as described ${ }^{16}$. All real-time PCR primers were synthesized by Sigma-Genosys (Cambridgeshire, UK) except for VE-cadherin (a FAM-TAMRA primer probe 
(Integrated DNA Technologies, INC., Coralville, IA, USA)). PCR was performed using an iCycler MyIQ (Bio-Rad, Veenendael, The Netherlands) in $25 \mu \mathrm{l}$ volume containing $0.8 \mu \mathrm{l}$ cDNA, 1xSYBR® Green PCR master mix (Eurogentec, Liege, Belgium) spiked with 20nM fluorescein (Bio-Rad, Veenendael, The Netherlands), and $400 \mathrm{nM}$ of each primer. Data was analyzed with the Sequence Detection System software (Applied Biosystems). Experiments were performed twice in duplicate.

\section{Xenograft assays and intravital microscopy}

All animal experiments were approved by the local animal ethics committee. $10^{6}$ EW7 cells were injected subcutaneously into the flank of Swiss/nude mice and tumors measured with calipers. On day 28, mice were anesthetized with ketamin/xylazine ${ }^{17}$ and intravital microscopy was performed as described before ${ }^{18}$. In two mice FITC dextran (MW $500 \mathrm{kDa}, 500 \mu \mathrm{g}$ ) was injected intravenously (i.v.) in the tail vein. In these mice imaging was performed before and after injection. Two other mice were given an intraperitoneal injection with pimonidazole 60 minutes before sacrifice ( $2 \mathrm{mg}$ in $200 \mu \mathrm{l}$; Natural Pharmacia International, Research Triangle Park, NC). Sections of xenografts were labeled with anti-von Willebrand factor (1:200, DAKOCytomation, Glostrup, Denmark) and anti-CD31 antibody (1:250, Pharmingen, BD Company, Woerden, the Netherlands). Pimonidazole was detected using FITC labeled anti-pimonidazole antibody (1:50 dilution; Hypoxyprobe-1 Mab1; Chemicon International Inc.) and HRPconjugated anti-FITC antibody (1:200 times dilution, clone 5D6.2; Chemicon International, Temecula, CA).

In some experiments $200 \mu \mathrm{g}$ anti-endothelial antibody (MECA20, a kind gift from Dr. A. Duijvestijn ${ }^{19}$ ) was administered i.v. followed after 15 minutes by perfusion with Chinese ink (Pelikan, Germany). Sections from those xenografts were labeled with peroxidase labeled goat anti-rat Ig and counterstained with hematoxylin.

\section{Statistical analyses}

Real-time RT-PCR data were statistically analyzed using Mann-Whitney U tests (using SPSS-10 software). P values below 0.05 were considered statistically significant. Statistical significance of experimental parameters to clinical outcome was assessed by Whitney $\mathrm{U}$ test to compare between groups and log Rank test and a Cox regression test were done for survival analysis. 


\section{Results}

\section{The amount of blood lakes in Ewing's sarcoma correlates to clinical outcome}

In a unique series of Ewing sarcoma tissue biopsy samples, selected from patients before radiation or chemotherapy was started, we observed that microvessel density in these tumors, assessed by labeling of endothelial cells (MVD), was relatively low compared to other tumors (Figure 1A). This led us to hypothesize that the blood lakes we observed in $92 \%$ of these tumors might play an important role in the tumor circulation (Figure 1B). Supporting this notion, the blood lakes were not associated with evidence of coagulation and/or local necrosis. The cells lining the blood lakes did not label with the endothelial markers, CD31 and CD34. However, they expressed CD99, a marker of Ewing sarcoma cells and light- (Figure 1B) and electron-microscopic (not shown) examination clearly demonstrated that the lake-lining cells were tumor cells and not endothelial cells. The presence of tumor cell lined blood lakes, has been described as vasculogenic mimicry. Vasculogenic mimicry was originally recognized in melanoma as periodic acid Schiff's reagent (PAS) positive loops that contained red blood cells (10). Also the presence of PAS positive loops was examined in Ewing sarcoma, which revealed that such loops were present in $68 \%$ of the patients (Figure 1C). Notably, all tumors with PAS-positive networks also contained blood lakes.

To address the significance of the blood lakes, we examined whether clinical outcomes correlated with the number of blood lakes. Interestingly, the number of blood lakes, quantified as the percentage of tumor area containing lakes, was significantly higher in the patients that subsequently died (75\% higher as compared to the group of patients still alive at the time of data analysis, Figure 1D, $\mathrm{p}<0.05)$.

\section{Ewing's sarcoma tumors are angiogenic; lack of correlation to clinical outcome}

In tumors we observed a high level of proliferation (mean number of Ki-67-positive tumor cells $51.4 \%$, SD $\pm 30.4 \%$ ). Highly proliferative tumors usually exhibit a high level of angiogenic signaling. On the other hand, the low microvessel density that we observed in the tumors suggested that these tumors might have limited angiogenic potential. We therefore investigated angiogenesis using several approaches and found evidence that Ewing sarcomas are highly angiogenic. First, we found that $22 \%$ of CD31/CD34 positive vessels had one or more Ki-67-positive nuclei (Figure 2A). Second, in all Ewing sarcoma tissues we found high mRNA expression levels of the angiogenic growth factors VEGF-A, bFGF, PIGF and angiopoietin-1, comparable to those found in other angiogenic tumors such as breast carcinoma and fibrosarcoma (Figure 2B). Third, we observed high VEGF protein expression in approximately $100 \%$ of tumor cells (Figure 2C), in line with high circulating VEGF serum levels in Ewing sarcoma patients. Fourth, the cell lines EW7 and RD-ES, which give rise to tumors with typical Ewing sarcoma morphology following injection into athymic mice (see also Figure 4), express high levels of angiogenic growth factors in vitro (Figure 2B). Intriguingly, in the 
patient tissues neither microvessel density nor the number of proliferating endothelial cells showed significant association with clinical outcome (Figure 2D and 2E).
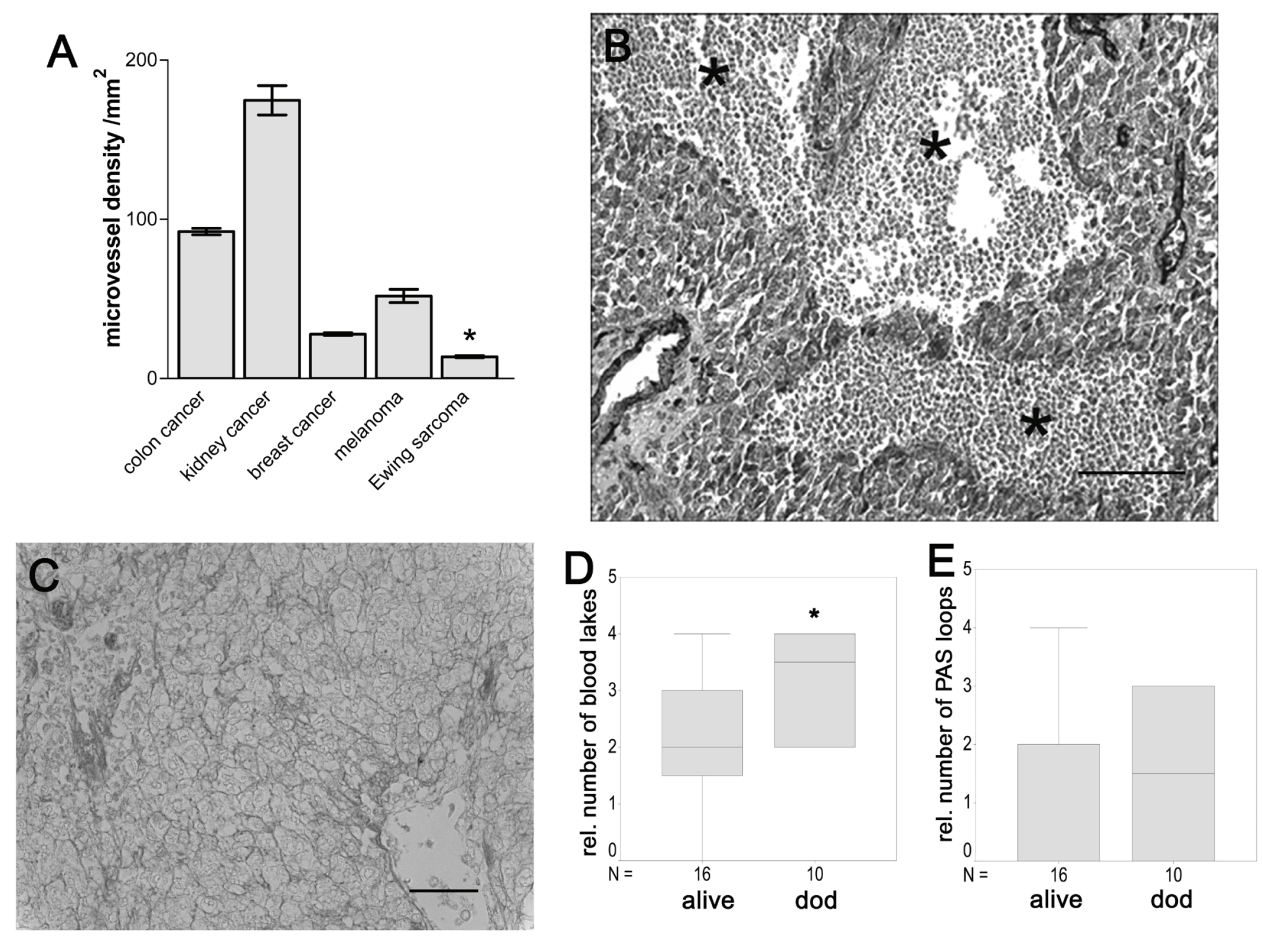

Figure 1. Vasculogenic mimicry in Ewing's sarcoma.

A. Microvessel density quantification in several tumor types. ${ }^{*} \mathrm{p}<0.05$ compared to the other tumor types. B. Ewing sarcoma patient tumor tissue stained with CD31/CD34 and counterstained with hematoxylin/eosin. Non-endothelial cell lined structures containing erythrocytes, or blood lakes, are identified by asterisks. C. Periodic acid Schiff's staining of Ewing sarcoma. The scale bars in B and C represent $100 \mu \mathrm{m}$. D-E. Quantification of blood lakes $\left(\mathbf{D},{ }^{*} \mathrm{p}<0.04\right)$ and PAS positive loops $(\mathrm{E})$ in relation to clinical outcome (dod, death of disease). 

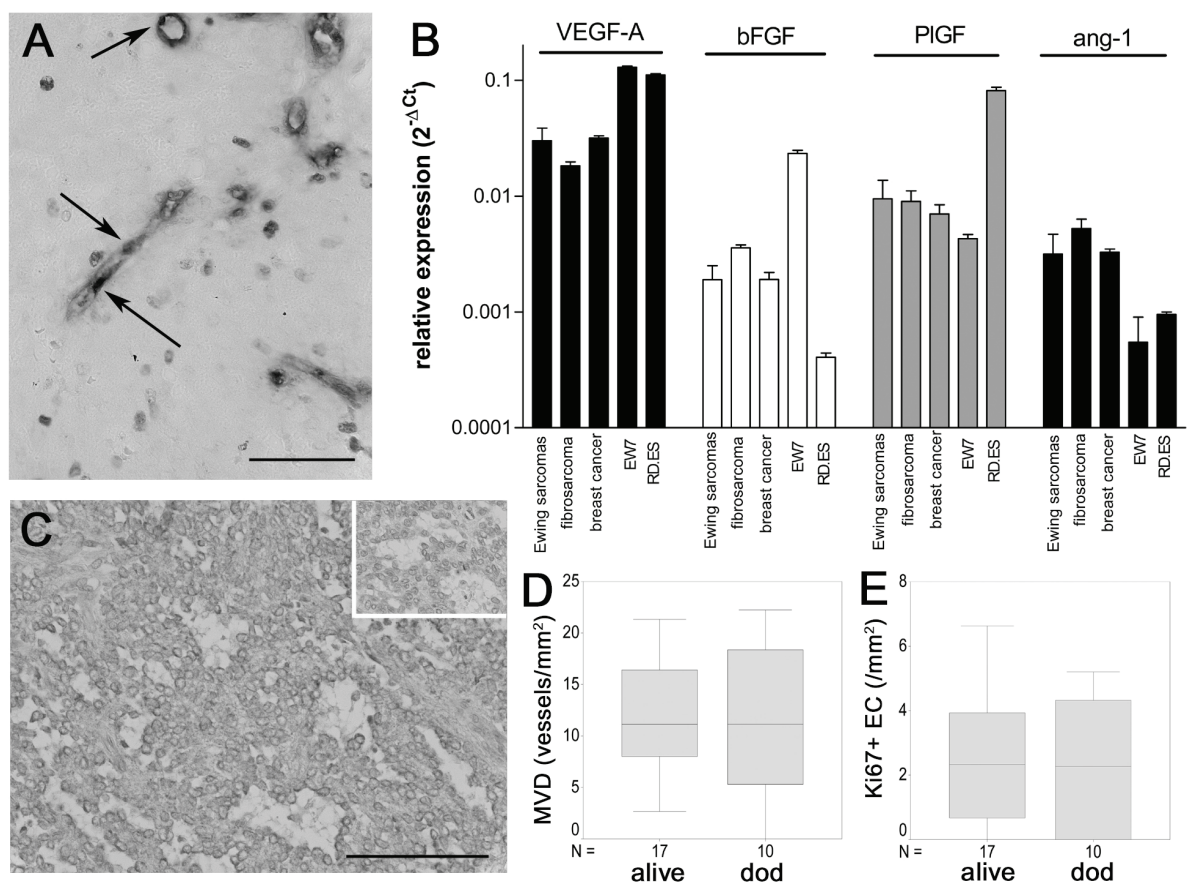

Figure 2. Ewing's sarcoma are highly angiogenic.

A. Double staining of Ewing sarcoma tissue with CD31/34 (blue) and Ki-67 (brown), indicating high numbers of proliferating endothelial cells (arrows, scale bar represents $100 \mu \mathrm{m}$ ). B. Mean relative expression (in $2^{-\Delta C t}$, corrected for housekeeping gene $\beta$-actin) VEGF-A, bFGF, PlGF and angiopoietin-1 expression in Ewing sarcoma, fibrosarcoma, breast cancer tissue, and Ewing sarcoma tumor cell lines EW7 and RD-ES as measured by quantitative real-time RT-PCR. C. VEGF expression in Ewing sarcoma (conjugate control in upper right corner inset, scale bar represents $100 \mu \mathrm{m}$ ). D-E. Angiogenesis parameters MVD (D) and proliferating EC (E) do not correlate to clinical outcome.

Ewing's sarcoma cells form vasculogenic structures in vitro and express VM related genes

To investigate the capacity of different Ewing saroma cell lines to display VM in vitro, we used 3-dimensional collagen matrix tube formation assays and performed direct comparisons with a range of melanoma cell lines. The aggressive EW7 cell line (known to have a high tumorigenicity in mice) efficiently formed a network of tubular structures (Figure 3A) comparable to the melanoma cell lines MUM-2B and C8161, which are aggressive and display VM in vitro (not shown) $(10,20)$. The less aggressive A673 and RD-ES Ewing sarcoma cell lines (known to have a low tumorigenicity in mice) showed an intermediate activity, forming a few tubular structures (Figure 3B and 3C), while SIM/EW27 cells formed hardly any structures at all (Figure 3D) comparable to the non-aggressive and VM-negative melanoma cell lines MUM-2C and C81-61 (not shown). Similar results were found on Matrigel (Figure 3E-H). 

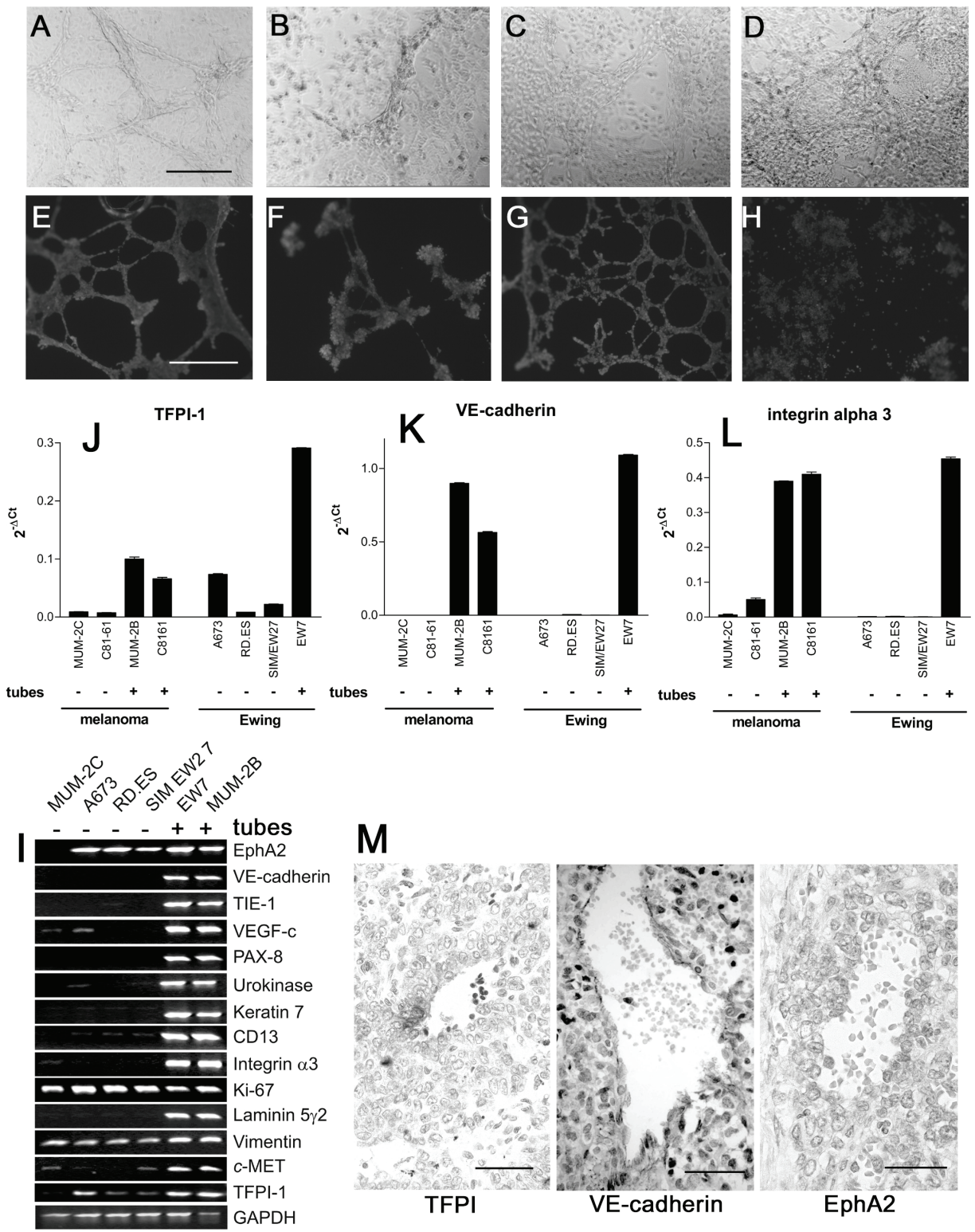

Figure 3. Ewing's sarcoma cells form tubular structures in vitro and express VM specific genes.

A-D. Ewing sarcoma cell lines EW7 (A), A673 (B), RD-ES (C) and SIM-EW27 (D) in 3D culture on collagen type I matrix. E-H. EW7 cells (E), A673 Ewing sarcoma cells (F), MUM-2B aggressive melanoma cells (G) and MUM-2C non-aggressive melanoma cells $(\mathrm{H})$ on a Matrigel 3D matrix stained with calcein. I. Gene expression measured by semi-quantitative RT-PCR in the Ewing sarcoma cell lines in comparison to the VM positive melanoma cell line MUM-2B and the VM negative cell line MUM-2C. The housekeeping gene, GAPDH, was used to control for equal loading. J-L. Quantitative real-time RTPCR confirmation of VE-cadherin (J), integrin $\alpha 3$ (K) and TFPI-1 (L) gene expression of VE-cadherin in 
melanoma and Ewing sarcoma cell lines. The $\mathrm{Ct}$ values are corrected for the expression of housekeeping genes. Statistical significance determined by Mann-Whitney test. M. Staining of Ewing sarcoma tissue sections with TFPI, VE-cadherin and EphA2 antibody. Scale bars in A, E (for A-H) and M represent 100 $\mu \mathrm{m}$.

Using semi-quantitative RT-PCR, we found that genes associated with VMrelated tumor cell plasticity in melanoma ${ }^{20}$ were expressed in the EW7 Ewing sarcoma cell line (Figure 3I). We went on to perform quantitative real-time RT-PCR (qRT-PCR) and found that integrin $\alpha 3$, VE-cadherin, Tissue Factor Pathway Inhibitor-1 (Figure 3JL), EphA2, laminin5 $\gamma 2$, Tie-1, neuropilin-1 and endoglin (data not shown) were all highly overexpressed in EW7 and melanoma cell lines MUM-2B and C8161. Expression was lower or absent in Ewing's cell lines A673, RD-ES and SIM-EW27 and the nonaggressive melanoma cell lines MUM-2C and C81-61, consistent with the degree of vasculogenic mimicry in three-dimensional culture (Figure 3J-L).

To address whether these genes are expressed in vivo in Ewing sarcoma, we used qRT-PCR to assay TFPI-1, VE-cadherin and EphA2, in frozen material from patients, and found that all three were expressed at a high level. Furthermore, using immunohistochemistry, we observed that TFPI-1/2, VE-cadherin and EphA2 protein was present in tumor cells lining the vasculogenic mimicry structures (Figure 2M).

\section{Blood lake structures in Ewing's sarcoma are part of the circulation}

To study the functionality of blood lake structures in vivo, EW7 tumors were grown s.c. in the flank of athymic mice. Tumors grew rapidly and we observed numerous lakes, especially in the outer rim of these tumors (Figure 4A and 4B), a distribution which has been previously described in melanomas ${ }^{21}$. The cells lining these lakes were negative for vWF and CD31. We used several approaches to investigate whether blood was flowing through these lakes. First, mice carrying EW7 tumors were intravenously injected with MECA20, an antibody specifically recognizing mouse endothelial cells. After 15 minutes, mice were sacrificed and perfused with an India ink suspension. We found ink both in MECA20 staining vessels as well as in vascular structures negative for MECA-20 and directly lined by tumor cells (Figure 4C). Second, intravital microscopy was performed. The vasculogenic structures were characterized by irregular profiles and slow blood flow (Figure $4 \mathrm{D}$, a video image can be viewed on www.fdg.unimaas.nl/AngiogenesisLab). Such vasculogenic structures were not present in LS174T colon carcinoma tumors. In a third approach, the connection of vasculogenic structures in EW7 tumors with the circulation was demonstrated when fluorescence was visualized in the vasculogenic structures after i.v. injection of a FITC-conjugated dextran (Figure 4E). 

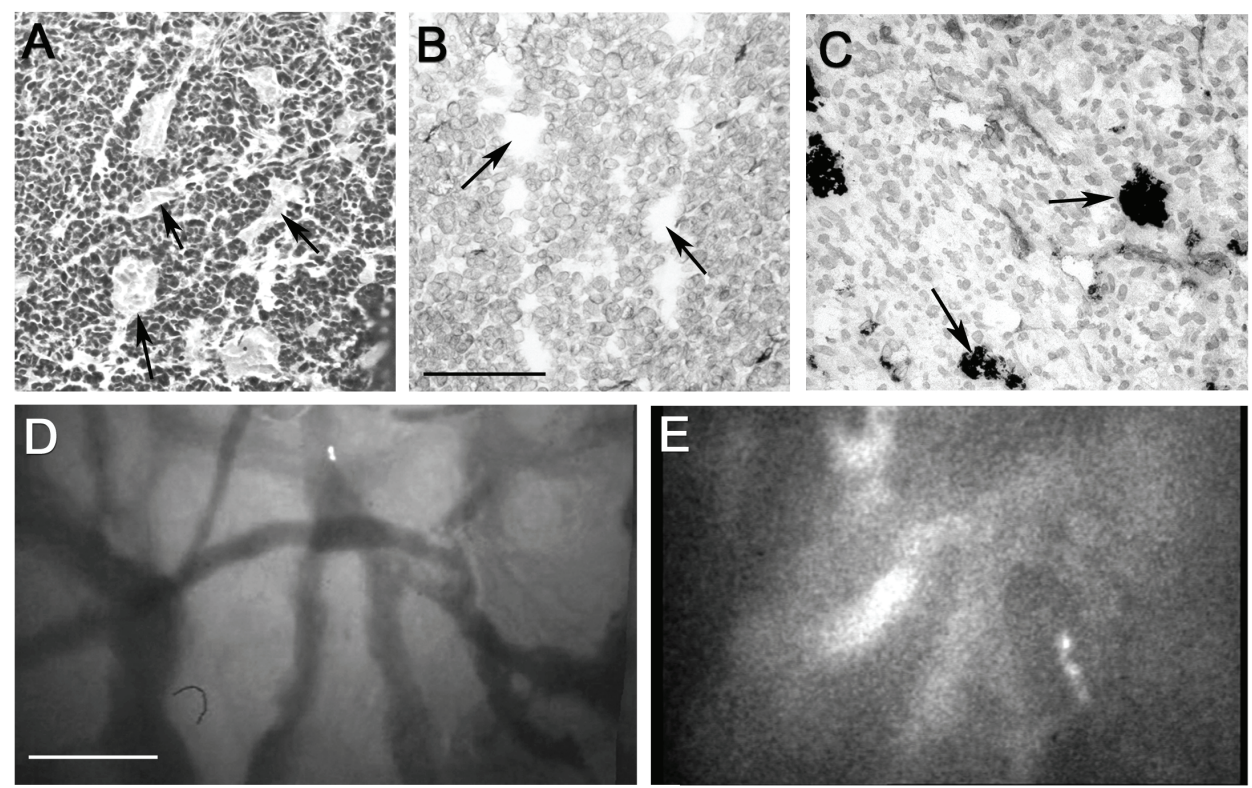

Figure 4. VM structures in Ewing's sarcoma are part of the circulation.

A-B. EW7 Ewing sarcoma xenograft tumor tissue stained with H\&E (A, paraffin embedded tissue) and CD31 (B, frozen tissue). C. EW7 tumor of a mouse sacrificed 10 min after injection of MECA-20 and India ink. In A-C blood lakes are indicated by arrows and the bar in B represent $100 \mu \mathrm{m}$. D. An intravital microscopic image of Ewing sarcoma (a video image can be viewed on www.fdg.unimaas.nl/AngiogenesisLab). E. Intravital microscopic image of an Ewing sarcoma tumor in a mouse injected i.v. with FITC-dextran. Bar in D $(100 \mu \mathrm{m})$ is valid for D and E.

\section{Blood flow in vasculogenic structures is inefficient; role of hypoxia}

Somewhat unexpectedly, the abundant presence of blood lakes and PAS-positive loops in the patient tissues coincided with high levels of VEGF (and other angiogenic growth factors) and ongoing angiogenesis (high numbers of proliferating endothelial cells). We therefore considered whether VEGF is instrumental in the induction of blood lakes and tubes by tumor cells. However, this seems unlikely since (i) VEGF did not augment tube formation of EW7 or MUM-2B cells in the in vitro tube formation assay as examined at concentrations of $1-50 \mathrm{ng} / \mathrm{ml}$ (Figure 5F), (ii) VEGF did not increase expression of genes involved in tube formation by tumor cells, neither in tube forming nor in non-tube forming tumor cells (Figure 5G) and (iii) addition of a VEGF blocking antibody was also not able to block or inhibit in vitro tube formation by the tumor cells (Figure 5H)). Results are shown for TFPI-1 (Figure 5F), similar results were found for VEGFR-1 and -2, Tie-1, Neuropilin-1, laminin $5 \gamma 2$ and EphA2. Furthermore, when comparing the VEGF RNA expression levels between tumors with higher amounts of blood lakes to tumors with lower numbers of lakes this did not yield a difference in expression (data not shown). 
Although we did not find a relationship between tube formation by tumor cells and VEGF, a factor that is regulated by hypoxia, we investigated the expression of hypoxia-inducible factor $1 \alpha(\mathrm{HIF} 1 \alpha)$. This is a transcription factor potently stabilized under hypoxic conditions, which acts as a master regulator of gene expression in response to changes in oxygen tension ${ }^{22-24}$. Interestingly, we found HIF1 $\alpha$ protein around the blood lakes, but not around CD31+ vessels (Figure 5B and 5C). Further evidence of HIF1 $\alpha$ activation was provided by the observation that the glucose transporter, GLUT1, another HIF1 $\alpha$ target gene was also highly expressed in these regions (Figure 5D). Since HIF1 $\alpha$ can be activated by other parameters besides low oxygen, we injected pimonidazole in Ewing sarcoma tumor bearing mice to assess local oxygenation. This nitroimidazole forms adducts with cellular proteins only when oxygen tension is reduced. Like HIF1 $\alpha$ protein, pimonidazole adducts were observed around the blood lakes, consistent with the notion that these regions are hypoxic (Figure 5E, the tumors from mice not injected with pimonidazole did not stain positive (not shown)). Taken together, these finding suggested that hypoxic activation of HIF1 $\alpha$ might be involved in driving vasculogenic mimicry.
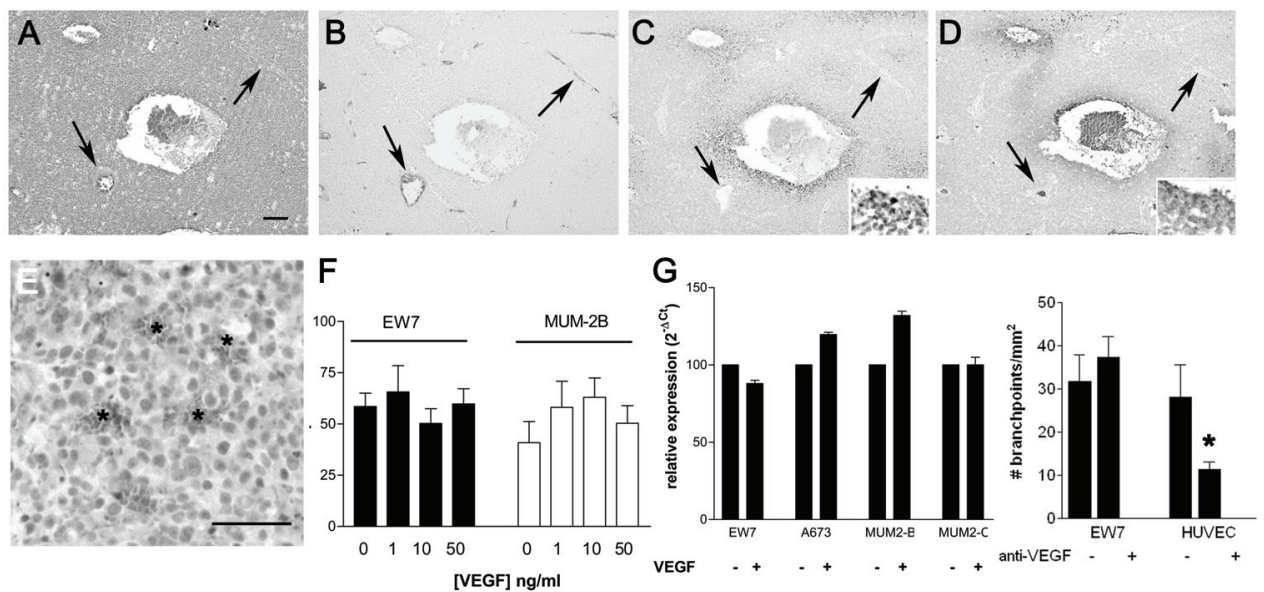

Figure 5. Blood lakes and hypoxia.

A. Ewing sarcoma H\&E stained tumor section. B-D. CD31, HIF1 $\alpha$ and GLUT1 stainings, respectively. Arrows indicate regular blood vessels. E. Pimonidazole adduct formation around blood lakes in a Ewing sarcoma mouse tumor. F. VEGF regulation of tube formation by EW7 cells cultured on Matrigel. G. Regulation of vasculogenic mimicry associated gene (TFPI1) expression in EW7 by incubation for 48 hours in $10 \mathrm{ng} / \mathrm{ml}$ VEGF, MUM-2B and MUM-2C cells. H. Incubation of EW7 cells on a 3D matrix with blocking VEGF antibody, as a positive control human umbilical vein derived endothelial cells (HUVEC) were used. Scale bars indicate $50 \mu \mathrm{m}$. 


\section{Discussion}

Despite the clinically aggressive behavior of Ewing's sarcoma, a relatively low number of microvessels was observed in this tumor type as compared to other malignancies. We demonstrated using several techniques that this was not due to a low angiogenic potential. Instead, the high angiogenic potential was illustrated by the high numbers of proliferating endothelial cells (although total number of vessels was low) and the high expression level (both RNA and protein) of angiogenic growth factors in the patient tissues as well as in the cell lines. The low amount of regular blood vessels together with the abundant presence of blood lakes and PAS-positive loops (vascular-like tube formation by tumor cells), suggested a contribution of the blood lakes to circulation that might be considered vasculogenic structures as described earlier 10, 12, 13. We therefore suggest that Ewing sarcoma tumor cells cooperate in the formation of a circulatory system such as has been described as vasculogenic mimicry in aggressive melanoma. Interestingly, whereas in most tumors vasculogenic mimicry is present in $10-40 \%$ of cases, Ewing sarcoma is the first tumor in which vasculogenic mimicry is so abundantly present (blood lakes in $92 \%$ of cases). In Ewing sarcoma, the amount of blood lakes and presence of PAS positive loops, in contrast to the classical angiogenesis parameters, correlated with survival, confirming that vasculogenic mimicry is an indicator of poor prognosis ${ }^{10,25}$.

The vascular-like tube formation by Ewing sarcoma tumor cells was confirmed in a 3D-culture system using human cell lines such as EW7, grown on a collagen matrix. Aggressive EW7 Ewing sarcoma cells rapidly formed vascular-like tubes in this system. In addition, EW7 cells injected into athymic mice gave rise to tumors with Ewing sarcoma morphology and blood lakes in vivo.

Furthermore, based on the similarities with the gene expression profiles in vasculogenic melanoma cells ${ }^{13}, 26$, it was suggested that tube formation in Ewing sarcoma was due to a similar plasticity and dedifferentiation of tumor cells, that gained an endothelial phenotype. We demonstrated that the genes involved in this process, such as TFPIs, EphA-2 and VE-cadherin ${ }^{10,27}$, are also highly expressed in the patient tissues and aggressive vascular-like tube forming EW7 cells. In contrast, less aggressive Ewing sarcoma cells did not or less efficiently form these tubes and do not overexpress these genes. It is interesting in this context that one of the diagnostic indicators for Ewing sarcoma is a translocation of chromosomes 11 and 22, which involves the Fli-1 gene on chromosome 11 and the EWS gene on chromosome $22{ }^{28,29}$. In diagnostic pathology, Fli-1 antibodies are used as markers for Ewing sarcoma and for endothelial cells/vascular tumors. The protein that is formed by the Fli- 1 gene is usually specifically expressed by endothelial cells. This translocation might play a role in the tumor cell plasticity seen in Ewing sarcoma.

Critical proof for the contribution of non-endothelial cell lined structures in circulation was the demonstration of blood flow in these structures. Using intravital microscopy and immunohistochemistry after injection of anti-endothelium antibody 
and India ink, we were able to demonstrate blood flow in the non-endothelial cell lined vascular structures. This blood flow was observed to be very slow, which urged us to study oxygenation in the tumor tissue. When assessing the Ewing sarcoma tissue samples for hypoxia, we found that the tumor cells surrounding the blood lakes did express HIF1 $\alpha$, a transcription factor known to play a role in the expression of VEGF, as well as GLUT1, indicative of inefficient oxygen delivery by these structures. Possible explanations for this would include the very slow blood flow through these channels, and/or the possibility that they act primarily as a circulatory system draining blood from the tumor.

It is likely that the hypoxia that is induced in these tumors has led to the high expression of VEGF (and maybe other angiogenic factors) and resultant endothelial cell proliferation as observed in the patient tissues. An important possibility is that vascular-like tube formation by tumor cells might be induced by VEGF or other angiogenic factors. In fact, tube formation has previously been reported to be enhanced by VEGF in vitro ${ }^{30}$. In contrast, in our study we were not able to show that VEGF enhances or induces vascular-like tube formation by tumor cells. Although this could reflect the difference in tumor models and assay systems, we were also not able to demonstrate differences in expression of the genes involved in tube formation in response to VEGF (Figure 5). Therefore, we favor the view that in Ewing sarcoma, blood lake and PAS-loop formation is not induced or supported by VEGF. We anticipate that hypoxia via induction of HIF1 $\alpha$ is able to enhance VM. Interestingly, both HIF1 $\alpha$ and vasculogenic mimicry associated genes, i.e. EphA2 and laminin-5 signal via the PI3/K pathway ${ }^{31,32}$. Furthermore, blockade of this signal transduction pathway blocks VM and the expression of the genes involved in this process ${ }^{33}$. In addition, for Tie- 1 it has been shown that it can be upregulated by HIF $1 \alpha^{34}$.

The results of this study strongly suggest that plasticity of Ewing sarcoma tumors is associated with the contribution of tumor cells to contribute to circulation. This presumably explains, at least in part, why the microvessel density is unusually low for such an aggressive tumor. This scenario may have impact on the treatment of tumors with angiogenesis inhibitors that act directly on endothelial cells. As we have demonstrated before, dedifferentiating tumor cells do not acquire sensitivity to angiogenesis inhibitors ${ }^{35}$, suggesting that an anti-angiogenesis protocol may lead to only a partial regression of the tumor. Since vascular-like tube formation is much less frequent and/or less well recognized in other tumor types, it is possible that there is an important relationship between these structure and response to therapy, which has been overlooked in trials with angiogenesis inhibitors. Up to now, no data are available on such trials in Ewing sarcoma patients. We suggest that it would be particularly informative to seek a relationship between the presence of vasculogenic structures and the response to anti-angiogenesis therapy. Furthermore, an interesting possibility is that anti-angiogenesis therapy may result in a selective growth advantage for cells exhibiting vasculogenic mimicry, allowing drug induced resistance to occur. 
It seems likely that angiogenesis therapy may be more effective when combined with other forms of cancer therapies to eradicate vasculogenic tube formation, explaining the good results of combination between anti-angiogenesis therapy and conventional cancer therapies in (pre-)clinical studies 36-38. The Ewing sarcoma model with its abundant vasculogenic structures may be an ideal model to develop and test therapies designed to counteract vasculogenic tube formation by attacking tumor cells that take part in the formation of vascular lakes, e.g. through CD99 directed therapy ${ }^{39}$. 


\section{References}

1. Ushigome S, M. R., Sorensen PH. World Health organizaton Classification of Tumours; Pathology and genetics, Tumours of Soft Tissue and Bone. (ed. Fletcher CDM, U. K., Mertens F) (ARC Press, International Agency for Research on Cancer, Lyon, 2002).

2. Rodriguez-Galindo, C., Spunt, S. L. \& Pappo, A. S. Treatment of Ewing sarcoma family of tumors: current status and outlook for the future. Med Pediatr Oncol 40, 276-87 (2003).

3. Kennedy, J. G., Frelinghuysen, P. \& Hoang, B. H. Ewing sarcoma: current concepts in diagnosis and treatment. Curr Opin Pediatr 15, 53-7 (2003).

4. Sinkovics, J. G., Plager, C., Ayala, A. G., Lindberg, R. D. \& Samuels, M. L. Ewing sarcoma: its course and treatment in 50 adult patients. Oncology 37, 114-9 (1980).

5. Ewing, J. The Classic: Diffuse endothelioma of bone. Proceedings of the New York Pathological Society. 1921;12:17. Clin Orthop Relat Res 450, 25-7 (2006).

6. Bossi, P. et al. Angiogenesis in colorectal tumors: microvessel quantitation in adenomas and carcinomas with clinicopathological correlations. Cancer Res 55, 5049-53 (1995).

7. Uzzan, B., Nicolas, P., Cucherat, M. \& Perret, G. Y. Microvessel density as a prognostic factor in women with breast cancer: a systematic review of the literature and meta-analysis. Cancer Res 64, 2941-55 (2004).

8. Holzer, G. et al. Concentration of vascular endothelial growth factor (VEGF) in the serum of patients with malignant bone tumors. Med Pediatr Oncol 36, 601-4 (2001).

9. van der Woude, H. J. et al. Changes in tumor perfusion induced by chemotherapy in bone sarcomas: color Doppler flow imaging compared with contrast-enhanced MR imaging and three-phase bone scintigraphy. Radiology 191, 421-31 (1994).

10. Maniotis, A. J. et al. Vascular channel formation by human melanoma cells in vivo and in vitro: vasculogenic mimicry. Am J Pathol 155, 739-52 (1999).

11. Shirakawa, K. et al. Vasculogenic mimicry and pseudo-comedo formation in breast cancer. Int J Cancer 99, 821-8 (2002).

12. Sood, A. K. et al. The clinical significance of tumor cell-lined vasculature in ovarian carcinoma: implications for anti-vasculogenic therapy. Cancer Biol Ther 1, 661-4 (2002).

13. Hendrix, M. J., Seftor, E. A., Hess, A. R. \& Seftor, R. E. Vasculogenic mimicry and tumour-cell plasticity: lessons from melanoma. Nat Rev Cancer 3, 411-21 (2003).

14. Shirakawa, K. et al. Hemodynamics in vasculogenic mimicry and angiogenesis of inflammatory breast cancer xenograft. Cancer Res 62, 560-6 (2002).

15. Paulussen, M. et al. [EICESS 92 (European Intergroup Cooperative Ewing's Sarcoma Study)-preliminary results]. Klin Padiatr 211, 276-83 (1999).

16. Thijssen, V. L., Brandwijk, R. J., Dings, R. P. \& Griffioen, A. W. Angiogenesis gene expression profiling in xenograft models to study cellular interactions. Exp Cell Res 299, 286-93 (2004).

17. van der Schaft, D. W. et al. The designer anti-angiogenic peptide anginex targets tumor endothelial cells and inhibits tumor growth in animal models. Faseb J 16, 1991-3 (2002).

18. Dirkx, A. E. et al. Tumor angiogenesis modulates leukocyte-vessel wall interactions in vivo by reducing endothelial adhesion molecule expression. Cancer Res 63, 2322-9 (2003).

19. Duijvestijn, A. M., Kerkhove, M., Bargatze, R. F. \& Butcher, E. C. Lymphoid tissue- and inflammation-specific endothelial cell differentiation defined by monoclonal antibodies. J Immunol 138, 713-9 (1987).

20. Seftor, E. A. et al. Molecular determinants of human uveal melanoma invasion and metastasis. Clin Exp Metastasis 19, 233-46 (2002).

21. Folberg, R. \& Maniotis, A. J. Vasculogenic mimicry. Apmis 112, 508-25 (2004).

22. Ratcliffe, P. J., Pugh, C. W. \& Maxwell, P. H. Targeting tumors through the HIF system. Nat Med 6, 1315-6 (2000).

23. Ratcliffe, P. J., O'Rourke, J. F., Maxwell, P. H. \& Pugh, C. W. Oxygen sensing, hypoxiainducible factor-1 and the regulation of mammalian gene expression. J Exp Biol 201, 1153-62 (1998).

24. Maxwell, P. H. et al. Hypoxia-inducible factor-1 modulates gene expression in solid tumors and influences both angiogenesis and tumor growth. Proc Natl Acad Sci U S A 94, 8104-9 (1997). 
25. Sun, B., Zhang, S., Zhao, X., Zhang, W. \& Hao, X. Vasculogenic mimicry is associated with poor survival in patients with mesothelial sarcomas and alveolar rhabdomyosarcomas. Int J Oncol 25, 1609-14 (2004).

26. Hendrix, M. J., Seftor, E. A., Hess, A. R. \& Seftor, R. E. Molecular plasticity of human melanoma cells. Oncogene 22, 3070-5 (2003).

27. Hendrix, M. J. et al. Expression and functional significance of VE-cadherin in aggressive human melanoma cells: role in vasculogenic mimicry. Proc Natl Acad Sci U S A 98, 8018-23 (2001).

28. Delattre, O. et al. The Ewing family of tumors--a subgroup of small-round-cell tumors defined by specific chimeric transcripts. N Engl J Med 331, 294-9 (1994).

29. Zucman, J. et al. Cloning and characterization of the Ewing's sarcoma and peripheral neuroepithelioma $\mathrm{t}(11 ; 22)$ translocation breakpoints. Genes Chromosomes Cancer 5, 271-7 (1992).

30. Rybak, S. M. et al. "Vasocrine" formation of tumor cell-lined vascular spaces: implications for rational design of antiangiogenic therapies. Cancer Res 63, 2812-9 (2003).

31. Mazure, N. M., Chen, E. Y., Laderoute, K. R. \& Giaccia, A. J. Induction of vascular endothelial growth factor by hypoxia is modulated by a phosphatidylinositol 3-kinase/Akt signaling pathway in Ha-ras-transformed cells through a hypoxia inducible factor-1 transcriptional element. Blood 90, 3322-31 (1997).

32. Sandau, K. B., Faus, H. G. \& Brune, B. Induction of hypoxia-inducible-factor 1 by nitric oxide is mediated via the PI 3K pathway. Biochem Biophys Res Commun 278, 263-7 (2000).

33. Hess, A. R., Seftor, E. A., Seftor, R. E. \& Hendrix, M. J. Phosphoinositide 3-kinase regulates membrane Type 1-matrix metalloproteinase (MMP) and MMP-2 activity during melanoma cell vasculogenic mimicry. Cancer Res 63, 4757-62 (2003).

34. McCarthy, M. J., Crowther, M., Bell, P. R. \& Brindle, N. P. The endothelial receptor tyrosine kinase tie-1 is upregulated by hypoxia and vascular endothelial growth factor. FEBS Lett 423 , 334-8 (1998).

35. van der Schaft, D. W. et al. Effects of angiogenesis inhibitors on vascular network formation by human endothelial and melanoma cells. J Natl Cancer Inst 96, 1473-7 (2004).

36. Koukourakis, M. I. et al. The effect of trastuzumab/docatexel combination on breast cancer angiogenesis: dichotomus effect predictable by the HIFI alpha/VEGF pre-treatment status? Anticancer Res 23, 1673-80 (2003).

37. Hurwitz, H. et al. Bevacizumab plus irinotecan, fluorouracil, and leucovorin for metastatic colorectal cancer. N Engl J Med 350, 2335-42 (2004).

38. Goodman, L. Persistence--luck--Avastin. J Clin Invest 113, 934 (2004).

39. Scotlandi, K. et al. CD99 engagement: an effective therapeutic strategy for Ewing tumors. Cancer Res 60, 5134-42 (2000). 



\section{Chapter 6}

\section{Involvement of hypoxia and HIF-1 $\alpha$ in tumor cell plasticity}

Femke Hillen, Twan van den Beucken, Petra Hautvast,

Bradly G. Wouters, Arjan W. Griffioen

In preparation 


\section{Abstract}

The term "vasculogenic mimicry" was introduced to describe the plasticity of tumor cells and their masquerade as endothelial cells. Such plastic tumor cells tend to dedifferentiate and express stem cell related genes. The exact mechanisms of vasculogenic mimicry have not been elucidated yet. We compared non-aggressive tumor cells with vasculogenic mimicry positive aggressive tumor cells from various tumor types by microarray analysis. The results indicated that a high number of hypoxia inducible factor 1 (HIF1)- $\alpha$ regulated genes were differentially expressed. Furthermore, when highly aggressive tumor cells are cultured under low oxygen levels, HIF1-alpha protein is more upregulated than in non-aggressive tumor cells. In a $3 \mathrm{D}$ matrigel assay, the aggressive tumor cells, showed enhanced tube formation under hypoxic conditions. Importantly, silencing of the HIF-1 $\alpha$ gene in 2 different aggressive tumor cell lines by transient and stable RNA interference resulted in down-regulation of vasculogenic mimicry related genes, such as VE-cadherin, EphrinA2, TFPI1, Tie-1 and Laminin C2. Moreover, the stable HIF-1 $\alpha$ knock down cells demonstrated less invasiveness in collagen matrix. In conclusion, our results implicate hypoxia and HIF1alpha in the establishment of vasculogenic tube formation by tumor cells. These results suggest that hypoxia and HIF1-alpha may be targets for therapy in aggressive tumors.

\section{Introduction}

Plasticity of tumor cells occurs through genetic instability and is a characteristic of aggressive tumours in which tumour cells dedifferentiate to an endothelial phenotype. It has been shown that such tumor cells have the capacity to form tube-like structures that can conduct blood and contribute to circulation. There is evidence that endothelium associated genes such as VE-cadherin, Ephrin A2 and tissue factor pathway inhibitors, CD34, tyrosine kinase receptor 1, neuropilin 1, E-selectin and endoglin (CD105) are highly upregulated in aggressive, vasculogenic mimicry positive tumor cells ${ }^{1}$. It has been hypothesized that this transcriptional program provides tumour cells with a secondary circulation system of vasculogenic structures lined by tumour cells, independently of angiogenesis ${ }^{2}$.

The exact mechanisms underlying vasculogenic mimicry still need to be unravelled. Several molecules have been identified to have a functional role. For example, phosphoinositide 3-kinase (PI3K) was proposed as the key player in activating the transmembrane metalloproteinase MT1-MMP ${ }^{1}$. This protease activates matrix metalloproteinase-2 (MMP2) that cleaves laminin $5 \gamma 2$ into pro-migratory fragments used for tumour cell migration in vasculogenic mimicry ${ }^{3}$. There is also a role for VE-cadherin and Ephrin A2 since downregulation of these genes in melanoma cells results in an abrogation of their ability to form vasculogenic-like structures ${ }^{4}$. VEcadherin can even regulate the expression of EphA2 through its receptor ephrin-A1. So far, several other molecules like tissue factor pathway inhibitor 2, focal adhesion 
kinase, cyclooxygenase-2, bone morphogenetic protein-4, insuline-like growth factor binding protein 3, Nodal, and Mig-7, mostly found by means of siRNA techniques or anti-body blocking techniques, have been described to play a role in vasculogenic mimicry ${ }^{5-10}$. In contrast several growth factors, such as basic fibroblast growth factor (bFGF), vascular endothelial growth factor (VEGF), transforming Growth Factor- $\beta$, platelet derived growth factor (PDGF), and tumour necrosis factor- $\alpha$ were found not to be involved in the process ${ }^{2,11}$. Still our knowledge of vasculogenic mimicry remains limited at present. Therefore better understanding of the mechanisms behind this process is important for the development of novel and more effective cancer therapies.

Hypoxia has been identified as a primary regulator of tumor progression by inducing the angiogenic switch. The key regulator of hypoxia-induced angiogenesis is hypoxia inducible factor- $1 \alpha$ (HIF- $1 \alpha$ ). Under hypoxic conditions HIF-1 $\alpha$ binds on specific hypoxia response elements in the promoter regions of several genes that are important in angiogenesis such as VEGF, endothelial nitric oxide synthase, PDGF and bFGF. We hypothesised that hypoxia, being a driving force in tumor progression and specific gene expression, could be a mediator of the development of tumor cell plasticity. We found that both HIF- $1 \alpha$ protein and HIF- $1 \alpha$ related genes are more expressed in aggressive tumor cells and that hypoxic conditions could induce tube formation. Silencing of HIF-1 $\alpha$ mRNA resulted in a downregulation of vasculogenic mimicry related genes and in a less invasive phenotype.

\section{Material and methods}

\section{Cell cultures and conditions}

Melanoma cell lines MUM2B, MUM2C, Ewing sarcoma cell lines EW7, SIMEW27, and breast carcinoma cell lines MDA-MB231, MCF7 were used. Melanoma and Ewing sarcoma cell lines were maintained in RPMI 1640, supplemented with 10\% FCS and 2 $\mathrm{mM}$ glutamine. Breast carcinoma cell lines were cultured with DMEM supplemented with $10 \%$ FCS and $2 \mathrm{mM}$ glutamine. Cells were grown on standard culture dishes except for the SIMEW27, which were grown on gelatin-coated culture dishes. All culture media and standard cell culture materials were obtained form Life Technologies (Breda, the Netherlands) and cells were maintained in a humified incubator at $37^{\circ} \mathrm{C}$ in $5 \%$ of $\mathrm{CO}_{2}$.

For hypoxic exposure, cells were transferred into a MACS VA500 microaerophilic workstation (Don Whitley Scientific, Shipley, UK). The atmosphere in the chamber

consisted of $5 \% \mathrm{H}_{2}, 5 \% \mathrm{CO}_{2}, 0 \%$ or $0.2 \% \mathrm{O}_{2}$, and $90 \% \mathrm{~N}_{2}$. Mimicking of hypoxic conditions was performed with $300 \mathrm{nM} \mathrm{CoCl}_{2}$ (Merck, Darmstadt, Germany) for 3 to 6 hours. 
|Chapter 6

\section{Microarrays and data processing}

Total RNA was isolated from the cell lines EW7, SIMEW27, MDA-MB231 and MCF7 using RNeasy (Qiagen, Venlo, the Netherlands), followed by RNase-free DNase treatment (Qiagen, Hilden, Germany). RNA quantity and purity were determined using the Nanodrop ND-1000 spectrophotometer (Nanodrop Technologies, Wilmington, USA) and RNA integrity was determined using the Bioanalyzer 2100 (Agilent Technologies, Palo Alto, USA). Five $\mu$ g total RNA was amplified using the one-cycle 3 'amplification and target labeling reagents as recommended by the manufacturer (Affymetrix, Santa Clara, USA). Biotin labelled target complementary RNA (cRNA) was fractionated and hybridized to Human Genome U133A Plus 2.0 Arrays as recommended by the manufacturer (Affymetrix). Affymetrix GeneChip ${ }^{\circledR}$ Operating Software (GCOS 1.4) was used to control the GeneChip Fluidics Station 450 and Scanner 3000 (7G upgrade). Affymetrix GCOS, version 1.4 was used to analyze image data. For each transcript represented on the array by a probe set, the expression algorithm computed the detection call (present, absent, or marginal), the detection pvalue, and the signal which is an average intensity value for each probe set. This resulted in a table with 54,675 probe sets.

\section{RNA isolation, cDNA synthesis and quantitative Real-Time RT-PCR}

Total RNA was isolated from cells with the RNeasy mini kit (Qiagen, Venlo, The Netherlands) according to the supplier's protocol. Possible genomic DNA contamination was removed by on column DNaseI treatment for $15 \mathrm{~min}$ at room temperature. Concentration and quality of the RNA was analysed on the NanoDrop ND-1000 (Nanodrop Technologies Inc., Wilmington, USA). A total amount of $100 \mathrm{ng}$ total RNA was used for cDNA synthesis with the iScript cDNA synthesis kit (Bio-Rad Laboratories B.V., Veenendaal, The Netherlands) according to the supplier's protocol. Quantitative PCR was performed with the iCycler (Bio-Rad) in a total volume of $25 \mathrm{ml}$ on $30 \mathrm{ng}$ cDNA with the iQ SYBR Green Supermix (Bio-Rad) and $400 \mathrm{nM}$ forward and reverse primer. The primers used for this study are listed in table 1. Primers were synthesized by Eurogentec (Seraing, Belgium). Graphs represent relative expression normalised to the expression of cyclophilin $\mathrm{A}$, since $\beta$-actin was influenced by hypoxic conditions.

\section{Western blotting}

Cells were washed twice with ice-cold PBS, scraped of on ice and harvested in cold lysisbuffer (50mM Hepes, $150 \mathrm{mM} \mathrm{KCl}, 1 \mathrm{mM}$ EDTA, 2mM DTT, $0.2 \%$ Tween-20 and 1 tablet of proteinase inhibitor cocktail (Roche Diagnostics $\mathrm{GmbH}$, Mannheim, Germany) per $25 \mathrm{ml}$ ). Protein concentration was measured with Micro BCA protein assay kit (Pierce, Rockford, IL, USA). Equal amounts of protein were boiled for $5 \mathrm{~min}$ in sample buffer $(10 \mathrm{mM}$ Tris pH 6.8, 1mM EDTA, 2.5\% SDS, 5\% $\beta$-mercapto-ethanol, $10 \%$ glycerol, $0.05 \%$ bromo phenol blue) and.separated by SDS-polyacrylamide gel electrophoresis. Subsequently proteins were transferred to a nitrocellulose membrane 


\begin{tabular}{lll}
\hline \multicolumn{2}{l}{ Table 1 Quantitative real-time PCR primers } & \\
Gene name & Forward $\left(5^{\prime}->3^{\prime}\right)$ & Reverse $\left(5^{\prime}->3^{\prime}\right)$ \\
\hline NT5 & CACCAAGGTTCAGCAGATCC & ACACGGTGAACCAGATAGTGC \\
TGM2 & ACGAGGCCAGTGTAGACAGTC & TCCTCCACAGCATCTCTTAGTG \\
MIHC & GAAAGGAGTCTTGCTCGTGC & AATCTGCAGCTAGGATACAACTT \\
PAI1 & GCAGATTCAAGCAGCTATGG & TGTGGTGCTGATCTCATCCT \\
uPA & TTCCATCGAACTGTGACTGTC & CTCCGAATTCTTGGGCAG \\
ITGA3 & AAGGGACCTTCAGGTGCA & TGTAGCCGGTGATTTACCAT \\
IL8 & ATACTCCAAACCTTTCCACC & TCCAGACAGAGCTCTCTTCC \\
EGFR & AATAACTGTGAGGTGGTCCTTG & CATAACCAGCCACCTCCTG \\
CYR61 & GACAGCCAGTGTACAGCAGC & TCACACTCAAACATCCAGCG \\
CCNT2 & GTAGATAGTGTCACTGGTGTGCC & GAATTAGAGGTACTGGCGC \\
DCTN2 & ACCTGAGGATGATCAAGCG & CTTGAACTTGTCATAGGCAGC \\
NCOA3 & GCCAGAGATATGAAACAATGC & GCGTGCCACACAGATCATA \\
HIF-1 $\alpha$ & CGTTCCTTCGATCAGTTGTC & TCAGTGGTGGCAGTGGTAGT \\
GLUT-1 & CTTCACTGTCGTGTCGCTG & CGATGGTCATGAGTATGGCA \\
VEGF-A & AAGGAGGAGGGCAGAATCAT & CCAGGCCCTCGTCATTG \\
VE-cadherin & TCCCGGAGCAGAAGACGT & GAGAAAAGAAAGAGAGCATGGATTG \\
Laminin5 $\gamma 2$ & CCAACGAAATGGGTCTCCTG & CTAGTCGTTGGGCTGAGCTAAC \\
EphA-2 & AGACGCTGAAAGCCGGCTAC & CAGGGCCCCATTCTCCATG \\
TFPI-1 & TTTGTGSSGSTGGTCCGAAT & AGACACCATGAGGGACCG \\
TFPI-2 & AGTGTGGACGACCAGTGTGAGG & TGCGCAGAAGCCCATACAAG \\
Tie-1 & CCCCGCTGGTCTCGTTCTC & CACAATGGTCGACCAGTCC \\
NRP-1 & CCCGAGAGAGCCACTCATG & GTCATCACATTCATCCACCAA \\
Cylcophilin A & CTCGAATAAGTTTGACTTGTGTT & CTAGGCATGGGAGGGAACA \\
$\beta$-actin & GCTGTGCTACGTCGCCCTG & GGAGGACTGGAAGCAGCC \\
\hline
\end{tabular}

(Protran nitrocellulose transfer membrane, Whatman GmbH, Dassel, Germany ). Nonspecific binding was prevented by incubation with 3\% Blotting Grade Blocker non-fat dry milk (BioRad Laboratories, Hercules, CA, USA) in PBS. Membranes were incubated $\mathrm{ON}$ at $4^{\circ} \mathrm{C}$ with antibodies against HIF-1 $\alpha$ (1:250 dilution, BD, Transduction Laboratories, Erembodegem, Belgium) or $\beta$-actin (1:20000 dilution, MP Biomedicals, Amsterdam, the Netherlands). Protein bands were detected using rabbit-anti mouse IgG-HRP (Dakocytomation, Glostrup, Denmark) in combination with ECL (ECL Plus Western Blotting detection system, Amersham, Buckinghamshire, UK).

\section{Three dimensional tube formation}

Vasculogenic tube formation was tested using commercial Matrigel (BD Biocoat, Woerden, the Netherlands). $40 \mu \mathrm{l}$ of Matrigel was coated in a 96 well on ice, incubated at $37^{\circ} \mathrm{C}$ for 30 minutes and cells were plated at 20,000 cells per well for $6 \mathrm{hrs}$ or $24 \mathrm{hrs}$ under normoxic or hypoxic conditions $\left(0 \%\right.$ of $\left.\mathrm{O}_{2}\right)$. Quantification of tube formation was executed by counting the amount of branchpoints.

\section{Stable transfection}

Stable knockdown of HIF-1 $\alpha$ was achieved by expressing a 19bp stem-loop shRNA against HIF-1 $\alpha$ (sense target sequence 5'-GGACAAGTCACCACAGGAC-3'). The 
shRNA cassette was subcloned from pSUPER(kindly provided by E.H. Gort, University Medical Centre Utrecht) into pRETROSUPER as an EcoRI / XhoI fragment. As a negative control (mock), the same vector without the construct was used. $5.10^{5}$ cells were transfected together with $2 \mu$ g vector using $100 \mu \mathrm{l} \mathrm{V}$-buffer and program V-20 of the Nucleofector system (Amaxa). Afterwards $500 \mu \mathrm{l}$ medium was added and cells were seeded in a 6 well containing $1.5 \mathrm{ml}$ medium. To achieve stable knockdown clones, cells were selected with $0.5 \mu \mathrm{g} / \mathrm{ml}$ puromycine dihydrochloride (Sigma Aldrich, St. Louis, MO, USA). After 10 days, 9 knock down clones and 6 mock transfected clones (of each cell line) were isolated from the 6 well and cultured in selective medium for another 2 weeks.

\section{Invasion assay}

The invasiveness of cells was tested in three dimensional assays in collagen gels. Harvested tumor cells were grown overnight in Petri dishes to form spheroids. Next, the spheroids were placed in a three dimensional collagen gel containing in 8 volumes of vitrogen-100(Collagen), 1 volume 10x concentrated a-MEM (Life Technologies) and 1 volume of $11.76 \mathrm{mg} / \mathrm{ml}$ sodium bicarbonate. $100 \mu \mathrm{l}$ of this mixture was suspended with $10 \mu \mathrm{l}$ of spheroid suspension and placed in a well of a 96-well culture plate, after which gelation was allowed to take place at $37{ }^{\circ} \mathrm{C}$ for $30 \mathrm{~min}$. After gelation, RPMI medium was applied on top of the gel. The sprouting, migration and invasion of cells of spheroids was observed for $48 \mathrm{hrs}$.

\section{Proliferation and migration measurements}

Tumor cell proliferation was measured using a $[3 \mathrm{H}]$ thymidine incorporation assay as described previously ${ }^{12}$. Tumor cells were seeded at 6,000 cells per well in a 96-well plate and cultured for 30h. During the last $6 \mathrm{~h}$ of the assay, the culture was pulsed with 0.3 ACi [methyl-3H] thymidine (Amersham Life Science) per well. Activity was measured using liquid scintillation. Three independent experiments were done and in each experiments and measurements were done in triplicate. Migration of endothelial cells was measured using the wound assay ${ }^{12}$. In brief, confluent monolayers of tumor cells were wounded using the blunt end of a $200 \mu \mathrm{l}$ pipette tip. Cultures were washed and medium was replaced. Wound width was measured in triplicate cultures at four predefined locations at start and at 2, 4, 6, and $8 \mathrm{~h}$ after wounding.

\section{Statistical analysis}

All values are given as mean values \pm SE. Statistical analyses of the quantitative realtime RT-PCR, tube formation assay and proliferation assay were done using the MannWhitney rank sum test, which was done in SPSS 12.0.1 software (SPSS, Chicago, IL). Migration assay data were analyzed by using two-way ANOVA (GraphPad Prism 3.0, GraphPad, San Diego, CA). All values are two-sided and $P$ values $<0.05$ were considered statistically significant. 


\section{Results}

Highly plastic and aggressive tumor cells express more HIF-1a related genes than nonaggressive tumor cells

To identify the gene profile of aggressive tumor cells that display a vasculogenic mimicry phenotype, we performed microarray comparisons of Ewing sarcoma cell lines (EW7 versus SIMEW7) and breast carcinoma cell lines (MDA-MB231 versus MCF7). Analysis revealed a differential expression in VM+ (EW7 and MDA-MB231) versus VM- (SIMEW27 and MCF7) tumor cells. We found 101 transcripts, that corresponded to 84 unique genes, were more than 10-fold upregulated (Table 2). Out of these, 9 genes were selected for validation by quantitative real-time analysis from three different RNA isolations. Validation was extrapolated to MUM2B and MUM2C cells, two cell lines that have been characterized before as being VM+ and VM- (Figure 1) ${ }^{1}$.

Because we hypothesized that hypoxia could be involved in tumor cell plasticity, we screened for genes that were differentially expressed and known to be regulated by hypoxia and/or HIF- $1 \alpha{ }^{13}$. We found 16 genes that were more than two-fold upregulated in VM+ versus VM- cells in both the VM+ cell lines or, in some cases only one of the VM+ cell lines (Table 3).

Table 3 Differential expression of HIF- $1 \alpha$ regulated genes

\begin{tabular}{lccl}
\hline & $\begin{array}{c}\text { fold change } \\
\text { EW7/SIMEW27 }\end{array}$ & $\begin{array}{c}\text { fold change } \\
\text { MDA-MB321/MCF7 }\end{array}$ & gene function \\
\hline IGFBP1 & 17 & 23 & cell survival and proliferation \\
IGFBP3 & 9 & 13 & cell survival and proliferation \\
TGF alpha & 5 & 3 & cell survival and motility \\
ADM & 7 & 9 & cell survival \\
cMET & 9 & 8 & cell motility \\
VIM & 2 & 49 & cytoskeleton structure \\
ETS-1 & 17 & 16 & transcriptional regulation \\
NT5 & 66 & 16 & nucleotide metabolism \\
PAI-1 & 40 & 25 & ECM metabolism \\
uPAR & 19 & 4 & ECM metabolism \\
TGM2 & 71 & 28 & amino acid metabolism \\
transferrin $R$ & 2,2 & 1,35 & iron metabolism \\
ENO1 & 1,8 & 2,24 & glucose metabolism \\
LDHA1 & 2,33 & 2,41 & glucose metabolism \\
PGK1 & 1,9 & 2,29 & glucose metabolism \\
PKM2 & 2,4 & 1,86 & glucose metabolism \\
\hline & & &
\end{tabular}


|Chapter 6






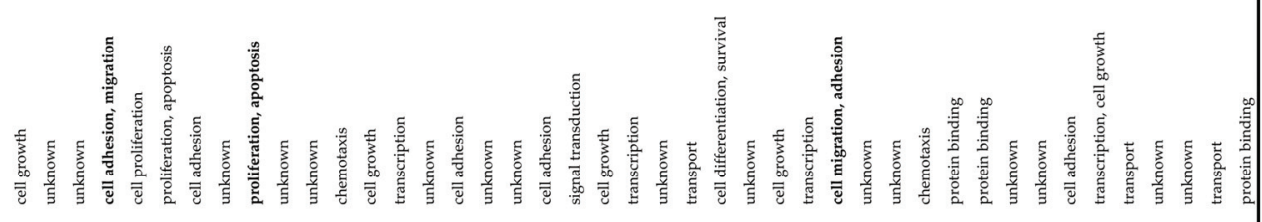

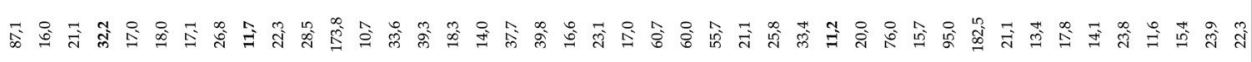

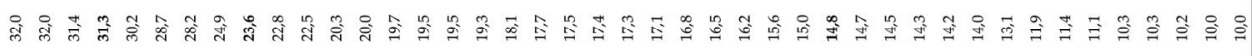



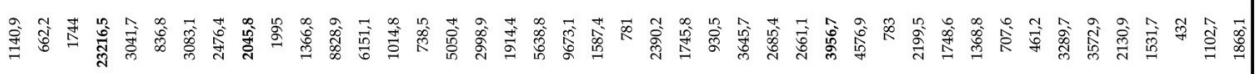

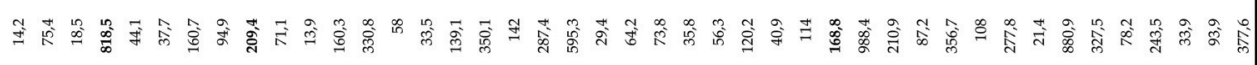

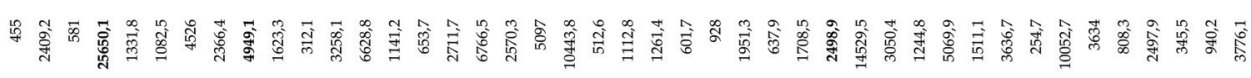

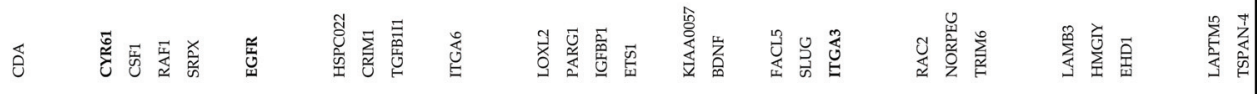

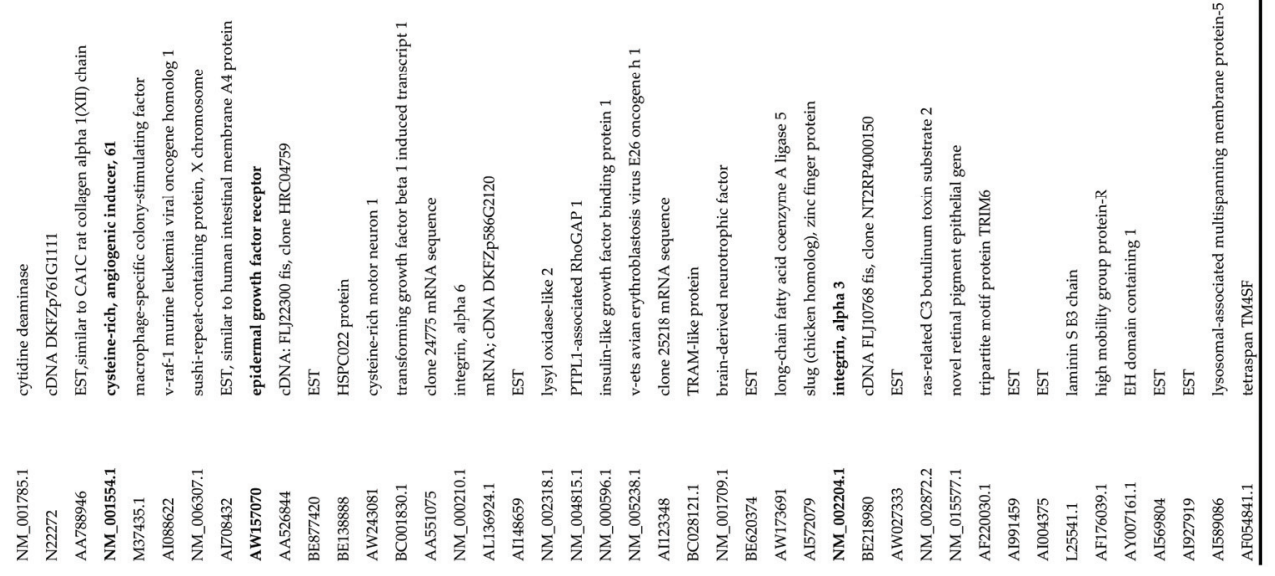


|Chapter 6

\section{Vasculogenic mimicry positive cells produce more HIF-1a protein under hypoxia}

The four cell lines, EW7, SIMEW27, MUM2B and MUM2C, were further used for in vitro analysis. Cells were incubated for $6 \mathrm{hrs}$ under normoxic or hypoxic conditions $\left(0,2 \% \mathrm{O}_{2}\right)$. Although there was no correlation between VM positivity and the expression of HIF-1 $\alpha$ under normoxic conditions, interestingly, under hypoxic conditions a higher expression of HIF-1 $\alpha$ protein was induced in the VM+ cells (figure $2 \mathrm{~A}$ ).
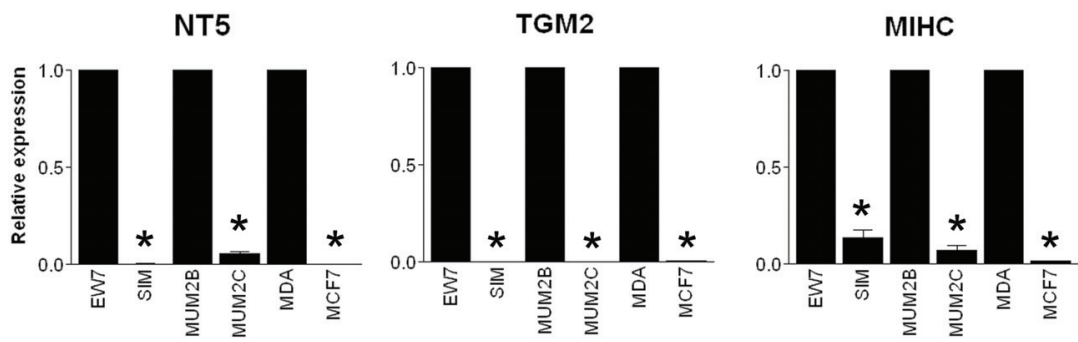

PAI-1

uPA

ITGA3
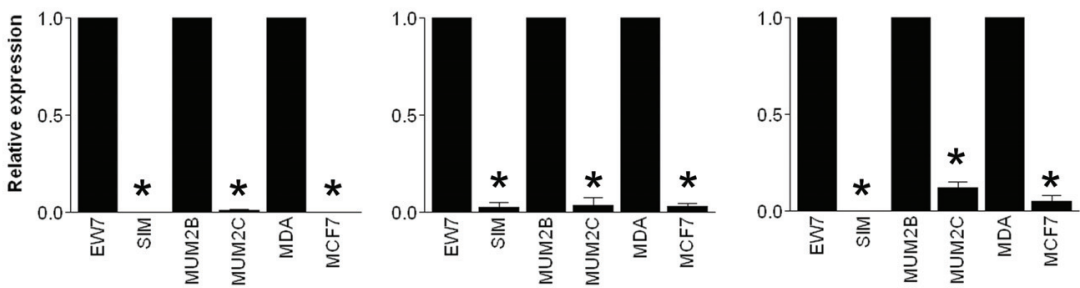

IL8

EGFR

CYR61


Figure 1. Transcriptional validation of 10-fold upregulated genes by quantitative real-time RT-PCR. Relative mRNA expression of selected genes in VM+ tumor cells (EW7, MUM2B, MDA-MB231) versus VM- tumor cells (respectively SIMEW27, MUM2C, MCF-7). Columns represent the mean of three independent experiments, bars represent the SE.

\section{Hypoxia stimulates sprouting in vitro}

The effect of hypoxia on sprouting was tested with EW7, SIMEW27, MUM2B and MUM2C cell lines in Matrigel. Only EW7 and MUM2B were able to form tubes under these conditions (figure $2 \mathrm{~B}-\mathrm{C}$ ). When incubated for $6 \mathrm{hrs}$ under hypoxia, tube formation was increased. After $24 \mathrm{hrs}$, a significant upregulation of tube formation was observed for EW7 cells. For MUM2B a significant upregulation was already seen after 6 
hrs. In contrast, the VM- cell lines SIMEW27 and MUM2C fail to form tube-like structures under both normoxic and hypoxic conditions (figure $2 \mathrm{D}$ ).

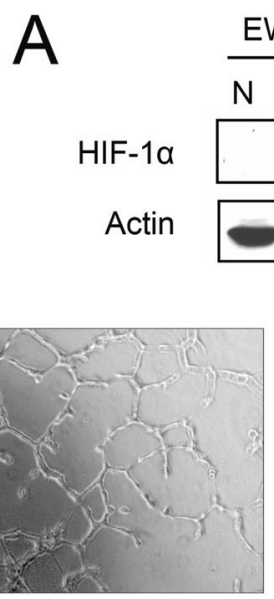

EW7 normoxia 24 hrs

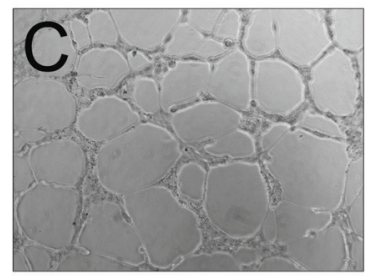

EW7 hypoxia 24 hrs

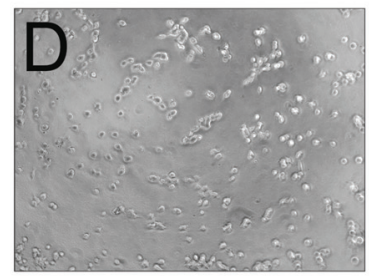

SIM hypoxia 24 hrs
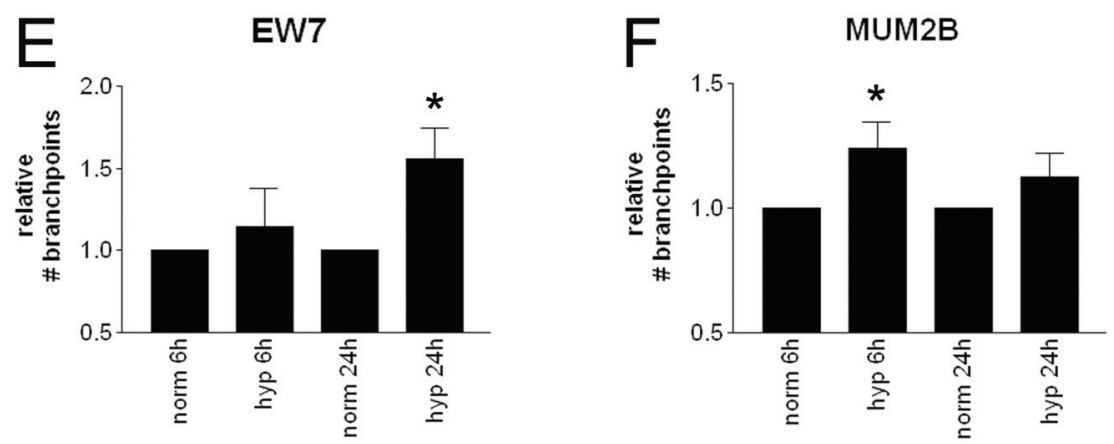

Figure 2. Effect of hypoxic conditions on vasculogenic mimicry positive and negative cells.

A. HIF-1 $\alpha$ protein expression in EW7, SIMEW7, MUM2B and MUM2C cells exposed for $6 \mathrm{~h}$ to hypoxia $\left(0.2 \%\right.$ of $\left.\mathrm{O}_{2}\right)$ or normoxia. B-D. Representative pictures of EW7 cells after $24 \mathrm{hrs}$ normoxia (B) and $24 \mathrm{hrs}$ hypoxia (C) and SIMEW7 cells after 24 hrs hypoxia (D) seeded on matrigel. E-F. Quantification of tube formation assay of both EW7 and MUM2B (means of 3 different experiments that were performed in triplo, quantified by two independent observers, bars represent SE).

Stable HIF-1a knock down results in impaired expression of vasculogenic mimicry related genes and reduced-invasive phenotype

To study the role of HIF- $1 \alpha$ in VM, we created stable HIF- $1 \alpha$ knock-down clones of both EW7 and MUM2B cells. These clones were incubated with $300 \mathrm{nM} \mathrm{CoCl}_{2}$ for $4 \mathrm{hrs}$ and RNA was isolated. These clones demonstrated suppression of the HIF-1 $\alpha$ regulated genes VEGF, GLUT-1. Interestingly, the vasculogenic mimicry related genes TFPI-1, Lamin C2, Tie-1, EphA2 were also suppressed (figure 3 A-C). It was already described 
Chapter 6

that matrix components and the microenvironment are important in the formation of vasculogenic structures ${ }^{14}$. To mimic a $3 \mathrm{D}$ environment that is more similar to in vivo situations, we designed a new collagen matrix assay to observe phenotypic differences of these cells. After $24 \mathrm{hrs}$, a clear difference was observed between the control spheroids and the spheroids of HIF- $1 \alpha$ knock-down cells. For both EW7 and MUM2B, the control cells (mock transfected) proliferated, grew out of the spheroids and invaded in the matrix, while the HIF- $1 \alpha$ knock down cells formed long stretched cells but showed no evidence of similar proliferation and migration. Under hypoxic conditions, similar results were observed (figure $3 \mathrm{D}$ ). To exclude possible differences in proliferation or migration of the different clones, we performed a proliferation assay and a migration wound assay. We found that clone EW7 HIF kd 2 and MUM2B HIF kd 6 had a significant higher amount of proliferation than the mock transfected cells (figure $3 \mathrm{E}$ ). The EW7 HIF kd 8 did not show any difference. In the wound assay, we could not detect significant difference between the different clones. The clone MUM2B HIF kd 6 showed a significant difference in migratory characteristics after 4 hours (figure $3 \mathrm{~F}-\mathrm{G}$ ). 


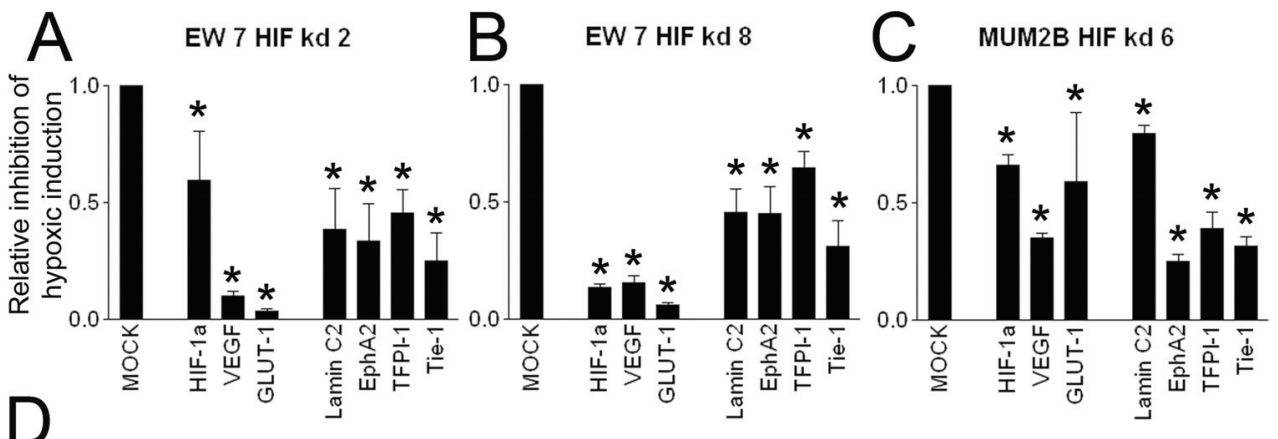

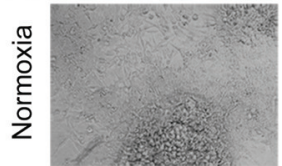

EW7 MOCK
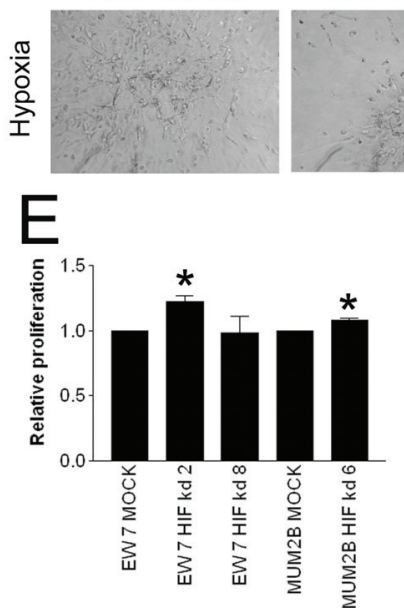

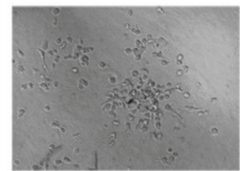

EW7 HIF kd 8
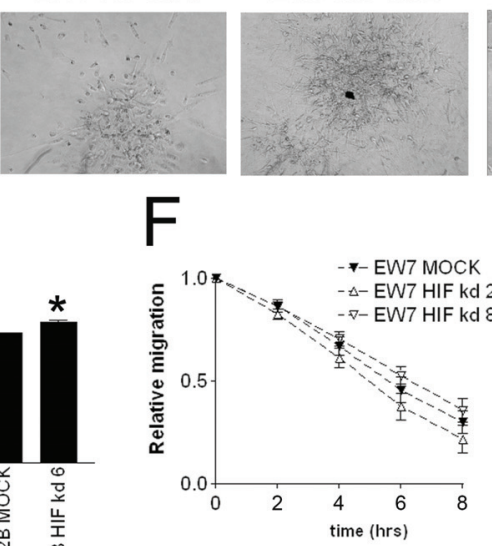

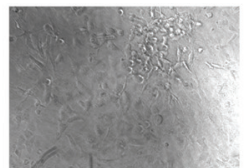

MUM2B MOCK

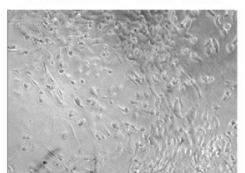

G
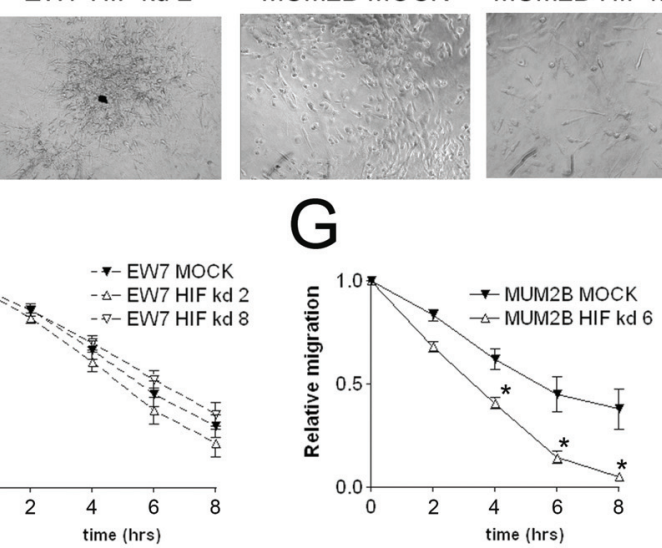

Figure 3. Gene expression alteration and invasivion changes of a stable HIF-1 $\alpha$ knock down cells.

A-C. After induction by hypoxic conditions, two EW7 clones (EW7 HIF kd 2 and EW7 HIF kd8) and one MUM2B clone (MUM2B HIF kd 6) show downregulation in HIF-1 $\alpha$ mRNA and in downstream genes like VEGF and GLUT-1. Also, vasculogenic mimicry related genes were suppressed. D. Spheroids of stable knock down cells and mock transfected control cells were less capable to invade the matrix. E. Relative proliferation of different mock and HIF-1 $\alpha$ knock down clones of EW7 and MUM2B. F-G. Relative migration of different mock and HIF- $1 \alpha$ knock down clones of EW7 and MUM2B. 


\section{Discussion}

Hypoxia has been a major subject in the field of cancer therapy for years. In tumors, hypoxia has been correlated with invasion, metastasis and patient death ${ }^{15}$. Moreover, hypoxia is a key player in the 'angiogenic switch' during tumor development. One of the main regulators of the molecular mechanisms involved in response to hypoxia is hypoxia inducible factor- 1 alfa (HIF- $1 \alpha$ ). HIF- $1 \alpha$ regulates the transcription of many genes that are involved in a conversion in a more invasive/metastatic phenotype ${ }^{16}$. Earlier research showed that the microenvironment is important in the induction of vasculogenic mimicry ${ }^{17}$. Moreover, it was suggested that hypoxia might be involved in tumor cell plasticity. We have observed previously that HIF-1 $\alpha$ and GLUT-1 expression is enhanced around blood lakes and not around regular blood vessels in Ewing sarcomas ${ }^{11}$. A B16 xenograft inoculated in a mouse ischemic limb also showed more presence of vasculogenic mimicry ${ }^{18}$.

To further identify the role of hypoxia in vasculogenic mimicry (VM), a process that also contributes to aggressiveness of the tumor, we performed a microarray analysis comparing different VM+ and VM- cell lines. We identified several genes, that are known to be regulated by hypoxia and/or HIF-1 $\alpha$, and that were upregulated in $\mathrm{VM}+$ cells versus VM- cells. Most of these genes are involved in cell survival, cell motility and cell proliferation and extra cellular matrix metabolism which can contribute to cancer invasiveness and aggressiveness. In addition, VM+ cell lines produced more HIF-1 $\alpha$ protein than VM- cells after being exposed to hypoxic conditions. Moreover, we could confirm previous data of Rybak et al concerning the induction of tube formation on matrigel by $\mathrm{VM}+$ cells due to an hypoxic environment with a Ewing sarcoma cell line and a melanoma cell line ${ }^{19}$. To investigate whether HIF$1 \alpha$ plays a role in vasculogenic mimicry we generated HIF- $1 \alpha$ knock down of VM+ cells, EW7 and MUM2B. Interestingly, the downregulation of HIF-1 $\alpha$ resulted, next to an effect on known downregulated HIF-1 $\alpha$ genes such as VEGF and GLUT-1, also in the downregulation of genes that are related to tumor cell plasticity. In these cells, a difference observed in matrix-invasiveness was observed. In contrast to HIF-1 $\alpha$ knock down that were suppressed in growth, the control cells could proliferate, migrate and invade through the collagen matrix. This was not due to higher proliferation or migration capacities of the control cells. Some HIF-1 $\alpha$ knock down clones demonstrated even a higher proliferation rate that the control cells.

In our array data we found a high expression of membrane type- 1 matrix metalloproteinase (MT1-MMP) (3.86 fold for EW7/SIMEW27 and 10.56 fold for MDAMB231). MT1-MMP was found to confer tumor cells with a 3D growth advantage and was identified as a tumor-derived growth factor that regulates tumor cell proliferation ${ }^{20}$. The protein has also been described to be important in vasculogenic mimicry. It was described that the interaction between lamin C2, MMP-2 and MT1-MMP could remodel the extra cellular matrix microenvironment ${ }^{3}$. Afterwards, PI3 kinase (PI3K) was reported to affect especially MT1-MMP ${ }^{21}$. Moreover, an important pathway that 
regulates angiogenic and oncogenic signalling through HIF- $1 \alpha$ is the PI3K/Akt/mTOR pathway ${ }^{13}$. It may be postulated that the remodelling of extra cellular matrix in vasculogenic mimicry positive cells and tumors could be due to the involvement of hypoxia and HIF-1 $\alpha$. In malignant gliomas and hepatocellular carcinoma, HIF-1 $\alpha$ was already described to induce also the activation of invasive-related molecules such as MMPs ${ }^{22}$. Also in the ischemic limb model, inoculated with a xenograft, of Sun et al., an increase of MMP-2 and MMP-9, together with a more vasculogenic mimicry channels, was observed in the ischemic group ${ }^{18}$.

In conclusion, our results implicate hypoxia and HIF1-alpha in the establishment of vasculogenic mimicry. This may provide opportunities for targeting of this pathway as a treatment option in cancer. A number of strategies that target hypoxia and hypoxia inducible factors have been developed ${ }^{23}$. Which component should be the best target for vasculogenic mimicry, is a challenging new research field that needs further investigation. Since previous studies and our results described the importance of PI3K, HIF-1 $\alpha$ and MMPs in vasculogenic mimicry and/or tumor progression, components that target the PI3K pathway are therefore the first potential targets to use for anti-vasculogenic mimicry. 


\section{References}

1. Hendrix, M. J., Seftor, E. A., Hess, A. R. \& Seftor, R. E. Vasculogenic mimicry and tumour-cell plasticity: lessons from melanoma. Nat Rev Cancer 3, 411-21 (2003).

2. Maniotis, A. J. et al. Vascular channel formation by human melanoma cells in vivo and in vitro: vasculogenic mimicry. Am J Pathol 155, 739-52 (1999).

3. Seftor, R. E. et al. Cooperative interactions of laminin 5 gamma2 chain, matrix metalloproteinase-2, and membrane type-1-matrix/metalloproteinase are required for mimicry of embryonic vasculogenesis by aggressive melanoma. Cancer Res 61, 6322-7 (2001).

4. Hendrix, M. J. et al. Expression and functional significance of VE-cadherin in aggressive human melanoma cells: role in vasculogenic mimicry. Proc Natl Acad Sci U S A 98, 8018-23 (2001).

5. Hess, A. R. et al. Focal adhesion kinase promotes the aggressive melanoma phenotype. Cancer Res 65, 9851-60 (2005).

6. Basu, G. D. et al. A novel role for cyclooxygenase-2 in regulating vascular channel formation by human breast cancer cells. Breast Cancer Res 8, R69 (2006).

7. Rothhammer, T., Bataille, F., Spruss, T., Eissner, G. \& Bosserhoff, A. K. Functional implication of BMP4 expression on angiogenesis in malignant melanoma. Oncogene (2006).

8. Xi, Y. et al. Association of insulin-like growth factor binding protein-3 expression with melanoma progression. Mol Cancer Ther 5, 3078-84 (2006).

9. Topczewska, J. M. et al. Embryonic and tumorigenic pathways converge via Nodal signaling: role in melanoma aggressiveness. Nat Med 12, 925-32 (2006).

10. Petty, A. P., Garman, K. L., Winn, V. D., Spidel, C. M. \& Lindsey, J. S. Overexpression of carcinoma and embryonic cytotrophoblast cell-specific Mig-7 induces invasion and vessel-like structure formation. Am J Pathol 170, 1763-80 (2007).

11. van der Schaft, D. W. et al. Tumor cell plasticity in Ewing sarcoma, an alternative circulatory system stimulated by hypoxia. Cancer Res 65, 11520-8 (2005).

12. van der Schaft, D. W. et al. The designer anti-angiogenic peptide anginex targets tumor endothelial cells and inhibits tumor growth in animal models. Faseb J 16, 1991-3 (2002).

13. Semenza, G. L. Targeting HIF-1 for cancer therapy. Nat Rev Cancer 3, 721-32 (2003).

14. Postovit, L. M., Seftor, E. A., Seftor, R. E. \& Hendrix, M. J. Influence of the microenvironment on melanoma cell fate determination and phenotype. Cancer Res 66, 7833-6 (2006).

15. Vaupel, P. \& Mayer, A. Hypoxia in cancer: significance and impact on clinical outcome. Cancer Metastasis Rev 26, 225-39 (2007).

16. Semenza, G. L. Hypoxia-inducible factor 1: oxygen homeostasis and disease pathophysiology. Trends Mol Med 7, 345-50 (2001).

17. Seftor, E. A. et al. Epigenetic transdifferentiation of normal melanocytes by a metastatic melanoma microenvironment. Cancer Res 65, 10164-9 (2005).

18. Sun, B. et al. Hypoxia influences vasculogenic mimicry channel formation and tumor invasion-related protein expression in melanoma. Cancer Lett (2006).

19. Rybak, S. M. et al. "Vasocrine" formation of tumor cell-lined vascular spaces: implications for rational design of antiangiogenic therapies. Cancer Res 63, 2812-9 (2003).

20. Hotary, K. B. et al. Membrane type I matrix metalloproteinase usurps tumor growth control imposed by the three-dimensional extracellular matrix. Cell 114, 33-45 (2003).

21. Hess, A. R., Seftor, E. A., Seftor, R. E. \& Hendrix, M. J. Phosphoinositide 3-kinase regulates membrane Type 1-matrix metalloproteinase (MMP) and MMP-2 activity during melanoma cell vasculogenic mimicry. Cancer Res 63, 4757-62 (2003).

22. Fujiwara, S. et al. Silencing hypoxia-inducible factor-1alpha inhibits cell migration and invasion under hypoxic environment in malignant gliomas. Int J Oncol 30, 793-802 (2007).

23. Melillo, G. Targeting hypoxia cell signaling for cancer therapy. Cancer Metastasis Rev 26, 34152 (2007). 


\section{Chapter 7}

\section{General discussion}


Cancer is one of the leading causes of death in the Western countries, and its incidence is still rising. Increasing knowledge on mechanisms that regulate tumor growth and development of specific strategies to inhibit tumor growth are therefore urgently needed.

It is known for years that tumors can be considered as sites of inflammation and can be seen as "wounds that do not heal" 1 . Leukocytes can infiltrate into the tumor through rolling on, adhesion to and diapedesis through the tumor blood vessel wall. These processes are gouverned by the intricately regulated expression of endothelial adhesion molecules, such as ICAM-1, VCAM-1 and E-selectin. The expression of adhesion molecules on endothelial cells is a process that is regulated by several factors. Next to induction by inflammatory cytokines, suppression occurs through exposure to angiogenic factors. This downregulation, together with the unresponsiveness of tumor endothelial cells to inflammatory cytokines, is referred to as tumor endothelial cell anergy ${ }^{2}$. As a consequence, less leukocytes can enter the tumor and attack the tumor cells.

It is suggested that dedifferentiated tumor cells provide themselves of a secondary circulation system of vasculogenic structures lined by tumor cells, independently from the process of angiogenesis, a phenomenon called vasculogenic mimicry. In preliminary intravital microscopy experiments with a tumor model of Ewing sarcoma, we observed the circulation of leukocytes in vasculogenic mimicry channels. Interestingly, less adhesion and rolling interactions of leukocytes with the channel wall were detected in these vasculogenic mimicry channels, in comparison to tumor blood vessels. Because of this, and the knowledge that a) the presence of vasculogenic mimicry is associated with aggressive, progressed tumors, b) vasculogenic channels transport blood and c) tumor cells can execute an immunosuppressive role on leukocytes, we hypothesized that channels lined by tumor cells could be another mechanism of tumors to through up a barrier for leukocytes to enter into the tumor. To study this hypothesis in vitro, we made use of Ewing sarcoma and melanoma cell lines. Cutaneous melanoma is one of the human tumors which has been most extensively analyzed in terms of cell adhesion molecules. In melanomas, the expression of cell adhesion molecules such as integrins, ICAM-1, MCAM and cadherins has been associated with primary tumors and progression ${ }^{3,4}$. These adhesion molecules facilitate migration of tumor cells and thus the extravasation of tumor cells and subsequently the onset of metastasis. Importantly, the role of adhesion molecules, expressed by tumor cells, in capturing leukocytes has not been studied extensively. ICAM-1 null mice showed an enhanced level of liver metastasis of the B16 melanoma and a decreased amount of inflammatory cells according to the wild type mice ${ }^{5}$. Also in colon carcinoma, invasive breast cancer and gastric cancer the expression of ICAM-1 was associated with a good prognosis and with a higher infiltration of lymphoid cells ${ }^{6-}$ 8. We investigated the expression of several adhesion molecules such as CD44, MCAM, ICAM-1, VCAM-1 and E-selectin in aggressive (vasculogenic mimicry positive) versus 
non-aggressive (vasculogenic mimicry negative) cell lines, on mRNA and protein level. Unfortunately, we could not detect significant difference in the expression of adhesion molecules. Also, in an in vitro adhesion assay where we studied the interaction of leukocytes with a confluent layer of tumor cells, we also could not discriminate between aggressive and non-aggressive cell lines on basis of their leukocyte interactions. This research generated a lot of 'negative data' and did not directly provide answers to the question of involvement of vasculogenic mimicry in escape from immunity.

To further study our theory that vasculogenic mimicry channels could be involved in (the lack of) leukocyte infiltration in the tumor, we investigated the correlation of leukocytes with vasculogenic mimicry and angiogenesis in human melanoma tissues. Next to that, we analysed the prognostic value of leukocyte subsets in primary melanoma. Tumors that showed vasculogenic mimicry were characterised with a higher amount of leukocytes and with a poor survival for the patient. Both the presence of vasculogenic mimicry and a high amount of leukocytes are considered to be markers for aggressiveness in primary melanoma. In conclusion, we favour the view that our hypothesis that vasculogenic mimicry is involved in escape from immunity can be rejected. However, it could be suggested that the high infiltration of leukocytes in melanomas is reaction of the immune system to overcome the dedifferentiation of aggressive tumor cells.

In melanomas, immunotherapy has been considered potentially useful because this tumor type is characterised with a high amount of leukocytes which sometimes results in spontaneous regression. In our patient study, we observed that progressed melanoma are infiltrated by a higher amount of leukocytes, however, this correlated with a worse prognosis for the patient. Analysis of the activation status of the lymphocytes, revealed a low amount of activated lymphocytes in progressed melanomas. This suggested that these tumors have developed several mechanisms to escape from tumor immunity. The role of regulatory $\mathrm{T}$ cells, which are able to suppress the activity of CD8+ and CD4+ T cells, has been investigated in other tumors types such as ovarian cancer ${ }^{9}$, 10 , gastrointestinal tumors ${ }^{11}$, Hodgkin's lymphoma ${ }^{12}$ and breast cancer ${ }^{13,14}$ and was correlated with progression. We are the first to report that the amount of regulatory $\mathrm{T}$ cells does not predict survival in primary melanoma, however, these cells are similarly recruited as the other subsets of lymphocytes and other leukocytes and could in that way counteract immunosurveillance in the tumor. It is clear that the evaluation of the immunosuppressive character of the total immune infiltrate is needed to predict survival and to evaluate the effect of immunotherapy.

One of the first attempts of immunotherapy, by administration of interleukin2 , in melanoma and renal cell carcinoma, resulted in 10-20\% of effectiveness ${ }^{15-18}$. Clinical trials of tumor-specific immunotherapy (i.e. vaccination strategies), however, have so far been disappointing, with response rates lower than $5 \%{ }^{19}$. These data suggest a minor future for immunotherapy in cancer treatment. Nevertheless the knowledge on immunosuppressive cells and cytokines inspired researchers to develop 
new strategies. Recent experimental findings report a $50 \%$ response rate in patients with metastatic melanoma after lymphodepletion prior to adoptive transfer of engineered tumor-specific lymphocytes. These patients were treated with in vitro expanded tumor infiltrating lymphocytes and interleukin-2, host immunodepletion and chemotherapy which resulted in both the elimination of regulatory $\mathrm{T}$ cells and other competing cytokine producing cells of the immune system. ${ }^{20,21}$. This promising strategy opens new possibilities for anti-tumor therapies.

Although in melanomas most attention has been focused on tumor infiltrating lymphocytes, other subsets are also present. Interestingly, in our patient group we observed that the subsets of leukocytes that infiltrated the most from peritumoral areas to intratumoral areas, where B cells, macrophages and polymorphonuclear cells. There is more and more evidence that the role of $\mathrm{B}$ cells and macrophages in tumors is not inhibitory but rather immunosuppressive. First attempts to unravel the exact contribution of B cells in tumor immunity was done in B cell-deficient mice. Mice with deficient mature B cells rejected the tumor and executed an enhanced antitumor immunity while wild type mice did not. It was demonstrated that priming of B cells resulted in disabled CD4+ helper $\mathrm{T}$ cells ${ }^{22,23}$. B cell depletion in patients with $\mathrm{B}$ cell lymphoma, renal cell carcinoma and melanoma also showed strong tumor specific $\mathrm{T}$ cell responses ${ }^{24,25}$. In contrast, in melanoma CD80+ B cells in combination with a higher amount of CD8+ cytotoxic cells correlated with a good prognosis ${ }^{26}$. Also tumor associated macrophages (TAM) have contradictory effects on tumor growth. TAMs are capable of killing tumor cells and can produce angiostatic compounds. On the other hand, they can also produce pro-angiogenic compounds (like VEGF, bFGF, interleukin8 , TNF- $\alpha$ and several matrix metalloproteinases) and stimulate tumor progression. In addition, TAMs respond to hypoxia by up-regulating the hypoxia-inducible factors HIF-1 and HIF-2 and subsequently VEGF 27,28 . In melanoma patients, a role of TAMs was described in the downregulation of tumor-specificity of T cells en NK cells ${ }^{29}$. Although the contribution of polymorphonuclear cells (PMN) has been controversial, improvement of PMN cytotoxicity was obtained after the injection of specific antibodies for oncogene products, like epidermal growth factor and ERBB2 ${ }^{30}$. Also the administration of recombinant interleukin-2 in patients with advanced malignant melanoma and renal cell carcinoma activated PMN effector activity ${ }^{31,32}$. These data suggest that the infiltration of both B cells and macrophages should be prevented while the stimulation of the activity and infiltration of PMN could be beneficial for the patient. It is clear that the role of these leukocyte subsets in tumor immunosurveillance needs further investigation.

A second target in tumor inhibition is tumor vascularisation. One of the best characterised vascularisation types is angiogenesis. Tumor angiogenesis is essential for tumor growth and metastasis, and is regulated by the production of pro-angiogenic factors mainly by tumor cells. Measurement of angiogenesis is commonly assessed by the quantification of the amount of blood vessels or microvessel density. Although 
these methods seems reproducible between different observers, several studies reported controversial findings. With the development of angiogenesis inhibitors, of which several clinical trials are ongoing worldwide, detailed knowledge of the vascular characteristics of a tumor is becoming essential. Although the goal of anti-angiogenesis strategies is to inhibit tumor growth, evaluation of an anti-angiogenesis therapy through the assessment of tumor growth is not totally fair since several other mechanisms can influence cancer outgrowth. Proper quantification of angiogenesis is needed. It has been suggested that angiogenesis is best evaluated through detection of proliferating endothelial cells ${ }^{33}$. In chapter 3 , we demonstrated that the quantification of the amount of proliferating endothelial cells is a better parameter for ongoing angiogenesis than microvessel density in primary melanoma. In addition, in other tumor types, such as hepatocellular carcinoma, colon carcinoma and renal cell carcinoma, this parameter for active angiogenesis could be correlated to tumor progression or survival ${ }^{34}, 35$. Since patients diagnosed with a Breslow depth smaller than $0.75 \mathrm{~mm}$ still can have metastasis, parameters that correlate to tumor progression, additional to the measurement of Breslow depth, should be investigated at time of diagnosis. Therefore, it should be considered to use the evaluation of the fraction of proliferating endothelial cells in the diagnosis of cancer stages and in the application and evaluation of anti-angiogenesis strategies.

Next to angiogenesis, several other types of tumor vascularisation exist. In this thesis we focussed on the presence of vasculogenic mimicry in solid tumors. In this process dedifferentiated tumor cells provide themselves of a secondary circulation system of vasculogenic structures lined by tumor cells, independently from angiogenesis ${ }^{36}$.

As already mentioned in the introduction, there are three different phenomena that are described to represent vasculogenic mimicry: PAS patterns, blood lakes and mosaic vessels. It can be postulated that these three forms have different origins of development. First, the formation of PAS patterns was thought to be a reorganization of tumor cells and an enhanced expression of extracellular matrix molecules that could transport plasma. Next, with the discovery of blood lakes, it was thought that due to high pressure of blood, tumor cells are forced into a tube-like structure. The term 'blood lake' suggests only the presence of erythrocytes in a certain region of the tumor. In chapter chapter 5, however, we describe the detection of blood flow in these structures. Therefore a more suitable term for these structures would be blood rivers. The development of mosaic vessels, partly lined by endothelial cells and partly by tumor cells, could be due to a deficit of endothelial cells during the formation of blood vessels. Tumor cells take over the place of endothelial cells since they have a higher proliferation rate. Aggressive tumor cells have been described with highly migratory characteristics. In addition, it was postulated that mosaic vessels could be a precondition of vasculogenic structures that are lined only by tumor cells.

In discussions about vasculogenic mimicry, the question arises frequently why the tumor forms these vessel-like structures. It is thought that due to the high 
proliferation rate of these aggressive tumors, there is an urgent need for more nutrients and oxygen. Vasculogenic channels are formed due to the lack of sufficient regular blood vessels. With the addition of these extra vasculogenic structures that also transport blood, the tumor is able to continue its exuberant growth. However, there is a report on the development of vasculogenic mimicry before the onset of angiogenesis ${ }^{37}$. In this study, several mice with a B16 melanoma xenograft were sacrificed every day form day 11 to day 22 after tumor inoculation. It was resported that a positive correlation exists between the amount of blood vessels and the size of the tumor, while the amount of vasculogenic mimicry was inversely correlated. It was suggested that during tumor expansion vasculogenic mimicry channels are replaced by endotheliumdependent vessels.

Important to mention is that not only tumor cells but also other cell types have been described to 'mimic' endothelial cells. The same phenomenon of pseudovasculogenesis was observed in human placenta where cytotrophoblast cells replace resident maternal endothelium, creating a hybrid uterine vasculature ${ }^{38}$. Furthermore, there was a close relationship found between tumor cells and endothelial cells in B-cell lymphomas where lymphoma specific genetic aberrations were also found in microvascular endothelial cells ${ }^{39}$. A recent paper described the same behaviour of macrophages, isolated from patients with multiple myeloma, who were able to express endothelial specific markers after stimulation of VEGF and bFGF and to form capillarylike structures in vitro. In addition, in bone marrow biopsies of patients with multiple myeloma, they detected mosaic vessels lined by both endothelial cells and macrophages ${ }^{40}$. These new findings highly suggest the existence of vasculogenic mimicry in both pathological and physiological conditions. However, the evidence that next to tumor cells, also other cell types can mimic endothelial cells, makes targeting strategies to inhibit tumor growth even more difficult.

Independent of these structures being functional or not, it is important to note that the presence of vasculogenic mimicry in different tumor types was a significant factor to predict survival ${ }^{41}$. By H\&E and PAS staining this marker of tumor aggressiveness is easy to assess and should be included as an additional parameter in the diagnosis of patients. We are the first to describe the presence of tumor cell plasticity in the tumor type Ewing sarcoma (chapter 5). Moreover, the presence of tumor cell plasticity was associated with poor survival and explains the aggressive character of this tumor type, just as in melanomas. In contrast, several parameters related to angiogenesis could not predict survival. These results demonstrate the important role of vasculogenic mimicry in the aggressiveness of a tumor and the need to implicate it in general patient diagnosis.

Microarray analysis, comparing highly invasive and poorly invasive melanoma cells, revealed tumor cells with a dedifferentiated phenotype with endothelial specific genes ${ }^{36}$. Since than, research groups, challenged by the existence of vasculogenic mimicry, have been mainly focussing on individual genes that are involved in vasculogenic mimicry by means of siRNA techniques or by techniques 
making use of blocking antibodies. Importantly, it is not one gene that drives the whole process of vasculogenic mimicry. This whole process could be considered as an genetic aberration or a mutation in tumor cells that induces directly or indirectly changes in expression of other genes. Therefore, it is important to unravel the mechanism or pathways that are involved in tumor cell dedifferentiation. Previous research showed us that the microenvironment is important in the induction of vasculogenic mimicry. Normal epidermal melanocytes, exposed to an extracellular matrix conditioned by metastatic cutaneous melanoma, were demonstrated to reprogram to a genotype with specific genes that were associated with the ability to form vasculogenic-like networks 42. In chapter 6 , we describe another component of the microenvironment, the oxygen level, that has an stimulatory role in the process of vasculogenic mimicry. Hypoxic conditions could induce the formation of vasculogenic structures in vitro. Furthermore, downregulation of one of the most important hypoxia transcription factors, hypoxia inducible factor- $1 \alpha$ (HIF- $1 \alpha)$, could inhibit the matrix-invasiveness of aggressive cell lines and downregulated the expression of several genes that are related to vasculogenic mimicry. The finding that hypoxia is involved in vasculogenic mimicry is important because also angiogenesis is stimulated by these conditions. This implicates that both vascularisation types could be targeted by a similar strategy that inhibits hypoxia.

The induction of dedifferentiation of tumor cells by hypoxia has been reported before. In neuroblastoma, ductal breast carcinoma and prostate carcinoma, it has been reported that hypoxia alters the gene expression patterns of tumor cells into an stem cell-like phenotype ${ }^{43-45}$. These findings strengthen the idea that hypoxia is an important promoter of tumor dedifferentiation and development.

Hypoxia is a main subject in the field of cancer therapy for years. Hypoxic tumors are more aggressive and resistant to anti-neoplastic treatments such as radiotherapy and chemotherapy ${ }^{46}$. Moreover, hypoxia is a key player in the 'angiogenic switch' during tumor development. The downregulation of HIF-1 $\alpha$, one of the main regulators of the molecular mechanisms involved in response to hypoxia, could have an immediate effect on the transcription of HIF-1 $\alpha$ downstream genes that are involved in a conversion of a tumor cell in a more aggressive phenotype. This could inhibit tumor growth and is thus a potential new target in cancer treatment ${ }^{47}$. Which component should be the best target for vasculogenic mimicry, is a challenging new research field that needs further investigation. Nevertheless, gene expression profiling of vasculogenic mimicry positive versus vasculogenic mimicry negative cell lines, revealed the importance of the gene phosphoinositide- 3 kinase (PI3K) in the process of tumor cell plasticity ${ }^{48}$. Components that target the PI3K/Akt pathway are therefore the first potential targets to use for anti-vasculogenic mimicry. However, since these antihypoxia strategy should target both angiogenesis, vasculogenic mimicry and increase radiosensitization, a multitarget therapy of different HIF-1 $\alpha$ inhibitors could be an advantage in the clinic. 
While most research on hypoxia has been focussed on HIF-1 $\alpha$ expression in tumor cells, there is evidence that HIF- $2 \alpha$ is not only expressed in endothelial cells but is also upregulated in various tumor types ${ }^{49}$. The mechanisms of protein stabilization of HIF- $1 \alpha$ and HIF- $2 \alpha$ and their mode of transcriptional activation are highly similar, but differences are continued to be discovered. It has been demonstrated that HIF- $2 \alpha$ can promote an aggressive phenotype in neuroblastomas ${ }^{50}$. Under hypoxia, HIF- $1 \alpha$ was transiently stabilised and executed acute responses, while HIF-2 $\alpha$ accumulated and mediated a prolonged hypoxic gene activation. HIF- $2 \alpha$ was even the dominant active HIF at physiological oxygen concentrations $\left(5 \%\right.$ of $\left.\mathrm{O}_{2}\right)$ and induced hypoxiadriven genes that known to be regulated at hypoxic conditions $\left(1 \%\right.$ of $\left.\mathrm{O}_{2}\right)$ by HIF- $1 \alpha$. Furthermore, there are genes reported to be target genes of HIF-2 $\alpha$. MT1-MMP, erythropoietin, PAI-1, VEGF, TGF- $\alpha$ and lysyl oxidase have been reported as predominant targets of HIF- $2 \alpha{ }^{51-56}$. Oct-4, a transcription factor involved in maintaining pluripotentiality of embryonic stem cells and thus also in regulating differentiation, seems to be regulated exclusively by HIF- $2 \alpha{ }^{57}$. Le Bras et al. reported the regulation of VE-cadherin by HIF-2 $\alpha$ and also suggested that HIF- $2 \alpha$, since it is regulating several endothelial markers, is important in inducing endothelial specificity of gene expression and could be a mediator of vasculogenic mimicry. It is clear that due to the recent findings, the role of HIF-2 $\alpha$ in tumor cell plasticity should be investigated.

Combining therapies directed against different mechanisms or targets is currently a growing concept. In chapter 2, we suggested already that, to be able to target all different kinds of tumor vascularisations, a multimodal anti-vascular approach is needed. But next to a variety of vessel structures that contribute to tumor progression and resistance in radiotherapy due to hypoxia, also the development of chemoresistance is a persistent problem. In general, taken into consideration that a tumor, by virtue of its genetic drift and selection of mutated daughter cells, has an evolutionary drive that results in counteracting new targeting strategies, a multimodal cocktail of treatments could be an advantage in the clinic. However, for each tumor type such a multimodal therapy should be developed. This means a good follow up of all therapies by suitable surrogate markers and imaging techniques. The ultimate goal in cancer therapies will be to stay ahead of the rapid evolutionary genetic adaptations of the tumor cells by continuously evaluating and adapting the cocktail of treatment. In conclusion, the important question in cancer treatment may not be "how to stop the tumor cells from growing" but should be extended with "how to beat the "natural selection' of tumor cells". 


\section{References}

1. Dvorak, H. F. Tumors: wounds that do not heal. Similarities between tumor stroma generation and wound healing. N Engl J Med 315, 1650-9 (1986).

2. Dirkx, A. E. et al. Tumor angiogenesis modulates leukocyte-vessel wall interactions in vivo by reducing endothelial adhesion molecule expression. Cancer Res 63, 2322-9 (2003).

3. Johnson, J. P. Cell adhesion molecules in the development and progression of malignant melanoma. Cancer Metastasis Rev 18, 345-57 (1999).

4. Haritopoulos, K. N. et al. ICAM-1 and beta(3) integrin immunoexpression in malignant melanoma cells: can they be used as additional predictors? Apmis 111, 421-9 (2003).

5. Marvin, M. R., Southall, J. C., Trokhan, S., DeRosa, C. \& Chabot, J. Liver metastases are enhanced in homozygous deletionally mutant ICAM-1 or LFA-1 mice. J Surg Res 80, 143-8 (1998).

6. Maeda, K., Kai, K., Hayashi, T., Hasegawa, K. \& Matsumura, T. Intercellular adhesion molecule-1 (ICAM-1) and lymphocyte function-associated antigen-1 (LFA-1) contribute to the elimination of equine herpesvirus type 1 (EHV-1) from the lungs of intranasally infected BALB/c mice. J Comp Pathol 130, 162-70 (2004).

7. Fujihara, T. et al. Decrease in ICAM-1 expression on gastric cancer cells is correlated with lymph node metastasis. Gastric Cancer 2, 221-225 (1999).

8. Ogawa, Y. et al. Expression of intercellular adhesion molecule-1 in invasive breast cancer reflects low growth potential, negative lymph node involvement, and good prognosis. Clin Cancer Res 4, 31-6 (1998).

9. Woo, E. Y. et al. Regulatory CD4(+)CD25(+) T cells in tumors from patients with early-stage non-small cell lung cancer and late-stage ovarian cancer. Cancer Res 61, 4766-72 (2001).

10. Wolf, D. et al. The expression of the regulatory $\mathrm{T}$ cell-specific forkhead box transcription factor FoxP3 is associated with poor prognosis in ovarian cancer. Clin Cancer Res 11, 8326-31 (2005).

11. Sasada, T., Kimura, M., Yoshida, Y., Kanai, M. \& Takabayashi, A. CD4+CD25+ regulatory T cells in patients with gastrointestinal malignancies: possible involvement of regulatory $\mathrm{T}$ cells in disease progression. Cancer 98, 1089-99 (2003).

12. Alvaro, T. et al. Outcome in Hodgkin's lymphoma can be predicted from the presence of accompanying cytotoxic and regulatory T cells. Clin Cancer Res 11, 1467-73 (2005).

13. Hiraoka, N., Onozato, K., Kosuge, T. \& Hirohashi, S. Prevalence of FOXP3+ regulatory T cells increases during the progression of pancreatic ductal adenocarcinoma and its premalignant lesions. Clin Cancer Res 12, 5423-34 (2006).

14. Bates, G. J. et al. Quantification of regulatory T cells enables the identification of high-risk breast cancer patients and those at risk of late relapse. J Clin Oncol 24, 5373-80 (2006).

15. Rosenberg, S. A. et al. Observations on the systemic administration of autologous lymphokine-activated killer cells and recombinant interleukin-2 to patients with metastatic cancer. N Engl J Med 313, 1485-92 (1985).

16. Dutcher, J. P. et al. A phase II study of interleukin-2 and lymphokine-activated killer cells in patients with metastatic malignant melanoma. J Clin Oncol 7, 477-85 (1989).

17. Rosenberg, S. A. et al. Treatment of 283 consecutive patients with metastatic melanoma or renal cell cancer using high-dose bolus interleukin 2. Jama 271, 907-13 (1994).

18. Legha, S. S., Gianan, M. A., Plager, C., Eton, O. E. \& Papadopoulous, N. E. Evaluation of interleukin-2 administered by continuous infusion in patients with metastatic melanoma. Cancer 77, 89-96 (1996).

19. Rosenberg, S. A., Yang, J. C. \& Restifo, N. P. Cancer immunotherapy: moving beyond current vaccines. Nat Med 10, 909-15 (2004).

20. Dudley, M. E. et al. Cancer regression and autoimmunity in patients after clonal repopulation with antitumor lymphocytes. Science 298, 850-4 (2002).

21. Morgan, R. A. et al. Cancer regression in patients after transfer of genetically engineered lymphocytes. Science 314, 126-9 (2006). 
22. Qin, Z. et al. B cells inhibit induction of T cell-dependent tumor immunity. Nat Med 4, 627-30 (1998).

23. Perricone, M. A. et al. Enhanced efficacy of melanoma vaccines in the absence of B lymphocytes. J Immunother 27, 273-81 (2004).

24. Aklilu, M. et al. Depletion of normal B cells with rituximab as an adjunct to IL-2 therapy for renal cell carcinoma and melanoma. Ann Oncol 15, 1109-14 (2004).

25. Neelapu, S. S. et al. Vaccine-induced tumor-specific immunity despite severe B-cell depletion in mantle cell lymphoma. Nat Med 11, 986-91 (2005).

26. Martinez-Escribano, J. A. et al. Changes in the number of CD80(+), CD86(+), and CD28(+) peripheral blood lymphocytes have prognostic value in melanoma patients. Hum Immunol 64, 796-801 (2003).

27. Bingle, L., Brown, N. J. \& Lewis, C. E. The role of tumour-associated macrophages in tumour progression: implications for new anticancer therapies. J Pathol 196, 254-65 (2002).

28. Lewis, C. E. \& Pollard, J. W. Distinct role of macrophages in different tumor microenvironments. Cancer Res 66, 605-12 (2006).

29. Kono, K. et al. Hydrogen peroxide secreted by tumor-derived macrophages down-modulates signal-transducing zeta molecules and inhibits tumor-specific $\mathrm{T}$ cell-and natural killer cellmediated cytotoxicity. Eur J Immunol 26, 1308-13 (1996).

30. van de Winkel, J. G., Bast, B. \& de Gast, G. C. Immunotherapeutic potential of bispecific antibodies. Immunol Today 18, 562-4 (1997).

31. Rosenberg, S. A. et al. Experience with the use of high-dose interleukin-2 in the treatment of 652 cancer patients. Ann Surg 210, 474-84; discussion 484-5 (1989).

32. Ghosh, A. K., Dazzi, H., Thatcher, N. \& Moore, M. Lack of correlation between peripheral blood lymphokine-activated killer (LAK) cell function and clinical response in patients with advanced malignant melanoma receiving recombinant interleukin 2. Int J Cancer 43, 410-4 (1989).

33. Vermeulen, P. B. et al. Second international consensus on the methodology and criteria of evaluation of angiogenesis quantification in solid human tumours. Eur J Cancer 38, 1564-79 (2002).

34. Imura, S., Miyake, H., Izumi, K., Tashiro, S. \& Uehara, H. Correlation of vascular endothelial cell proliferation with microvessel density and expression of vascular endothelial growth factor and basic fibroblast growth factor in hepatocellular carcinoma. J Med Invest 51, 202-9 (2004).

35. Baeten, C. I., Castermans, K., Hillen, H. F. \& Griffioen, A. W. Proliferating endothelial cells and leukocyte infiltration as prognostic markers in colorectal cancer. Clin Gastroenterol Hepatol 4, 1351-7 (2006).

36. Maniotis, A. J. et al. Vascular channel formation by human melanoma cells in vivo and in vitro: vasculogenic mimicry. Am J Pathol 155, 739-52 (1999).

37. Zhang, S. et al. Microcirculation patterns in different stages of melanoma growth. Oncol Rep 15, 15-20 (2006).

38. Red-Horse, K. et al. Trophoblast differentiation during embryo implantation and formation of the maternal-fetal interface. J Clin Invest 114, 744-54 (2004).

39. Streubel, B. et al. Lymphoma-specific genetic aberrations in microvascular endothelial cells in B-cell lymphomas. N Engl J Med 351, 250-9 (2004).

40. Scavelli, C. et al. Vasculogenic mimicry by bone marrow macrophages in patients with multiple myeloma. Oncogene (2007).

41. Folberg, R. \& Maniotis, A. J. Vasculogenic mimicry. Apmis 112, 508-25 (2004).

42. Seftor, E. A. et al. Epigenetic transdifferentiation of normal melanocytes by a metastatic melanoma microenvironment. Cancer Res 65, 10164-9 (2005).

43. Jogi, A. et al. Hypoxia alters gene expression in human neuroblastoma cells toward an immature and neural crest-like phenotype. Proc Natl Acad Sci U S A 99, 7021-6 (2002).

44. Helczynska, K. et al. Hypoxia promotes a dedifferentiated phenotype in ductal breast carcinoma in situ. Cancer Res 63, 1441-4 (2003).

45. Ghafar, M. A. et al. Acute hypoxia increases the aggressive characteristics and survival properties of prostate cancer cells. Prostate 54, 58-67 (2003). 
46. Unruh, A. et al. The hypoxia-inducible factor-1 alpha is a negative factor for tumor therapy. Oncogene 22, 3213-20 (2003).

47. Semenza, G. L. Targeting HIF-1 for cancer therapy. Nat Rev Cancer 3, 721-32 (2003).

48. Hendrix, M. J., Seftor, E. A., Hess, A. R. \& Seftor, R. E. Vasculogenic mimicry and tumour-cell plasticity: lessons from melanoma. Nat Rev Cancer 3, 411-21 (2003).

49. Talks, K. L. et al. The expression and distribution of the hypoxia-inducible factors HIF-1alpha and HIF-2alpha in normal human tissues, cancers, and tumor-associated macrophages. Am J Pathol 157, 411-21 (2000).

50. Holmquist-Mengelbier, L. et al. Recruitment of HIF-1alpha and HIF-2alpha to common target genes is differentially regulated in neuroblastoma: HIF-2alpha promotes an aggressive phenotype. Cancer Cell 10, 413-23 (2006).

51. Sato, M. et al. The PAI-1 gene as a direct target of endothelial PAS domain protein-1 in adenocarcinoma A549 cells. Am J Respir Cell Mol Biol 31, 209-15 (2004).

52. Warnecke, C. et al. Differentiating the functional role of hypoxia-inducible factor (HIF)-1alpha and HIF-2alpha (EPAS-1) by the use of RNA interference: erythropoietin is a HIF-2alpha target gene in Hep3B and Kelly cells. Faseb J 18, 1462-4 (2004).

53. Petrella, B. L., Lohi, J. \& Brinckerhoff, C. E. Identification of membrane type-1 matrix metalloproteinase as a target of hypoxia-inducible factor-2 alpha in von Hippel-Lindau renal cell carcinoma. Oncogene 24, 1043-52 (2005).

54. Hu, C. J., Wang, L. Y., Chodosh, L. A., Keith, B. \& Simon, M. C. Differential roles of hypoxiainducible factor 1alpha (HIF-1alpha) and HIF-2alpha in hypoxic gene regulation. Mol Cell Biol 23, 9361-74 (2003).

55. Gunaratnam, L. et al. Hypoxia inducible factor activates the transforming growth factoralpha/epidermal growth factor receptor growth stimulatory pathway in VHL(-/-) renal cell carcinoma cells. J Biol Chem 278, 44966-74 (2003).

56. Wang, V., Davis, D. A., Haque, M., Huang, L. E. \& Yarchoan, R. Differential gene upregulation by hypoxia-inducible factor-1alpha and hypoxia-inducible factor-2alpha in HEK293T cells. Cancer Res 65, 3299-306 (2005).

57. Covello, K. L. et al. HIF-2alpha regulates Oct-4: effects of hypoxia on stem cell function, embryonic development, and tumor growth. Genes Dev 20, 557-70 (2006). 



\section{Summary}

Tumor growth is mainly restricted due to the diffusion limit of oxygen and nutrients. In order to grow beyond a size of $1-2 \mathrm{~mm}^{3}$, the tumour switches to an angiogenic phenotype and attracts blood vessels from the surrounding stroma. Angiogenesis, the growth of new capillary vessels out of pre-existing ones, is regulated by a variety of pro- and anti-angiogenic factors, and is a prerequisite for further outgrowth of the tumor and for metastasis formation. With the discovery of the first angiogenic growth factors, 30 years ago, researchers postulated optimistically that the inhibition of angiogenesis in tumors could be a challenging and promising strategy in treatment of cancer. However, clinical trials did show limited results in comparison to the initial mouse studies. In 1999, the process of vasculogenic mimicry, in which tumor cells of aggressive tumors dedifferentiate into an endothelial phenotype and make tube-like structures, was discovered. This mechanism provides tumour cells with a secondary circulation system of vasculogenic structures lined by tumour cells, independently of angiogenesis, and contributes to the aggressiveness of a tumor. The presence of vasculogenic mimicry in tumor samples of patients has been correlated to poor survival in several tumor types. The recent findings on the 'plastic' endothelial-like phenotype of melanoma and other tumour cells confused the field of cancer biology. The presence of vasculogenic mimicry could (partly) explain the limited success of anti-angiogenesis strategies, since these treatments are targeting tumor specific endothelial cells and not tumor cells. Little is known about the role of this secondary circulation system in tumors. In this thesis, the role of vasculogenic mimicry in tumor biology was investigated.

In chapter 2, we described different vascularisation types that are present in solid tumors. It is clear now that tumors, next to sprouting angiogenesis, have different forms of tumor vasculature that stimulate tumor progression and metastasis. Processes including intussusceptive angiogenesis, the recruitment of endothelial progenitor cells, vessel co-option, vasculogenic mimicry and lymphangiogenesis, are also important for tumor outgrowth. We summarizes the different mechanisms of tumour vascularisation, the molecular players that are involved and their relevance in clinical practice. While most research has been done on sprouting angiogenesis, the exact mechanisms that are involved in other types of vascularisation are less known. Nevertheless, these mechanisms contribute to tumor blood circulation and are important targets for therapy. Finally, we anticipate that combination of a multimodal anti-vascular approach, representing anti-angiogenesis, anti-lymphangiogenesis and vasculogenic mimicry targeting, together with chemotherapy may become the best possible strategy in the fight against cancer.

To investigate the relationship between vasculogenic mimicry, angiogenesis and the immune system in tumors, 58 patients with a primary melanoma were selected. By 
means of immunohistochemistry on tumor samples we got insight in the relationship between these 3 processes and their contribution to tumor progression. In chapter 3, we described a new technique to quantify the amount of active angiogenesis. To accomplish this we used a immunohistochemical double staining, in which we stained both the blood vessels (with CD31/CD34) and the proliferating cells (with Ki-67 antibody) in a tumor. We found that the amount of proliferating endothelial cells was a better parameter for patient survival than quantifying only the amount of blood vessels.

In chapter 4, we analysed the role of immune infiltration ( $\mathrm{T}$ cells, cytotoxic $\mathrm{T}$ cells, B cells, macrophages, polymorphonuclear cells, regulatory $\mathrm{T}$ cells and activation status of lymphocytes) in tumor progression and the correlation with the amount of active angiogenesis and the presence of vasculogenic mimicry. Both the amount of immune infiltration and the presence of vasculogenic mimicry were correlated with the aggressiveness of the tumor. In addition, the amount of activated lymphocytes (CD69) is an important parameter to analyse the functionality of the immune reaction of the tumor.

In chapter 5, we described the presence of vasculogenic mimicry in Ewing sarcoma. This tumor is a rare, but aggressive type of cancer characterised by the large numbers of blood lakes (erythrocytes surrounded by tumor cells). Although these tumors are characterised with high expression of VEGF, we detected a low amount of blood vessels. This could be explained by the presence of vasculogenic mimicry which turned out to be a good parameter to predict patient survival. Ewing sarcoma cell lines were able to form vasculogenic structures in vitro and showed the specific gene expression profile for vasculogenic mimicry positive cells. We analysed the role of VEGF in the stimulation of vasculogenic mimicry, but unfortunately, we could not detect an influence of VEGF on this process. We did find expression of HIF-1 $\alpha$, a marker for hypoxia, around the observed blood lakes but not around the regular tumor blood vessels. In chapter 6 , we further investigated the role of hypoxia and HIF-1 $\alpha$ in vasculogenic mimicry. Microarray analysis comparing aggressive (vasculogenic mimicry positive) cell lines with non-aggressive (vasculogenic mimicry negative) cell lines, revealed a higher expression of several HIF-1 $\alpha$ related genes in the aggressive cell lines. Moreover, hypoxic conditions stimulated the formation of vasculogenic structures in vitro and the HIF-1 $\alpha$ protein expression was higher in the aggressive cell lines than in non-aggressive cell lines. Downregulation of HIF-1 $\alpha$ resulted in the downregulation of HIF-1 $\alpha$ downstream genes. Importantly, also the expression of genes related to vasculogenic mimicry were downregulated and a less matrix-invasive phenotype was observed. We concluded that there is a role of hypoxia and HIF-1 $\alpha$ in inducing vasculogenic mimicry and that this knowledge is important to develop new anti-vasculogenic mimicry strategies. 
In this thesis, we investigated the role of vasculogenic mimicry in tumor progression. Vasculogenic mimicry is clearly contributing to the aggressiveness of the tumor. These vasculogenic channels form a functional secondary circulation system that is stimulated by hypoxic conditions. This new knowledge on vasculogenic mimicry can contribute to the development of new therapeutic strategies for several types of aggressive tumors. 



\section{Samenvatting}

De groei van tumoren wordt in sterke mate bepaald door de toevoer van zuurstof en nutriënten. Als een tumor groter wordt dan $2 \mathrm{~mm}$ in diameter, gaat deze groeifactoren uitscheiden, waardoor bloedvaten die rond de tumor gelegen zijn, worden gestimuleerd in groei. De vorming van nieuwe vaten uit reeds bestaande, wordt angiogenese genoemd. Angiogenese is niet alleen noodzakelijk voor de groei van tumoren maar maakt ook metastasering van de tumor mogelijk. Zo'n 30 jaar geleden, bij de ontdekking van de eerste angiogene groeifactoren, werd er gepostuleerd dat de inhibitie van angiogenese in tumoren een belangrijke therapeutische uitdaging of zelfs de oplossing zou zijn voor de behandeling van kanker. Naast de aanleg van reguliere bloedvaten, werd in 1999 ontdekt dat ook agressieve tumorcellen in staat zijn om zelf bloedvat-achtige structuren te vormen, een proces dat vasculaire mimicry (nabootsing) wordt genoemd. Dit zorgde voor heel wat ophef in het kankeronderzoek. Omdat deze vaatstructuren kunnen bijdragen aan de bloedcirculatie in de tumor, onafhankelijk van het proces van angiogenese, zijn zij mede verantwoordelijk voor de agressiviteit van de tumor. De aanwezigheid van vasculaire mimicry is daarom een indicatie voor een slechte prognose voor de patiënt. Bovendien bemoeilijkt het proces van vasculaire mimicry het onderzoek aan angiogenese en kan dit een verklaring zijn voor het beperkte succes van de recent ontwikkelde anti-angiogenese therapieën. Deze therapieën zijn immers gebaseerd op het verwoesten van endotheelcellen en laten de tumorcellen ongemoeid. Omdat vasculaire mimicry pas recent ontdekt is, weten we heel weinig over de rol van dit secundaire circulatie systeem in tumoren. In dit proefschrift werd de rol van vasculaire mimicry in de biologie van tumoren bestudeerd.

In hoofdstuk 2 werden de verschillende vaatstructuren in een tumor beschreven. Naast reguliere tumorangiogenese zijn er ook andere vaatstructuren die kunnen bijdragen aan de progressie van de tumor. Intussusceptieve angiogenese, bloedvat co-optie, het rekruteren van endotheelstamcellen, vasculaire mimicry en de aanleg van lymfevaten zijn andere processen die een rol spelen in een tumorgroei. We gaven een overzicht van de verschillende tumorvaatstructuren, de moleculaire mechanismen en de klinische relevantie. Veel onderzoek werd reeds gedaan aan reguliere tumorangiogenese. Mechanismen van de aanleg van andere vaatstructuren zijn minder bekend. Toch dragen deze bij aan de bloedcirculatie in de tumor en vormen daarom targets voor therapie. Een multi-modale antivasculaire strategie zou een goede aanpak kunnen zijn om tumorgroei en metastasering te remmen.

Voor het bestuderen van de relatie tussen vasculaire mimicry, angiogenese en de immunologische reactie in een tumor, werden 58 patiënten geselecteerd met een primair melanoom. Aan de hand van immunohistochemische kleuringen op 
tumormateriaal kon er inzicht worden verkregen in de relatie tussen deze drie processen en hun rol in tumorprogressie. In hoofdstuk 3 werd een nieuwe techniek ontwikkeld om de hoeveelheid actieve angiogenese in een tumor te kunnen kwantificeren. Hiervoor werd een immunohistochemische dubbelkleuring uitgevoerd, waarbij zowel de bloedvaten (met CD31/CD34 antilichaam) als de prolifererende cellen (met Ki-67 antilichaam) in een tumor werden aangekleurd. In primaire melanomen vonden we dat de hoeveelheid prolifererende endotheelcellen, of actieve angiogenese, een betere parameter is dan enkel het aantal bloedvaten voor het voorspellen van overleving van patiënten met een primair melanoom.

In hoofdstuk 4 analyseerden we de rol van het ontstekingsinfiltraat ( $T$ cellen, cytotoxische $\mathrm{T}$ cellen, $\mathrm{B}$ cellen, macrofagen, polymorfonucleaire cellen, regulatoire $\mathrm{T}$ cellen en geactiveerde lymfocyten) in tumorprogressie en de correlatie met de hoeveelheid actieve angiogenese en de aanwezigheid van vasculaire mimicry. Zowel vasculaire mimicry als de hoeveelheid infiltraat bleken merkers van agressiviteit van de tumor. Bovendien geeft de hoeveelheid geactiveerde lymphocyten ons een duidelijker beeld over de functionaliteit van de immuunreactie in de tumor.

In hoofdstuk 5 beschreven we de aanwezigheid van vasculaire mimicry in het tumortype Ewing sarcoma. Ewing sarcoma is een zeldzame, maar agressieve tumor die gekenmerkt wordt door een grote hoeveelheid (meren van) rode bloedcellen die gelegen zijn tussen tumorcellen. Ondanks dat deze tumoren worden gekenmerkt door hoge expressie van VEGF, vonden we slechts een lage hoeveelheid vaten in de tumoren. Dit bleek te berusten op de aanwezigheid van vasculaire mimicry en was in dit tumortype ook een parameter voor het voorspellen van overleving van een patiënt. Ook in vitro maakten Ewing sarcoma cellijnen vasculaire structuren en ze vertoonden het specifieke genexpressieprofiel van vasculaire mimicry. We onderzochten de rol van VEGF in de stimulatie van het proces van vasculaire mimicry. VEGF bleek geen invloed te hebben op het stimuleren van dit proces. We vonden wel expressie van HIF$1 \alpha$, een merker voor hypoxie, rond de geobserveerde meren van rode bloedcellen en niet rond de standaard bloedvaten. In hoofdstuk 6 werd de rol van hypoxie en HIF-1 $\alpha$ in vasculaire mimicry verder onderzocht. Uit de analyse van een microarray experiment, waarbij we agressieve (vasculaire mimicry positieve) cellijnen ten opzichte van niet-agressieve (vasculaire mimicry negatieve) cellijnen vergelijken, was er een hogere expressie van meerdere HIF-1 $\alpha$ gerelateerde genen in de agressieve cellijnen. Daarenboven stimuleerden hypoxische condities de vorming van vasculaire structuren in vitro en de eiwitexpressie van HIF-1 $\alpha$ was in de agressieve cellijnen ook hoger dan in niet-agressieve cellijnen. Wanneer de expressie van HIF-1 $\alpha$ werd onderdrukt, bleek niet enkel de expressie van HIF-1 $\alpha$ gerelateerde genen lager te zijn, maar ook de expressie vasculaire mimicry gerelateerde genen bleek negatief beïnvloed te worden. Uit deze resultaten kunnen we besluiten dat er een mogelijke rol is van hypoxie en HIF-1 $\alpha$ in de vorming van vasculaire mimicry en dat deze kennis kan gebruikt worden voor het ontwikkelen van anti-vasculaire mimicry strategieën. 
In dit proefschrift bestudeerden we de rol van vasculaire mimicry in tumorprogressie. Vasculaire mimicry draagt duidelijk bij tot de agressiviteit van een tumor. Deze tumorvaatstructuren zijn een functioneel secundair circulatiesysteem dat gestimuleerd wordt door hypoxische omstandigheden. Deze nieuwe kennis over het mechanisme van vasculaire mimicry kan bijdragen aan het ontwikkelen van nieuwe therapeutische mogelijkheden voor verschillende types van agressieve tumoren. 

|Dankwoord

\section{Dankwoord}

“...het zijn de invloeden van zon, regen en wind die verklaren waarom dit beukennootje juist tot deze boom moest uitgroeien..."

(Thomas Rosenboom, Hoog aan de wind)

Mijn droom om een steentje bij te dragen aan het kankeronderzoek werd reeds geboren in 1995, toen een superenthousiaste lerares biologie mij de eerste beginselen van de genetica uit de doeken deed. En hier sta ik nu, bijna 13 jaar later... De laatste 4 jaar van mijn promotieonderzoek waren intense jaren die me helemaal hebben ondergedompeld in de wereld van het onderzoek. Hierbij heb ik veel hulp en steun gehad van collega's, vrienden en familie.

Professor Griffioen, Arjan, je wist me van in het begin te boeien met je verhalen over (grote) wetenschap(pers), maar ook met je kennis over algemene weetjes zoals wijn, munten, Amerika, orgels, muziek en actualiteit. Ook van je kritische verbeteringen van mijn manuscripten heb ik veel geleerd! We hebben "samen gestreden in de oorlog tegen kanker" en ik ben heel blij dat we samen dit mooie boekje kunnen afleveren.

Professor Daemen, beste Mat, jou wil ik bedanken voor de mogelijkheid om mijn promotieonderzoek op jouw afdeling uit te voeren en voor je luisterend oor tijdens mijn AIO-dipjes.

Veerle, Debby en Karolien, wij vormden een goed team zo drie jaar samen op het hoeklab. Ik ben heel blij dat ik met alle onderwerpen, werk of prive, bij jullie telkens terecht kon. Bedankt voor de gezellig tijd met veel humor en steun. Veerle, voor bioinformatica en moleculaire info kon altijd bij jou terecht voor een eenvoudige, praktische uitleg. Je hebt me ook Limburg leren ontdekken en nadien van leren houden, bedankt voor de "inburgeringcursus" de eerste jaren. Bovendien toon je, als eerste, in onze groep, dat moederschap en AIOschap te combineren is. Veel succes met het afmaken van je boekje!! Debby, ik denk dat iedere AIO wel opkijkt naar jou doorzettingsvermogen en kennis, je bent een inspiratiebron voor mij geweest. Je impulsieve uitspraken zorgden af en toe voor hilariteit, maar ik zou niet willen dat je dat aan jezelf verandert!! Bedankt voor al je promotietips. Karolien, labbench-maatje, mede-immunoloog, we zijn met de jaren meer en meer naar mekaar toegegroeid (en dan bedoel ik niet dat ik meer en meer jouw bench inpalmde tijdens mijn experimenten, $(-)$ ). Met jou had ik regelmatig inspirerende discussies over de verschillende subsets van leukocyten en cytokines die me achteraf soms nog meer verwarden. Het was erg fijn om samen de laatste loodjes te dragen aan het einde van onze promotie. Veel succes in Luik, je zal daar goed kunnen uitblinken in je kunnen, daar ben ik van overtuigd. Bedankt dat je me wil bijstaan als paranimf!! 
Vivian, ook jij maakte deel uit van de gezelligheid op het hoeklab. Onze gezellige koffie-dates zal ik niet snel vergeten!! Veel succes met het afschrijven van je boekje. Toni, me has enseñado que los 'labmidgets' son los responsables para lo que falla en los experimentos. Aunque operan por la noche (cuando no estamos), duermo mejor sabiendo que no es por mi culpa :-). Muchas gracias por tu sentido de humor que me hayas transmitido durante los experimentos y por mantener el animo en el laboratorio. Suerte con tu futura carrera en la ciencia. Ricardo, de verhalen over je gistbereidingen zullen nog lang op de afdeling rondgaan. Je bent nu reeds een tijdje aan je nieuwe "recept" bezig in Nijmegen, veel succes met je verdere leven in het oosten. Coen, bedankt voor me in te werken in de immunohistochemie, je was er altijd met een nieuwe oplossing als een kleuring het weer niet wilde doen. Veel succes met je verder loopbaan in het westen.

Daarnaast wil ik natuurlijk ook de analisten bedanken die ik gedurende mijn vier jaar als gezellige collega's op het lab heb gehad. Petra, bedankt voor je grote inzet in het hypoxie onderzoek en andere projecten die niet gepubliceerd zijn. Loes, jij was altijd bereid om kleine, onverwachte klusjes te doen, maar vooral onze leuke gesprekken zullen me bij blijven. Edith, met je meer-dan-30 jaar-ervaring heb je me meermaals bij jouw over de vloer zien komen met weeral eens een "vraagje", bedankt voor al je praktische oplossingen. Sarah, iedereen denkt dat je een stille Belg bent, maar ik weet wel beter, ik vond onze na-17h-gesprekken hartstikke gezellig. Sietske, je hebt me geïnspireerd met je gewaagde carrière switch! Nicole en Kim, ook al is ons tijd samen op het hoeklab al een tijdje geleden, ik vind het nog steeds gezellig om met jullie "in de gang" te kletsen. Anouk, ook jij hebt een belangrijke bijdrage geleverd in de melanomenstudies tijdens je stage.

Ook hebben we op het lab nog enkele post-docs op het lab rondrennen. Judy, jij was (letterlijk) de vliegende Hollander op het lab, gelukkig is dat in je post-doc periode al wat afgenomen. Je was steeds bereid om een (voor mij) nieuwe techniek uit te leggen. Victor, galectin-man, bedankt voor je kritische en goede tips tijdens besprekingen en in manuscripten. Sebastien, you decided to continue your career as a scientist in sunny San Francisco, a good choice! Ingrid, thanks for your critical remarks and ideas in my research. I'm glad to know Karolien is in (your) good hands. All of you, succes with your research!

Ook mijn kamergenootjes van op de "unie" wil ik bedanken voor de gezelligheid. Natasja, Kitty, Judith en Dirk, we hebben veel lief en leed gedeeld, maar ook veel gelachen. Natasja, bedankt voor de inspiratie voor stelling 7. Kitty, bedankt voor je layout tips. Dirk en Judith, veel succes in Amerika!

Verder wil ik ook de mensen van het secretariaat en de diagnostiek bedanken, met name Cor en Elly, die steeds weer met het juiste papier of advies voor me klaar 
stonden. Ook dank aan Ton, David, Veronique en Patrick, zonder jullie pathologische kennis had ik mijn eerste drie onderzoeken niet kunnen publiceren. Bedankt voor jullie inzet en snelle werk. Eric, jouw onophoudelijke interesse en inzet heeft er voor gezorgd dat we toch samen die GFP publicatie zullen hebben!!! Richard en Rik, jullie doorstonden zonder geklaag de beetjes van mijn naakte muisjes (en dan zeggen dat naakte muizen rustig zijn). Bedankt bij het uittesten van de tumor-muis modellen. Ook wil ik natuurlijk de naakte muisjes bedanken die zich hebben opgeofferd voor mijn onderzoek.

De gezelligheid op 'de pathologie' en op 'de unie' zal ik niet snel vergeten. Cardio's, Epigenetica angels en mijn verschillende babbel-kamers op de unie, ik bedank iedereen voor de leuke gesprekken in de gang (waarbij veelal het thema reizen het gespreksonderwerp was (:)).

Het goede evenwicht tussen werk-ontspanning heb ik vooral aan vrienden en familie te danken die me steeds wisten te prikkelen met andere "wereldkennis". Elsa, Goudameid, jij bent de ontspanning voor mij!! Samen brusselen, fietsen of wandelen. Op onze ontdekkingsreizen wist je me altijd een vakantiegevoel te geven (ook al was het maar een paar uur). Bedankt dat je mijn paranimf wil zijn. Ka'tje en Griet, onze zonnige momenten aan de Antwerpse kade of Maastrichtste Maas zijn verslavend, laat het maar snel weer lente worden!! Eva, guapa, het is heerlijk om met jouw Spaanse cultuur te delen met of zonder capuccino. Je hebt me ook ondergedompeld (met flamencokleding) in jouw 'home town' Jerez, bedankt voor de gastvrijheid van je hele familie. Harlinde, jij hebt me altijd geboeid met je verhalen over je geneeskunde studie, je bent mede verantwoordelijk voor mijn keuze voor het humane onderzoek ipv voor de plantenveredeling. Fokko en Heleen, lieve zeemensjes, het kan gewoon geen toeval zijn dat we mekaar tegen zijn gekomen in San Cristobal de las Casas en nog minder dat we mekaar steeds weer tegenkwamen tijdens de reis in Guatemala. Jullie hebben me de reiskriebels bezorgt (ja nog meer!!), om net zoals jullie, tot na mijn $70^{\text {ste }}$ de wereld te ontdekken.

Frans, Paula, Monique \& Bas, Kristel \& Mark, Francois \& Mariska, jullie hebben me helemaal opgenomen in jullie familie. De fysieke arbeid op de boerderij, met de neus in de buitenlucht, is altijd een heerlijke ontspanning geweest (beter dan fitness, he Frans). Zussie en Chris, jullie wisten me steeds te steunen maar ik geniet vooral van jullie twee prinsesjes die me steeds weer meenemen in hun magisch kinder-droom-wereldje. Romina en Eleni, jullie zijn schatjes! Mam en pap, jullie staan al jullie hele leven klaar voor mij: dat energieke kind dat altijd weer nieuwe dingen wil kennen/leren/ervaren. Nog steeds komen jullie met ontspanningstips voor een leuke tentoonstelling of een mooie wandeling. Ik heb erg genoten van al onze fietstochten in het groene Limburg! Bedankt voor alles!

Stefan, lieverdje, mijn Zahir, natuurmens, ontspanning nummer 1!, jij bent diegene die er elke dag voor me was. Ik ben heel blij dat ik met jou mijn leven kan delen. 



\section{Curriculum vitae}

Femke Hillen was born on June $17^{\text {th }}$ 1980, in Leuven, Belgium. She obtained her secondary school diploma in 1998 at the Heilig Hart Instituut in Heverlee. In the same year, she started her academic education at the University of Leuven with the specialisation Bio-engineer in Cell- and Gene Biotechnology. After an internship of 9 months on tumor angiogenesis in the Laboratory of Experimental Oncology at the Academic Hospital Gasthuisberg in Leuven, she obtained her MSc degree in June 2003. From October 2003 until September 2007 she worked as a PhD student at the Faculty of Health, Medicine and Life Sciences at Maastricht University. Under the supervision of prof. dr. Arjan Griffioen, in the Angiogenesis Laboratory at the Department of Pathology, she investigated the involvement of a specific vascularisation type, which is refered to as vasculogenic mimicry, in tumorigenesis. As of November 2007, she will be working as a molecular biologist at the Virga Jesse Hospital in Hasselt, Belgium. 



\section{Publications}

Hillen F, van den Beucken T, Hautvast P, Wouters BG, Griffioen AW. Involvement of hypoxia and HIF-1 $\alpha$ in tumor cell plasticity. In preparation

Hillen F, Kaijzel EL, Castermans K, oude Egbrink MGA, Löwik CWGM, Griffioen AW. A transgenic Tie2-GFP athymic mouse model; a tool for vascular biology in xenograft tumors. Submitted

Hillen F, Griffioen AW. Alternative tumor vascularisation, beyond tumor angiogenesis. Cancer and Metastasis Reviews, 2007, In press

Hillen F, Baeten CIM, van de Winkel A, Creytens D, Winnepenninckx V, van der Schaft DW, Griffioen AW. Leukocyte infiltration and tumor cell plasticity are parameters of aggressiveness in primary cutaneous melanoma. Cancer Immunology, Immunotherapy, 2008, 57(1):97-106

Hillen F, van de Winkel A, Creytens D, Vermeulen AHM, Griffioen AW. Proliferating endothelial cells, but not microvessel density, is a prognostic parameter in human cutaneous melanoma. Melanoma Research, 2006, 16(5): 453-457

Hillen F, Melotte V, van Beijnum JW, Griffioen AW. Endothelial cell biology. In: Staton $C A$, Lewis $C$, Bicknell $R$, editors. Angiogenesis assays: a critical appraisal of current techniques. 2006, Chapter 1,1-28. London, United Kingdom: John Wiley and Sons

van der Schaft DW, Hillen F, Pauwels P, Kirschmann DA, Castermans K, Egbrink MG, Tran MG, Sciot R, Hauben E, Hogendoorn PC, Delattre O, Maxwell PH, Hendrix MJ, Griffioen AW. Tumor cell plasticity in Ewing sarcoma, an alternative circulatory system stimulated by hypoxia. Cancer Research, 2005, 65 (24:) 11520-8

Kuijpers D.I.M., Hillen F, Frank J. Occupational peri-ocular contact dermatitis due to sensitization with black rubber components. Contact Dermatitis, 2006, 55: 77-80

Baeten CI, Castermans K, Lammering G, Hillen F, Wouters BG, Hillen HF, Griffioen AW, Baeten CG. Effects of radiotherapy and chemotherapy on angiogenesis and leukocyte infiltration in rectal cancer. Int J Radiat Oncol Biol Phys. 2006 Nov 15;66(4):1219-1227.

Baeten CIM, van der Schaft DW, Hillen F, Pauwels P, de Bruine AP, Baeten CGMI, Hillen HFP, Griffioen AW. Intratumoral extravascular erythrocytes as a new prognostic marker in colorectal cancer. In preparation 
